


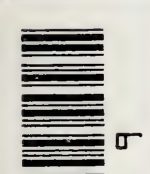

昰

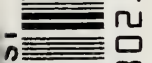

$\mathrm{n} \equiv \mathrm{m}$

吅

u를

듬

$\Longrightarrow \mathrm{m}$

$\square$

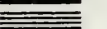

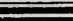





\section{ELEMENTE}

DEP

\section{ALLGEMEINEN PHYSIOLOGIE}

KURZ UND LEICHTFASSLICH

DARGESTELLT

VON

W. PREYER

O. PROFESSOR DER PHYSIOLOGIE UND DIREKTOR DES PHYSIOLOGISCHEN

INSTITUTES DER UNIVERSITĀT JENA.

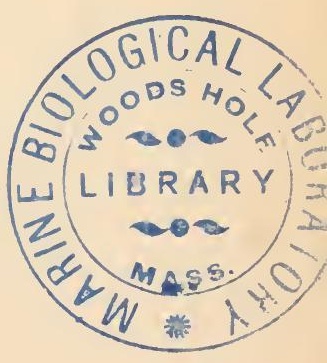

LEIPZIG,

TH. GRIEBEN'S VERLAG (L. FERNAU).

1883. 
$085 \times 3$

Druck von Metzger \& Wittig in Leipzig. 


\section{VORWORT.}

Die „Elemente der allgemeinen Physiologie“ sind aus meinen Universitäts - Vorlesungen hervorgegangen. Sie bilden die Einführung in die „Specielle Physiologie des Menschen und der Tiere" und können auch als Einleitung zur Pflanzenphysiologie dienen, indem sie die vorhandenen Lehrbücher ergänzen. Zunächst für Studierende der Medizin und Naturwissenschaft bestimmt, welche die Primitien der Physik, Chemie und Anatomie inne haben und sich dem Studium der Physiologie zuwenden, werden diese „Elemente“ auch dem am Abschlusse seiner Studienzeit angelangten Mediziner und Naturwissenschafter als kurze zusammenfassende Darstellung der Grundlagen der Lebenserforschung nützlich sein können. Der Fachwissenschaft ferner Stehenden sei zur Orientierung über die Geschichte und den gegenwärtigen Stand der Lebenswissenschaft diese kleine Schrift ebenfalls empfohlen.

J e n a, am 4. März 1883.

\section{Der Verfasser.}





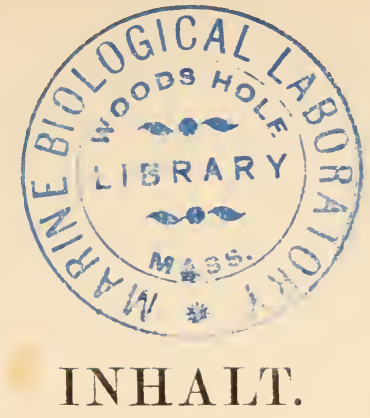

Einleitung

Seite

Die Aufgabe der Physiologie 3. - Ihr Verhältnis zu anderen Wissenschaften 4. - Methodik 11.

Geschichte der Physiologie

Der Name 19. - Einteilung 22. - Erste Periode 22. - Zweite Periode 28. - Dritte Periode 32. - Vierte Periode 40. - Fünfte Periode 49. - Entwicklung im ganzen 55.

Physiologische Litteratur . . . . . . . . .

Systematische Werke und Lehrbücher 59. - Encyklopädien und Lexika 62. -- Zeitschriften 62. - Jahresberichte, listorische und bibliographische Werke 64 . - Grundlegende Werke für einzelne Abschnitte und Richtungen der Physiologie 66. - Anleitungen zum Arbeiten in Laboratorium 68. - Verhältnis der allgemeinen Physiologie zu der speciellen in der Litteratur 69.

Allgemeine Physiologie oder Bionomie . . . . . . 71

I. Vom Wesen des Lebens. . . . . . . . 7?

Der Lebensbegriff 73. - Die Lebensbedingungen 75. - Die Lebensfähigkeit 83. - Unterscheidung der anorganischen toten Wesen von den organischen lebenden Wesen 86. - Die Kontinuität des Lebens 86. - Die Hypothesen über den Ursprung der ersten lebenden Wesen 88. - Unzulässigkeit des Dogmas von der Urzeugung 88. - Unzulänglichkeit der Hypothese von deu Kosmozoen 90. - Ursprung des Toten 92. - Der Begriff des Todes 93. - Die Lebensdauer 94. - Die Lebensalter 96. 
II. Vom Inhalt der lebenden Körper

Die organischen Elemente 98. - Verbindungsweisen der organischen Elemente in den lebenden Körpern 102. - Immediatbestandteile 104. - Die Verteilung der organisehen Elemente 108. - Unzulässigkeit der Annahme eines besonderen Lebensstoffes 109. - Das Protoplasma 111. - Verschiedenheit und Veränderlichkeit chemischer Verbindungen in ungleichen lebenden Körpern 120. - Bezugsquellen der organischen Elemente 122. - Abnorme chemische Bestandteile der lebenden Körper 125.

III. Von den Formen der lebenden Wesen . . Individualisation 128. - Die Zellen 130. - Die Gewebe 132. - Die Organe 135. - Die Organapparate 137. - Die Organismen 139. - Tiere und Pflanzen 141. - Vermeintliche Unterschiede zwischen Tier und Pflanze 142. - Abnorme Formen 144.

IV. Von den Kräften der lebenden Körper . . Die physischen Kräfte 147. - Die chemischen Kräfte 149. - Unzulässigkeit der Annahme einer besonderen Lebenskraft 155. - Unzulässigkeit der Annahme einer permanenten specifisch-vitalen Bewegung 158. - Notwendige Voraussetzungen 160. - Die Wärme als Ursache des Lebens 161.

V. Von den Funktionen der lebenden Körper. 166 Begriff der physiologischen Funktion 167. - Die Grundbedingungen jeder physiologischen Funktion 172. Reiz und Reizbarkeit 176. - Ursprung der physiologischen Funktionen 181. - Die physiologische Arbeitsteilung 184. - Konstanz der Funktionen bei wechselndem Substrat 188. - Funktionswechsel 190. - Symptomatologie der Funktionen 192. - Verlauf der Funktionen 193. - Unterbrechung und Wiederherstellung der Funktionen 194. - Die künstliche Nachahmung der Funktionen 195. - Die Vergleichung der Funktionen verschiedener Individuen 196. - Antagonismus und Korrelation der Funktionen 199. - Funktionsstörungen 200. - Namengebung und Geschichte der Erforschung der Funktionen 201. 
IV. Einteilung der physiologischen Funktionen . Ermittlung aller sämtlichen lebenden Wesen gemeinsamen Funktionen 203. - Die Grundfunktionen 204. - Die Selbsterhaltung und Arterhaltung 210. - Die Anpassung 211. - Übersicht der Funktionen des Protoplasma 212. - Die Einteilung der Lehre von den Funktionen der Tiere und des Menschen 214.

Die Aufgaben der speciellen Physiologie oder Biognosie des Henschen und der Tiere . . . . . . 215

I. Die Funktionen des Stoffwechsels . . . . 217 Die Lehre von den Saftströmungen 217. - Die Lehre von der Atmung 218. - Die Lehre von der Ernährung 218. - Die Lehre von den Absonderungen 219.

II. Die Funktionen des Kraftwechsels . . . . 220 Die Lehre von der tierischen Verbrennung 220. - Die Lehre von der tierischen Elektricität 221. - Die Lehre von der tierischen Bewegung 222. - Die Lehre von der Sinnesthätigkeit 223.

III. Die Funktionen des Formenwechsels

Die Lehre vom tierischen Wachstum 224. - Die Lehre von der Erzeugung der Tiere 224. - Die Lehre von der tierischen Entwicklung 225. - Die Lehre von der tierischen Vererbung 225. 


\section{EINLEITUNG.}

DIE AUFGABE DER PHYSIOLOGIE.

IHR VERHÄLTNIS ZU ANDEREN WISSENSCHAFTEN. IHRE METHODIK. 



\section{EINLEIT UNG.}

\section{Die Aufgabe der Physiologie.}

Aufgabe der Physiologie ist es, die Lebensvorgänge zu beschreiben und zu erklären. Dieselben heißen physiologische Funktionen. Nur die Funktionen der lebenden Körper als solcher, diese aber sämtlich, sind das Objekt der Physiologie. Diejenigen Eigenschaften der lebenden Körper dagegen, welche ihnen gemeinsam mit allen Naturobjekten zukommen, wie z. B. Ausdehnung, Schwere, sind als solche nicht Gegenstand physiologischer Untersuchung. Die Beschreibung des Baues und der stofflichen Zusammensetzung lebender Körper ist ebenfalls nicht ein Teil der Physiologie. Sie muß, weil die Struktur und die chemische Mannigfaltigkeit an sich keine Funktionen sind, von der reinen Physiologie ausgeschlossen bleiben. Durch diese Trennung wird letztere entlastet und kann, auf die Lebens vorgänge sich einschränkend, sich freier und gleichmäßig entfalten. Die reine Physiologie ist die Lehre von den Lebensfunktionen. 


\section{Das Verhältuis der Physiologie zu anderen Wissenschaften.}

Die Physiologie ist von allen Wissenschaften die vielseitigste, weil ihr Objekt, das Leben, von allen Wissenschaftsobjekten das vielseitigste ist. Wie alle Naturwissenschaften ist sie eine empirische oder Erfahrungswissenschaft und muß, wie die Physik, zuerst eine große Anzahl von einzelnen Thatsachen sammeln und genau feststellen, ehe sie eine einzige zu erklären vermag. Hierdurch erhält sie den Charakter einer beschreibenden Naturwissenschaft. Sie beschreibt die Lebenserscheinungen unabhängig von jeder Theorie, indem sie unmittelbar das Lebendige gleichsam in flagranti zu erfassen sucht. Die beschreibende Physiologie oder Funktionenlehre erhält durch diese Eigentümlichkeit eine von allen anderen Wissenschaften scharf abgesonderte Stellung und unverlierbare Selbständigkeit. Als erklärende Wissenschaft gehört die theoretische Physiologie zu den exakten Disciplinen wie die Physik. Sie unterscheidet sich aber von dieser wesentlich dadurch, daß sie großenteils eine angewandte Wissenschaft ist, und zwar hauptsächlich angewandte $\mathrm{Phy}$ sik, Chemie und Morphologie, deren Ergebnisse sie bei der Untersuchung der physiologischen Vorgänge verwertet. Die Naturvorgänge werden betrachtet von der reinen Physik nur insofern eine Kraft in eine andere verwandelt wird, von der reinen Chemie nur insofern stoffliche Änderungen dabei eintreten, von der reinen Morphologie nur insofern die Formen sich dabei ändern, von der reinen Physiologie aber insofern alle drei Änderungen zusammen stattfinden, wie es bei den lebenden Körpern der Fall ist. 
Schon die Bezeichnungen organische Physik, medizinische Physik, Biophysik, Zoophysik und Phytophysik lassen, ebenso wie mehrere Ausdrücke für einzelne Abteilungen der Physiologie, die Auffassung, daß diese in der Anwendung physikalischer Lehrsätze auf Lebenserscheinungen besteht, erkennen, z. B. Biomechanik, d. i. allgemeine Bewegungslehre der Organismen (Biokinetik), mit den beiden Unterabteilungen Biostatik oder Lehre vom Gleichgewicht der Organismen, und Biodynamik (Zoodynamik und Phytodynamik) oder Lehre von den Bewegungen der Organismen, im engeren Sinne Phoronomie. Ferner gehören hierher: Elektrophysiologie oder Lehre von den elektrischen Erscheinungen der lebenden Körper, Myophysik, Neurophysik, Psychophysik, Physiologische Optik und Akustik.

Mit der Anwendung physikalischer Lehren, der Mechanik, Akustik, Optik, Thermik, Elektrik auf die Lebenserscheinungen ist jedoch nur ein Teil der Physiologie, und nicht der größte, beschäftigt. Die Chemie ist ebenso notwendig zur Erforschung der physiologischen Funktionen. Die Physiologie ist nicht weniger eine angewandte Chemie, als eine angewandte Physik.

Auch dieses lassen manche Bezeichnungen erkennen, z. B. Biochemie, Zoochemie oder Tierchemie, Phytochemie oder Pflanzenchemie. Die chemische Untersuchung der Gewebe heift Histochemie, die der Nerven Neurochemie, der Muskeln Myochemie, des Harnes Urochemie, des Substrates der geistigen Prozesse Psychochemie. Die Biochemie zerfällt in zwei Teile, sofern sie zuerst nur die Bestandteile, d. h. die Elemente und die im Leben präexistierenden chemischen Verbindungen isoliert, und dann deren Bildung, Wechselwirkung, Zersetzung im Körper erforscht. Letzteres ist die eigentliche Aufgabe der physiologischen Chemie, oder Lehre vom Stoffwechsel, welche, wenn auch die Lehre von den chemischen Veränderungen in Krankheiten, d. h. 
die pathologische Chemie, hinzugenommen wird, die medizinische Chemie heißt. Die reine Physiologie ist demnach, weil sie die chemischen Veränderungen, welche Lebenserscheinungen sind, untersucht, selbst vielfach physiologische Chemie. Ihre charakteristische Arbeit besteht aber in der vereinigten Chemie und Physik der lebenden Körper und aller ihrer Teile.

Dabei muß das Fungierende, d. h. das lebende Individuum, vorher zergliedert sein. Denn eine Funktion ist nicht $\mathrm{zu}$ verstehen, wenn das Fungierende nicht bekannt ist. Diese Zergliederung, und dadurch die genaue Kenntnis des Baues der Organismen, wird von der Physiologie als unentbehrliche Grundlage vorausgesetzt. Die Morphologie der Organismen oder die Lehre von ihren Gestalten und von den Formen der sie unmittelbar zusammensetzenden Teile, geht der Physiologie vorher, und zwar ist die makroskopische und mikroskopische Anatomie des Menschen (Anthropotomie), der Tiere (Zootomie), der Pflanzen (Phytotomie) in allen ihren Teilen der Physiologie notwendiges Fundament. Die Histologie oder Gewebelehre, die Entwicklungsgeschichte der Formen lebender Körper und die vergleichende Anatomie sind nicht etwa nur Hilfswissenschaften der Funktionenlehre, sondern deren Grundlage, welche die Objekte der Untersuchung liefert. Die Kenntnis der Entwicklung der fungierenden Teile von Generation zu Generation rückwärts stammesgeschichtlich (phyletisch) oder phylogenetisch oder generell (genealogisch) und im Einzelwesen, dem Lebensalter nach, d. h. vor der Geburt oder pränatal (embryologisch), und nach der Geburt oder postnatal, zusammen in dividuell oder ontogenetisch, macht das Verständnis der Funktion erst möglich. Durch Vergleichung der fungierenden Teile in den verschiedensten Entwicklungsstufen wird erst die Einsicht in den Zusammenhang der Funktion mit ihrem organischen Substrate gewonnen. 
Hierdurch tritt die Physiologie in nahe Beziehungen zu der Zoologie oder Tierkunde, und zu der Phytologie oder Pflanzenkunde (Botanik), sowie zu der Anthropologie oder Menschenkunde. Es wird auch je nach dem Untersuchungsmaterial eine Anthropophysiologie, Zoophysiologie und Phytophysiologie unterschieden. Von ihnen zweigt sich ab eine Physiologie der weder pflanzlichen noch tierischen Wesen (Protisten).

Während diese physiologischen Wissenschaften aus den vorgenannten Disciplinen ihre Nahrung erhalten, bilden sie selbst wieder die Grundlage anderer Wissenschaften, namentlich der Pathologie. Ein besonderer Teil derselben, die $e x$ perimentelle Pathologie, ist auf kranke Organismen angewandte oder pathologische Physiologie. Die pathologische Anatomie bedarf zur Erklärung der Abweichungen des Kadavers von der Norm der Keuntnis der Funktionen. Die Lehre von den Mißbildungen oder Teratologie erwartet von der Physiologie Aufschluß über die Ursachen der von ihr behandelten Abnormitäten. In fast allen ihren Teilen ist die praktische Heilkunde oder Medizin, auch die Lehre von den Krankheiten der Tiere (Zoopathologie) und Pflanzen (Phytopathologie), von der Physiologie abhängig, welche ihr namentlich die Mittel zur Erkennung (Diagnose), Verhütung (Prophylaxe), Behandlung (Therapie) der Krankheiten an die Hand gibt und die Ursachen (Ätiologie) derselben aufhellt. Die Chirurgie oder Wundheilkunde kann ebensowenig wie die theoretische Geburtshilfe und Gynäkologie (Gyniatrik) oder Lehre von den Frauenkrankheiten ohne gründliche physiologische Kenntnisse wesentlich gefördert werden. Den gröbten Nutzen hat bisher von der Physiologie die Augenheilkunde oder Ophthalmiatrik gehabt. Die Psychopathologie (Psychiatrie oder Seelenheilkunde) erwartet von der Nervenphysiologie zumeist Förderung. Für den angehenden Arzt ist, gleichviel welcher Specialität er sich später zuzuwenden gedenkt, das Studium der Physiologie und fortdauernde Be- 
schäftigung mit ihr schon darum notwendig, weil man zur Erkennung einer Krankheit oder Abweichung von der Gesundheit, vor allem den lebenden Körper im gesunden $\mathrm{Zu}$ stande mit seinen verwickelten Prozessen möglichst genau kennen muß. Aber auch die Behandlung der Kranken erfordert diese Kenntnis. Immer mehr strebt die wissenschaftliche Arzneimittellehre oder Pharmakologie und die Giftlehre oder Toxikologie nach Erlösung von dem unkritischen post hoc ergo propter hoc und nach rationeller. Begründung des Rezepteschreibens. Nur durch Erforschung der physiologischen Wirkungen der Arzneien und Gifte kann der Arzt sich Rechenschaft über die Zulässigkeit seiner Verordnungen geben. Die Elektrotherapie ist unmittelbar aus der Elektrophysiologie hervorgegangen.

Auch die Gesundheitslehre oder Hygieine beruht wesentlich auf der Physiologie, sofern sie die Bedingungen, welche für die Erhaltung der Gesundheit notwendig sind, kennen muß, bevor sie die erforderlichen Maßregeln zur Herstellung derselben bestimmen kann. Jene Bedingungen ermittelt die Physiologie, indem sie die Lebensbedingungen erforscht, d. h. diejenigen Bedingungen, unter denen allein die Lebensvorgänge keine Störungen erfahren.

Die Landwirtschaftswissenschaft ist gleichfalls in ihren Hauptzweigen angewandte Tier- und Pflanzenphysiologie, besonders Ernährungslehre. Wer sich zum Lehrer dieser für das materielle Wohl der Menschen wichtigsten Disciplin ausbilden, wer es verstehen will, wie durch Pflanzen und durch Tiere die anorganischen Bestandteile des Erdbodens einerseits in Brod, andererseits in Fleisch und Milch und Eier verwandelt werden, muß sich gründlich mit der wissenschaftlichen Physiologie befreunden; sie ist für die Lehre vom Acker- und Pflanzenbau und die Tierproduktionslehre von bestimmendem Einflusse. Die rationelle Forstwirtschaft wird gefördert durch die Phytophysiologie. 
Mehrere nicht rein naturwissenschaftliche Fächer sind in manchen ihrer Fragen auf die Physiologie angewiesen. So kann die Psychologie ohne die empirische Begründung der Empfindungslehre durch die Physiologie der Sinnesorgane nicht fortschreiten.

Viele Fragen der forensischen oder gerichtlichen Medizin können nur auf Grund physiologischer Untersuchungen beantwortet werden.

Die Volkswirtschaftslehre, die Pädagogik, die Kulturgeschichte, die Sprachforschnng, die Ethik, die Asthetik und die Kunstuissenschaft, soweit auch ihre Ziele von denen der Physiologie abliegen, müssen, um sie zu erreichen, sich vielfältig bei dieser Rats erholen und manche Thatsache berücksichtigen, welche z. B. die Ernährung, die Gehirnfunktionen, die Stimme und Sprache, die Sinnesthätigkeit betreffen.

Von allen Wissenschaften ist die Physiologie das wirksamste Mittel zur Selbstkenntnis und Menschenkenntnis. Wer weiß, wie die Funktionen des eigenen Körpers miteinander zusammenhängen und wie abhängig namentlich alle psychischen Prozesse, das Gefühl, der Wille, das Denken, der Charakter, das Temperament von der Beschaffenheit der physischen Substrate sind, wird sich selbst und andere richtiger beurteilen, als der physiologisch ununterrichtete und bei der Erziehung den gröften Wert auf die Herstellung zuerst eines gesunden Körpers legen, namentlich nicht unter Vernachlässigung der physischen Erziehung in einem verkümmerten Körper eine starke Seele großziehen wollen.

Für die abstrakten Wissenschaften der Logik, Mathematik und Erkenntnislehre ist die Physiologie von Bedeutung, weil von ihr allein die Ermittelung der Bedingungen der jenen Disciplinen zu Grunde liegenden psychischen Akte zu erwarten steht. Sie selbst sind für die Verwertung physiolo- 
gischer Thatsachen und Erklärungen unentbehrliche Instrumente. Die physiologischen Erklärungen der Lebenserscheinungen als die einzig möglichen, $d . h$. als notwendig durch die Eigentümlichkeit der menschlichen Erkenntnismittel bedingt, nachzuweisen, ist dagegen nicht mehr Aufgabe der Physiologie, sondern der Philosophie, welche ihrerseits ebenso wie die übrigen genannten Disciplinen, obwohl sie der Physiologie wesentlich empfangend gegenübersteht, als eine Hilfswissenschaft derselben zu bezeichnen ist, weil sie teils zu neuen Forschungen Anlab geben, teils auf Bekanntes, Unerklärtes, neues Licht werfen kann.

Als Unterrichtsgegenstand nimmt die Physiologie eine eigentümliche Stelle ein. Sie ist reine Naturwissenschaft, wird aber meistens zur medizinischen Fakultät gezählt, weil sie als Universitätskollegium weit überwiegend von angehenden Medizinern gehört wird. Sie ist aber keineswegs in ihrem Fortbestand auf die Medizin allein angewiesen, und viele ihrer Ergebnisse würden auch in anderen Schulen, als den Universitäten, mit dem größten Nutzen für die heranwachsende Jugend elementar gelehrt werden können. Jedoch ist für das Verständnis akademischer physiologischer Vorträge das vorherige Studium der Anatomie, Physik und Chemie unerläßlich, wie aus dem obigen sich von selbst ergibt. 


\section{Methodik.}

Die Physiologie untersucht diejenigen Veränderungen lebender Körper, welche Lebensvorgänge sind, indem sie diese Vorgänge isoliert, die gefundenen Einzelthatsachen in der Form von Regeln oder allgemeinen Thatsachen vereinigt und Ursachen für die Regelmäßigkeit aufsucht, wo sie sich nicht mit der Regel und ihrer Einkleidung in eine Annäherungsformel begnügen muf.

1. Das erste Geschäft des Physiologen ist also empirisch und besteht in der Isolierung der einzelnen Lebensprozesse von anderen Erscheinungen und voneinander. Die Mittel zu dieser Analyse sind die Beobachtung und das Experiment (der Versuch).

Der lebende Körper wird betrachtet beim Beobachten:

im natürlichen Zustande in natürlicher Umgebung. beim Experimentieren

im natürlichen Zustande in künstlich veränderter

Umgebung,

im künstlich veränderten Zustande in natürlicher

Umgebung,

im künstlich veränderten Zustande in künstlich

veränderter Umgebung.

Sowohl die Beobachtung wie das Experiment muß sich auf möglichst verschiedene lebende Körper in möglichst verschiedenen Entwicklungszuständen erstrecken, weil der für eine Gruppe und einen Entwicklungszustand gültige Befund zunächst nur für diese Geltung hat und die verwickelten Lebenserscheinungen ohne die Vergleichung mit einfachen nicht verstanden werden können. 
Andererseits muß man sich hüten, die an noch so vielen Tieren gewonnenen Ergebnisse unmittelbar auf den Menschen $\mathrm{zu}$ übertragen, schon weil dessen Organisation, zumal sein Gehirn, viel verwickelter ist als die irgend eines Tieres.

Bei allen physiologischen Beobachtungen und Experimenten ist scharf zu unterscheiden der Befund an vollkommen lebendigen und gesunden Objekten von dem Befund an präparierten, nur noch teilweise lebenden, an kranken oder gar nicht mehr lebenden Objekten. Diese Unterscheidung ist oftmals vergessen worden, und dadurch entstehen folgenschwere Irrtümer, indem man unbefugterweise aus dem an totem und sterbendem Material Beobachteten auf das gleiche Verhalten im Leben schloß (besonders in der Elektrophysiologie).

Die Technik der physiologischen Beobachtungen und Experimente ist meistens verwickelt und aus den in physikalischen und chemischen Laboratorien allmählich ausgebildeten Methoden einerseits, den chirurgischen und anatomischen Operationen andererseits entstanden. Eine große Anzahl von Kunstgriffen ist aber erst in physiologischen Werkstätten erfunden worden, namentlich solche, welche auf die Verhinderung einer durch den Eingriff selbst herbeigeführten nicht beabsichtigten Störung abzielen; durch die specifisch physiologischen Operationen an lebenden Tieren, die. Vivisektionen, schon durch das Ergreifen und Fesseln, wird das Versuchstier in einen anomalen Zustand versetzt. Hierdurch werden die an Tieren gewonnenen Resultate sehr oft fehlerhaft. Vivisektionen können aber durch nichts ersetzt werden, und wo sie gesetzlich verboten sind, kann die Physiologie nicht gedeihen. Alle anderen Versuche, an Tieren und Pflanzen die Funktionen zu ergründen sind nicht entfernt ausreichend. Dieselben müssen aber in ausgedehnterem Maße, besonders in den landwirtschaftlichen Versuchsstationen, in zoologischen und botanischen Gärten, in 
Aquarien und Terrarien mit den reichen Hilfsmitteln der Physiologie ausgeführt werden. Die Zootechnik ist praktische Physiologie. Die physiologische Untersuchung lebender pelagischer Tiere und Pfianzen an der Meeresküste verspricht reiche Früchte. Der reisende Naturforscher pflegt in der Regel auf das Sammeln von einzelnen gelegentlichen physiologischen Beobachtungen sich zu beschränken; wenn er aber mit speciellen Fragen und mit den erforderlichen Apparaten ausgerüstet die Reise antritt, um an Ort und Stelle (namentlich in den Tropen) zu untersuchen, so kann er sicher sein, seiner Wissenschaft bessere Dienste zu leisten.

Endlich ist für den Physiologen die Selbstbeobachtung und die Beobachtung anderer Menschen, sowie das Experimentieren an sich selbst, an Kindern, Heranwachsenden, Erwachsenen, besonders in großen Heilanstalten jeder Art, soweit die Gesundheit der Patienten darunter nicht leidet, geboten. Die Vivisektion am Menschen wird häufig durch Krankheiten ersetzt, und die Kliniken liefern die beste Gelegenheit zu physiologischen Entdeckungen am Menschen, besonders wenn eine sorgfältige makroskopische und mikroskopische Untersuchung der Leichen konstante Beziehungen zwischen bestimmten anatomisch scharf begrenzbaren Teilen und der vorher im Leben beobachteten Funktionsstörung einen Zusammenhang der gestörten Funktion mit dem pathologisch veränderten Teil erkennen läßt. Daher wird die pathologische Anatomie für die Physiologie des Menschen von außerordentlicher Wichtigkeit.

2. Sind die einzelnen Erscheinungen von einander gesondert, so beginnt die andere, nicht mehr empirische, sondern abstraktive Thätigkeit des Physiologen, welche in der Erklärung derselben besteht, indem die durch Analyse gefundenen Thatsachen nun durch Synthese auf gemeinsame Principien zurückgeführt werden. 
Glauben, daß etwas sich so verhält oder so, ein Fürwalrhalten lediglich aus subjektiven Gründen entgegen dem objektiven Beweis oder ohne objektiv zureichende Gründe, ist in der Physiologie nicht Mittel der Untersuchung. Dogmen oder Glaubenssachen, welche mit der reinen Vernunft und mit der Erfahrung unvereinbar sind, können vielmehr nur als Objekte psychophysiologischer Forschung in der Physiologie betrachtet werden, sofern die Möglichkeit ihres Zustandekommens und ihr großer Einfluß auf die Entwicklung der Naturwissenschaft auf physiologischen Bedingungen beruht. Charakteristisch für das Dogma ist nicht etwa nur, daß es unbewiesen dasteht, sondern auch, daß es seiner Natur nach gar nicht bewiesen werden kann und dennoch für wahr gehalten wird. Darum gehört es nicht in eine exakte Wissenschaft wie die Physiologie.

Dagegen ist Meinen oder Fürwahrhalten aus subjektiv und objektiv unzureichenden Gründen unerläßlich für den Fortschritt in der Physiologie. Meinungssachen oder Нy о thesen können richtig sein, aber der objektive Beweis ist durch Vernunft oder Erfahrung noch zu liefern. Häufen sich die Wahrscheinlichkeitsgründe für die Richtigkeit einer Hypothese, so heißt sie Theorie.

Das einzige völlig befriedigende Fürwahrhalten ist das aus subjektiv und objektiv zureichenden Gründen, das Wissen. Das Gewußte oder die Thatsache ist in der Physiologie, wie in allen anderen Naturwissenschaften, gekennzeichnet dadurch, daß es jederzeit durch Erfahrung - Beobachtung und Experiment - und logisch-mathematische Deduktion bewiesen werden kann. Es bildet allein den Inhalt der physiologischen Lehrsätze.

Das Fürwahrhalten aus objektiv zureichenden Gründen, welche aber subjektiv nicht zureichen, also das Fürwahrhalten mit Widerstreben oder ohne die Befriedigung, welche 
das Wissen gibt, spielt bei vielen physiologischen Entdeckungen eine wichtige Rolle, indem es dem Zweifel, der Quelle aller Wahrheit, Spielraum gewährt. Die Ahnung oder Divination kann bei anhaltendem Nachdenken über physiologische Vorgänge in Verbindung mit der Phantasie auf den Weg führen, welcher unvermittelte Thatsachen miteinander verbindet. Jedoch ist der Wert des physiologischen Aperçu lediglich ein heuristischer, und so wahr es ist, daß vor jedem physiologischen Experiment, die an die Natur zu richtende Frage dem Experimentator völlig klar sein soll, so steht doch fest, daß manche physiologische Entdeckung lediglich dem Zufall zu verdanken ist. Leicht erzeugt aber dieser wie ein Einfall eine physiologische Fiktion, die sich zum Schaden der Forschung lange erhalten kann und nur indirekt dadurch nützt, daß die Widerlegung den Scharfsinn herausfordert.

Jedes physiologische System, welches auf Vollständigkeit Anspruch macht, ist genötigt, die zahlreichen und großen Lücken durch Vermutungen auszufüllen. Und weil diese immer subjektiv sind, gibt es kein physiologisches Lehrgebäude, das sich eines allgemeinen Beifalls erfreute. Die Physiologie kann noch nicht sämtliche Lebenserscheinungen aus einander entwickeln. Ihr fehlen noch zu sehr einfache Principien. Sind Reihen von einzelnen Thatsachen unter Regeln gebracht, die Gültigkeitsgrenzen der Regeln genau bestimmt, so wird die vermutete oder die geahnte Ursache experimentell geprüft. Aber selbst wenn diese Prüfung der Hypothese an der Erfahrung nichts gegen dieselbe zu Tage fördert, ist innerhalb des ganzen Gebietes der Physiologie die Gewißheit, daß sie richtig ist, nicht beweisbar. Immer läßt sich nur eine Wahrscheinlichkeit erzielen, welche freilich so groß werden kann, wenn die übereinstimmenden Erfahrungen im Laufe der Zeit sich immer mehr häufen, daß schließlich niemand an dem Ergebnis zweifelt. 
Wenn in dieser Beziehung die Physiologie alle Schwächen der induktiven Wissenschaften teilt, so ist sie doch in mehreren Abschnitten einer so durchaus deduktiven Behandlung fähig wie die reine Physik. Die Anwendung der Mathematik auf Probleme der physiologischen Mechanik, Optik, Akustik, Elektrik, Thermik hat bereits mehrfach die Fruchtbarkeit des deduktiven Verfahrens kennen gelehrt. Nur sind die dabei notwendig zu machenden Voraussetzungen in keinem Falle wegen der Kompliziertheit des Objektes als die einzig zulässigen anzusehen, daher stets die Schwierigkeit, eine physiologische Regel als notwendige Konsequenz eines Naturgesetzes zu erkennen, groß bleiben wird. 


\section{GESCHICHTE DER PHYSIOLOGIE.}

DER NAME. - EINTEILUNG DER GESCHICHTE. DIE FÜNF PERIODEN. - DIE ENTWICKLUNG IM GANZEN. DIE PHYSIOLOGISCHE LITTERATUR. 



\section{Der Name.}

Nicht zu allen Zeiten hat die Wissenschaft von den Lebenserscheinungen „Physiologie" geheißen, und dieser Ausdruck bedeutete ehedem etwas ganz anderes, als jetzt. "Physis" nannten die Griechen nicht nur die lebende Natur, das Zeugende, Wachsende, ( $\varphi$ v́w, ich wachse), sondern auch die Naturordnung und Natur im ganzen. Das Wort bezog sich auch auf leblose Körper und Kiräfte, wie noch jetzt

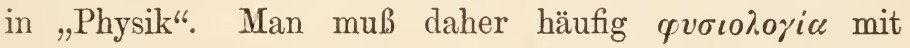
„Naturkunde, Naturerkenntnis, Naturlehre, Naturwissenschaft, Naturforschung" übersetzen, sofern natura gleichfalls nicht allein das geboren werdende, sondern auch das Anorganische bezeichnet. Außerdem bedeutete aber „Physiologie" genau dasselbe wie „Naturphilosophie“, und diese hatte mehrere Bedeutungen je nach dem Inhalte des Begriffes "Natur". Die sogenannte „rationale Physiologie“ oder "Physiologie der reinen Vernunft" versuchte die Natur elurch die Begriffe und Grundsätze der reinen Vernunft zu bestimmen, und abstrahierte vom Empirismus. Die „immanente Physiologie" betrachtete die Natur, wenn auch nur philosophisch, als Gegenstand der Erfahrung, sofern sie durch sinnliche Anschaung gegeben ist, $d$. h. die natura naturata der Scholastik. Die anempirische „transscendente Physiologie" spekulierte dagegen über „Dinge an sich", welche außerhalb der Erfahrung stehen, die natura naturans. Die „Philosophie der Natur" wurde auch zu Beginn des 19. Jahrhunderts wieder "Physiologie" genannt, und zwar, sofern 
sie sich auf Erfahrung gründet „empirische Physiologie". Alle diese Ausdrücke bedeuten etwas wesentlich anderes als "Lebenslehre" und sind zum Teil, wie "transscendente Physiologie" (eine imaginäre Naturlehre ohne Erfahrung) nur einzelnen Metaphysikern verständlich oder widerspruchsfrei.

Die Einschränkung des Inhaltes der Physiologie oder Naturuntersuchung im weitesten Sinne auf die Erforschung des Lebens findet sich im Altertum nirgends und im Mittelalter nicht allgemein. Eine Reihe von gemischten Disciplinen ging ihr in letzterem vorher, und wie im klassischen Altertum wurde eine besondere Lebenslehre im Sinne der modernen Physiologie von der Philosophie, Anatomie, Pathologie nicht abgetrennt. Ausdrücke, wie Philosophia corporis vivi, Philosophia hominis, auch Biosophia und "Mikrokosmographie" beziehen sich auch auf die Theorie der Krankheiten.

Die Geschichte der Physiologie in ihren Anfängen mit der der Naturlehre überhaupt, also der Naturphilosophie, den Spekulationen der "Ionischen Physiologen" zusammenfallend, ist dann innig verwachsen mit der Geschichte der Medizin; daher die Bezeichnungen Pars naturalis medicinae, "Theoretische Medizin“ und noch jetzt „Experimentelle Medizin", welche nur einen Teil der gegenwärtigen Physiologie ausmacht und zum Teil mehr der Experimentalpathologie entspricht. Die Physiologia corporis humani nannte man auch Anthropologia, die ganze Physiologie Oeconomia animalis oder "Dynamologie“ oder „Physio-

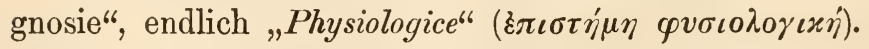

In der Gegenwart wird die Lebenslehre, Lebenskunde, Lebenswissenschaft teils im allgemeinsten Sinne Biologie genannt, welche die Erforschung des morphologischen und chemischen Verhaltens der gesunden und kranken lebenden Körper, ihrer Lebensbedingungen und aller dazu gehörigen 
organischen Hilfswissenschaften, auch Zoologie und Phytologie, sowie Tier - und Pflanzengeographie umfaßt, teils im engeren Sinne Physiologie oder Lehre ron den Funktionen lebender Wesen. Ein guter Ausdruck für die allgemeine Physiologie ist "Bionomie“, weil er anzeigt, daß es sich in ihr um die allgemeinen Gesetzmäßigkeiten aller Lebensprozesse handelt. Die besondere Physiologie, nämlich die Lehre von den Funktionen lebender Körper im einzelnen, befaßt sich dagegen mit der Beschreibung und Erklärung der Lebensprozesse auf Grund der bionomischen Lehrsätze.

Es soll demnach die generelle Physiologie oder allgemeine Funktionenlehre Bionomie, die specielle Biognosie heißen. Erstere spaltet sich in eine Zoonomie und Phytonomie, letztere in eine Zoognosie und Phytognosie, je nachdem die Funktionen der Tiere oder die der Pflanzen allgemein oder im einzelnen betrachtet werden.

In diesem Sinne ist die Physiologie eine junge Wissenschaft; aber wenn man ihrem Ursprunge nachforscht, muß man bis auf die Anfänge der Naturphilosophie und sogar der Heilkunde zurückgehen. Die Mutter der Physiologie ist die praktische Medizin, welche aber je mehr die anfangs nur sehr langsam, später immer schneller sich ausbildende Tochterwissenschaft sich entfaltete, um so mehr von ihr zurückempfing, so daß jetzt das Verhältnis sich umgekehrt hat: die praktische Medizin hängt von der Physiologie ab. Für ihre Ausbildung sind bestimmend gewesen die Fortschritte der Anatomie in erster Linie, für ihre Begründung als selbständige Wissenschaft die Physik und die Chemie. Die physiologischen Funktionen konnten erst streng wissenschaftlich in Angriff genommen und erklärt werden, nachdem die exakten Naturwissenschaften als solche fundiert waren, d. h. seit Galilei und Newton. 


\section{Einteilung.}

Man kann hiernach die Geschichte der Physiologie in fünf Perioden zusammenhängend darstellen, von denen jede, außer der ersten spekulativen Periode, durch einen Physiologen ersten Ranges, die vierte durch deren zwei charakterisiert ist, nämlich: Aristoteles (II), Galen (III), Harvey und Haller (IV), Johannes Müller (V).

\section{Erste Periode.}

Die erste Periode beginnt mit den Anfängen der Heilkunde in Indien, China und Ägypten. In den erhaltenen schriftlichen Überlieferungen finden sich mehrfach neben den wunderlichsten Ansichten über das Feuer, welches den Körper belebt, auffallend richtige Behauptungen, z. B. über das Blut, welches aus dem Chylus entstehe. Bei den Juden lassen manche diätetische und hygieinische Vorschriften schon um 1500 vielerlei physiologische Kenntnisse vermuten. Die Erklärungsversuche der Lebensvorgänge basierten aber auf willkürlichen phantastischen Annahmen von vier, auch fünf Elementen, Dämonen u. a.

Die Spekulationen des Thales von Milet (geb. 639) und der Ionischen Naturphilosophen, der sogenannten Physiologen, beschäftigen sich mit dem Ursprung des Lebens. Thales meinte ihn im flüssigen Aggregatzustand, im Wasser, suchen zu müssen, zu dem auch alles zurückkehre.

Anaximander von Milet (geb. 610) setzte an die Stelle des Wassers eine unbestimmte Materie, ( $\dot{\alpha} \theta \dot{\alpha} v \alpha \tau o v$ zai áv $\left.\omega^{\prime} \lambda \varepsilon \theta \varrho o v\right)$, welche dichter als Luft und dünner als 
Thasser gewesen sein soll. Der Anfang ( $\left.\dot{c} 0 \chi \hat{\imath}_{i}^{\prime}\right)$ war jeden-

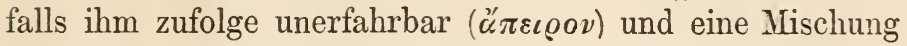
verschiedener Elemente. Die Tiere entstanden aus ihr im Schlamm durch die Einwirkung der Sonne, welche Blasen darin erzeugte. Zuletzt entwickelte sich der Mensch und zwar aus einem fischähnlichen Wesen im Wasser, das erst auf dem Lande menschenähnlich wurde. Diese oft verspottete Abstammung des Menschen von tierischen Vorfahren ist eine der merkwürdigsten Divinationen des Altertums. Sie konnte aber damals nicht thatsächlich begründet werden, weil es an Beobachtungen fehlte.

Xenophanes von Kolophon (um 540) nahm die Erde, Anaximenes ron Milet (geb. um 550) die Luft oder den gasigen Aggregatzustand als Ausgangspunkt an, wie noch heute die naturwissenschaftliche Kosmogonie. Die

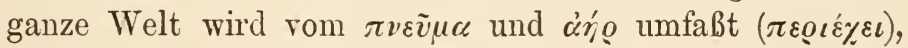
aus welcher alles entsteht, in welche alles zurückverwandelt wird. Die warme Luft ist das beseelte beseelende Princip auch für Di ogen es ron Apollonia (um 460), welcher zuerst behauptete, daß die Luft mit dem Blute durch die Gefäße in den Körper gelangt und eine Atmungstheorie aufstellte; dieser zufolge aber atmen auch die anorganischen Körper. Die Fische atmen mit dem Wasser Luft. Er kannte den Puls und die Eigenwärme der höheren Tiere.

Heraklit von Ephesos (um 500), der geniale Urheber der Lehre vom Fluß der Dinge, welcher den Begriff der Veränderung (das Werden, d. h. das Entstehen und Vergehen) zum Weltprincip machte, leitet das Leben vom Urfeuer ab. Die ganze Welt war ihm im Begriff teils aus dem Feuer zu entstehen, teils in es sich zurückzuverwandeln (der Weg nach unten und nach oben). Die Konstanz der Materie und den Kampf ("̣̌ı $)$ als Erzeuger aller Dinge verlangt Heraklit auch für das Lebende, das übrigens nur aus dem Samen des Vaters entstehe. 
Heraklit ist einer der größten Denker aller Zeiten. Er sprach bereits mit Entschiedenheit Ideen aus, welche die Darwinsche Entwicklungs- und Konkurrenz-Lehre 2300 Jahre später als neue bionomische Lehrsätze aufstellte.

Pythagoras (um 550) suchte in der Zahl das Wesen der Dinge, auch aller Lebenserscheinungen. Er machte eine der größten akustischen Entdeckungen, indem er die Beziehung der konsonanten Intervalle zu den kleinsten ganzen Zahlen auffand. Echt physiologisch ist sein Ausspruch, daß man Töne, die ununterbrochen gleichmäßig von der Geburt an das $\mathrm{Ohr}$ affizieren, nicht wahrnehmen kann, jeder Ton werde nur im Gegensatz zur Stille gehört. Pythagoras leugnete entschieden die Urzeugung, alle Tiere entstehen aus dem Samen. Ferner unterschied er den Verstand (voṽs) vom Gemüt (وvนós) und verlegte beide in das Gehirn.

Die Spekulationen der Eleaten, besonders des Zenon (um 460) sind für die Theorie der Sinne bedeutsam. "Der fliegende Pfeil ruht", wenn er im Dunkeln durch den instantanen elektrischen Funken beleuchtet wird. Freilich herrscht noch fast allgemein die erst von Aristoteles aufgegebene Ansicht, daß vom Auge etwas ausgehe $\mathrm{zu}$ dem gesehenen Objekt hin, wodurch dieses gleichsam wie mit Fühlfäden betastet werde. Dem Parmenides (um 500) war das Kalte und das Warme Grundprincip.

Anaxagoras (geb. um 500, gest. um 428) ließ aus den Homöomerien, in sich gleichartigen, aber voneinander verschiedenen Urteilchen im Chaos durch das ordnende Princip (voṽs) das Lebende entstehen. Weil der Mensch Hände habe, sei er allen Tieren überlegen. Seine Zeugungslehre wurde berühmt. Ihr zufolge geht der Embryo aus dem Samen des Mannes hervor, die Knaben werden rechts, die Mädchen links erzeugt. Diese und eine ähnliche auch Heraklit zugeschriebene Behauptung ist jetzt erst durch 
Geburten von Kindern beiderlei Geschlechts nach einseitiger Ovariotomie widerlegt.

Empedokles von Akragant (geb. um 490, gest. um $430)$ bildete die Lehre aus, der zufolge alles aus den vier „Elementen“ (

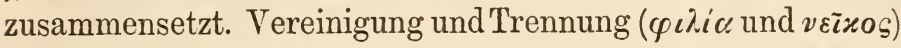
sind die weltbestimmenden Urkräfte. Die lebenden Wesen vervollkommneten sich allmählich. Sie entstanden (zuerst die Pflanzen, dann die Tiere) durch Zusammenfügung einzelner Teile. Viele aber (die Monstren) waren unfähig sich zu erhalten in dem allgemeinen Streit (ž॰ı); die lebensfähigen pflanzten sich fort. Hier sind noch deutlichere Anklänge an das Konkurrenzprincip Darwins, als bei Heraklit. Wie bei diesem ist die allbelebende Wärme von der größten Bedeutung. Ferner meint Empedokles, wenn das Blut nach oben gehe, entstehe Exspiration, nach unten Inspiration, und hat schon eine Ansicht über die Sinnesreize (áróg̣óoıcı), welche von den wahrgenommenen Dingen stammend auf die Organe einwirken. Ihm ist das Gehirn Seelensitz und Erzeuger des Samens. Er vergleicht schon den Pflanzensamen mit dem Tierei.

Die Atomisten, besonders Demokrit (gest. 361), des Leukipp Schüler, suchten alle Erscheinungen also auch die des Lebens, auf Bewegungen von Atomen zurückzuführen. Die Atome entstehen nicht und sind unzerstörbar. Jede Veränderung beruht auf Trennung und Verbindung derselben (Erhaltung der Materie). Die Atome sind das einzige Existierende, die Empfindungsarten, z. B. süß, warm, farbig existieren nur subjektiv und täuschen. Alle Empfindungsarten sind auf Tastempfindung zurückzuführen. Die Seele ist aus glatten kugeligen Atomen zusammengesetzt, wie das Feuer, und durchdringt das All, Wärme und die Lebenserscheinungen erzeugend. Die Atome derselben sind die beweglichsten. Nicht ein geistiges Princip, sondern mechanische 
Notwendigkeit oder das „Schicksal“ ist für die Weltgestaltung mit allen Lebenserscheinungen bestimmend.

Platon (geb. 429, gest. 348) wies der Seele des Menschen, die er teilte, als Sitze an: den Kopf für den Verstand (vožs),

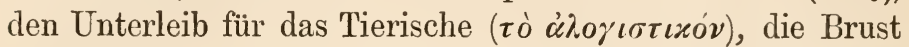
für das Gemüt $(\theta v \mu о \varepsilon \iota \delta \varepsilon s)$. Ihm war die ganze Welt ein lebendiges Wesen mit einer Seele. Alle lebenden Wesen, nämlich die Götter, die in der Luft, die im Wasser und die auf der Erde lebenden Körper sind ihm Entwicklungsformen der Uridee Mensch.

Wie Plato verlegte der Pythagoräer Philolaos die Vernunft und die Seele in das Gehirn (menschliches Princip), die Empfindung und Begierde in das Herz (tierisches Princip), die Ernährung in den Darm (pflanzliches Princip). Die Geschlechtsorgane vereinigen in sich alle drei Principien. Das Herz ist der Ursprung der Adern; in diesen befindet sich das in allen Gliedern stark bewegte Blut.

Ein anderer Pythagoräer, Alkmä on (um 500), bezeichnet das Gehirn als Sitz der Seele, mit welchem sämtliche Sinnesorgane zusammenhängen, so daß die Findrücke von außen auf besonderen Wegen in dasselbe eintreten. Er behauptete sonderbarer Weise, das Eierweiß, nicht der Dotter, sei die Nahrung bei den Tierembryonen und der Fötus des Menschen nehme durch den Mund im Uterus Nahrung auf. Ferner führte er, wie Empedokles, die Gesundheit auf das Gleichgewicht der vier Elemente, den Schlaf auf Änderung der Blutverteilung zurück. Ein dritter Pythagoräer, der Arzt Elolathes behauptete schon, die Gesundheit sei durch die Harmonie der Säfte des Körpers bedingt.

Hippokrates (geb. um 470, gest. um 364), der Vater der Medizin, hat um die Physiologie hauptsächlich das Verdienst, die luftigen Spekulationen der Naturphilosophen mehr oder weniger beseitigt und der Erfahrung eine größere 
Bedeutung für die Erkenntnis der Lebenserscheinungen zuerteilt $\mathrm{zu}$ haben. Aber soviel er auch beobachtete, erklärt hat er nicht. Das Gehirn ist ihm zufolge kalt und schleimig. Das Blut, der Schleim und die Galle (die schwarze aus der Milz und die gelbe aus der Leber) in einer gewissen

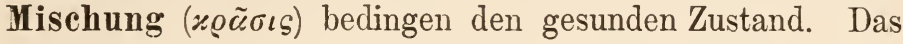
Blut entsteht in der Leber, gerinnt außerhalb der Gefäße, und durch Schlagen wird die Gerinnung verhindert. Es bilden sich dann Fasern (ives). Die Epiglottis verhindert das Eindringen der Speise in die Luftröhre. Die Herzklappen schließen dicht. Lebensursache ist die angeborene Wärme (žuчvтоv $\theta \varepsilon \rho \mu o ́ v)$, welche durch das im Herzen gebildete Pneuma in den Gefäßen bewegt wird. Das von den späteren Hippokratikern angenommene belebende Prin-

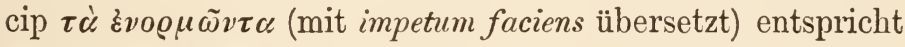
der Lebenskraft, auch der des Platon. Hippokrates selbst hat den Begriff nicht und bedient sich des Ausdrucks nicht.

Unter den ersten Nachfolgern des Hippokrates, welche als praktische Ärzte viel, als Physiologen nichts von Bedeutung leisteten, ragt Polybos hervor. Er beobachtete das bebrütete Hühnerei und schrieb das Entstehen der Knaben einer größeren Kraft des Samens zu.

Mit den ersten Hippokratikern schließt die erste Periode naturgemäß ab. Eine selbständige Physiologie existiert hier noch nicht. Spekulationen der Ärzte und Philosophen über das Leben ohne gründliche Beobachtungen, ohne Achtung vor den Thatsachen, kennzeichnen die ganze Epoche. Denn so vortrefflich Hippokrates als Arzt wirkte, beobachtend und eingreifend, so vieles er als Pathologe leistete, indem er empirisch begründete Regeln aufstellte und methodisch verfuhr - er sagte: der Arzt müsse die Natur des menschlichen Körpers erforschen, um über die Wirkungen der Krankheitsursachen urteilen zu können so wenig hat ihm die Physiologie als solche zu verdanken. 
Bemerkenswert ist in der ganzen Zeit die Neigung der besten Denker, das Leben auf Wärme (Feuer) zurückzuführen und einem gasförmigen Stoff eine Hauptrolle für die Inganghaltung des Lebens zuzuschreiben. Man wird an den Sauerstoff und die tierische Verbrennung erinnert.

\section{Zweite Periode.}

Die zweite Periode wird durch eben das charakterisiert, was der ersten fehlt; es werden physiologische Thatsachen gesammelt, durch Beobachten wird manche physiologische Entdeckung von Wichtigkeit gemacht und mit großem Scharfsinn, besonders von Aristoteles (geb. 384, gest. 322), in künstliche theoretische Verbindung gebracht. Es ließ sich sogar, durch Zusammenfassen aller physiologischen Angaben des Aristoteles über die Zeugung, Atmung, Ernährung, Sinnesthätigkeit ein System der Physiologie aufbauen, welches, trotz aller unkritischen dogmatischen Behauptungen und zahlloser Angriffe, Entstellungen und Zusätze fast zwei Jahrtausende hindurch unter dem Namen der aristotelischen Physiologie sich erhielt.

Aristoteles leitete alle Lebenserscheinungen $a b$ von der natïrlichen Wärme, die am Blute haftet. Centralherd der Wärme und Blutbewegung ist das schlagende Herz, von dem aus durch pulsierende Gefäße die Teile, wie Gärten mit Wasser durch immer aufs neue sich verzweigende Kanäle, mit Blut versorgt werden. Das Blut ernährt die Organe und verleiht ihnen Beweglichkeit und Empfindlichkeit. Die Luft wird beim Einatmen in die Lungen und von da in das Herz gebracht. Das Blut wird aus der im Magen und Darm verdauten Nahrung bereitet, indem daraus durch die

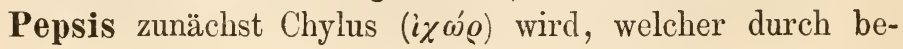


sondere Gefäße in das Herz gelangt. Die Wärme des Herzens erhält das Blut flüssig. Die unbrauchbaren Nahrungsreste verlassen durch Darm und Nieren den Körper. Der Harn wird aus dem in die Nieren fließenden Blute abgeschieden und geht durch die Ureteren in die Blase. Das Gehirn ist empfindungslos, kalt, blutleer, bereitet den Schleim, das Herz Sitz der Seele mit ihren Entelechien (Zweckthätigkeiten). Die Sinnesorgane finden sich am Kopf, damit sie vor übermäßiger Erwärmung durch das Blut geschützt seien. Die Sinneslehre des Aristoteles ist seine schwächste Theorie: Wasser ist der wesentliche Bestandteil der Augen, Luft das Wesentliche für das Ohr, dem sie den Schall zuführt, Wasser und Luft zusammen dem Geruch notwendig, Erde dem Tastsinn. Nur drei Farben werden unterschieden. Die Funktionen der Zeugungsteile werden ebenfalls in willkürlicher Weise beschrieben, aber in der Tiergeschichte und Zeugungslehre des Aristoteles, welche der älteste erhaltene Versuch einer vergleichenden Physiologie überhaupt ist, finden sich viele merkwürdige Angaben, Probleme und Entdeckungen. Die Parthenogenesis der Bienen, die Hektokotyliø der Cephalopoden waren Aristoteles bekannt. Er sagte, der Fötus werde durch die Nabelgefäfe mit dem Blute der Mutter ernährt, wie die Pflanze durch ihre Wurzeln, und er entdeckte das punctum saliens, nämlich das schlagende Herz in dem einige Tage bebrüteten Vogelei. Übrigens glaubte er an die Urzeugung vieler Tiere.

Die Aristotelische Physiologie hat den Vorzug, die Lebensvorgänge im Zusammenhange erklären zu wollen, den Fehler auf Grund einer Zweckmäligkeit zu erklären, durch Einsetzung der Entelechien. Dadurch leidet die causale Erklärung. Trotzdem hat das Gemisch von Dichtung und Wahrheit, welches zuerst als eine Art Codex der Physiologie, dann als Anregung zur Untersuchung wichtig war, fast ohne Unterbrechung bis in das siebzehnte Jahrhundert in hohem 
Ansehen gestanden, und noch jetzt sind noch lange nicht alle physiologischen Aussprüche des Aristoteles verständlich oder alle seine Irrtümer thatsächlich ausgemerzt.

Um die schnelle Verbreitung der physiologischen Lehren des Aristoteles erwarb sich die größten Verdienste Theophrast (geb. 371, gest. 286), der Begründer der Pflanzenphysiologie. Er schrieb auch ein Buch über die Empfindungen.

Straton von Lampsakos (um 340), der Physiker genannt, erklärte die Seele für die Summe der Empfindungen, schrieb über die Zeugung und über die menschliche Natur.

Originelle Hypothesen über die tierischen Säfte, den Puls, die "Lebensgeister" in den Arterien stellte der Arzt Praxagoras von Kos (um 350), unter den sogenannten Dogmatikern hervorragend, auf. Er war der Lehrer des ersten Experimental-Physiologen, des Herophilos (um 300). Diesem, der durch unmittelbare Naturbeobachtung wesentlich von den Dialektikern abweicht, sind vier Kräfte für das Leben maßgebend: die ernährende, erwärmende, empfindende, denkende Kraft. Ihm waren die gefüllten Chylusgefäfse, die Mesenterialdrüsen bekannt, ihm auch wird die Unterscheidung von Bewegungs- und Empfindungsnerven zugeschrieben. Er vervollständigte die Aristotelische Physiologie, lehrte, daß die Atmung auf einer Systole und Diastole der Lungen beruhe, daß das Pneuma durch die Lungen in das Blut trete, und meinte, der Puls entstehe durch eine vom Herzen ausgehende Thätigkeit der Arterien. Er und der ihm kongeniale Erasistratos (gest. 280), Häupter der Alexandrinischen Schule, haben auch darum für die Physiologie eine große Bedeutung, weil sie zuerst an Lebenden (und zwar an Ziegen und zum Tode verurteilten Verbrechern) Zergliederungen ausführten. Diese Vivisektionen waren aber unmethodisch. Erasistratos gelangte zwar zur Annahme der anatomischen Verbindung von Arterien und 
Venen durch die Kapillaren, hielt diese aber für verschlossen im gesunden Zustande. Er unterschied bereits Bewegungsund Empfindungsnerven, sah die leeren und gefüllten Chylusgefäße an lebenden oder eben getöteten Böcken und meinte, sie seien den Arterien ähnlich. Den Puls erklärte er für eine durch die Systole des Herzens verursachte Bewegung des Blutes und des Pneuma in den Arterien.

Unter den sehr zahlreichen Ärzten, welche von Alexandrien aus die Lehren des Aristoteles, Herophilos und Erasistratos nach allen Richtungen verbreiteten und anwandten, den sogenanten Empirikern, war kein namhafter Physiolog; die meisten verhielten sich gegen jede Theorie des Lebens gleichgültig, viele feindselig. Dasselbe gilt von den Mi th o dikern, von denen allein der vielseitige, besonders um die Physiologie der Schwangerschaft und Geburt hochverdiente Soranus (um 110 n.) die Lebenserscheinungen auch theoretisch betrachtet. Von den späteren Ärzten sind die Pneumatiker Athenaeus und Aretaeus (beide um 50 n.) zu nennen. Ersterer erklärte das Leben für eine Wirkung des Feuers und des Pneuma, verwarf die atomistische Erklärung und trat dem rohen Empirismus entgegen. Aretaeus wußte, daß das Arterienblut hellrot, das Venenblut dunkelrot ist. Er bleibt bei der angeborenen Wärme der Früheren als Lebensprincip, bedient sich aber - und zwar, wie es scheint, zum erstenmal - des Ausdrucks Lebens-

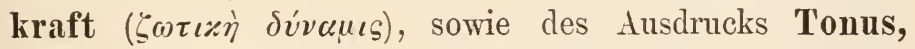
( óvo૬) wissenschaftlich, beiden Begriffen eine große Bedeutung zuschreibend. Er läßt das Blut in der Leber entstehen und das Pneuma, das Kalte und Warme, das Trockene und Feuchte, wie Athenaeus und die Früheren, bei den Lebensvorgängen die Hauptrollen spielen. Er ragt übrigens durch seine vorzügliche Beobachtungsgabe hervor. Ton anderen Ärzten dieser Periode ist für die Physiologie nicht unbedeutend: Rufus von Ephesos (um 50 n.), welcher alle körperliche Thätigkeit, nicht allein ILtilität und Empfindung 
auf die Nerven zurückführte und zum erstenmal die Herzbewegung und den Puls genau beschrieb. Am Pulse unterschied er Größe, Schnelligkeit, Fülle und Frequenz und untersuchte ihn in den verschiedenen Lebensaltern. Doch wird die Echtheit der Schrift darüber bezweifelt. Archigenes schrieb (um 100 n.) ausführlich über den Puls und über den Schmerz.

Alle anderen Mediziner dieser Zeit, unter denen die berühmtesten Ärzte, haben für die Physiologie wenig oder nichts von Bedeutung geleistet.

Auch die Naturphilosophen haben für die Entwicklung derselben nichts von Belang gethan, es sei denn, daß man die Erneuerung der demokritischen Atomistik durch die Epikuräer dahin rechnet. Der (um das Jahr 124 geborene) Arzt A s kle piades machte sogar den Versuch, eine atomistische Lehre von den Lebenserscheinungen im gesunden und kranken $\mathrm{Zu-}$ stande aufzustellen, vernachlässigte aber die Anatomie.

\section{Dritte Periode.}

Im ersten Jahrhundert der jetzigen Zählung gab es noch keine beschreibende und erklärende Wissenschaft vom Leben im gesunden Zustande. Die Zerfahrenheit, die Gleichgültigkeit und unverhohlene Abneigung gegen theoretische Untersuchungen unter den Ärzten, die unwissenschaftliche Ausübung der Heilkunde erreichten ihren Höhepunkt.

Da erschien Claudius Galenus von Pergamos (geb. 131 gest. um $200 \mathrm{n}$.). Mit ihm beginnt die dritte Periode. Inmitten der sich streitenden Parteien bildete er allein und zum erstenmal die Physiologie zu einer selbständigen Wissenschaft aus. Er schuf die Physiologie als Lehre von dem Gebrauch der Organe (usus partium), experimentierte an lebenden Tieren (besonders Schweinen) und stellte sich 
Fragen, welche er durch Vivisektionen beantwortete. Ferner trat Galen allen seinen Vorgängern und Zeitgenossen entgegen, indem er die Physiologie für die Grundlage der Medizin erklärte. Er ist endlich der erste, welcher die Funktionen methodisch und vollständig, soweit es zu seiner Zeit geschehen konnte, beschrieb und erklärte. Daß er dabei einerseits die Lebensvorgänge auf natürliche Ursachen zurückzuführen sucht, andererseits überall ihre Zweckmäßigkeit mit Ausdrücken der Bewunderung über die Weisheit des Schöpfers preist und mit zur Erklärung verwendet, ist um so begreiflicher, als Galen im wesentlichen sich auf Aristoteles stützt, wenn er ihm auch oft widerspricht. Durch Galen wurde erst die Aristotelische Physiologie, wie die Hippokratische Pathologie Gemeingut der Mediziner. Und daß die Galenische Physiologie anderthalb Jahrtausende, wo man sie kannte, in Geltung blieb, erklärt sich eben durch jene doppelseitige Behandlung. Denn die Ärzte acceptierten sie wegen ihres Materialismus und die Geistlichen wegen ihrer Teleologie. Da Galen ein außerordentlich scharfsinniger Denker, ein ungemein gelehrter, fleißiger, systematisierender, wahrheitsliebender Arbeiter und geschickter Arzt war, welcher die Praxis über der Forschung nicht vernachlässigte, und umgekehrt, so erscheint er von allen Medizinern am meisten befähigt, die Physiologie als Wissenschaft für sich zu begründen. Und daß in dem ganzen folgenden Jahrtausend Galens durch seine Geschlossenheit und Originalität imponierendes physiologisches System als Kanon galt, dem fast niemand ernstlich widersprach, zeugt für sein Genie. Die Geschichte keiner Wissenschaft kann von einem solchen Erfolge berichten. Der an den Namen Galen sich knüpfende Autoritätsglaube findet seines Gleichen nur in der Geschichte der Religionen und wird an Intensität und Dauer selbst von dem Glauben an Aristoteles nicht übertroffen.

Preyer, Physiologie. 
Die vier Elemente des Empedokles behält Galen bei, auch die ersten oder einfachen Qualitïten, Wärme, Kälte, Feuchtigkeit und Trockenheit des Aristoteles, und die Bestandteile der Gewebe - wie bei Hippokrates, Blut, Schleim und Galle (schwarze und gelbe) - sind ihm aus jenen Elementen zusammengesetzt. Sie heißen Kardinalsäfte. Durch die Mischung oder Krasis der Elemente entstehen die zweiten oder zusammengesetzten Qualitäten, d. h. die die Sinneseindrücke veranlassenden Eigenschaften der Dinge, das Farbige, das Harte, das Bittere usw. Eine ganz gleichmäßige Mischung der Kardinalsäfte macht die vollkommene Gesundheit aus, welche nicht vorkommt. Die gewöhnliche Gesundheit oder Euexie ist bedingt durch ein gewisses Verhältnis der festen zu den flüssigen Teilen. Die neun Temperamente, eines durch gleiche Mischung der vier ersten Qualitäten bedingt, vier einfach (nämlich ein warmes, kaltes, feuchtes, trockenes Temperament) und vier zusammengesetzt (sanguinisch, cholerisch, phlegmatisch, melancholisch) modifizieren die Gesundheit. Die Galenische Lehre von den Temperamenten, die Grundlage seiner Pathologie, ist noch immer nicht ganz durch Besseres ersetzt. Sie beruht auf sehr guten Beobachtungen.

Die Belebung wird durch die Seele bedingt. Die Lebensprozesse verursacht das dreifache Pneuma, das psychische im Gehirn und in den Nerven, das belebende

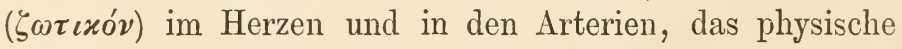
in der Leber und in den Venen. Die Kraftäußerungen dieser drei Imponderabilien, die psychische, sphygmische, physische Dynamis (entsprechend den Spiritus animales, vitales, naturales), bedürfen der Aufnahme des $\pi \nu \varepsilon \tilde{u} \mu c \zeta \omega-$ $\tau \iota x o ́ v$ (welches dem Sauerstoff entspricht) beim Atmen. Die psychische Dynamis bedingt das Vorstellen, das Gedächtnis, das Denken und teilt den Nerven das Vermögen zu empfinden, den Bewegungsorganen das Bewegungsvermögen 
mit. Die sphygmische Dynamis bedingt den Mut, den Zorn, die Charakterstärke und durch die Arterien, welche sie pulsieren macht, die Eigenwärme. Die physische Dynamis bedingt die sinnlichen Begierden und, durch die Venen, die Ernährung und Blutbildung. Jede Zustands-

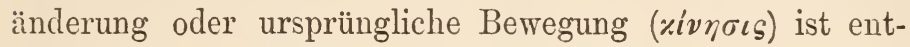
weder eine qualitative, $d . h$. stoffliche, chemische (alteratio

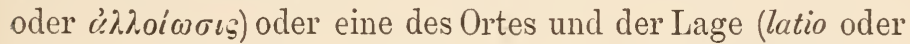
póoc). Alle andern Bewegungen sind zusammengesetzt, so auch alle Verrichtungen, Thätigkeiten, Arbeiten oder Leistungen des lebenden Körpers, d. h. die Fnergieen

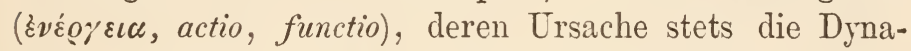
mis (facultas), d. h. das Vermögen (die Kraft), und deren Wirkung stets das Tollbrachte (čorov, upus, Werk) ist. So viele Thätigkeitsarten, Funktionen oder Energieen, so viele Fakultäten giebt es. Vor der Geburt des Menschen wirkt hauptsächlich die Entwicklungs-Funktion oder Genesis, welche aus der umändernden (chemischen) Energie (čv $\dot{\alpha} \lambda \lambda_{0} \iota \omega \tau\left(x \eta^{\prime}\right)$ und der bildenden (plastischen) sich zusammensetzt $\left(\dot{v} v \cdot \pi \lambda \boldsymbol{\alpha} \sigma \tau\left(\boldsymbol{x} \boldsymbol{i}^{\prime}\right)\right.$. Von der Geburt bis zum beendigten Manneswachstum wirkt die rermehrende Energie oder Auxesis, von da an bis zum Tode die ernährende Energie oder Threpsis hauptsächlich.

Die Energieen, Aktionen oder Funktionen sind entweder Hauptfunktionen ( $F$. principes), oder unterstïtzende Funktionen ( $F$. ministrae), letztere entweder allgemeine (publicae), den gesamten Körper betreffende, oder besondere (privatae), an einen Teil desselben gebundene. Durch die dreifache Lebenskraft ergeben sich drei Gruppen ron Funktionen: 1) Animalische und zwar a) Hauptfunktionen: die geistigen Thätigkeiten; b) unterstützende: Sinnesthätigkeit und willkürliche Bewegung; 2) Vitale und zwar a) Hauptfunktionen: Herzthätigkeit (im linken Herzen werden die Lebensgeister erzeugt und 
Wärme gebildet, was übrigens auch in der Leber geschehen soll, der Ursprungstätte der Venen), b) unterstützende: Atmung und Puls; 3) Naturale und zwar a) Hauptfunktionen: Ernährung und Wachstum, einerseits des Individuum, andererseits der Art (d. i.: Erzeugungs - oder Sexualfunktionen), b) unterstützende: die Anziehung ( $(\varepsilon \varepsilon \rho-$ $\gamma \varepsilon \iota \alpha \varepsilon \varepsilon x \tau \iota x \eta^{\prime}$, Attraktion), die Zurückhaltung (

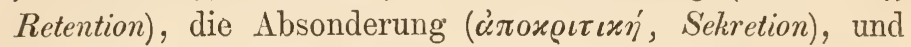
die Ausstoßung ( eignung, Assimilation (bei der Verdauung Concoctio) sind vorbereitende Funktionen: besonders Kauen (Mastikation), Schlucken (Deglutition), Chylusbildung (Chylifikation).

Von den physiologischen Experimentaluntersuchungen Galens sind hervorzuheben: Totale Quer - und Längstrennung des Rückenmarks, Durchschneidung des Nervus vagus und der Intercostalnerven mit Beobachtung der Respiration, Herzthätigkeit und Stimme dabei. Der Herzstoß entsteht durch Anschlag an die Brustwand. Das Blut wird aus dem Chylus in der Leber bereitet. Die Bewegungen kommen zu stande durch einen Zug der Nerven wie beim Klingelzug. Das von den Hohlvenen stammende venöse Blut, welches durch die Pulmonalarterie aus dem rechten Herzen in die Lungen gelangt, dient zur Ernährung der Lungen. Durch die Pulmonalvenen geht das eingeatmete Pneuma in das linke Herz, wo es das direkt durch die Herzscheidewand ebendahin aus dem rechten Herzen gelangte Blut belebt. Trotzdem Galen bewiesen hatte, daß die Arterien im Leben Blut und keine Luft enthalten, trotzdem er den Ductus arteriosus Botalli entdeckte, blieb er bei jener falschen Beschreibung des Lungenkreislaufs und meinte, die Anastomosen der Arterien und Venen im Körper seien da, damit auch die Venen den Nutzen des Pulses und der Atmung hätten. Überhaupt verdirbt Galen seine richtigen Vorstellungen durch die Erklärung nach Zwecken. Ihm 
geschieht, wie bei Aristoteles, alles im Körper entweder aus Notwendigkeit oder wegen eines Zweckes. Mit diesen beiden begründete er seine Theorien der Sinne, der Zeugung usw., so daß sämtliche zu seiner Zeit bekannten Lebenserscheinungen ron ihm irgendwelche Erklärung erhielten. Daher das Ansehen Galens in den unkritischen Jahrhunderten nach seinem Tode.

Nur Nemesius, Bischof in Phönicien, welcher im 4. Jahrhundert ein Buch über die Natur des Menschen schrieb und ihn einen Mikrokosmos nannte, ihn mit den Tieren und Pflanzen vergleichend, ragt etwas hervor unter den vielen Unselbständigen.

Die sogenannte Arabische Physiologie, deren Hauptvertreter der Arzt A vicenna aus Bokhara (geb. 980, gest. 1037) war, und die Physiologie der Arabisten im 14. Jahrhundert haben, ebensowenig wie die gleichfalls der unmittelbaren Naturforschung abholden, dem Bücherstudium zugethanen Scholastiker in Deutschland und die zahlreichen medizinischen Schulen im 15. Jahrhundert, die Aristotelische und Galenische Physiologie wesentlich modifiziert und keine bedeutende Entdeckung den überlieferten physiologischen Angaben hinzugefügt. Sie haben das Verdienst, viele alte Schriften von physiologischem Interesse durch Übersetzungen in das Arabische verbreitet und erhalten zu haben. Doch galt durchweg Galens Lehre auf diesem Gebiet uneingeschränkt und wurde teils erweitert, teils sklavisch nachgebetet. Kein Arzt oder Naturforscher von 200 bis 1500 kann als selbständiger Physiologe bezeichnet werden. Nur wenige Specialuntersuchungen von Bedeutung fallen in diesen langen Zeitraum. So hat Alhazen (gest. 1038) große Verdienste um die physiologische Optik. Er unterschied bereits im Auge das Kammerwasser von der Linse und dem Glaskörper und vier Häute, darunter eine tunica retisimilis und zeigte, daß von jedem Objektpunkt 
unzählige Lichtstrahlen in das Auge gelangen. Auch rersuchte er das Einfachsehen mit zwei Augen zu erklären und faßte das Größerwerden der Mondscheibe am Horizont als optische Täuschung auf. Auch Vitello (im 13. Jahrh.) förderte die Lehre rom Sehen. Salvino degli Armati gilt als Erfinder der Brillen (Ende des 13. Jahrh.). Leonardo da Vinci (geb. 1452, gest. 1519) gab schon eine auf die Camera obscura basierte Theorie des Sehens, die Maurolykus (geb. 1494, gest. 1575) vervollkommnete.

Albertus Magnus (gest. 1280) nahm bereits bestimmte Gehirncentren an mit Lokalisation der Funktionen.

Die berühmt gewesene Physiologie des Fernelius (geb. 1497, gest. 1558) ist noch Galenisch, so sehr er sich in einzelnen Punkten dem Galenismus entgegenstellte. Er meint, die verschiedenen Funktionen seien bedingt durch die verschiedene elementare Struktur der Organe und tremnte als einfaches geistiges Wesen die Anima von den materiellen Spiritus ab. Sie beherrscht die psychischen Vorgänge. Noch im 17. Jahrhundert wurden Universitätsvorlesungen über Physiologie nach Avicemna gehalten (z. B. in Würzburg).

In ihren Grundfesten erschüttert wurde aber diese Galenische Lehre durch den Theosophen Philippus Aureolus Theophrastus Paracelsus Bombastus von Hohenheim (geb. 1493, gest. 1541), welcher unter Annahme von mehreren dem Neuplatonismus entnommenen Toraussetzungen eine stark religiös gefärbte Auffassung des lebenden Organismus entwickelte, denselben für ein Werdendes und Vergehendes nicht fertiges erklärte, das Leben durch Fäulnis aus $\boldsymbol{M u}$ cilago entstehen ließ und es auf Sulphur, Mercurius und Sal zurückführte, d. h. auf verbrennliche, flüchtige und feuerfeste Elemente, und trotz seiner Verachtung der Anatomie durch große Originalität der Ideen bei vielen Medizinern Anklang fand. Er reformierte keineswegs die Physiologie, aber er setzte an die Stelle der alten Lehren 
ganz neue, trug Deutsch vor und brach hierdurch allein schon die Macht der physiologischen Scholastik des Aristoteles, Galen und Avicenna. Noch schärfer trat gegen Galen auf der Theosoph Joh. Baptista van $\mathrm{Helmont}$ (geb. 1577, gest. 1644), wesentlich Paracelsist, dem aber der Mensch nicht Mikrokosmos, Abbild der Natur, sondern Abbild Góttes war und als Lebensprincip ein Archeus insitus galt. Helmont begründete die Iehre von den Gasen (ron ihm stammt das ron "Chaos" abgeleitete Wort Gas), die Lehre von den Formenten (die Terdaumng durch die Magensäure beruht nach ilım auf Fermentwirkung), die Lehre ron den verschiedenen Graden des Lebens (vita minima s. prima, media, ultima). Der Begriff des latenten Lebens findet sich bei ihm zuerst, aber Helmont rernachlässigte die Anatomie, daher seine neuen Antigalenischen sehr christlichen Anschauungen und namentlich auf chemische Kenntnisse basierten Untersuchungen zwar erhebliche Fortschritte, aber keine gründliche Reform der Physiologie herbeiführten. Diese wurde erst durch die Ausbildung der Anatomie zu jener Zeit ermöglicht, und zwar ist der erste Anatom, welcher, obwohl warmer Verehrer Galens, ihm thatsächlich und entschieden widerspricht, Michael Servet, genannt Michael Villanoranus (geb. 1511, gest. 1553). Er beschriel zuerst ziemlich korrekt den Lungenkreislauf, leugnete wegen der Undurchgängigkeit des Herzseptum, daß Blut direkt rom rechten zum linken Herzen fließe, höchstens könne etwas durchschwitzen, und vertrat energisch seine Behauptung, daß in den Lungen das renöse Blut sich mit der eingeatmeten Luft rermischt. Den experimentellen Beweis dafür, daß die Lungenrenen Blut enthalten, lieferte erst Realdo Colom bo in Padua (1559), der Plagiator Servets, durch Tivisektionen. Der vielseitige Cesalpin (1571) war der Entdeckung des großen Blutkreislaufes nahe. Er untersuchte 
auch die Säftebewegung in den Pflanzen, welche er sehr bestimmt ron der der Tiere unterschied.

In diese Periode gehört auch Giambattista della Porta (geb. 1538, gest. 1615), der wiederum das Auge mit der Camera obscura verglich.

\section{Vierte Periode.}

Durch die Anthropotomie, besonders Vesals Werke und die zwar nicht zu begründende aber originale Theosophie, erwachte die Selbständigkeit des Denkens auf naturwissenschaftlichem Gebiete im 16. Jahrhundert und fand in den (im 13. Jahrhundert schon zum Teil gegründeten) Universitäten Nahrung und Pflege. Der Galenismus in der Medizin wankte, aber die Galenische Physiologie stand noch in allgemeinstem Ansehen, und durch die Wiederbelebung der klassischen Studien kam auch Aristoteles als Naturforscher trotz seiner Entelechien wieder zur Geltung. Da wurde mit einem Male von gewaltiger Hand das ganze ehrwürdige alte AristotelischGalenische Lehrgebäude der Physiologie niedergerissen.

William Harvey (geb. 1578, gest. 1657) war es, der durch die Entdeckung des Blutkreislaufes diese größte Leistung auf dem Gebiete der Physiologie vollbrachte und dadurch die Bahn für die Ausbildung der methodischen Experimentalphysiologie im eigentlichen Sinne schuf. Denn wenn auch schon die Alexandriner und Galen und die Paduaner Vivisektionen ausgeführt hatten, so waren sie darin doch fast ohne Nachfolger geblieben; es hatte wenigstens darin niemand das wichtigste Hilfsmittel physiologischer Forschung gefunden, sonst wäre der Blutumlauf früher entdeckt worden. Der Arzt Harvey steht als Experimentator, Denker, Lehrer, Schriftsteller und Reformator gleich gro $B$ da. Sein mit 
Hintansetzung des Autoritätsglaubens auf unmittelbare Beobachtung der lebendigen Natur unablässig gerichtetes Forschen mußte seinen Zeitgenossen ebenso befremdlich erscheinen, wie die Sicherheit, mit der er auf Grund desselben die hergebrachten Lehren für falsch erklärte. Seine Größe bekundet sich ebenso durch seine logische, aller Willkür abholde Nethode, durch die er die Irrtümer seiner Vorgänger bloßlegte und die Wabrheit auffand, wie durch die Tragweite seiner Entdeckung selbst, welche die Umgestaltung der gesamten Heilkunde bewirkt hat. Die 1628 erschienene Darstellung derselben ist sachlich und formal vollendet und noch jetzt mustergültig. Außerdem hat Harvey, von dem das berühmte "omne vivum ex oro" stammt, das große Verdienst, zum erstenmal an neugeborenen Tieren, an dem mit einem einfachen Vergrößerungsglase betrachteten Hühnerembryo und Säugetierfötus experimentiert zu haben. $\mathrm{Er}$ entdeckte, daG das Herz des letzteren lange vor der Geburt schlägt, was Servet trotz Galen geleugnet hatte. Von den Gegnern Harveys wirkte keiner nachhaltig, wohl aber sind seine Anhänger von großer Bedeutung für die schnelle Anerkennung seiner Lehre gewesen, namentlich Descartes (geb. 1596, gest. 1650). Diesem ist auch die Einsicht zu rerdanken, daß die lebenden Wesen physisch als Maschinen anzusehen sind. Er unterschied zuerst Reflexbewegungen von anderen Bewegungen, erkannte, daß die Wärme im Körper erzeugt wird, untersuchte die physiologischen Bedingungen der Leidenschaften, schuf eine ganz neue Theorie der sinnlichen Wahrnehmung. Unter anderem führte er die Accommodation des Auges auf Gestaltänderungen der Linse zurück, erkannte, daß die Pupille beim Nahesehen sich rerengt, ferner die auch von Scheiner (gest. 1650) gefundene Thatsache, daß nur ein Punkt auf einmal ganz deutlich gesehen werden kann, daß alle Mittel, die Entfernung zu schätzen, unsicher sind. Er verglich, 
wie Leonardo da Vinci 100 Jahre früher, das Auge mit einer Camera obscura und erörterte die Wirkung der Brillen. Auch die physiologische Akustik bereicherte Descartes. Er erkannte die von Mersenne (1618), dem trefflichen Akustiker, entdeckten Obertöne (den 2. und 3.) und gab eine rationelle Frklärung für die Ursache des Wohlklanges der durch kleine ganze Zahlen ausgedrückten Intervalle. Sogar die specifische Energie der Sinnesnerven spricht Descartes mit der größten Bestimmtheit aus und betont, daß die Dinge mit den Empfindungen nicht die geringste Ähnlichkeit haben. Diese und mehrere andere bedeutende physiologische Aperçus und Entdeckungen sichern Descartes eine hervorragende Stelle in der Geschichte der Physiologie, wenn er auch den Spiritus animales eine gewisse Rolle zuteilt und, was vor ihm übrigens Servet gethan hatte, den Sitz der Seele in die Zirbeldrüse verlegte. Er sagt aber, sie habe da nur ihren Hauptsitz und sei im ganzen Körper verbreitet.

Ferner wurde sehr früh Harvey verteidigt von Franz Deleboë Sylvius (geb. 1614, gest. 1672), welcher großen Wert auf die Anatomie als Grundlage der Physiologie legte. Er war zwar der mechanischen Erklärung, besonders der Atmung und Darmbewegung, zugethan, teilte aber den chemischen Prozessen, den Gärungen (Fermentationen) die Hauptrolle zu. Sein physiologisches System bildet den Ausgangspunkt der chemiatrischen oder jatrochemischen Schule in der Heilkunde.

Von ungleich größerer Bedeutung für die Ausbildung der Physiologie wurde die fast gleichzeitige Begründung der Biophysik durch den scharfsinnigen A lfo n s o B or elli (geb. 1608, gest. 1679), welcher, hierin zuerst in die Fußtapfen Harveys tretend, die von Galilei (1564 bis 1642) geschaffenen physikalischen Untersuchungsmethoden und Lehrsätze auf die Bewegungen der Tiere anwandte. Er war Mathematiker und vorzïglicher Physiker. Da vor ihm niemand von dieser Seite 
die Physiologie bearbeitet hatte, so fand er ein überaus fruchtbares Feld zu bebauen vor. Jedoch sind es weniger seine positiven Leistungen als seine damals ganz neue, jetzt wieder moderne Methode, welche ihm unsterblichen Ruhm sichert. Sein Lehrgebäude wurde die Grundlage der jatrophysischen, jatromechanischen, jatromathematischen Schule in der Medizin.

Nach der Erfindung des Mikroskopes bereicherten riele, besonders Malpighi und Leeuwenhoek (geb. 1632, gest. 1723), durch selbständige Beobachtungen über den Blutlauf in den Kapillaren, die Samenkörperchen und viele Gewebe, die Wissenschaft ron den Funktionen lebender Wesen, teils thatsächlich, teils theoretisch Harrey bestätigend.

Joh. Swamerdamm (geb. 1637, gest. 1685) stellte sogar myophysiologische Reizversuche an. Seine zahlreichen Beobachtungen sind für die rergleichende Physiologie, namentlich der Insekten, wichtig. Thomas Bartholin (geb. 1616, gest. 1680) untersuchte zuerst das Phosphorescieren derselben und anderer lebender Tiere, sowie rerwesender Stoffe (1669). Aselli entdeckte (1622) aufs neue, daß die Chylusgefäße in der Terdauung gefüllt sind.

Glisson (geb. 1597, gest. 1677) begründete eine rorläufige Lehre von der Irritabilität, welche die Ursache aller organischen Bewegung sei.

Mayow (geb. 1645, gest. 1679), ein ron seiner Zeit rerkannter Forscher ersten Ranges, überragt dieselbe durch erstaunlich klare Ansichten über die Verbrennung und Atmung, auch die Atmung des Ungeborenen. Er war der Entdeckung des Sauerstoffes, welchen er spiritus nitrocëreus nannte, selır nahe. Auch Willis (geb. 1622, gest. 1675 ) emancipierte sich schon von den unbefriedigenden Ausartungen sowohl der Jatrophysik, wie der Jatrochemie in der Physiologie, ebenso Baglivi (1673 bis 1707). Viele 
selbständige Untersuchungen fallen in diese Zeit, besonders von Gassendi (1592 bis 1655) und Sauveur (1653 bis 1716) über die auch ron Galilei behauptete Abhängigkeit der Tonhöhe von der Schwingungszahl, dann von Pascal (1653) ïber einige physiologische Wirkungen des Luftdruckes, sowie ron Mariotte (gest. 1684), dem Entdecker des blinden Fleckes, von Conrad Victor Schneider (1660) über die Schleimhäute (er widerlegte die alte Ansicht, daß das Gehirn Schleim absondere), von dem großen Astronomen Kepler (1571 bis 1630) über das Sehen, besonders die Accommodation, von Sanctorius (geb. 1561, gest. 1636) über die Perspiration, von Grimaldi (gest. 1663) über die Farben', von Hooke, der 1667 die Apnöe, von R. J. Camerarius (geb. 1665, gest. 1721), welcher die Sexualität der Pflanzen entdeckte. Kaspar Schott fand 1657, daß Injektion eines Purgans in die Venen eines Hundes, wie Einführung desselben in den Magen wirkt und Wein direkt in das Blut eingespritzt berauscht. Athanasius Kircher (geb. 1601) stellte viele merkwürdige, noch nicht gewürdigte physiologische Experimente an, z. B. über subjektive Farben. Ton ihm stammt aber das Experimentum mirabile mit dem erschreckten Huhn nicht her, obgleich es nach ihm benannt wird, sondern Daniel Schwenter beschreibt es bereits erheblich früher. Ein anderes Experimentum mirabile bezieht sich auf das embryonale Herz im geöffneten Ei. Auch Robert B oyle (geb. 1627, gest. 1691) stellte physiologische Versuche, besonders nach 0. v. Guericke's Vorgang mit der Luftpumpe an, über die Blutgase, über die Farben, über das Leuchten verwesender Stoffe, über die Ernährung der Pflanzen. Isaak Newton (geb. 1643, gest. 1727) nimmt schon durch seine Entdeckung der Abhängigkeit der Farben von der Brechbarkeit eine hervorragende Stelle in der Geschichte der Physiologie ein, die später durch Anwendung seiner Forschungsmethoden in die Reihe der exakten Disciplinen 
eintrat, nachdem einmal Harvey den Grund gelegt und F. Bacon (gest. 1626) von philosophischer Seite anregend gewirkt hatte.

Aber zunächst wurden von Unbefugten zahlreiche luftige Hypothesen aufgestellt, oft kritiklos die Annahmen der Physik und Chemie, z. B. der Äther, das Phlogiston auf physiologische Fragen angewendet und dadurch die ganze Physiologie bei vielen Ärzten in eben diesem glorreichen 17. Jahrhundert in Mißkredit gebracht. Selbst dem großen Boerhaave (geb. 1668, gest. 1738) gelang es nicht, ihr dauerndes und allgemeines Ansehen zu verschaffen, obwohl er die Wichtigkeit anatomischer (auch histologischer), chemischer und physikalischer Begründung hervorhob und die Extreme tadelte. Er ging bei der Lebenserklärung von der Bewegung aus, die durch das Nerrenprincip bewirkt sei. Seine Anhänger nannten seine Lehre „Dynamische Physiologie“ und hielten sie für epochemachend, obgleich er mehr durch Termeidung der Irrtümer seiner Torgänger und Zeitgenossen, als durch originale Schöpfungen die Physiologie förderte. Schon zu seiner Zeit gediehen die schlimmsten Ausartungen, welche von Harvey weit abführten und ungemein schädlich wirkten, namentlich das mechanisch-dynamische System von Friedr. Hoffmann (1660 bis 1742) und das animistische System ron Georg Ernst Stahl (1660 bis 1734). Jener nahm beseelte Monaden und einen Nerrenäther als Lebensursache an, dieser eine von ihm selbst nicht klar charakterisierte Anima, welche die Vorgänge im lebenden Körper unmittelbar beeinflusse. Der Schaden, welchen diese beiden sich bekämpfenden Systeme anrichteten, besteht hauptsächlich darin, daß an Stelle der von Harvey angewandten logisch-empirischen oder kausal-experimentellen Methode die Zwecke im Körper eine Hauptrolle spielten und die Achtung vor den Thatsachen verloren ging. Eine faktische Bereicherung durch irgendwelche bemerkenswerte Ent- 
deckung oder Erfindung erhielt die Physiologie durch keine der beiden geräuschvollen Schulen. Die Physiologie machte zu Anfang des vorigen Jahrhunderts Rückschritte durch bequeme Hypothesen hindurch, statt den 1628 durch die Entdeckung des Kreislaufs eröffneten, freilich mühsameren aber sicheren Bahnen weiter nachzugehen. Dem gänzlichen Verfall steuerte noch rechtzeitig Haller, mit welchem ein neuer Aufschwung der Physiologie beginnt.

Albrecht von Haller (1708 bis 1777) wird bezüglich seiner Verdienste um die Physiologie oft falsch beurteilt. Durch seine Irritabilitätslehre und andere experimentelle, im Harveyschen Geiste durchgeführte vorzügliche Untersuchungen, besonders seinen Streit mit Hamberger über die Atembewegungen bekundet er seine Selbständigkeit als Forscher und seinen scharfen Verstand, durch die erstaunlich vollständige Beherrschung des vor ihm geleisteten und die Kritik fast der gesamten physiologischen Arbeiten seiner Vorgänger war er mehr noch als durch eigene Untersuchungen in den Stand gesetzt, die Physiologie in umfassender Weise als eine besondere Wissenschaft in allen ihren Teilen neu darzustellen. Es war ihm beschieden, dieses Riesenwerk zu vollenden, und seine Schriften sind ein wahrer Thesaurus für die Geschichte der Physiologie. So groß aber seine Verdienste um die Physiologie sind, er hat sie weder durch eine epochemachende Entdeckung wie Harvey, noch durch eine neue Methode wie Descartes, noch durch eine entscheidende Experimental-Kritik der Arbeiten seiner Vorgänger gefördert, sondern durch fleißige Zusammenstellung des bis zu seiner Zeit geleisteten. Haller war nicht genial, aber so vollkommen beherrschte er die Thatsachen, daß seine Zusammenfassung derselben ihm den Ruhm des Begründers der neuen Physiologie verschaffte. Er war so sehr Anatom, daß er die Funktion als das ausschließliche 
Objekt der Physiologie nicht von der anatomischen Untersuchung zu trennen vermochte. Was er Physiologie nennt, ist in der That zum großen Teil eine durch Erläuterungen der Funktionen belebte Anatomie. Ferner war ihm der Begriff der Entwicklung zuwider. Er, der vortreffliche embryologische Untersuchungen ausführte, suchte mit einer gewissen Verblendung das Prädelineationsdogma gegen den genialen Begründer der Lehre von der Epigenesis Caspar Friedrich Wolff (geb. 1733, gest. 1794) aufrecht zu erhalten, so daß er die Einschachtelungstheorie geradezu mit seiner gewaltigen Autorität stützte. Endlich ist Hallers Abneigung gegen eine einheitliche Auffassung des lebenden Körpers als Maschine, welche ihn z. B. Descartes tadeln läßt, bemerkenswert. Seine fast beispiellose Thätigkeit als Kompilator, Kommentator (des Boerhaave), Herausgeber, Bibliograph, Referent und Recensent verhinderte vielleicht die Verfolgung physiologischer Probleme bis an ihre Grenzen durch das Denken. Immerhin beginnt mit Haller ein neuer Aufschwung, denn er zuerst gab eine vollständige Darstellung der Physiologie auf streng empirischer und naturwissenschaftlicher Basis, und er zuerst erkannte die Bedeutung der Erregbarkeit der Muskeln als einer von der Glisson'schen allgemeinen nicht klar erfaßten organischen Erregbarkeit verschiedenen Lebenseigenschaft.

Seine Irritabilitätslehre wurde nach zwei Richtungen entstellt: einmal durch John Brown (geb. 1735, gest. 1788), dessen widerspruchsvolles System in der Physiologie wenig Erfolg hatte und bei den Ärzten viel Unheil anrichtete, sodann durch die Anhänger des sogenannten Vitalismus, welche namentlich in Deutschland den Fortschritt in der Physiologie erschwert haben.

Während trotz desselben in Italien Spallanzani (geb. 1729, gest. 1799) und Felix Fontana (geb. 1730, gest. 1805), beide rührige Experimentatoren, in Frankreich 
der junge Bichat (geb. 1771, gest. 1802) und Vicq. d'Azyr (geb. 1748, gest. 1794), in England Stephen Hales (geb. 1677, gest. 1761), der Begründer der Hämostatik (1733) und Erforscher der Saftbewegung in den Pflanzen, sowie der große Pathologe John Hunter (geb. 1728, gest. 1793), in Holland J. Ingen-Houß (geb. 1730, gest. 1799), welcher die Atmung der Pflanzen und die Aufnahme der Kohlensïure durch die Pflanzen entdeckte, durch mannigfaltige bedeutende Leistungen die reine Physiologie bereichert hatten, kräftig die Thatsache von subjektiven Zuthaten, wie Haller, frei haltend, überwucherten in Deutschland die Lehren von der Lebenskraft, unter Vernachlässigung der mechanischen und chemischen Prozesse im lebenden Körper, das methodische Experimentieren.

Zwar arbeiteten auch in Deutschland nach Hallers Tode einige wenige, besonders J. G. Kölreuter (geb. 1733, gest. 1806) und C. G. Sprengel (geb. 1750, gest. 1816), die großen Pflanzenphysiologen, ferner of N.Eberle (geb.1798, gest. 1834), der Entdecker des künd, (1) Magensaftes und der Wirkung des Bauchspeichels auf Stärke und Fette, in rorzüglicher Weise experimentell, aber sie wurden damals nicht anerkannt, und im allgemeinen versank hauptsächlich durch den Einfluß der Philosophie in Deutschland die Physiologie in dem Sande der Spekulation. Sogar die größte Entdeckung auf dem Gebiete der Chemie, die des Sauerstoffes durch Priestley (1774) und Lavoisier, hatte keineswegs sogleich die Hebung physiologischer Forschung zur Folge, obwohl mit ihr die Grundlinien einer Theorie der Respiration, wie sie 100 Jahre früher schon Mayow geschaffen hatte, von Lavoisier (1777) aufs neue gefunden, die Sauerstoffaufnahme des venösen Blutes in der Lunge von Girtanner (1790) bewiesen war. Die Physiologen, auch Reil (geb. 1759, gest. 1813) und Blumenbach (geb. 1752, gest. 1840), waren, wie Burdach und Oken, 
zu sehr Naturphilosophen. Selbst nach der fundamentalen Entdeckung (1811 und 1821) der funktionellen Verschiedenheit der hinteren und vorderen Rückenmarksnerven durch Charles Bell (geb. 1774, gest. 1842) und der Entdeckung des Noeud vital (1812) durch Le gallo is (geb. 1770, gest. 1814) behielt in Deutschland das Spekulieren die Oberhand über die Empirie.

Nur in einem Gebiete, dem der Elektrophysiologie, wurde mit großem Erfolge von vielen experimentell gearbeitet. Die 1773 von Walsh und 1782 von Broussonet entdeckten elektrischen Entladungen der Zitterfische und völlig unabhängig davon die von Galvani (geb. 1737, gest. 1798) entdeckte tierische Elektricität, welche Volta nicht anerkennen wollte, führten zu umfangreichen Forschungen. Besonders Alexander von Humboldt (1797), J. W. Ritter (geb. 1776, gest. 1810) und Chr. Heinr. Pfaff (geb. 1773, gest. 1852) förderten Galvanis Lehre.

Im übrigen kam die Physiologie durch Zersplitterung in Gefahr, ihre mühsam errungene Selbständigkeit einzubüßen, trotzdem eine Reihe von Lehrbüchern der Physiologie von Hildebrandt, Prochaska, Autenrieth und anderen bereits das zerstreute Material zu sammeln suchte.

Ihre Wiederherstellung und völlige Neugestaltung verdankt sie Johannes Müller.

\section{Fünfte Periode.}

Johannes Müller (geb. 1801, gest. 185̌) steht unerreicht da in der Geschichte der Physiologie, weil er der einzige ist, welcher der Vielseitigkeit derselben gerecht wurde. Indem er zum erstenmal die physikalisch-chemische Untersuchung mit der vergleichenden Anatomie und der 
Entwicklungsgeschichte verband, schuf er die vergleichende Physiologie. Er erklärt: „Durch die vergleichendanatomische Betrachtung der Organe in der Tierwelt und in der Entwicklungsgeschichte lernen wir erst das Wesenhafte der Organbildung und den physiologischen Begriff der Organe kennen. Darum kann die Physiologie nur eine vergleichende sein" (1827). Joh. Müller, eine durchaus philosophische Natur, Schöpfer der Lehre von der specifischen Energie der Nerven und Begründer der physiologischen Psychologie, Physiker und eminenter Morphologe zugleich, auch hierin seinen Lehrer K. A. Rudolphi (geb. 1771, gest. 1832) weit übertreffend, Beobachter und Experimentator ersten Ranges, mit einem Thatsachensinn und einer Arbeitskraft wie sehr wenige begabt, vereinigte in glücklichster Weise scheinbar weit von einander entfernte Gebiete zu einem organischen Ganzen. Das Wissen des Aristoteles, der systematisierende Sinn Galens, das methodische Forschen Harveys, der eiserne Fleiß Hallers finden in ihm ihre Vertretung. Einzeln waren schon zu seiner Zeit die verschiedenen Richtungen ausgebildet, aber niemand als er konnte sie vereinigen.

F. Magendie (geb. 1783, gest. 1855), einer der geschicktesten Vivisektoren, hatte die Experimentalphysiologie aufs neue belebt, besonders durch die Bestätigung der Bellschen Entdeckung, Ignaz Döllinger (geb. 1770) hatte mit Karl Ernst von Baer (geb. 1792, gest. 1876) die specielle Embryologie begründet, Etienne GeoffroySaint-Hilaire (geb. 1772, gest. 1844) die funktionelle und morphologische Äquivalenz der Organe unterschieden, Lamarck (1809), der Begründer der Descendenzlehre, den Einfluß der Funktion auf die Organe erkannt, deren Gebrauch und Nichtgebrauch für die Gestaltung er hervorhob, George Cuvier (geb. 1769, gest. 1832) hatte die Funktionen scharf zu trennen und aus der Funktion 
das Organ zu bestimmen gesucht, Richerand (1801), G. R. Treviranus (1802) und Fourcault (1829) die Mediziner zum Denken über Fragen der allgemeinen Physiologie angeregt, Berzelius (geb. 1779, gest. 1848) nach den Vorarbeiten von Fourcroy und Vauquelin die Tierchemie begründet, Th. de Saussure (geb. 1767, gest. 1845) die Pflanzenphysiologie reformiert, Chladni (1802) die Akustik, Kant (1781) die kritische Grundlage jeder künftigen Theorie der Sinne geschaffen, Purkinje (geb. 1787, gest. 1869) die Selbstbeobachtung zum erstenmal physiologisch richtig verwertet - und aus allen diesen voneinander unabhängig sich bildenden Wissenschaften baute Joh. Müller die neue Physiologie auf.

So umfassend war jedoch sein Werk, daß schon vor seinem Tode das von ihm zu einem harmonischen Ganzen vereinigte wieder in selbständige physiologische Disciplinen divergierte. Von diesen hat die physikalische die größten Erfolge gehabt und zwar wesentlich durch eine der wichtigsten Entdeckungen aller Zeiten, durch die Entdeckung des mechanischen Wärmeäquivalents (1840), welches der Arzt Julius Robert Mayer aus Heilbronn (geb. 1814, gest. 1878) fand.

Als Schiffsarzt sah er in Batavia bei Aderlässen an Europäern unmittelbar nach der Ankunft das venöse Blut heller rot als im Norden und vermutete, die Ursache sei die höhere Temperatur der heißen Zone. Denn die Eigenwärme des Menschen, durch Oxydation im Körper erzeugt, wie eben die Sauerstoffabnahme des Blutes in den Venen wahrscheinlich macht, ist bei Menschen aller Zonen nahezu gleich, folglich muß die Wärmeproduktion zur Wärmeabgabe in einem bestimmten Verhältnis stehen. Nehmen die Wärmeverluste zu, dann steigt die Wärmebildung; nehmen die Wärmeverluste ab, dann vermindert sich auch die Wärmebildung. Daher im tropischen Klima die Sauerstoffabnahme im Venenblut vermindert, dieses Blut heller rot und zugleich die Menge der 
oxydierten Stoffe, somit auch der täglichen Nahrung geringer, weil die Wärmeverluste geringer. Die Nahrung dient nämlich beim Erwachsenen größtenteils zur Wärmebildung durch Verbrennung, nur zum kleineren Teil zur Erneuerung der Gewebe und Organe. Nun wird aber mittelst der letzteren auch durch Reibung und allerlei Bewegungen, mit einem Wort durch Arbeit, Wärme erzeugt. Stammt diese Wärme auch von den Oxydationen im Körper oder nicht? Mayer nahm ersteres an und behauptete: die bei Verbrennung einer bestimmten Menge eines beliebigen Stoffes gelieferte Wärmemenge ist unveränderlich, gleichviel wie die Verbrennung stattfindet. Folglich könne auch der Organismus die durch Oxydation der Nahrung erzeugbare Wärmemenge weder vermehren noch vermindern, möge er arbeiten oder nicht. Denn sonst müßte der Organismus Wärme aus nichts erzeugen, oder Wärme verschwinden lassen können. Ist aber die Summe der durch Oxydation erzeugten Wärmemengen plus der durch Arbeit erzeugbaren genau gleich der Wärmemenge, welche durch vollständige Verbrennung der Nahrung hervorgebracht wird, dann muß die sämtliche durch Kraftaufwand oder mechanisch erzeugbare Wärme in einem bestimmten Größenverhältnis zu der dabei aufgewendeten Arbeit stehen. Andernfalls könnte bei derselben Arbeit und Nahrungsmenge das eine Mal viel, das andere Mal wenig Wärme entstehen und damit wäre die Gesamtmenge der aus einem bestimmten Nahrungsquantum durch Oxydation erzielbaren Wärme nicht unveränderlich und der vorausgesetzte Grundsatz falsch. Dieser Grundsatz verlangt also eine konstante Beziehung zwischen Wärme und Arbeit. Erstere wird durch Erwärmung des Wassers gemessen, letztere durch Heben von Lasten. Mayer bestimmte nun, wie hoch ein gewisses Gewicht gehoben werden muß, um beim Herabsinken durch Reibung oder Druck dasselbe Gewicht Wasser um einen Grad zu er- 
wärmen. Spätere genauere Versuche als die seinigen ergaben, daß 1000 Gramm durch ihre Fallkraft, wenn sie 424 Neter tief herabfallen, ebensoviel Wasser von $0^{\circ} \mathrm{um}$ $1^{0}$ erwärmen, d. h. 424 Meterkilogramm oder Kilogrammmeter ist das mechanische Wärmeäquivalent, welches besagt, daß dieselbe Wärmemenge, welche 1 Kilo Wasser von $0^{0}$ um $1^{0}$ erwärmt 424 Kilo 1 Meter hoch hebt, oder 1 Kilo 424 Meter hoch hebt, indem sie der dazu erforderlichen Kraft gleich ist.

Hiermit war die mechanische Wärmetheorie und die neue rein physikalische Physiologie begründet. Obgleich bis jetzt durch diese auf physiologischem Boden erstandene von einem mathematisch ungeschulten und physikalisch nicht durchgebildeten Arzt (mittelst einer von Galilei und Newton nicht übertroffenen logischen Kraft) ohne Vorarbeiten entdeckte, experimentell begründete und in ihrer ungeheuren Tragweite schon 1842 erkannte Wahrheit von dem konstanten Verhältnis der Wärme und Arbeit die theoretische Physik und praktische Mechanik - zumal die Maschinenkunde - viel mehr gefördert worden sind, als die Physiologie, als insbesondere die Lehre von der tierischen Wärme, ist die Anwendung streng physikalischer Denkweise und Lehrart seitdem erst in der Physiologie herrschend geworden. Ernst Heinrich Weber (geb. 1795, gest. 1878) hatte als einer der ersten die physikalische, exakte Methode nach anderer Richtung mit glänzendem Erfolge sogar schon vorher angewendet, nämlich von 1820 an, in seinen Arbeiten über das Sehen und Hören, desgleichen Eduard Weber (geb. 1806, gest. 1871), der Entdecker der Hemmungsnerven, und A. W. Volkmann (geb. 1801, gest. 1877), aber anfangs standen sie ziemlich isoliert.

Die Umgestaltung der morphologischen Biologie durch die Begründung der Zellenlehre und die Vervollkommnung des Mikroskopes haben wiederum von einer ganz anderen 
Seite her die Physiologie gefördert. Die Lehre vom Leben der Zellen oder Elementarorganismen tritt immer mehr in den Vordergrund bei der Untersuchung aller Lebensprozesse, zumal seit Begründung der Cellularpathologie. Doch existiert bis jetzt noch keine zusammenhängende Cellularphysiologie, obwohl sie bereits von Theodor Schwann (geb. 1810, gest. 1882) angestrebt wurde (1839), auch M. Schleiden (geb. 1804, gest 1881) schon 1838 das früher nur anders (z. B. von Oken als Urschleim) bezeichnete Protoplasma in den Pflanzenzellen entdeckte und Max Schultze (geb. 1825, gest. 1874) durch den Nachweis der Übereinstimmung des tierischen und pflanzlichen Protoplasma die wichtigsten Beiträge dazu geliefert hat.

Die ganze weitgehende Spaltung der Physiologie in der Neuzeit in die physikalische und in eine überwiegend chemische von Justus von Liebig (geb. 1803, gest. 1873) inaugurierte Richtung, denen sich eine eklektische, besonders durch M. J. P. Flourens (geb. 1794, gest. 1867) und Claude Bernard (geb. 1813, gest. 1878) vervollkommnete vivisektorische anschließt, ist hauptsächlich durch die seit 1828, seit Begründung der synthetischen Chemie durchWöhler (geb. 1800, gest. 1882) beginnendeVerdrängung des Vitalismus bedingt, welche eine starke Vernachlässigung allgemeinerer historischer und zusammenfassender Untersuchungen im Gebiete der Physiologie zur Folge hatte. Auch ist vorläufig die von Joh. Müller begründete vergleichende Physiologie gegen die chemischen und physikalischen Untersuchungen einzelner Funktionen einzelner Tiere in den Hintergrund getreten, eine experimentelle Embryologie und Zeugungslehre, überhaupt die eingehende Berücksichtigung der Entwicklung des fungierenden Substrates in der Funktionenlehre auf Grund der von Charles Darwin (geb. 1809, gest. 1882) begründeten Lehre von der Konkurrenz, Selektion, Erblichkeit und Variabilität (1859), 
welche die Gestaltung der organischen Natur wesentlich bestimmen, der Zukunft vorbehalten. Die großen Fortschritte der Chemie und Physik haben es mit sich gebracht, daß man mit denjenigen Lebensvorgängen, welche sich sogleich als überwiegend chemisch und physikalisch zu erkennen geben, sich fast ausschließlich befaßt, die schwierigern Prozesse noch nicht vornehmend. Denn auch die experimentale Psychologie ist wesentlich Physik der Sinnesorgane, die Erforschung der Psychogenesis erst im Entstehen.

Nachdem die specielle Chemie und Physik einzelner organischer Apparate in der Gegenwart erstaunlich schnell zu einer großen Anzahl wichtiger Entdeckungen und Erfindungen geführt haben, wird es nötig, die allgemeine Physiologie zu rehabilitieren und sowohl vergleichend (phylogenetisch), als entwicklungsgeschichtlich (ontogenetisch) $\mathrm{zu}$ arbeiten, was aber eine eingehende Würdigung des massenhaften morphologischen Materials erfordert.

\section{Die Entwicklung der Physiologie im ganzen.}

Aus der Geschichte der Physiologie ergibt sich im allgemeinen eine fortschreitende Entwicklung, welche mehrfach durch Stillstand und durch Rückschritt unterbrochen wurde. Eine Kurve von ungefähr folgender Gestalt stellt im großen und ganzen die ungleich fortschreitende Entwicklung der Physiologie dar:

In der ersten Periode (I) gehörte die Physiologie als rein spekulative Disciplin zu der Naturphilosophie, in der zweiten (II) war sie wesentlich beschreibend, unselbständig, der Zoologie, der Anatomie, der Pathologie zugeteilt, in der dritten (III), der längsten von allen, erscheint sie dogmatisch, empirisch noch schlecht begründet, beschrei- 
bend, teleologisch erklärend, hauptsächlich mit der Anatomie und Medizin verbunden, in der vierten (IV) kommt die experimentelle Methode und mit ihr unter Beseitigung der Teleologie und Scholastik die kausale Erklärung zur Geltung, die Anatomie bildet die Grundlage und es findet ihre völlige Trennung von der Medizin statt, aber noch wird sie nur in fester Verbindung mit der Anatomie behandelt und durch Naturphilosophie geschädigt.

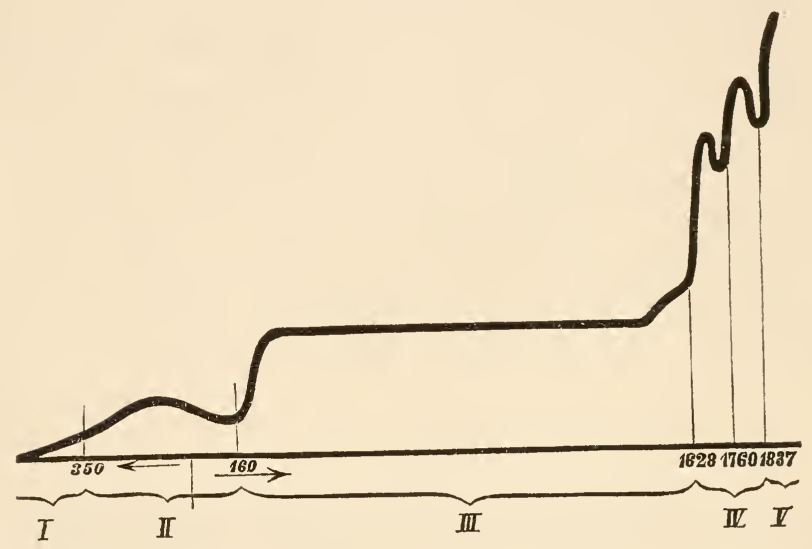

In der fünften Periode (V) lockern sich beide Verhält_ nisse, die Physiologie wird Chemie und Physik der lebenden Körper und setzt die Anatomie voraus. Sie ist aber in Gefahr ihre eben errungene Selbständigkeit durch Zersplitterung zu verlieren. Ihr Verhältnis zur Medizin hat sich umgekehrt, indem diese nun von der Physiologie abhängig wird.

Von dem der Physiologie und Morphologie gemeinsamen Gebiete der Entwicklungslehre ausgehend wird in der Zukunft auf ihre eigene Geschichte sich stützend die reine Physiologie als genetische Lehre von den Funktionen sich einen neuen dominierenden Standpunkt erobern. Denn 
nicht allein wie die Lebenserscheinungen sind, sondern wie sie geworden, ist die Frage. Und nicht nur was zu seiner Zeit für wahr gehalten wird, muß der Physiologe wissen, sondern auch was bedeutende Denker der Vergangenheit für wahr hielten. Historische Studien sind sowohl dem Lernenden, wie dem, der auf der Höhe seiner Wissenschaft bleiben will, notwendig. Denn das Lernen wird wesentlich erleichtert, wenn die Lehrsätze nicht fertig doktrinär, wie sie jetzt gerade lauten, ihm vorgetragen, sondern historisch mit Bezugnahme auf die Zeiten, in denen ihre Begrüder lebten und auf die Thätigkeit dieser entwickelt werden. Der Forscher, welcher die Geschichte der von ihm untersuchten Probleme kennt, vermeidet leichter Irrtümer, in die vor ihm andere gerieten und macht nicht Entdeckungen und Erfindungen, die schon gemacht sind. stellt auch nicht Hypothesen und Theorien als neu auf, welche schon da waren. In der Gegenwart, wo die Geschichte der Physiologie kaum einen Bearbeiter findet, ist es nützlich hierauf besonders die Aufmerksamkeit zu lenken.

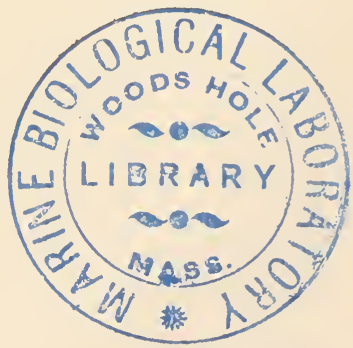




\section{Physiologische Litteratur.}

Ein einzelnes, das gesamte Gebiet der neueren Physiologie umfassendes Werk existiert nicht.

Die Encyklopädien und Realwörterbücher der Anatomie und Physiologie sind veraltet oder ungleichmäßig bearbeitet oder unvollständig.

Die neueren Lehr- und Handbücher sowie die gedruckten akademischen Vorlesungen über Physiologie sind meistens überladen mit rein physikalischen, rein chemischen und rein histologischen Auseinandersetzungen und behandeln die einzelnen Abschnitte mit ungleicher Ausführlichkeit.

Die periodischen Zeitschriften und Publikationen gelehrter Gesellschaften und wissenschaftlicher Kongresse enthalten außer physiologischen auch andere teils naturwissenschaftliche, teils medizinische Abhandlungen.

Kataloge oder Repertorien, welche nur physiologische Schriften und diese sämtlich berücksichtigen, werden nicht ediert. Jahresberichte und referierende medizinische Zeitschriften treten an deren Stelle.

Rein physiologische für sich erschienene Monographien und Dissertationen sind nicht zahlreich.

Die Litteratur keiner Wissenschaft ist so zerstreut und so schwer zu übersehen, wie die der Physiologie. In anatomischen, physikalischen, chemischen, medizinischen, zoologischen, botanischen, philosophischen, psychologischen. 
anthropologischen, landwirtschaftlichen, hygieinischen Büchern und Zeitschriften finden sich viele physiologische Originaluntersuchungen.

Im folgenden sind einige der wichtigsten physiologischen Werke zusammengestellt.

\section{Systematische Werke und Lehrbücher.}

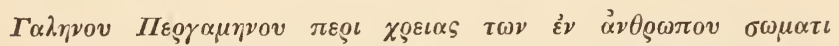

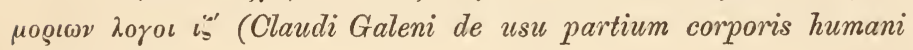
$\left.i^{i b r i} X V I I\right)$.

Ebn-Sina: El-Kanũn fil tebb (Avicennae Canon medicae liber primus). Der erste Abschnitt des ersten Buches enthält die Lehre von den Funktionen.

Joh. Fernel: De naturali parte medicinae libri septem. 1542.

Joh. Bohn: Circulus anatomico-physiologicus s. Oeconomia corporis animalis. 1680.

J. B. van Helmont: Ortus medicinae id est initia physicae inaudita. 1648.

Descartes: De homine. 1662.

Borelli: De motu animalium. 1680. Rom.

F. Deleboë Sylvius: Disputationes medicae. 1659.

Boerharve: Institutiones medicae. 1708.

Fr. Hoffmann: 1) Philosophia corporis humani vivi et sani. 1718; 2) Physiologia. 1746.

A. v. Haller: Elementa physiologiae corporis humani. 1757-1766. Acht Bände. Auctarium. 1780.

A. v. Haller: Grundriß der Physiologie. Nach Wrisbergs Ausgabe übersetzt und mit Anmerkungen von S. Th. Sömmering und Ph. Fr. Meckel. Berlin 1788. 
J. H. Autenrieth: Handbuch der empirischen menschlichen Physiologie. Tübingen 1801 und 1802. Drei Bände.

C. L. Dumas: Principes de physiologie. 2. Aufl. Paris 1806. 4 Bde.

J. F. Blumenbach: Institutiones physiologicae. 1787. 3. Aufl. 1810.

Ph. F. Walther: Physiologie des Menschen mit durchgängiger Rücksicht auf die comparative Physiologie der Thiere. Landshut 1807. 2 Bde.

Lenhossek: Physiologia medicinalis. 1816. Fünf Bände.

F. Magendie: Précis élémentaire de physiologie. 1816. 2. Aufl. 1825. Zwei Bände.

C. A Rudolphi: Grundriß der Physiologie. Berlin 1821-1823. Zwei Bände.

Joh. Müller: 1) Grundriß der Vorlesungen über die Physiologie. Bonn 1827. 2) Handbuch der Physiologie des Menschen. 1833. 4. Aufl. 2 Bde. 1844.

C. Ludwig: Lehrbuch der Physiologie des Menschen. 2 Bände. 2. Aufl. 1858-1861.

G. R. Treviranus: Biologie. Göttingen 1803-1823. 6 Bände.

Otto Funke's Lehrbuch der Physiologie für akademische Vorlesungen und zum Selbstudium. 6. Aufl. von A. Grünhagen. 2 Bde. 1876-1880.

G. Valentin: Lehrbuch der Physiologie des Menschen für Ärzte und Studirende. 2 Bde. 1844.

F. A. Longet: Traité de Physiologie. 2. Aufl. 2 Bde. $1860-1861$.

Joh. Ranke: Grundzüge der Physiologie des Menschen mit Rücksicht auf die Gesundheitspflege. 1. Aufl. 1868. 4. Aufl. 1881. 
E. Brücke: Vorlesungen über Physiologie. 2 Bde. 2. und 3. Aufl 1881 und 1882. (Unter des Verfassers Aufsicht nach stenographischen Aufzeichnungen herausgegeben).

Ludimar Hermann: Grundriß der Physiologie des Menschen. 7. Aufl. 1882.

K. Vierordt: Grundriß der Physiologie des Menschen. 1. Aufl. 1859. 5. Aufl. 1879.

W. Wundt: Lehrbuch der Physiologie des Menschen. 4. Aufl. 1878.

M. Foster: Lehrbuch der Physiologie. Übers. von Kleinenberg und Brückner. Heidelberg 1881.

C. Bergmann und R. Leuckart: Anatomisch-physiologische Übersicht des Thierreichs. Vergleichende Anatomie und Physiologie. 1855.

C. F. Burdach: Die Physiologie als Erfahrungswissenschaft. 2. Aufl. der drei ersten Bände 1835-1838.

A. Richerand: Nouveaux éléments de Physiologie. 8. Aufl. Paris 1820. 2 Bde.

A. Fourcault: Lois de l'organisme vivant ou application des lois physico-chimiques à la physiologie. Paris 1829. 2 Bde.

H. Milne-Edwards: Leçons sur la physiologie et l'anatomie comparée. 1857-1880. Vierzehn Bände.

Außerdem Lehrbücher der Physiologie des Menschen von J. Béclard, Beaunis, Carpenter, Huxley, Flint, Kirkes, Dalton, Donders, Panum, Budge, Landois, Fick, Steiner u. v. a. Endlich mehrere neue Werke über Pflanzenphysiologie. 


\section{Encyklopädien und Lexika.}

Handwörterbuch der Physiologie herausgegeben von Rud. Wagner. 4 Bde. 1842 bis 1853.

Cyclopaedia of Anatomy and Physiology von B. Todd. 5 Bde. 1835 bis 1859.

Anatomisch-physiologisches Realwörterbuch, herausgegeben von J. F. Pierer und (vom 4. bis 7. Bande) von N. Choulant. 8 Bde. 1816 bis 1829.

Handbuch der Physiologie, herausgegeben von L. Hermann. Seit 1879. (Sammelwerk).

\section{Zeitschriften.}

1) Archiv für die Physiologie von J. C. Reil und (vom 7. Band an) Autenrieth. 12 Bde. Halle 1796-1815. Fortsetzung:

Deutsches Archiv für die Physiologie von J. F. Meckel. 8 Bde. Halle 1815-1823. Fortsetzung:

Archiv für Anatomie und Physiologie von J. F. Meckel. 6 Bde. Leipzig 1826-1832. Fortsetzung:

Archiv für Anatomie, Physiologie und wissenschaftliche Medizin von Johannes Müller. 25 Bde. Berlin 1834-1858. Fortsetzung unter demselben Titel von C. B. Reichert und E. du Bois-Reymond 1859-1876.

\section{Geteilt:}

Zeitschrift für Anatomie und Entwicklungsgeschichte von W. His und Braune seit 1876, und Archiv für Physiologie von E. du Bois-Reymond, seit 1877.

2) Archivfür die gesammte Physiologie des Menschen und der Thiere von E. F. W. Pflüger. Bonn. Seit 1868. 
3) Zeitschrift für Biologie, herausg. seit 1865 von Buhl, Pettenkofer, Voit und Radlkofer, seit 1875 von den drei erstgenannten, seit 1880 von $\mathrm{P}$. und $\mathrm{V}$.

4) Journal de Physiologie expérimentale et pathologique von F. Magendie. 11 Bde. Paris 1821 bis 1831.

5) Zeitschrift für die organische Physik von C. F. Heusinger. 4 Bde. Eisenach 1827 bis 1828.

6) Zeitschrift für Physiologie von Friedr. Tiedemann, Gottfr. Reinhold Treviranus und Lud. Chr. Treviranus. 5 Bde. 1824 bis 1833. Auch u. d. T.: „Untersuchungen über die Natur des Menschen, der Thiere und der Pflanzen".

7) Journal de l'anatomie et la physiologie normales et pathologiques de l'homme et des animaux von Ch. Robin in Paris, seit 1864 .

8) Archives de physiologie normale et pathologique von Brown-Séquard, Charcot, Vulpian (in Paris) seit 1868.

9) Journal of physiology, herausgegeben von Mi i hael Foster in Cambridge, seit 1878.

10) Journal of Anatomy and Physiology von Humphry, Turner und MacKendrick. 16 Bde. 1882.

11) Archives Italiennes de Biologie von C. Emery und A. Mosso. Turin. Seit 1881.

12) Annales des sciences naturelles, comprenant la Physiologie animale et végétale, l'Anatomie comparée des deux règnes, la Zoologie, la Botanique etc. Paris. Seit 1824 ohne Unterbrechung.

13) Archives de Zoologie expérimentale et générale von Lacaze-Duthiers. Paris. Seit 1872.

14) Archives de Biologie von Éd. van Beneden und Ch. van Bambeke, seit 1880 . 
15) Zeitschrift für wissenschaftliche Zoologie von C. J. von Siebold und A. von Kölliker. Leipzig. Von 1849 an.

16) Archiv für pathologische Anatomie und $\mathrm{Physiologie}$ und für klinische Medizin von R. Virchow [und B. Reinhardt]. Berlin. Seit 1847. Vom 4. Bande an von V. allein.

17) Archiv für Naturgeschichte von Wiegmann, fortgesetzt von Erichson und Troschel. Berlin. Seit 1835.

18) Untersuchungen zur Naturlehre des Menschen und der Thiere, herausgegeben von Jac. Moleschott. Seit 1857.

Viele wichtige physiologische Originalabhandlungen finden sich auch in den Archiven und Zeitschriften für innere Medizin, für klinische Medizin, für rationelle Medizin, für Heilkunde, für Gynäkologie, für Geburtshilfe und Gynäkologie, für experimentelle Pathologie und Pharmakologie, für mikroskopische Anatomie, Morphologie, Landwirthschaft u. v. a.

An die physiologischen Zeitschriften reihen sich an die zahlreichen Sammlungen von Arbeiten aus physiologischen Instituten der Universitäten, besonders in Deutschland.

\section{Jahresberichte, historische und biblio- graphische Werke.}

1834 bis 1837: Jahresberichte über die Fortschritte der Physiologie von Joh. Müller in seinem Archiv;

1838 bis 1846: von Th. L. Bischoff ebenda.

1836 bis 1843: im Repertorium für Anatomie und Physiologie, von G. Valentin. 8 Bde. Berlin, Bern und St. Gallen $1836-1846$.

1856 bis 1871: von G. Meißner in der "Zeitschrift für rationelle Medizin". Deren Fortsetzung:

Seit 1872 von Mehreren in den selbständig erscheinenden „Jahresberichten über die Fortschritte der Anatomie und Physiologie." Leipzig. Herausgeber: F. Hofmann und G. Schwalbe. 
1841 bis 1865: Jahresberichte von mehreren in Canstatts "Jahresbericht über die Fortschritte der gesammten Medicin" und deren Fortsetzung (seit 1866 von Virchow und Hirsch).

1822 bis 1849: in Frorieps Notizen (101 Bde.), Referate und Bibliographie.

Seit 1863 Referate im Centralblatt für die medicinischen Wissenschaften. Berlin. Jährlich ein Band.

Seit 1881 Referate im Biologischen Centralblatt. Erlangen.

1817 bis 1848: in Okens Isis viele vergleichend physiologische Nitteilungen.

1800 bis 1873: Titel naturwissenschaftlicher, besonders auch physiologischer Abhandlungen in periodischen Zeitschriften und Publikationen gelehrter Körperschaften nach den Namen der Autoren alphabetisch in: Catalogue of scientific Papers, compiled and published by the Royal Society of London. 8 Bde.

1700 bis 1846: Titel von Büchern zur vergleichenden Physiologie in Engelmanns Bibliotheca historico-naturalis 1846. 1. Bd. S. 203 bis 288.

1848 bis 1867: Bibliotheca anatomica et physiologica oder Verzeichniß aller auf dem Gebiete der Anatomie und Physiologie in den letzten 20 Jahren im Deutschen Buchhandel erschienenen Bücher und Zeitschriften. Von Adolph Büchting. Nordhausen 1868.

Zur Ergänzung dienen zahlreiche Antiquar - Kataloge naturwissenschaftlicher und medizinischer Bücher.

Seit 1834: Physiologische Bibliographie in Schmidts Jahrbüchern der gesammten Medicin.

Von den ältesten Zeiten bis 1776: Bibliotheca anatomica qua scripta ad anatomen et physiologiam facientia a rerum initiis recensentur auctore Alberto von Haller. 2 Bde. (Für Geschichte und Litteratur der Physiologie bis 1776 wichtig).

Preyer, Physiologie. 
Von den ältesten Zeiten an: Versuch einer pragmatischen Geschichte der Arzneykunde von Kurt Sprengel. 3. Aufl. 1. Teil 1821.

Von den ältesten Zeiten an: Lehrbuch der Geschichte der Medicin von H. Haeser. (Beide wichtig für die Geschichte der Physiologie).

Geschichte der Pflanzenphysiologie von 1583 bis 1860 in "Geschichte der Botanik vom 16. Jahrh. bis 1860" von Julius Sachs. 1875. S. 387 bis 612 .

Von den ältesten Zeiten bis 1863: Biographisch-literarisches Handwörterbuch zur Geschichte der exacten Wissenschaften von J. C. Poggendorff. 1863. Zwei Bände. (Biographisch und bibliographisch).

\section{Grundlegende Werke für einzelne Abschnitte und Richtungen der Physiologie.}

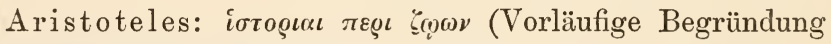
der vergleichenden Physiologie).

William Harvey: Exercitatio anatomica de motu cordis et sanguinis in animalibus. 1628. (Begründung der Lehre vom Blutkreislauf und der vivisectorischen Experimentalphysiologie).

Stephen Hales: Statical essays containing vegetable and animal staticks. 1731 bis 1733 (Begründung der Hämostatik).

John Mayow: Tractatus quinque medico-physici 1669. (Vorläufige Begründung der Respirationslehre).

Lavoisier: Sur la respiration des animaux et sur les changements qui arrivent à l'air en passant par leur poumon. 1777. (Definitive Begründung der Respirationslehre).

Justus von Liebig: Die Thier-Chemie oder die organische 
Chemie in ihrer Anwendung auf Physiologie und Pathologie. 1842. 3. Aufl. 1846. (Begründung der Ernährungslehre).

A. v. Haller: Von den reizbaren Theilen des menschlichen Körpers. 1756. (Begründung der Muskelphysiologie).

Charles Bell: On the nerves: giving an account of some experiments on their structure and functions, which lead to a new arrangement of the system. 1821. (Begründung der speciellen Nervenphysiologie).

Luigi (Aloisio) Galvani: De viribus electricitatis in motu musculari. 1791. (Begründung der Elektrophysiologie).

E. du Bois-Reymond: Untersuchungen über thierische Elektricität 1848 bis 1860. (Reform der Elektrophysiologie).

Legallois: Expériences sur le principe de la vie. Paris 1812. (Entdeckung des ersten nervösen Centrums).

J oh. Müller: Zur vergleichenden Physiologie des Gesichtssinnes 1826. (Vorlüufige Begründung der physiologischen Optik).

H. Helmholtz: Handbuch der physiologischen Optik 1856 bis 1867. (Definitive Begründung derselben).

C. F. Chladni: Die Akustik 1802. (Vorläufige Begründung der physiologischen Akustik).

H. Helmholtz: Die Lehre von den Tonempfindungen, 1. Ausg. 1862. 4. Ausg. 1878. (Definitive Begründung derselben).

G. Th. Fechner: Elemente der Psychophysik 1860. (Begründung der Psychophysik).

William Harvey: De generatione animatium, 1651. (Begründung der experimentalen Embryologie).

Caspar Friedr. Wolff: Theoria generationis, 1759. (Begründung der Epigenesis-Lehre).

Xav. Bichat: Recherches physiologiques sur la vie et la moit. An VIII. (Begründung der Thanatologie). 
Lamarck: Philosophie zoologique. 1809. (Vorläufige Begründung der Descendenzlehre).

Charles Darwin: On the Origin of Species. 1. Aufl. 1859. (Begründung der Entwicklungslehre auf Grund der Konkurrenz, Selektion, Erblichkeit und Variabilität).

Th. Schwann: Mikroskopische Untersuchungen über die Uebereinstimmung in der Struktur und dem Wachsthum der Thiere und Pflanzen. 1839.(Begründung der Physiologie der Zelle).

J. Henle: Allgemeine Anatomie. Lehre von den Mischungs- und Formbestandtheilen des menschlichen Körpers. 1841. (Enthält die erste Darstellung der Physiologie der Gewebe).

Julius Robert Mayer: Die organische Bewegung in ihrem Zusammenhange mit dem Stoffwechsel. Heilbronn 1845. (Begründung der Lehre vom Kraftwechsel).

Außerdem sind mehrere Lehrbücher der Pflanzenphysiologie, der physiologischen Chemie (Biochemie) und der medizinischen Physik (Biophysik), sowie der Entwicklungsgeschichte, der vergleichenden Anatomie, der Gewebelehre und Pathologie der physiologischen Litteratur zuzuzählen, desgleichen psychologische Werke und eine Reihe von Handbüchern über die Untersuchung einzelner Funktionen und tierischer Säfte zu praktischen, namentlich landwirtschaftlichen und medizinischen Zwecken.

Für das Arbeiten im physiologischen Laboratorium geben Anleitungen:

Richard Gscheidlen: Physiologische Methodik. Ein Handbuch der praktischen Physiologie. Seit 1876.

E. Cyon: Methodik der physiologischen Experimente und Vivisektionen. Mit Atlas. 1876. 
Claude Bernard und Huette: Piécis iconogiaphique de médecine operatoire et d'anatomie chirurgicale. 1873 (mit 113 Tafeln).

Die neuere allgemeine Physiologie verfügt über keine deutsche Litteratur für sich. Einige ihrer Probleme pflegen in den Lehrbüchern der speciellen Physiologie erwähnt und hier und da ausführlicher in denselben abgehandelt zu werden. Andere bleiben unberührt. Die Leçons sur les phénomènes de la vie communs aux animaux et aux végétaux von Cl. Bernard (Paris 187S) sind das einzige neuere selbständige Werk über allgemeine Physiologie. Sehr viele Beiträge dazu enthalten die „Generelle Morphologie der Organismen" von E. Häckel (1866), sowie die ebenfalls auf dem Boden der Entwicklungslehre stehenden Werke von H. Spencer, namentlich The principles of Biology (1864 bis 1867). Diesen einerseits rom morphologischen, andererseits vom philosophischen Standpunkt ausgehenden größeren Arbeiten reihen sich kleinere an, wie die überwiegend chemische "Allgemeine Biologie" von F. HoppeSeyler (1877) und die wichtigen Abhandlungen über „Die Elementarorganismen" von E. Brücke (1861) und ,über die physiologische Verbrennung“" von E. F. W. Pflüger (1875). Die „Allgemeine Physiologie des körperlichen Lebens" von R. H. Lotze (1851) hat in den drei auf ihr Erscheinen folgenden, mehr der Detailforschung zugewendeten Decennien keine würdige Nacheiferung gefunden. Die Notwendigkeit einer allgemeinen Physiologie ist aber selbstverständlich, und das Verhältnis derselben, der Bionomie, zur speciellen Physiologie oder Biognosie wird natürlich und scharf bestimmt dadurch, daß der Untersuchung der einzelnen Funktionen, welche den Gegenstand der Biognosie aus- 
machen, vorhergehen muß eine Betrachtung der sämtlichen lebenden Körpern und Körperkomplexen gemeinsam zukommenden Lebenseigenschaften. Diese sind Objekt der Bionomie, welche sich demnach namentlich befaßt mit dem Wesen des Lebens und Sterbens, mit dem Inhalt, den Formen, den Kräften aller lebenden Körper, soweit sie bei allen übereinstimmen, und mit dem Begriff der organischen Thätigkeit oder physiologischen Funktion. Auch die Ursachen der Verschiedenheiten lebender Körper und die Einteilung ihrer Funktionen gehören in die allgemeine Physiologie. 


\section{ALLGEMEINE PHYSIOLOGIE}

ODER

\section{BIONOMIE.}





\section{Vom Wesen des Lebens.}

\section{Der Lebensbegriff.}

Keiner der zahlreichen Versuche, den Lebensbegriff zu definieren hat sich eines dauernden oder allgemeinen Beifalls zu erfreuen gehabt. Die Schwierigkeit der Definition liegt hauptsächlich darin, daß alles Lebende veränderlich ist, der Begriff der Veränderung aber noch nicht genau bestimmt wurde. Zunächst genïgt hier festzuhalten, daß in keinen zwei Zeitpunkten der Zustand eines lebenden Kïörpers oder Körrperkomplexes derselbe ist. Seine Zustände wechseln, und ohne Zustandswechsel, d. h. Veränderung, gibt es kein Leben. Da ferner alles Lebende im Raum ist, indem nur Körper leben, alle Veränderung im Raume aber Bewegung heißt, so folgt: Ohne Bewegung gibt es kein Leben. Nit dem Begriff der Bewegung ist aber keineswegs der Lebensbegriff gegeben. Denn wenn auch jedes Leben Bewegung enthält, so ist doch nicht jede Bewegung Leben. JIan findet zwar vielleicht jede bekannte Art der Bewegung in irgend welchem oder an irgend welchem lebenden Körper oder Körperkomplex zu irgend einer Zeit; es fragt sich aber, ob man eine Art der Bewegung in allen lebenden Körpern findet, welche nicht auch außerhalb derselben vorkommt? Erfahrungsmäßig ist die Gesamtheit der Bewegungen in jedem lebenden Körper höchst verwickelt. 
Und wenn man sagt: Das Leben ist ein höchst verwickelter eigentümlicher Bewegungskomplex, so spricht man nur eine Thatsache aus. Worin das Eigentümliche besteht, ob es aus dem Zusammensein der nie fehlenden chemischen und physikalischen Vorgänge als eine Resultierende sich in allen Einzelheiten ableiten läßt oder ob es eine auf jene nicht zurückführbare, ausschließlich im Lebenden vorhandene ursprüngliche Bewegungsart oder Bewegungsursache gibt, ist streitig.

Die Eigentümlichkeit des Leben genannten Bewegungskomplexes wird nämlich durch Thatsachen bedingt, mit welchen die Physik und die Chemie sich gar nicht befassen, weil sie ohne Umgestaltung ihrer Grundsätze dieselben nicht erklären können. Diese beiden Wissenschaften können, ihrer Begrenzung nach, nur mit physikalischen und chemischen Eigenschaften der Körper sich befassen; dazu gehört aber das Psychische und die Entwicklung nicht. Beide sind weder physikalische noch chemische, sondern physiologische Wissenschaftsobjekte.

Nichtsdestoweniger kann die Physiologie nicht hoffen, beide, wie alle diejenigen Bewegungen, welche den Lebenserscheinungen zu Grunde liegen, dem Verständnis näher zu bringen, wenn sie nicht genau die Methoden der Physik und Chemie beibehält. Denn diese sind es allein, welche sich bis jetzt bewährt haben. Die Kräfte, mit denen die Physik und Chemie operieren, sind dieselben, wie diejenigen, mit denen die Physiologie operiert, und wo diese nicht mehr ausreichen, bleibt die Untersuchungsmethode dieselbe, weil sie die logische ist; aber es ist nicht notwendig mit dem Erforschen der Lebensvorgänge aufzuhören, wenn die gegenwärtig geltenden Voraussetzungen der Physik und der Chemie nicht mehr zutreffen, wie es z. B. bei dem Auftreten psychischer Vorgänge im Embryo im bebrüteten Ei der Fall zu sein scheint. Gerade da zeigt sich am 
deutlichsten die Selbständigkeit der Physiologie, welche zu einer Änderung des traditionellen Begriffes der Materie drängt. Denn selbst die auf ihren jetzigen Grundlagen noch so weit geführte Molekularphysik und synthetische Chemie können das Ei aus den physischen Molekülen und chemischen Elementen, in die es zerlegt wird, nicht einmal theoretisch, geschweige denn faktisch so wieder zusammensetzen, daß es nach dem Errärmen in der Luft in ein Tier mit psychischen Eigenschaften sich umwandelte, welches wiederum ein ebensolches $\mathrm{Ei}$ hervorzubringen vermöchte. Sie können es nicht, weil bei der künstlichen Synthese die Erblichkeit verloren ginge.

Diese alltägliche Thatsache, daß Lebendes und Lebensfähiges ausschließlich durch die Vermittelung von Lebendem, Psychisches ausschließlich durch die Vermittelung von Psychischem erzeugt wird, ist für den Bewegungskomplex, welcher Leben heißt und mit der Gesamtheit der physiologischen Funktionen gleichbedeutend ist, charakteristisch.

Eine künftige Definition des Lebensbegriffs muß demnach dieses Merkmal enthalten.

\section{Die Lebensbedingungen.}

Die zur Erhaltung des Lebens aller den Erdball bevölkermden lebenden Körper notwendigen Bedingungen sind teils äußere, teils innere. Jene müssen in der Umgebung der lebenden Körper verwirklicht sein, diese in ihnen selbst. Beiderlei Bedingungen sind teils unmittelbare teils mittelbare.

Die unmittelbaren äußeren Lebensbedingungen können nicht in Wegfall kommen, ohne daß entweder sofort oder nach einem im Verhältnis zur mittleren Lebensdauer kurzen 
Zeitraum das Leben erlischt, die mittelbaren sind zur Erhaltung des vollständigen Lebens notwendig. Ihr Wegfall hat nur eine partielle Beeinträchtigung der Lebensvorgänge zur Folge, nicht einen Stillstand der Gesamtheit derselben.

Unmittelbare innere Lebensbedingungen sind eine gewisse Struktur, eine gewisse stoffliche Zusammensetzung und gewisse Kräfte, mit deren Fortfall das Leben aufhört. Mittelbare innere Lebensbedingung endlich ist die Integrität des lebenden Körpers, welche zwar bis zu einem gewissen Grade gestört sein kann, ohne daß das Leben erlischt, nicht aber ohne Beeinträchtigung des vollständigen Lebens

So klar auch diese Bestimmungen sind, so leicht sich für jede der vier Bedingungsklassen einzelnes Thatsächliche angeben läßt, eine vollständige Aufzählung aller äußeren und inneren Bedingungen auch nur für einen einzigen lebenden Körper, ja nur für Eine Lebenserscheinung desselben, würde nur eine Physiologie von idealer Vollendung zu geben imstande sein. Denn wenn sämtliche Bedingungen des Lebens genau bekannt wären, wäre auch das Bedingte, nämlich das Leben selbst, genau bekannt, als die notwendige Folge jener Bedingungen erkannt und dadurch in allen Punkten begriffen.

Die Physiologie muß nun von der völligen Begreiflichkeit des Lebens in allen Punkten ausgehen. Denn thäte sie es nicht, so fiele ihr die Aufgabe zu, anzugeben, wo das begreifliche Unbegriffene von dem unbegreiflichen Unbegriffenen abgegrenzt wäre, was unmöglich ist, weil von den zur Zeit unbegriffenen Lebenserscheinungen nicht ausgesagt werden kann, ob sie begreiflich sein werden oder nicht. Also zielt die Physiologie auf Ermittelung aller Lebensbedingungen $a b$, und statt mit der Aufzählung derselben beginnen zu können, endigt sie vielmehr damit. Aber der allgemeinen Physiologie fällt es zu, die Natur jener Bedingungen, welche sämtlichen lebenden Körpern ohne Ausnahme zukommen, im allgemeinen anzugeben. Deren 
Anzahl kann wegen der großen Mannigfaltigkeit der letzteren natürlich nur klein sein.

Über die allgemeinsten äußeren Lebensbedingungen läßt sich noch am ehesten etwas Bestimmtes sagen. Denn die Erfahrung lehrt, dab Leben nur da stattfindet und nur da möglich ist, wo gewisse Gase, Wasser und gewisse feste chemische Verbindungen in solcher Beschaffenheit und Menge vorhanden sind, daß sie von den lebenden Körpern aufgenommen werden können, teils ununterbrochen, teils mit kurzen Pausen.

Die Gase sind in der den Erdball an allen Punkten seiner Oberfläche meilenhoch bedeckenden atmosphärischen Luft enthalten. Aber weder vom Sauerstoffgas, noch von dem Kohlensäuregas, noch vom Stickgas läßt sich die Unentbehrlichkeit für alles Lebende beweisen. Ganz allgemein gültig ist der Satz nicht, daß gasförmiger oder rom Wasser absorbierter, jedenfalls freier Sauerstoff für die gesamten lebenden Körper unerläßliches Lebenserfordernis sei, wie es thatsächlich für alle höher entwickelten der Fall ist. Aber aus Versuchen über die zur Inganghaltung gewisser Gärungsprozesse erforderlichen Gase hat man geschlossen, daß einzelne niedere lebende Körper, An aërobien, nicht nur ohne jede Spur freien Sauerstoffes leben, sondern durch Sauerstoffgaszufuhr zu Grunde gehen, während umgekehrt alle anderen lebenden Körper, die Aërobien, nach Sauerstoffgasentziehung aufhören zu leben. Die behauptete Existenz solcher Anaërobien läßt sich bis jetzt nicht widerlegen. Mehrere Versuche guter Beobachter sprechen dafür. Andere machen aber die völlige Abwesenheit des Sauerstoffgases in den untersuchten Gemischen zweifelhaft, und stützen die Behauptung, es sei nur das Übermaß des Sauerstoffes für das Bakterienleben gefährlich, die Zufuhr müsse eine beschränkte sein, in faulenden Flüssigkeiten bewirke aber gänzlicher Mangel an Sauertoff eine vollkommene Sistierung 
der Fäulnis, indem die organisierten Fäulniserreger und deren angebliche Keime unwiderruflich zu Grunde gingen. Auch die Gewebe des Körpers höherer Tiere können durch Zufuhr gasförmigen Sauerstoffes ihre Lebensthätigkeit verlieren. Die Widersprüche sind so groß, daß man zunächst die Annahme zu prüfen haben wird, ob nicht bei allen Versuchen, bei welchen angeblich „jede Spur gasförmigen Sauerstoffes" fehlte, dennoch kleine Mengen vorhanden waren. Ergibt diese Experimentalkritik völlige Abwesenheit von Sauerstoffgas in den Flüssigkeiten, welche lebende Körper enthalten, so wird zu prüfen sein, ob nicht durch irgendwelchen noch zu entdeckenden Vorgang Sauerstoffgas daselbst frei wird in dem Maße, als er von jenen Lebensprozessen verbraucht wird. Jedenfalls steht einstweilen die Frage, ob zum Leben ausnahmslos freies Sauerstoffgas erforderlich sei, so, daß man nicht mehr unbedingt mit Ja antworten kann.

Die Kohlensäure der Luft ist nachweislich für die Erhaltung vieler lebender Körper unersetzlich, nämlich der meisten Pflanzen. Für die höheren Tiere dagegen ist das Kohlensäuregas in der sie umgebenden Luft nicht nur überflüssig, sondern wenn seine Menge zunimmt, gefährlich. Also kann auch dieses Gas nicht als unerläßlich für das gesamte Leben angesehen werden.

Das freie Stickstoffgas fehlt zwar nirgends in der Natur, wo Leben ist, aber es kann künstlich durch andere Gase, z. B. Sauerstoffgas und Wasserstoffgas in der Luft ersetzt werden, ohne daß in dem stickgasfreien Gasgemenge jedes Leben aufhörte. Also ist es nicht unerläflich zum Leben.

Man kann somit nur das Vorhandensein von Gasen (der atmosphärischen Luft) als notwendig für den Ablauf des Lebensvorganges bezeichnen. In völlig gasfreiem Wasser findet kein Leben statt, nicht aber ist mit Sicherheit ein einzelnes Gas für alles Leben ohne Ausnahme als not- 
wendig erkannt. Man kann nur sagen: Ohne Luft kein Leben. Alles Lebendige atmet.

Die zweite Bedingung, das Vorhandensein von Wasser in tropfbarer Form in nächster Nähe des lebenden Körpers ist allgemein anerkannt. Wenn irgendwelcher noch so kleiner, selbständiges Leben zeigender Körper in völlige Trockenheit gebracht wird, auf trockenes Land in trockener Luft, so erlischt sein Leben in kürzester Frist. Hierüber herrscht Einstimmigkeit. Ohne Wasser kein Leben. Alles Lebendige ist feucht.

Die dritte Bedingung, das Vorhandensein ron gewissen festen chemischen Verbindungen, sei es in Lösung, sei es in fester Form in erreichbarer Nähe des lebenden Körpers ist gleichfalls allgemein anerkannt. Aber welche Verbindungen etwa für sämtliche lebenden Körper notwendig seien, kann noch nicht angegeben werden. Es ist sogar zweifelhaft, ob es eine einzige noch so einfache in demjenigen Gemenge von chemischen Verbindungen, welche physiologisch Nahrung heißt, vorkommende Verbindung giebt, welche notwendig in der Nahrung aller lebenden Körper enthalten sein muß, wenn das Leben derselben im Gang bleiben soll. Viele Pflanzen können zwar in Luft und Wasser, welches genau bekannte Salze aufgelöst enthält, d. h. in künstlichen Nährflüssigkeiten normal leben, aber ob von diesen gelösten Verbindungen Eine notwendig in aller Nahrung der kleinsten und größten Tiere vorhanden sein müsse, ob sie nicht durch andere Verbindungen ersetzt werden könne, ist fraglich. In sogenannten reinen wässerigen lufthaltigen Lösungen von Magnesiumsulphat oder von Natriumacetat können Schizomyceten wachsen und lange leben, obgleich darin keine Phosphor- und keine Eisenverbindungen nachweisbar sind, welche in der Nahrung der Pflanzen sonst vorhanden sein müssen. Die tierische Nahrung muß ausnahmslos komplizierte Produkte der pflanz- 
lichen oder tierischen Lebensthätigkeit enthalten, deren die meisten Pflanzen nicht bedürfen. Sie muf außerdem Salze enthalten. Man kann aber nicht von einem derselben behaupten, es finde sich in jeder Nahrung vor. Nur daß Salze in jeder Nahrung enthalten sein müssen, steht fest; sie sind, wie jene anderen chemischen Verbindungen, Nährstoffe, und man muß sie als allgemeine Lebensbedingung bezeichnen. Ohne Nahrung kein Leben. Alles Lebendige ernährt sich.

Mit der Feststellung dieser drei Erfordernisse, Luft, Wasser, Nahrung, ist die allgemeine Bestimmung der unmittelbaren äußeren Lebensbedingungen nicht beendigt. $\mathrm{Zu}$ der stofflichen Bedingtheit kommt eine physikalische hinzu.

Die Luft, mag sie atmosphärisch oder im Wasser aufgelöst oder von der Erde verdichtet sein, muß nicht nur überhaupt in einer gewissen großen Menge, sondern im kleinen Raum in großer Menge disponibel sein, d. h. eine gewisse Spannung haben. Der variable Luftdruck kann zwar noch viel mehr variieren, als er es in der Natur thut, ohne alles Leben zum Stillstand zu bringen; aber eine untere Grenze, welche für verschiedene lebende Körper sehr ungleich ist, darf er nicht überschreiten. Die numerische Begrenzung kann allgemein für alles Lebendige nicht angegeben werden. Denn die meisten Pflanzen kömnen z. B. bei einer Kohlensäurespannung weiter leben, welche für Tiere lebensgefährlich ist, aber nicht wie diese bei einer Kohlensäurespannung Null in dem sie umgebenden Medium. Umgekehrt hört das pflanzliche Leben noch lange nicht auf bei einer sehr niedrigen Partiarspannung des Sauerstoffes, welche weit unterhalb der von den Tieren ertragenen Verdünnung oder Verminderung der Gasmenge liegt. Man kann nur im allgemeinen sagen, daß die erforderlichen Gase, sei es Sauerstoff, sei es Stickstoff, sei 
es Kohlensäure, einzeln und zusammen eine vom Gas und vom einzelnen lebenden Objekt abhängige untere Grenze der positiven, in Millimetern oder Centimetern einer Quecksilbersäule ausdrückbare Spannung haben müssen. Zugleich aber dürfen die Gase eine obere Druckgrenze nicht überschreiten, welche gleichfalls mit dem lebenden Objekt und dem Gas und Gasgemenge variiert. Auch hier ist also eine Grenzzahl nicht für alles Leben unbedingt angebbar, besonders bemerkenswert aber, daß bei sehr hohem Druck auch reines Sauerstoffgas giftig oder wenigstens lebensgefährlich für alle lebenden Köorper, auch die kleinsten, wird. Alles Leben hängt ab rom Luftdruck, und der minimale und maximale Barometerstand ist allemal bestimmbar. Dagegen wurde bis jetzt die Grenze des noch Lebenserscheinungen gestattenden Wasserdruckes nicht gefunden. Die größten oceanischen Tiefen sind belebt. Aus den Tiefseelotungen der neueren Zeit geht nicht hervor, daß in den größten, mit dem Senkblei erreichten Tiefen von einer geographischen Meile kein Leben mehr stattfindet. Vielmehr spricht der Umstand, daß die aus mehreren tausend Meter Tiefe heraufgeholten Tiere oben zerplatzt ankamen, wegen des schnellen Druckwechsels, dafür, daß sie an jenen gewaltigen Druck des Wassers in der Tiefe sich adaptiert hatten. Jedenfalls bildet die unübersehbare Fülle des Lebens auf dem Meeresboden und in großen Tiefen, also unter hohem Wasserdruck, den stärksten Kiontrast zu dem Nangel alles Lebens bei enorm gesteigertem Luftdruck. Während in jenem Falle siebenhundert Atmosphären vertragen werden, genügen in diesem schon sieben, um alle Lebensthätigkeit zu beendigen. Freilich hat in jenem eine langsame Anpassung stattgefunden, in diesem nicht.

Eine fernere fundamentale Lebensbedingung ist die Wärme. Innerhalb sehr enger Temperaturgrenzen ist alles Leben eingeschlossen. Kälte ist ebenso der Feind desPreyer, Physiologie. 
selben wie Hitze, und kein Leben ist imstande auszudauern, wenn die Temperatur sich unter dem Gefrierpunkt des Wassers überall in seiner unmittelbaren Umgebung hält. Man kann sich zwar vorstellen, daß ein arktisches Tier sich lange in Luft von Null Grad von eiskalter Nahrung und eiskaltem Wasser am Leben erhält, nicht aber ist bei dauernder Abkühlung der Luft erheblich unter dem Eispunkt die Ernährung mit festgefrorener Nahrung und Eis statt Wasser annehmbar. Auch die unter dem Schnee vegetierenden Pflanzen haben dicht an ihrer Oberfläche eine Temperatur von mehr als Null Grad. Schon die Unersetzbarkeit des tropfbar flüssigen Wassers macht es verständlich, daß alle lebenden Körper dicht an ihrer Oberfläche, wenn sie im Eise weiterleben, ein wärmeres Medium als dieses haben. Die größten bisher an der Erdoberfläche gemessenen Kältegrade übersteigen $60^{\circ} \mathrm{C}$. nicht. Aber weit oberhalb dieses Wärme-Minimum ist selbst der resistenteste Organismus schon in Lebensgefahr, wenn die Kälte anhält.

Die obere Temperaturgrenze ist ebensowenig für alles Lebende angebbar wie die untere. Die einzelnen Teile der lebenden Körper zeigen gegen Temperaturerhöhungen sehr ungleiche Resistenz. Doch läßt sich für alle im Wasser lebenden Wesen mit Wahrscheinlichkeit behaupten, daß ihr Leben erlischt, ehe das Wasser $60^{\circ}$ erreicht. Für alle lebenden Körper giebt es ein Temperatur-Optimum.

Nehmen die Wärme-Schwingungen an Wellenlänge ab, an Geschwindigkeit zu, so werden sie Lichtschwingungen, und diese sind für die meisten lebenden Körper ebenfalls unersetzlich. Alle grünen Pflanzen bedürfen des Lichtes, um die Kohlensäure der Luft zu zerlegen, und die Mehrzahl der Tiere würde, wenn plötzlich anhaltende Finsternis einträte, bald zu Grunde gehen, schon weil sie sich nicht mehr zurechtfinden, nicht mehr die erforderliche Nahrung suchen könnte. 


\section{Die Lebensfähigkeit.}

(Vitalität, Viabilité.)

Es giebt zahlreiche verschiedenartige entwickelte und unentwickelte lebende Wesen, deren Lebensprozesse durch Entziehung von äußeren Lebensbedingungen, durch Trockenheit, Kälte, durch Nahrungs- und Luftentziehung zum vollkommenen Stillstand gebracht werden können, ohne daß sie ihre Lebensfähigkeit verlieren, indem sie aufs neue anfangen zu leben, sowie jenen Bedingungen wieder genügt wird. Diese in der freien Natur häufig vorkommende Wiederbelebung heißt Anabiose.

Sie wird z. B. bei hartgefrorenen Fischen und Fröschen durch langsame Erwärmung, bei eingetrockneten Rotiferen, Makrobioten und Anguillulinen durch langsame Anfeuchtung bewirkt. Aber es besteht eine große Schwierigkeit, die Lebensfähigkeit im einzelnen Fall zu bestimmen. Mißlingen die Wiederbelebungsversuche, dann kann doch vor Anstellung derselben Lebenstähigkeit vorhanden gewesen sein.

Aus der Thatsache der Anabiose folgt die Notwendigkeit, den kontradiktorischen Gegensatz von "lebend", die Negation "nicht lebend" oder "leblos" von dem konträren Gegensatz "tot" streng zu unterscheiden.

Stirbt ein lebender Körper, so hat die Lebensmaschine eine irreparable Schädigung erlitten. Er ist dann leblos (funktionslos) und zugleich lebensunfähig (funktionsunfähig), im eigentlichen Sinne tot, wie ein anorganischer Körper.

Hört ein lebender Körper auf zu leben, ohne eine unheilbare Schädigung erlitten zu haben, so ist er leblos und zugleich lebensfähig, nämlich der Wiederbelebung fähig (funktionsfähig). Man sollte diese Wesen allein scheintot im eigentlichen Sinne nennen. Das Wort ist aber 
auch eine Bezeichnung für die Herabsetzung sämtlicher Lebensprozesse ohne Erlöschen derselben. Diese Art des Scheintodes wird richtig vita minima, fälschlich ,latentes Leben" genannt. Er ist nur herabgesetztes wirkliches, aktuelles oder kinetisches Leben und entspricht der Lethargie höherer Tiere und Pflanzen im gewöhnlichen Winterschlaf. Der wahre Scheintod dagegen, ein Zustand ohne die geringste lebendige Bewegung, entspricht dem vorrätigen oder potentiellen Leben. In diesem $\mathrm{Zu}$ stande befinden sich viele niedere Tiere im Winterschlaf und Sommerschlaf und sämtliche entwicklungsfähige, aber noch nicht in der Entwicklung begriffene Keime. Sie sind der Anabiose fähig und der unversehrten Uhr vergleichbar, welche, obwohl aufgezogen, deshalb nicht geht, weil das Pendel nicht schwingt.

Nicht alle lebenden Körper können in diesen Zustand versetzt werden, weil bei vielen der Akt der Entziehung der unmittelbaren äußeren Lebensbedingungen unmittelbare innere Lebensbedingungen mit aufhebt, nämlich tödliche Strukturänderungen oder chemische Zersetzungen herbeiführt. Auch kann die Anabiose an demselben Objekt nicht unendlich oft wiederholt werden, weil schon jede Entziehung einer fundamentalen Lebensbedingung und jede Wiederherstellung derselben Schädlichkeiten mit sich bringt, welche, je öfter der Versuch stattfindet, um so mehr durch Summierung nachteilig wirken.

Je länger die vollkommene Leblosigkeit gedauert hat (bei entwickelten Tieren nachgewiesenermaßen über drei Decennien, bei Pflanzensamen anderthalb Jahrtausende), um so länger ist im allgemeinen die zur Wiederbelebung erforderliche Zeit.

Ausgetrocknete Rädertierchen können weit über den Siedepunkt des Wassers erhitzt und längere Zeit im luftleeren Raume aufbewahrt werden ohne zu sterben, hart- 
gefrorene Fische und Amphibien weit unterhalb des Eispunktes aufbewahrt werden, ohne zu sterben, wenn nur die Abkühlung und nachherige Erwärmung langsam und doch nicht zu langsam geschieht.

Die Lebensfähigkeit der pflanzlichen und tierischen Eier heißt Keimfähigkeit.

Zu den Ursachen des Erlöschens der Keimfähigkeit und Lebensfähigkeit der potentiell lebenden, also thatsächlich leblosen Wesen nach einem endlichen Zeitraum gehören namentlich Änderungen der Kohäsion und Elasticität der Gewebe, sowie Umsetzung der potentiellen Energie in kinetische, welche auch bei anorganischen Naturkörpern und Kunstprodukten im Laufe der Zeit stattfindet (bei der Verwitterung, beim Verfall). Jene Umsetzung geschieht bei jeñen Wesen ohne Lebensäußerung kontinuierlich, bei der Auslösung, welche die Wiederbelebung zur Folge hat, plötzlich.

Nach Eintritt der Anabiose wechseln die beiden Zustände der Thätigkeit und $R$ uhe wie bei allen aktuell lebenden Wesen miteinander ab. Aber auch in der Ruhe bleibt das Leben aktuell.

Demnach sind folgende organische Zustände zu unterscheiden:

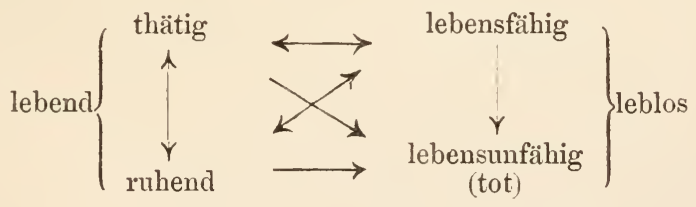

Nur in den Richtungen, welche die Pfeile angeben, kann ein Zustand in den anderen übergehen.

Lebend und thätig ist z. B. die kontrahierte Muskelfaser, die erregte Nervenfaser im lebenden Tier.

Lebend und ruhend ist z. B. die expandierte Muskelfaser, die unerregte Nervenfaser im lebenden Tier.

Die Ruhe ist hierbei, wie überall, nur relativ, da auch 
in den unerregten Teilen, im unbewegten lebenden Protoplasma, Umsetzungen stattfinden.

Leblos und lebensfähig ist z. B. das unversehrte befruchtete Ei, der unversehrte festgefrorene Fisch, das intakte, trockene, kalte Rädertier im Vakuum.

Leblos und lebensunfähig ist z. B. das unbefruchtete Wirbeltier-Ei, das verbrannte Tier, die versteinerte Pflanze, die Kohlensäure.

\section{Unterscheidung der anorganischen toten Wesen von den organischen lebenden Wesen.}

Die vielen Bemühungen eine den lebenden Wesen ausnahmslos und jederzeit nachweislich zukommende physikalische oder chemische oder morphologische Eigenschaft zu finden, welche keinem einzigen anorganischen (lebensunfähigen) Wesen zu keiner Zeit zukäme, sind vergeblich gewesen.

Eine sorgfältige Kritik der traditionellen Unterscheidungsmerkmale führt jedesmal zu diesem negativen Ergebnis.

Doch ist durch die neue Entwicklungslehre ein physiologischer Unterschied erkannt worden. Denn diese zeigt, daß in allen lebenden Wesen so lange sie leben - und nicht länger - ohne Unterbrechung Neubildungen stattfinden, welche jedem lebensunfähigen anorganischen Wesen zu jeder Zeit fehlen, Vorgänge, die auf der Thatsache der Erblichkeit beruhen und zusammenhängen mit der

\section{Kontinnität des Lebens.}

Alle lebenden Wesen entstehen ausschließlich aus lebenden Wesen. Jedes hat Vorfahren, welche ihm ähnlich sind: eine Erfahrungsthatsache. 
Alle anorganischen Körper können in verschiedener Weise aus Körpern erhalten werden oder entstehen, welche ihnen unähnlich sind, sie haben keine Vorfahren (Ahnen). Ein Kochsalzwürfel z. B. entsteht durch Vereinigung von Chlor und Natrium, die ihm ganz unähnlich sind, durch Konzentration einer Salzlösung, die ihm gar nicht gleicht, durch Einwirkung von Salzsäure auf Soda und in mannigfaltigster anderer Weise aus Körpern, die keine morphologische Ähnlichkeit mit ihm haben.

Die Begriffe Ähnlichkeit (Affinität, Verwandtschaft) und Abstammung hängen fest zusammen und das sie enthaltende Gesetz von der Kontinuität oder Permanenz des Lebens ist ron demselben Range wie das von der Erhaltung der Kraft und das von der Erhaltung der Materie. Es wird daher zweckmäßig als das Gesetz von der Erhaltung des Lebens diesen beiden an die Seite gestellt.

Das Gesetz von der Erhaltung der Kraft sagt: Es kann nicht neue Kraft entstehen, wo nicht vorher Kraft war.

Das Gesetz ron der Erhaltung der Materie sagt: Es kann nicht neue Materie entstehen, wo nicht rorher Materie war.

Das Gesetz von der Erhaltung des Lebens sagt: Es kann nicht neues Leben entstehen, wo nicht vorher Leben war.

Schon hieraus ergiebt sich, daß ein Fragen nach dem Ursprung des Lebens nicht weniger transscendent sein wird, als ein Fragen nach dem Ursprung der Materie mit ihren Kräften. Bezüglich der letzteren gilt als Axiom, daß sie keinen Ursprung haben, sondern ewig sind, anderenfalls wären doch einmal Stoffe und Kräfte aus Nichts entstanden. Bezüglich des Lebens ist die Einsicht, daß es keinen Anfang hat, noch nicht allgemein. 


\section{Die Hypothesen iiber den Ursprung der ersten lebenden Wesen.}

Die Frage nach dem Ursprung des Lebens (Biogenesis) fällt zusammen mit der Frage nach der Entstehung der ersten lebenden Körper, weil Leben ausschließlich an Körpern haftet. Die Frage nach der Entstehung der gegenwärtigen lebenden Körper ist dagegen ein ganz anderes Problem. Jene ist nur auf spekulativem Wege zu beantworten, weil Erfahrungen über die Bedingungen der ersten Lebensaiußerungen in der Urzeit fehlen. Diese ist der Beobachtung und dem Experiment zugänglich, da fortwährend neue lebende Körper erzeugt werden und sich entwickeln.

Auf die Frage: Wie sind die ersten lebenden Körper auf der Erde entstanden? giebt es eine dogmatische und eine hypothetische Antwort, das Dogma der Urzeugung und die kosmozoische Hypothese.

\section{Unzulässigkeit des Dogmas von der Urzeugung.}

Das Dogma der Urzeugung - Generatio spontanea, originaria, aequivoca, primaria, primigena, primitiva, automatica oder Autogonie, Archigonie, Archibiose, Abiogenesis, Heterogenesis, Selbstzeugung, Urerzeugung - behauptet, in früheren Zeiten sei die Erdoberfläche zu heiß gewesen, um Leben zu gestatten, es sei daher anorganisches, totes, für sich nicht lebensfähiges Material, als die Abkühlung einen gewissen Grad erreicht hatte, auf unerklärte Weise synthetisch zu lebenden Wesen, die sich dann zu anderen entwickelten, vereinigt worden: elternlose Zeugung 
Dieser Glaube widerspricht dem Gesetz von der Erhaltung oder der Kontinuität des Lebens, welche dadurch unterbrochen würde, daß irgend einmal eine Generation ohne vorhergegangene Generationen entstanden wäre, steht also als alogisches Postulat genau auf demselben Boden, wie der Glaube an das Perpetuum mobile in der Mechanik, welches dem Gesetz von der Kontinuität der Kraft widerspricht und wie der Glaube an die Erzeugung von Stickstoff in der Pflanze, welcher dem Axiom von der Permanenz der Materie widerspricht. Außerdem widerspricht er der Erfahrung, welche trotz zahlloser Experimente und Forschungen nicht ein lebendes Wesen obne Eltern kennen gelehrt hat. Doch könnte hiergegen eingewendet werden, negative Ergebnisse bewiesen nicht die Unmöglichkeit.

Daher ist es von großer Wichtigkeit, festzuhalten, daß selbst im Falle ein solches Experiment nicht in sich verfehlt wäre, es bei positivem Resultat doch nichts über die Entstehung der ersten lebenden Körper lehren würde, weil die verwendeten, leicht faulenden Ingredienzien selbst von lebenden Wesen hergenommen sind. Also würde eine Erzeugung ohne Termittelung von Lebensthätigkeit nicht erwiesen sein. Daß bloße Vermengung von Elementen oder von Kohlensäure, Wasser, Luft und Salzen keine Protozoen oder Protophyten liefert, ist allgemein anerkannt. Niemand versucht ein Feuer aus Asche, Kohlensäure und anderen Verbrennungsprodukten herzustellen ohne verbrennliches Material.

Die Fehlerquellen der Experimente, welche angeblich die Urzeugung beweisen sollen, sind so zahlreich, daß mit der größten Sicherheit behauptet werden kann, alle positiven Resultate solcher Experimente erklären sich nur aus ihren Fehlern.

Endlich: Ebenso sicher wie der Satz, daß irgend einmal alle lebenden Organismen als solche zu leben 
aufhören müssen, ist der Satz, daß alle geboren sind. Die Wahrscheinlichkeit einen Organismus zu finden, welcher nicht von einem anderen geboren wäre oder abstammte ist gerade so gering, wie die einen Organismus ohne Lebensende zu finden. Denn die Zahl der Fälle, welche durch induktive Generalisation zu dem unbestrittenen Satze führten, daß jedes lebende Individuum einmal sterben oder als solches nicht mehr sein wird, ist nicht größer, als die Zahl der Fälle, welche ebenso durch induktive Generalisation zu dem Satze führen, daß jedes lebende Individuum einmal von einem anderen lebenden Individuum abgespalten wurde.

Die Setzung einer Urzeugung ist also unlogisch aus drei Gründen: 1) widerspricht sie den anerkannten Naturgesetzen, 2) widerspricht sie den Ergebnissen aller Beobachtungen und Experimente, 3) ist sie so unwahrscheinlich wie ein lebendes Individuum, dessen Dauer als solches kein Ende fände.

Die dogmatische Antwort, der zufolge die ersten lebenden Wesen durch Verbindung anorganischer Teile, welche an sich nicht lebensfähig waren, entstanden sein sollen, ist hiernach genau ebenso unzulässig in der Physiologie, wie das Schöpfungsdogma. In jenem Falle wird verlangt, daß neues Leben von selbst entstehen soll, wo vorher keines war, in diesem, daß Leben durch übernatürliche Eingriffe entstehen soll, wo vorher keines war. In beiden Fällen verzichtet also der Verstand auf sein Recht, den Lebensursprung $\mathrm{zu}$ verstehen.

\section{Unzulänglichkeit der Hypothese von den Kosmozoen.}

Die Mikrozoen des Weltraums oder Kosmozoen sind sehr kleine, entwickelte und unentwickelte, pflanzliche und 
tierische lebensfähige Körper, von welchen angenommen wird, daß sie, sei es für sich, sei es an Meteoriten haftend von einem Weltkörper auf den anderen gelangen und sich daselbst entwickeln.

Dieser Hypothese. zufolge hätte es schon vor der Bildung des Planetensystems im Weltraum den gegenwärtigen ähnliche lebensfähige Wesen gegeben, welche ihre Lebensfähigkeit Jahrmillionde unter den ungünstigsten Verhältnissen behalten mußten: eine höchst unwahrscheinliche Annahme. Die Frage nach dem Lebensursprung wird außerdem durch dieselbe nicht beantwortet, sondern vertagt. Auch hat man in Neteoriten zwar Kohlenstoffverbindungen, aber keine lebensfähigen Keime aufgefunden.

Somit ist zwar die kosmozoische Hypothese nicht als unzulässig widerlegt, aber als unzulänglich und ungenügend begründet anzusehen.

Da die Urzeugung der Erfahrung und Logik widerstreitet, und da die kosmozoische Hypothese die Frage nach dem Ursprung des Lebendigen nicht beantwortet, eine Erschaffung aus Nichts den Gesetzen von der Erhaltung der Kraft und von der Erhaltung der Naterie widerspricht, so kann keine von diesen drei Ansichten acceptiert werden.

Wenn aber das Leben nicht auf der leblosen Erde durch Synthese von lebensunfähigen Stoffen entstand, wie die Urzeugung verlangt, und wenn es auch nicht von außen auf die Erde gekommen ist, wie die kosmozoische Hypothese und die Schöpfungsdogmatik verlangen, dann bleibt nur noch die eine Möglichkeit, daß es überhaupt nicht entstanden ist, daß also die Fragestellung falsch war. Die Frage nach der ersten Entstehung lebender Körper auf der Erde setzt voraus, daß anfangs nur lebloses Anorganisches vorhanden war. Diese Voraussetzung ist durch nichts zu begründen. Vielmehr ist zunächst $z u$ fragen nach dem 


\section{Ursprung des Toten.}

Wie entsteht und entstand das Anorganische? Totes entsteht gegenwärtig nur, wo Lebendes war, ist also nicht ursprünglich. Der Begriff des Toten setzt den Begriff des Gelebthabens voraus, nicht aber setzt der Begriff des Lebens den des Tot-gewesen-seins voraus.

Anorganische Körper werden gegenwärtig erzeugt:

1) aus lebenden Körpern als Resultat der Lebensvorgänge in ihnen (aus Leichen, Excrementen, Schalen, Knochenresten usw.);

2) durch Zersetzung lebloser und lebender Körper;

3) durch Synthese aus leblosen Körpern.

Lebende Körper werden dagegen erzeugt:

einzig aus anderen lebenden Körpern als Resultat der Lebensvorgänge in ihnen, welche das anorganische vitalisieren: Omne vivum e vivo.

Von dem, was gegenwärtig anorganisch ist, entstand ein sehr großer Teil nachweislich durch Lebensprozesse untergegangener bekannter lebender Körper. Die Abhängigkeit der anorganischen Natur von den tierischen und pflanzlichen Lebensprozessen giebt sich namentlich durch die ganze Gebirge bildenden sogenannten zoogenen und phytogenen Ablagerungen zu erkennen, welche ihrerseits wieder auf die Organismenwelt modifizierend zurückwirken. Der bezüglich seiner Entstehung unverstandene Rest des Anorganischen der Gegenwart kann durch Lebensprozesse untergegangener unbekannter lebender Körper entstanden sein. Diese wurden während der zunehmenden Abkühlung der Erdkruste durch Anpassung immer demjenigen Material ähnlicher, aus welchem die gegenwärtig lebenden Formen sich entwickelten und entwickeln, demjenigen Protoplasma, welches die Hitze nicht mehr verträgt. Von den zahlreichen früheren bei höherer Temperatur lebenden Komplexen, an 
denen sich alle Elemente beteiligten, mußten durch die Abkuihlung die meisten erstarren. Das jetzige Protoplasma blieb als lebensfähige Kombination übrig.

Das Protoplasma findet sich jederzeit in jedem lebenden Körper.

Es charakterisiert das Lebende dadurch, daß es entwicklungsfähig ist.

Alles Lebendige entwickelt sich, alles Anorganis che nicht. Jeder lebende Körper zeigt vermöge dieser Eigentümlichkeit des Protoplasma zeitlebens die vorhin erwähnten Neubildungsprozesse, welche zugleich mit Rückbildungen stattfinden. In jedem geht, so lange er lebt, eine Protoplasma-Umbildung vor sich.

Hiermit ist definitiv ein wesentlicher Unterschied der lebenden und toten Naturkörper gegeben.

\section{Der Begriff des Todes.}

Tot heißen diejenigen Körper, welche keiner physiologischen Funktion fähig sind.

Der Eintritt des Todes oder das Sterben beruht auf einer unheilbaren Schädigung der inneren Lebensbedingungen, d. h. der Struktur oder des Chemismus des lebenden Komplexes.

Nur Körper sterben, nur Individuen, nicht Materie, nicht Kiräfte, nicht Bewegungen, nicht das Leben. Vielmehr heißt die eine Art des Lebensendes der Individuen welche durch jene Schädigung verursasht ist, "Tod" und der Vorgang seines Eintritts „Sterben." Die Todesursachen sind zweifach: entweder summieren sich geringfügige Schädlichkeiten allmählich und führen zum sogeannnten natürlichen Tode, oder es wirken plötzlich erhebliche Schädlichkeiten ein und verursachen den sogenannten unnatürlichen Tod. 
Der partielle Tod bezieht sich auf das Erlöschen einzelner Funktionen, der totale auf das aller, d. h. des Lebens.

Die Zeichen des Todes sind sämtlich unsicher. Es kann sogar ein Teil eines leblosen Tieres, einer leblosen Pflanze in Fäulnis übergegangen sein und doch der übrige Teil unter Umständen wiederbelebt werden.

Im Hinblick auf die im Gegensatz zur Dauerhaftigkeit und Haltbarkeit sehr vieler anorganischer Körper höchst auffallende Zersetzbarkeit aller lebenden Gebilde erscheint die Fortdauer auch nur eines einzigen Atomkomplexes nach dem Tode (als Grund einer individuellen Unsterblichkeit) unwahrscheinlich. Die Organismen sind alle sterblich, aber vermöge der Fortpflanzung (Verjüngung durch Vermehrung) und (bei Menschen) der Überlieferung erhalten ihre Leistungen oft eine weit über den Tod hinausreichende Dauer, deren Grenze unbestimmbar ist.

Eine zusammenfassende Darstellung der auf das Sterben und den Tod bezüglichen Erscheinungen, eine Wissenschaft vom Tode oder Thanatologie auf Grund der neueren Naturanschauungen, als wesentlicher Teil der allgemeinen Physiologie, existiert noch nicht.

\section{Die Lebensdaner.}

Der Zeitraum von der Erzeugung eines lebenden Körpers an bis zu dem Ende seines Daseins als solchen heift die Lebensdauer. Sie variiert je nach der erblichen Beschaffenheit und der Umgebung sehr erheblich, beträgt in einigen Fällen nur wenige Stunden, sogar Minuten, in anderen ein paar Jahrtausende. Doch darf in der beschränkten Dauer der Einzelexistenz kein Unterscheidungsmerkmal des Lebenden und Toten gefunden werden, weil auch 
die toten Körper sämtlich einen Anfang und ein Ende in der Zeit haben. Jede Maschine bleibt nur eine zeitlang arbeitsfähig, jeder Krystall hat eine beschränkte Dauer als solcher. Da man aber von der zerbrochenen Maschine und dem aufgelösten Krystall nicht zu sagen pflegt, daß sie gestorben sind, so könnte in dem Tode selbst als der Beendigung des Lebens der einzelnen Körper ein Lebensmerkmal gefunden werden. Man könnte sagen: „Nur was fähig ist zu sterben lebt." Jedoch ist nicht der Tod in allen Fällen das Ende des Lebens, z. B. nicht, wenn eine Amöbe sich unter Durchmischung ihres Protoplasma in zwei Teile teilt, welche als junge Amöben weiter leben. In diesem Falle hat das Leben der Mutter ein Ende und sie stirbt nicht. Also ist die Lebensdauer des Einzelwesens nicht allgemein durch den Tod begrenzt, d. h. durch eine unheilbare Schädigung innerer Lebensbedingungen. Sie kann auch durch das Gegenteil, eine so üppige Begünstigung derselben, daß Teilung des lebenden Körpers eintritt, begrenzt werden, indem die Sonderexistenz aufhört, um in zwei nenen Einzelwesen fortzudauern, also nicht mehr als solche.

Eine andere Begrenzung der Lebensdauer tritt ein, wenn äußere unmittelbare Lebensbedingungen fehlen, ohne daß die Lebensfähigkeit erlischt. Hier aber kann bei Wiederherstellung jener Bedingungen (Anabiose) dieselbe Sonderexistenz wie ror dem Scheintode wiederbeginnen und man hat, um hier die wahre Lebensdauer zu finden, die Zeit von der Erzeugung bis zu dem definitiven Lebensende um die im Scheintode ohne die geringste Lebensthätigkeit verbrachte zu kürzen.

Die Verlängerung des Lebens wird durch die beste Anpassung an die Umgebung erzielt, hingegen die Verkürzung des Lebens durch schlechte Anpassung, welche jedoch nur beim Menschen - zur Selbsttötung führen kann, 
verursacht. Die Verlängerung wird durch reichliche, die Verkürzung durch knappe Erfüllung aller Lebensbedingungen wesentlich mitbedingt.

\section{Die Lebensalter.}

Jedes lebende Wesen durchläuft von dem Augenblick seiner Entstehung an ein Stadium fortschreitender (aufsteigender, anaplastischer) Entwicklung oder zunehmender Energie, und wenn es nicht während desselben durch den Tod oder Teilung sein aktuelles Sonderleben beendigt, nachher ein Stadium rückschreitender (absteigender, kataplastischer) Entwicklung oder abnehmender Energie. Der erste Lebensabschnitt entspricht dann der Jugend (Embryonalzeit, Fötalperiode, Säuglingsalter, Kindheit, Knaben- und Mädchen-Alter, Jünglings- und Jungfrauen-Alter), der zweite dem Alter (Mannes- und Greisen-Alter). Zwischen beiden liegt ein dynamischer Gleichgewichtszustand der Reife.

Die Dauer der Lebensalter hängt von den äußeren und inneren Lebensbedingungen $\mathrm{ab}$. Im allgemeinen gilt, daß die Zeit der Reife und des Alterns um so länger dauert, je langsamer die fortschreitende Entwicklung vor sich ging. Doch sind die hier zusammenwirkenden Faktoren sehr verwickelt. Auch ist es Thatsache, daß vom Anfang an neben anaplastischen auch kataplastische Prozesse, und später neben diesen auch jene stattfinden, so zwar, daß vom Anfang an die fortschreitende Entwicklung in keinem Augenblick ohne den antagonistischen Prozeß des Verfalles stattfindet. Die Differenzierung der Zellen im Embryo geht nicht olıne Bildung von Exkreten vor sich, und bis an das Lebensende des Hundertjährigen, auch wenn der Verfall noch so rapide und eingreifend wird, dauert die Neu- 
bildung protoplasmatischer Lymphkörperchen geradeso fort wie bei dem Kinde, nur nicht so intensir und im Vergleiche zu den Rückbildungsvorgängen spärlicher. Der Marasmus im höchsten Alter ist jedoch nicht eine notwendige physiologische Erscheinung, sondern wie das Verdorren eines Baumes durch äußere Schädlichkeiten in letzter Instanz bedingt.

Über die Anzahl der Lebensalter des Menschen sind, weil es an entscheidenden Gründen für eine bestimmte Einteilung fehlt, die Ansichten rerschieden. Zwischen dem Lebensanfang (der Conception) und dem Lebensende bildet die Geburt den kritischen Punkt, welcher deshalb oft nicht überlebt wird, weil die dann eintretenden physiologischen Veränderungen lebensgefährlich sind. So scharf scheiden sich die folgenden Perioden des Lebens nicht von einander und auch nicht entfernt so präcise wie z. B. die Zustände der Raupe, der Puppe, des fertigen Insektes. Im menschlichen Leben liefern die Entwöhnung, die Pubertät, die erste Entbindung, die klimakterische Epoche, die Vollendung des Längenwachstumes physiologische Gründe zur Einteilung. Wegen der individuellen Schwankungsbreite bleibt aber der Willkür ein großer Spielraum, so daß von verschiedenen Autoren zwei, drei, vier und fünf, auch sechs, sieben, acht und neun, sogar zehn und zwölf Lebensalter unterschieden worden sind. 


\section{Vom Inhalt der lebenden Körper.}

Die den lebenden Kiörper zusammensetzenden Stoffe, d. h. seinen Inhalt, zu bestimmen, ist keine physiologische, sondern eine chemische Aufgabe. Während aber die Chemie, welche sich mit der Reindarstellung und Analyse der Stoffe und ihrer Synthese aus den nicht mehr analysierbaren Elementen beschäftigt, die von ihr dargestellten Verbindungen, Gemische und Gemenge mit gleichem Interesse untersucht, gleichviel ob sie Produkte des tierischen und pflanzlichen Stoffwechsels oder mineralischen Ursprunges sind, ist es für die Physiologie von der gröBten Bedeutung zu wissen, ob die aus lebenden Teilen dargestellten chemischen Verbindungen auch als solche in ihnen vorher existierten oder erst während der chemischen Untersuchung entstanden. Denn nur im ersteren Falle sind die Ergebnisse der chemischen Analysen lebender Teile physiologisch verwertbar. Nur sofern sich ein chemischer Bestandteil des Körpers an dessen Funktionen beteiligt, ist er von physiologischem Interesse. Daher müssen die Physiologen bei jedem Stoffe prüfen, ob er im Leben schon da war oder erst nach dem Tode entstand.

\section{Die organischen Elemente.}

Wesentliche elementare Bestandteile der gegenwärtigen lebenden Wesen, welche aus den meisten und höchst- 
wahrscheinlich aus allen durch Zerstörung mittels verschiedener Eingriffe zu jeder Zeit wenn auch zum Teil bisweilen nur in Spuren erhalten werden können, sind

$\begin{array}{llll}\text { Kohlenstoff } & \text { Stickstoff } & \text { Chlor } & \text { Calcium } \\ \text { Sauerstoff } & \text { Schwefel } & \text { Kalium } & \text { Magnesium } \\ \text { Wasserstoff } & \text { Phosphor } & \text { Natrium } & \text { Eisen }\end{array}$

Wahrscheinlich kommen auch allen zu Silicium und Fluor.

Von diesen vierzehn organischen Elementen kommen überhaupt in lebenden Körpern allgemein normalerweise im elementaren Zustande frei vor nur Sauerstoff und Stickstoff, Wasserstoff nur sporadisch, Schwefel nur bei Schizophyten, Kohlenstoff und Eisen nicht normalerweise.

A c c ess or ische organische Elemente, welche nur in einzelnen lebenden Körpern nachgewiesen werden können, sind:

Jod und Brom in pelagischen Tieren und Pflanzen;

Mangan im Getreide - dadurch auch im menschlichen Blut - auch in Seetieren verschiedenster Art;

Kupfer konstant im Cephalopodenblut und in den Federn des Pisangvogels;

Lithium in der Tabakpflanze inkonstant, in Seepflanzen;

Rubidium in einigen Pflanzen (Kaffee und Thee) und Seemuscheln; in letzteren (Austern) auch Cäsium;

Strontium konstant in einigen oceanischen Radiolarien (?);

Zink konstant in einigen Pflanzen;

Arsenik in den Geweben der Arsenikesser;

Kobalt, Nickel, Bor, Baryum in Spuren in Seepflanzen; 
Aluminium in Lycopodium-Arten konstant;

Antimon, Blei, Cer, Chrom, Gold, Platin, Quecksilber, Silber, Wismut, Zinn gelangen in Arzneimitteln in den Körper. Aber auch alle übrigen chemischen Grundstoffe können ohne Zweifel in geeigneten Verbindungen so in höhere Organismen eingeführt werden, daß sie nach oft wiederholter Verabreichung in kleinen Mengen in den Sekreten und in einzelnen Organen nachgewiesen werden können. Sie sind dann ebensowenig von physiologischer Bedeutung wie die zufällig in Tiere und Pflanzen gelangten fremden Elemente, welche nur in bestimmten Lokalitäten, z. B. in der Nähe von Zinkhütten, in ihnen gefunden werden.

Das Wenige, was bis jetzt von dem konstanten Vorkommen einzelner accessorischer Elemente (Kupfer, Mangan, Strontium, Aluminium) in immer denselben Teilen einzelner Tier- und Pflanzen-Arten bekannt ist, zeigt eine in physiologischer Hinsicht merkwürdige elektive chemische Thätigkeit der Gewebe und - bei einzelligen Radiolarien gewisser Protoplasma-Arten an. Daß z. B. pelagische Tiere, wie Pinna, gerade das Mangan (in ihrem Bojanusschen Organ) aufspeichern, aber nicht dessen sonstigen Begleiter, das Eisen, scheint paradox. Die Vorstellung, daß es sich hier um erbliche Momente aus einer Zeit her handeln kann, in der noch andere Elemente, als die gegenwärtigen zwölf oder vierzehn zu den organischen Elementen gehörten, reicht nicht aus, wenn man den hohen Kupfergehalt des Turacines in den roten Federn des Turaco, die schon der Regen entfärbt, mit hereinziehen will.

In den unbekannten vor der Bildung des jetzigen Protoplasma bei höherer Temperatur der Erdoberfläche allein möglichen lebenden Körpern komnten freilich alle übrigen Elemente, auch die schwer schmelzbaren Metalle wesentliche Bestandteile sein.

Bei der Beantwortung der Frage, wie es kommt, daß 
gerade nur die genannten zwölf oder vierzehn Elemente, also nur der fünfte Teil der bekannten chemischen Grundstoffe, aus den lebenden Körpern erhalten werden können, ist die Gesamtheit der Eigenschaften der vierzehn organischen Elemente in Betracht zu ziehen. Namentlich die große Zahl ihrer Verbindungen, ihr relativ niedriges Atomgewicht, ihre specifischen Gewichte und die Art, wie sie untereinander zu Verbindungen zusammentreten, sowie die Unbeständigkeit der Mehrzahl dieser Verbindungen sind charakteristisch für die organischen Elemente.

Der Kohlenstoff ist von allen bekannten Elementen das am schwersten schmelzbare und am wenigsten flüchtige; Stickstoff, Sauerstoff und Wasserstoff lassen sich am schwersten zи Flüssigkeiten verdichten; Phosphor, Kalium und Natrium verbinden sich besonders leicht mit Sauerstoff, Chlor mit Wasserstoff. Schwefel, Calcium, Magnesium und Eisen gehören zu den verbreitetsten Elementen in der Natur. Überhaupt ist sehr beachtenswert, daß die häufigsten Gesteine, beziehentlich die in ihnen vorkommenden Mineralien, Verbindungen sind von Silicium (Quarz), Calcium (Kalkstein), Magnesium (Talk), Wasserstoff(Eis), Kalium und Natrium (Silikate), Chlor (Steinsalz), Schwefel (Gips), Kohlenstoff (Steinkohle), Eisen (Erzgesteine), Aluminium (Thon) und Sauerstoff. Also mit Ausnahme des Aluminium sind die verbreitetsten mineralischen Elemente zugleich die verbreitetsten organischen Elemente. Diese Thatsache läßt die kaum übersehbare Mannigfaltigkeit der lebenden Körper und ihrer Metamorphosen nur um so erstaunlicher erscheinen. Die ganze Fülle des tierischen und pflanzlichen Lebens ist schließlich an die Verbindungen von nur etwa einem Dutzend derselben Elemente geknüpft, welche in den Felsen und Krystallen erstarrt und im Meere in einfacherer, zum Teil aber auch (im Wasser, im Steinsalz) in derselben Weise miteinander verbunden den wesentlichen Teil der Erdkruste bilden. 


\section{Verbindungsweisen der organischen Elemente in den lebenden Körpern.}

Binäre Verbindungen sind nicht zahlreich. Beispiele: Wasser, Chloride der Alkalien, Calciumfluorid, Grubengas, Chlorwasserstoff.

Ternäre Verbindungen sind sehr zahlreich. Beispiele: die Fette, die Kohlenhydrate, Milchsäuren, Fette Säuren, Alkalisulfate, Kohlensäurehydrat, Karbonate der Erden und der Alkalien, Triphosphate.

Quaternäre Verbindungen sind, ebenfalls sehr zahlreich. Beispiele: Harnstoff, Harnsäure, Seifen, Laktate, Mono- und Di-Phosphate.

Quinäre Verbindungen, wie Taurin, Urate, Lecithine, sind zahlreich, und wenn man die Albumine und verwandte leicht veränderliche Stoffe als chemische Verbindungen gelten läßt, von der größten Mannigfaltigkeit.

Auch aus sechs Elementen zusammengesetzte (senäre) Verbindungen (wie das Natriumtaurocholat) sind in den lebenden Körpern vertreten, und zwar in allen, wenn man die Alkalialbuminate als Verbindungen gelten läßt.

Die Hämoglobinate im roten Blute sind aus sieben Elementen (C, H, N, O, S, Fe, Ka) zusammengesetzt (septenär).

Bilden die vierzehn wesentlichen organischen Elemente die Ecken eines Vierzehneckes, so kann man durch geradlinige Verbindungen der vierzehn Punkte untereinander übersichtlich machen, mit welchen Elementen verbunden jedes Element im lebenden Körper vorkommt.

Weitaus die meisten Verbindungen geht der Sauerst off ein und zwar mit den sämtlichen übrigen Elementen, außer mit Chlor und Fluor.

Alle Kohlenstoffverbindungen der lebenden Körper bis auf einige wenige ron untergeordneter physiologischer 
Bedeutung (Rhodanalkali, Grubengas, Indol) enthalten Sauerstoff und Wasserstoff, viele Stickstoff, Schwefel, Phosphor, Natrium, Kalium, Calcium, Magnesium, Eisen. Chlorhaltige Kohlenstoffrerbindungen sind nicht nachgewiesen.

Die weitaus überwiegende Mehrzahl der Wasserst offverbindungen ist kohlenstoff - und sauerstoffhaltig, der Menge nach nimmt aber das Wasser die erste Stelle ein. Der Wasserstoff findet sich mit allen anderen Elementen chemisch rerbunden im Körper vor, außer mit Fluor.

Die Stickstoff verbindungen sind, außer einer sehr geringen Anzahl, kohlenstoff-, wasserstoff - und sauerstoffhaltig; viele enthalten Schwefel, Phosphor, Kalium, Natrium, Eisen, wenige Calcium und Magnesium.

Die Schwefelverbindungen sind teils kohlenstoffhaltig und dann sehr kompliziert, teils kohlenstofffrei und dann sauerstoffhaltig und nicht kompliziert; nur die Sulphocyanide und der Schwefelwasserstoff sind sauerstofffreie Schwefelverbindungen, welche aber nicht konstant vorkommen und physiologisch eine geringe Bedeutung haben. Der Schwefel kommt chemisch verbunden ror mit den meisten anderen organischen Elementen. Verbindungen desselben mit Phosphor, Chlor, Fluor und Silicium sind jedoch nicht nachgewiesen.

Die Phosphorverbindungen sind teils kohlenstoffhaltig und dann immer auch wasserstoff-, stickstoff- und sauerstoffhaltig, teils kohlenstofffrei und dann immer sauerstoffhaltig. Der Phosphor ist im lebenden Körper sehr häufig verbunden mit Natrium, Kalium, Calcium, Magnesium (Phosphate); Verbindungen desselben mit Chlor, Schwefel, Silicium und Fluor sind nicht nachgewiesen.

Die Chlorverbindungen (Chloride) sind kohlenstofffrei, nicht zahlreich, die meisten binär, das nur in kleinen Mengen vorkommende Chlorammonium ternär. Chlor ist in lebenden Körpern in Verbindung mit Wasserstoff, 
Natrium, Kalium, Calcium, Magnesium, Stickstoff, aber nicht in Verbindung mit Kohlenstoff, Sauerstoff, Phosphor, Schwefel, Fluor und Silicium nachgewiesen. Das chlorhaltige Hämin (C, H, N, O, Fe, Cl enthaltend) gehört nicht zu den normalen Bestandteilen lebender Körper.

Die Eisenverbindungen sind nicht zahlreich, zum Teil sehr kompliziert und kohlenstoffhaltig (Hämoglobine), zum Teil weniger kompliziert, und dann sowohl kohlenstofffrei, als auch kohlenstoffhaltig, in allen Fällen sauerstoffhaltig.

Die Natriumverbindungen sind teils kohlenstoffhaltig, teils kohlenstofffrei und zeigen trotz ihrer Isomorphie mit den Kaliumverbindungen, von denen sonst dasselbe gilt, wichtige Verschiedenheiten in ihrem physiologischen Verhalten (z. B. dem kontraktilen embryonalen Gewebe gegenüber), so daß auf Verschiedenheiten ihrer chemischen Verbindungsweisen im lebenden Körper geschlossen werden muß.

Die verbreitetsten Verbindungen des Calcium und des Magnesium sind die Phosphate und Karbonate, doch gehen beide auch kompliziertere Verbindungen mit fetten Säuren, Farbstoffen usw. ein.

Ob Fluor in anderer Verbindung als mit Calcium vorkommt, ist fraglich, desgleichen ob Silicium in Kohlenstoffverbindungen oder nur in Silikaten präexistiert.

\section{Immediatbestandteile.}

Es ist schwierig, mit Sicherheit festzustellen, ob eine aus lebenden Teilen erhaltene chemische Verbindung vorher in denselben als solche enthalten war. Inquiline Stoffe oder Immediatbestandteile heißen nur solche Verbindungen, deren Präexistenz feststeht. Die Methoden 
zum Beweise der letzteren (namentlich die Anwendung der Kälte, die optische Untersuchung lebender Gewebe) sind noch unvollkommen oder unvollständig, daher die Anzahl der als präexistierend erkannten Verbindungen relativ klein. Es gehören dazu für die Mehrzahl lebender Wesen: Wasser, Kohlensäure und Karbonate, Chloralkalien, Phosphate, Sulfate, fixe Säuren, organische Basen, Alkohole (besonders Kohlenhydrate) und Äther (namentlich Fette), und wichtigste Immediatbestandteile aller lebenden Wesen sind zu jeder Zeit ihres Lebens die in der lebenden Zelle in fortwährender Zersetzung befindlichen Albumine.

Die Aggregatzustände dieser und vieler anderer inquiliner Stoffe wechseln oft schnell: Gasiges verflüssigt sich, Flüssiges verdampft und erstarrt, Festes schmilzt und löst sich. Es bilden sich Gemenge von Flüssigkeiten, deren eine in der anderen unlöslich ist, Emulsionen, und besonders leicht vereinigen sich feste organische Teile mit Flüssigkeit, so daß sie quellen. Die Quellungserscheinungen berechtigen jedoch nicht zur Aufstellung eines festweichen oder festflüssigen Aggregatzustandes. In solchen Fällen ist vielmehr ein Teil fest, der andere flüssig oder weich.

Diese veränderlichen Zustände erschweren die Reingewinnung der Immediatbestandteile schon durch die oft unmögliche Trennung ihrer Träger. Am wenigsten eignet sich dazu die chemische Zersetzung durch Veraschung der getrockneten Gewebe. Beim Veraschen an der Luft bilden sich z. B. Sulfate, Phosphate, Karbonate, wo vorher keine Spuren von ihnen existierten, sondern an ihrer Stelle Gemenge von Albuminen, Lecithinen und anderen schwefelhaltigen und phosphorhaltigen Verbindungen, deren Schwefel, Phosphor, Kohlenstoff erst durch den atmosphärischen Sauerstoff beim Erhitzen oxydiert wird, so daß die entsprechenden Säuren erst dann gebildet werden.

Unter diesen Umständen ist es vom bionomischen 
Standpunkt aus nicht thunlich, ein einfaches Verzeichnis der aus lebenden Körpern dargestellten chemischen Verbindungen zusammenzustellen und für sich zu betrachten, weil dadurch unwesentliche und nur in minimalen Mengen oder nur ganz vereinzelt vorkommende biochemische Stoffe den wichtigen gleichgeordnet würden und die richtige Beurteilung der chemischen Zusammensetzung lebender Gebilde, vor allem den Beweis der Präexistenz der aus ihnen dargestellten Stoffe verlangt. Dagegen ist die minutiöseste chemische Untersuchung, die vollständige Berücksichtigung aller bei einer einzelnen Funktion in Frage kommenden chemischen Verbindungen in der speciellen Physiologie unerläßlich, weil keine Funktion ohne chemische Änderungen zustande kommt.

Übrigens sind viele, wenn nicht die meisten Immediatbestandteile in so kleinen Mengen vorhanden, daß ihre Reindarstellung aus dem Gemenge der sogenannten Extraktivstoffe, d. h. derjenigen Stoffe, welche mittels verschiedener Lösungsmittel aus dem trockenen Rückstande der tierischen und pflanzlichen Säfte, Organe oder Organapparate gewonnen werden, nur in relativ wenigen Fällen gelingt. Sicher ist die weit überwiegende Mehrzahl der chemischen Verbindungen in lebenden Körpern noch unbekannt, ihre Entdeckung und Untersuchung Hauptaufgabe der Biochemie. Dabei kann jede Eigenschaft derselben physiologisch bedeutsam werden.

Namentlich sind für die Immediatbestandteile je nach ihrer Natur behufs etwaiger physiologischer Verwertungen folgende Punkte zu berücksichtigen:

Namen und Litteratur. Geschichte der Entdeckung im lebenden Körper.

Vorkommen außerhalb der lebenden Körper und innerhalb derselben: in welchen Teilen? in welchen Zuständen? wo gasig, wo flüssig, wo fest? 
Krystallogenese, Krystallformen, Pseudomorphosen und Arten der Amorphie.

Specifisches Gewicht oder Dichte (Dichtigkeit). Porosität. Kohäsion. Dehnbarkeit, Biegsamkeit, Geschmeidigkeit (Milde), Sprödigkeit, Zersprengbarkeit, Spaltbarkeit, Bruch, Härte, Festigkeit (Zug-, Bruch-, Druck-, Torsions-Festigkeit), Elasticität. Das Schweben und Sinken in Flüssigkeiten, das Schwimmen auf Flüssigkeiten. Der Auftrieb. Die Emulgierbarkeit.

Die, Kondensierbarkeit, Zusammendrückbarkeit, Viskosität, Tropfenbildung.

Die Löslichkeit (von Gasen in Gasen, Gasen in Flüssigkeiten, festen Körpern in Flüssigkeiten, Flüssigkeiten in Flüssigkeiten). Das Lösungsvermögen.

Die Diffundibilität, das osmotische Äquivalent, die Filtrierbarkeit, Kapillarität, Adhäsion (fester Körper an festen, flüssiger an festen, gasiger an festen, flüssiger und flüssiger, flïssiger und gasiger, gasiger und gasiger Körper). Das Quellungsvermögen. Das Imbibitionsvermögen, Verdichtungsvermögen (fester Körper für Gase). Die Hygroskopie. Das Verhalten beim Trocknen, im Vakuum.

Elektrische Eigenschaften: Verhalten bei der Elektrolyse. Elektrisches Leitungsvermögen.

Paramagnetisch oder Diamagnetisch?

Optische Eigenschaften: Farbe, Glanz, Lichtbrechung, Spektrum. Pellucidität. Fluorescenz. Phosphorescenz.

Thermische Eigenschaften: Ausdehnung. Wärmeleitung. Diathermansie. Specifische Wärme. Verhalten beim Erwärmen (Zersetzbarkeit) und Abkühlen. Dampfspannung. Latente Dampfwärme. Schmelzpunkt. Erstarrungspunkt. Brennbarkeit. Verbrennung. Verbrennungswärme. Temperaturen bei Auflösung. Koagulierbarkeit. Explodierbarkeit, Flüchtigkeit.

Chemische Zusammensetzung: Qualitativ, quantitativ. 
Empirische Formel. Kinystallwasser. Äquivalent - und Molekulargewicht. Zersetzungsprodukte. Verbindungen. Chemische Konstitution und rationelle Formel. Künstliche Synthese.

Nachweis im lebenden Körper: Makrochemische und mikrochemische Reaktionen. Geschmack. Geruch. Darstellung im großen, im kleinen. Quantitative Bestimmung. Sogenannte Kontakterscheinungen.

Veränderungen des lebenden Körpers nach Einführung größerer Mengen.

Ursprung im lebenden Körper.

Veränderungen der eingeführten und der im lebenden Körper entstandenen Immediatbestandteile in diesem.

Jeder dieser Punkte kann bei dem einen oder anderen Immediatbestandteile eines lebenden Körpers für die Erklärung von Lebenserscheinungen in Betracht kommen. Daher muß die Physiologie von ihnen allen Kenntnis nehmen.

\section{Die Verteilung der organischen Elemente.}

In jedem Teile jedes lebenden Wesens findet sich Wasser und zwar im ganzen stets mehr als die Hälfte, bei pelagischen Tieren (z. B. Medusen) und vielen Pflanzen weit über neunzig Prozent. In der Regel verlieren Weichteile zwei Drittel bis drei Viertel ihres Gewichtes beim Trocknen, viele Säfte vier Fünftel bis neun Zehntel, auch über 98 Prozent. Die festen Teile (Knochen, Schalen, Panzer, Stützgewebe, Holz u. a.) sind durchweg relativ wasserarm und enthalten Kalk-, Talk-, Kiesel-Verbindungen oder wie die Chitingebilde Kohlenstoff, Wasserstoff, Sauerstoff 
und Stickstoff in schwer löslichen Verbindungen, das Holz Kohlenstoff, Wasserstoff, Sauerstoff in unlöslicher Cellulose und im Xylogen. In den Säften aller Pflanzen und Tiere sind höchstwahrscheinlich aufgelöst Kalium- und Natriumchlorid, Phosphate, Kohlensäure (oder Karbonate), Eiweißderivate und mehrere andere Kohlenstoffverbindungen. Eisen findet sich normalerweise ebenso wie Schwefel in der Asche fast jedes beliebigen pflanzlichen oder tierischen Gewebes, bei höheren Tieren relativ reichlich im Blut, Phosphor relatir reichlich im Nervengewebe.

Die Kaliumverbindungen kommen meistens zusammen vor mit Natriumverbindungen, die Calcium- mit Magnesiumverbindungen; doch sind die Terhältnisse der Mengen in dem einen wie in dem anderen Fall sehr wechselnd.

Ton allen Elementen ist in den belebten Körpern wie in der leblosen Natur - der Sauerstoff das verbreitetste und nimmt dem Gewicht nach in jedem lebenden Körper die erste Stelle ein.

\section{Unzulässigkeit der Annahme eines besonderen} Lebensstoffes.

Da die Materie in beiderlei Wesen dieselbe ist, so müssen die Ausdrücke „lebendige Materie“ und „organische Materie" vermieden werden.

In der Chemie bedeuten organische Terbindungen Kohlenstoffverbindungen. Diese aber sind physiologisch geradeso anorganisch, d. h. für sich lebensunfähig, wie irgend eine andere echte chemische Verbindung.

Das körperliche Leben besteht wesentlich in einer Umsetzung von komplizierten chemischen Verbindungen in einfache chemische Verbindungen und Zusammensetzung der 
ersteren aus letzteren durch den Stoffwechsel in entgegengesetzter Richtung. Es ist kein Grund angebbar, weshalb bei diesen chemischen Umsetzungen auch nur Eine dauerhafte Verbindung resultieren sollte, welche nicht auch auf anderem Wege herstellbar wäre, zumal mehrere Lebensprodukte bereits künstlich dargestellt worden sind.

Noch weniger zulässig ist die Annahme eines elementaren Lebensstoffes neben den organischen Elementen, welcher in der anorganischen Natur nicht vorkäme. Denn vermöge seiner Natur als Element müßte er unzerstörbar, also in der Leiche oder im Körper im Augenblick des Sterbens, somit doch wieder in der anorganischen Welt auffindbar sein. Wollte man aber annehmen, daß dieser elementare Lebensstoff mit dem Erlöschen des Lebens verschwände, so widerspräche dieses dem Gesetz von der Erhaltung der Materie. Die Anwendung dieses physikalischen und chemischen Axiomes auf physiologische Vorgänge verlangt, daß kein Element durch den Lebenschemismus vermehrt oder vermindert oder in seinen ursprünglichen Eigenschaften im geringsten verändert werde, womit die Erfahrung übereinstimmt, sofern die aus den Organismen dargestellten chemischen Elemente mit den aus Gesteinen erhaltenen identisch sind, auch nicht der mindeste Grund vorliegt, ihnen im lebenden Körper andere Valenzen, Atomgewichte, Iolekulargewichte zuzuschreiben, als außerhalb derselben. Ebenso wenig berechtigt wie die „Lebensmaterie", der Ylech, Lebensäther, der Lebenssaft, das Lebenselixir, ist daher die Bevorzugung eines der wesentlichen organischen Elemente vor den anderen als eines specifischen Lebensstoffes. Der Sauerstoff ist nicht mehr und nicht weniger Lebensstoff (Lebensgas und Lebensluft) wie der Kohlenstoff, Stickstoff, Wasserstoff usw. Der sogenannten Kohlenstofftheorie des Lebens, welche alle Funktionen lebender Körper in letzter Instanz auf die Eigenschaften der sehr zahl- 
reichen und komplizierten Kohlenstoffverbindungen zurückzuführen strebt, läft sich mit gleichem Erfolge eine Stickstofftheorie, Sauerstofftheorie usw. gegenüberstellen. Denn kein wesentliches organisches Element darf fehlen, wo Leben erscheinen oder vorhandenes Leben bestehen bleiben soll. Alle wesentlichen organischen Elemente sind Lebensstoffe, weil alle zum Leben notwendig sind.

Da nun die eigentümlichen Verbindungen derselben im lebenden Körper zu anderen Erscheinungen führen, als in der anorganischen Natur ihre weniger veränderlichen Verbindungen, so ist es notwendig, jene Erscheinungen (der Entwicklung und der psychischen Funktionen) schon mit der Kompliziertheit und Veränderlichkeit des einfachsten lebenden Stoffgemenges in Zusammenhang zu bringen, mit dem Protoplasma.

Denn wenn nicht im Protoplasma der jüngsten Eier, auch der nur parthenogenetisch sich fortpflanzenden Wesen, die potentielle Kraft oder Anlage zur morphotischen, funktionellen und insbesondere psychischen Entwicklung präexistierte, dann ist schlechterdings unverständlich, woher jene weder auf physikalischen noch auf chemischen Eigenschaften der Protoplasmateile zurückführbare Entwicklung in dieselben hineinkommen sollte.

\section{Das Protoplasma.}

Das Protoplasma oder die Sarkode wird auch wohl einfach als die kontraktile Substanz bezeichnet.

Der Ausdruck „Protoplasma,“ ursprünglich nur phytologisch, hat allmählich einen solchen Umfang erhalten, daß er häufig zu Mißverständnissen führt, indem man in mancher Hinsicht ähnliche sich bewegende, wenig und sehr 
weit differenzierte Stoffgemenge (in Ganglienzellen, Muskelfasern) ziemlich kritiklos immer mit demselben Ausdruck "Protoplasma" (auch „Plasma," „Bioplasma") bezeichnet. Es wird, um wenigstens das tierische Protoplasma ron dem pflanzlichen zu unterscheiden, nützlich sein, jenes $\mathrm{Zoo-}$ plasma, dieses Phytoplasma zu nennen.

Protoplasma kommt in jedem lebenden Körper ohne Ausnahme zu jeder Zeit seines Lebens vor, und zwar entweder aktuell lebend (in beweglicher Form in Zellen eingeschlossen, aber auch frei) oder potentiell lebend (in Keimen, Eiern, Embryonen, aber auch in entwickelten Organismen).

Die Versuche, das Protoplasma (der Myxomyceten) in größeren Mengen zu isolieren, sind bis jetzt nur unvollkommen gewesen, daher die Untersuchung seiner Lebenseigenschaften höchst schwierig. Fest steht, daß trockenes Protoplasma (z. B. der Rädertierchen) bei großer Hitze (bis $140^{\circ} \mathrm{C}$.) oder im Vakuum seine Lebensfähigkeit nicht notwendig verliert und einzelne Bacillen-Arten nach mehr als siebenstündigem Kochen in Wasser nicht zerstört werden. Ebenso behält das Protoplasma-Eis im festgefrorenen Ei (z. B. des Huhnes) seine Keimfähigkeit. So lange es aktuell lebt, ist jedes Protoplasma eine Flüssigkeit mit darin aufgeschwemmten festen Teilchen, und es enthält sehr häufig auch andere Flüssigkeiten in Vakuolen oder Kügelchen. Nan kann daher das Protoplasma im allgemeinen eine Emulsion nennen. Aber es zeigt sehr große Verschiedenheiten der Viskosität.

In manchen Fällen ist es so dünnflüssig und enthält so wenige Körnchen (Mikrosome), daß es fast homogen erscheint (Hyaloplasma), wie eine wasserhelle Lösung von farblosen Salzen; in anderen ist es zähflüssig und schwer beweglich, teigartig, und enthält dann viele feste Teilchen in relativ geringer Flüssigkeitsmenge. Auch kommen Gas- 
bläschen im Protoplasma vor, und es entläßt immer dann, wenn es in trockener Umgebung verharrt, große Mengen Wasserdampf. Folglich hängt die Konsistenz des Protoplasma wesentlich $a b$ von seiner unmittelbaren Umgebung. Ist die Verdunstung erschwert, dann muß es im allgemeinen dünnflüssiger sein, als nach Wasserverlust in warmer, trockener Umgebung, oder in konzentrierteren Lösungen, welche ihm Wasser durch Osmose entziehen. Außerdem hat das Protoplasma die Eigenschaft sehr klebrig zu sein, so lange es lebt, so daß es an anderen Körpern auch im Wasser leicht haften bleibt. Es läßt sich dann (zwischen Objektträger und Deckglas) leicht zusammendrücken, ist in hohem Grade preßbar und ausdehnbar. Doch kann es nach geringerem Druck vermöge seiner zwar geringen aber vollkommenen Elasticität die frühere Form schnell wieder annehmen.

Ferner ist das dickflüssige Protoplasma sehr quellbar. da es leicht große Flüssigkeitsmengen aufnimmt, sich damit imbibiert und mit erheblicher Volumzunahme aufquillt. Sein specifisches Gewicht muf größer als 1 und (wenigstens in vielen Fällen) kleiner als 1,030 sein, weil die Leukocyten im Blutserum emporsteigen, in sehr verdünnten Salzlösungen untersinken. Die wechselnde Beschaffenheit der Einschlüsse des Protoplasma bedingt jedoch eine wechselnde Dichte und Kohäsion desselben. Doch ist bemerkenswert, daß selbst wenn relativ sehr große Fremdkörper vom Protoplasma umschlossen sind, dasselbe nicht leicht zerreibt und trotz seiner Weichheit durch Schneiden oft schwer geteilt werden kann. Die größere oder geringere Verschiebbarkeit der Teilchen des Protoplasma steigt und fällt mit dem Flüssigkeitsquantum, das es enthält. Alles Protoplasma nimmt die Kugelform leicht an, wenn es in geeigneten Flüssigkeiten (Seewasser, Flußwasser, Gewebesäften u. a.) nicht an festen Körpern adhäriert.

Bezüglich der Struktur ist es sehr schwierig zu entPreyer, Physiologie. 
scheiden, ob die nur bei stärkster Vergrößerung sichtbaren Netze und Fäden als Ausdruck einer bleibenden Anordnung der Teilchen anzusehen sind (Spongioplasma) oder nur in gewissen Zuständen auftreten. Jedenfalls sind dieselben veränderlich. Eine Verschiedenheit der Oberfläche vom Inneren, welche zur Unterscheidung eines Endoplasma und Ektoplasma führt, ist nicht in allen Fällen erkennbar und der hyaline Saum (das Ektoplasma) höchst veränderlich. Ebenso ist gewiß, daß die Körnchen im Protoplasma sich zum Teil in der Flüssigkeit desselben auflösen können, Kerne sich in ihm bilden (aus Karyoplasma). Das Protoplasma im Kern nicht passend Nucleoplasma statt Karyoplasma genannt ist stets verschieden von dem des Zellenleibes (Kytoplasma).

Schon aus diesen Thatsachen folgt, daß das Protoplasma keine chemische Verbindung ist; es ist ein Gemenge von festen und flüssigen sehr komplizierten chemischen Verbindungen, welche während des aktuellen Lebens sich in schneller ununterbrochener Zersetzung und Neubildung befinden, so daß es schwierig ist, von einer einzelnen aus ihm erhaltenen chemischen Verbindung mit unveränderlichen Eigenschaften die Präexistenz zu beweisen. Sicher präexistieren konstant in jedem Protoplasma Wasser, Salze (wahrscheinlich konstant Natriumund Kalium-Chlorid, die Phosphate des Calcium, Magnesium, Natrium, Kalium), Albumine und wahrscheinlich meistens neutrale Fette und Kohlenhydrate. Auch Pigmente und Fermente sind nachgewiesen. Unter den Zersetzungsprodukten, zumal bei der Fäulnis, welche sehr leicht eintritt wo totes differenziertes Protoplasma sich anhäuft, lassen sich zahlreiche Säuren und Ammoniakderivate nachweisen. Unter den chemischen Reaktionen, welche verwendbar sind, ist kaum eine makrochemische angebbar. Alle töten das Protoplasma schnell. Die mikrochemische Xanthoproteïnreaktion beweist die Anwesenheit von Albu- 
minstoffen. Die Imbibition des Protoplasma mit farbigen Flüssigkeiten verläuft im Ieben anders als im Tode. Das sich leicht färbende Protoplasma hat den Namen Chromatoplasma erhalten. Doch ist jedenfalls die Färbung des lebenden Protoplasma, namentlich die Bildung des grünen in den Pflanzen und einigen Tieren, mit tiefgehenden Änderungen desselben verbunden, so daß z. B. die Chlorophyllkörner schon als Differenzierungsprodukt zu bezeichnen sind, während die Tinktion toten Protoplasmas mit Karmin u. dgl. einen einfacheren Vorgang repräsentiert.

Überhaupt ist das chemische und physikalische Verhalten des lebenden Protoplasma von dem des toten wesentlich verschieden. Die Verbrennung nach den Methoden der organischen Elementar-Analyse könnte daher, selbst wenn dazu genügende Mengen rein dargestellt würden, nichts über den Chemismus im Protoplasma oder die elementare Zusammensetzung seiner Bestandteile kennen lehren, sondern nur die elementare Zusammensetzung des ganzen Gemenges aus Kohlenstoff, Wasserstoff, Stickstoff usw. in inkonstanten Verhältnissen. Die Veraschung zeigt auch mit Sicherheit nur die Anwesenheit der sonst aus lebenden Körpern darstellbaren Elemente, nicht irgend eine Terbindung als präexistent an. Doch ist fast gexviß, daß außer den Luftbestandteilen Stickstoff und Sauerstoff kein Element normal frei im lebenden Protoplasma konstant vorkommt. Von anderen Elementen ist nur Schwefel (in Krystallen) in einigen Schizophyten beobachtet worden, was für ein starkes reducierendes Vermögen spricht. Dieses ist auch durch andere Versuche bewiesen, schließt aber selbstverständlich eine Wärmebildung durch oxydative Prozesse nicht aus.

Die charakteristische Eigenschaft des Protoplasma ist seine Beweglichkeit. Von den zahlreichen Bewegungserscheinungen sind namentlich merkwürdig die Strömungen und Formänderungen. 
In den Rhizopoden und sehr vielen Pflanzenzellen, wie in dem noch nicht differenzierten beweglichen Gemenge der Eizelle auch der höchsten Tiere, sieht man Körnchenströmungen, welche in den Ausläufern der Sarkode in centripetaler wie centrifugaler Richtung durch die Fortbewegung sehr kleiner Partikel erkennbar sind. Die Foraminiferen, deren ganzer Körper nur aus Sarkode besteht, zeigen diese Körnchenströmungen ebenso wie die mit einer Centralkapsel versehenen Radiolarien. Weder die Schalen der Foraminiferen, noch die auffallend symmetrischen Gerüste der Radiolarien bedingen einen physiologischen Unterschied im Verhalten der Sarkode bezüglich jener Ströme. Den größten Wechsel zeigen diese in dem rotierenden und cirkulierenden Plasma vieler Pflanzenzellen und Infusorien.

Noch mannigfaltiger als die Strömungen sind aber die mit Formänderungen verbundenen Bewegungen, welche, weil sie zuerst an Amöben wahrgenommen wurden, allgemein als amöboide Protoplasmabewegungen bezeichnet und auf eine dem Protoplasma specifisch eigentümliche Kontraktilität bezogen werden. Geht man von der Kugelgestalt aus, so beginnt die amöboide Bewegung mit einer Erhebung oder mehreren Erhebungen, welche zunehmen, so daß bald eine förmliche Protuberanz entsteht. Diese nimmt an Höhe zu und kann bis zur mehrfachen Länge des Kugeldurchmessers wachsen und immer dünner werdend die erwähnten Körnchenströmungen kaum noch erkennen lassen. Solche Fortsätze heißen Pseudopodien oder Scheinfüße. Dieselben sind oft sehr zahlreich, oft werden sie alle schnell wieder eingezogen. Manchmal verschmelzen zwei miteinander oder umschließen einen kleinen an der klebrigen Oberfläche adhärierenden Fremdkörper. Auf diese Weise gelangen viele feste Nahrungspartikel in die Protoplasmamasse, wo sie zum Teil assimiliert, $d . h$. in Protoplasma verwandelt werden; zum Teil verlassen sie 
während der Durchmischung die Masse wieder als Exkrete, wie besonders deutlich bei den Myxomyceten zu sehen ist. Die Exkretion ist nicht so zu verstehen, als wenn nach Aufnahme beliebiger Partikel (Fetttropfen, Diatomeen u. a.) das nicht Assimilierbare sogleich ausgestofen würde. Es verbleibt oft lange Zeit im Inneren. Aber das Endstadium der langen Reihe von Prozessen, die in der Assimilation und Dissimilation aufeinanderfolgen, ist die Ausscheidung von nicht assimilierbaren und dissimilierten Körpern, ist die Exkretion. Die Abscheidung von Flüssigkeiten in Vakuolen, auch von festen Teilen und Gasen im Inneren der Protoplasmamasse, ist hingegen einem Sekretionsvorgange vergleichbar. Die Körnchen oder Jikrosome selbst, welche sich in jedem strömenden Protoplasma finden, sind vermutlich teils schon zur Ausscheidung fertige Reste verbrauchter Nahrung, teils noch nicht assimilierte Nahrung. Übrigens ist es ungleich schwerer, die Ausstoßung auch größerer Partikel zu sehen, als die Aufnahme künstlich zugesetzter Farbstoffkörnchen, Fetttröpfchen u. dgl., oder im gewohnten Medium suspendierter Teilchen mittelst der klebrigen Fortsätze.

Eine andere wichtige Konsequenz der amöboiden Bewegungen ist die Lokomotion der freien protoplasmatischen Gebilde und zwar der Amöben im Wasser, wie der Leukocyten (farblosen Blutkörper, Lymphkörper) in Geweben höherer Tiere. Wenn nämlich eine lange Pseudopodie ausgestreckt worden, fliebt oft alles Protoplasma in das Ende derselben, und so kommt ein Ortswechsel zustande, welcher durch Wiederholung des Prozesses zu Wanderungen über große Strecken führen kann. Die Auswanderung farbloser Blutkörper aus den Blutgefäßen kann so massenhaft ror sich gehen, daß viele Millionen derselben bei Entzündungen zur Eiterbildung zusammentreten. Die Wanderzellen im Bindegewebe bewegen sich wahrscheinlich auch ohne solche Anlässe reichlich von einem Orte zum anderen. 
Obgleich diese lokomotorischen Kontraktionen und Expansionen mit sehr ungleicher, immer aber geringer Geschwindigkeit vor sich gehen und dem Anscheine nach vollkommen ziellos sind, muß doch für viele freilebende niedere Protoplasmagebilde wegen eines öfters eintretenden Richtungswechsels der Bewegung die Möglichkeit erwogen werden, ob nicht eine Auswahl der Ziele stattfinden könne. Die Vampyrella begibt sich von einer leeren (chlorophyllfreien) Algenzelle zu einer grünen und saugt sie förmlich aus, als wenn Willkür und weitgehendes Unterscheidungsvermögen vorhanden wären. Jedenfalls lält sich die Empfindlichkeit des Protoplasma gegen Licht und Sauerstoffmangel schon als die Vorstufe einer Sinnesthätigkeit ansehen. Bei ungleicher Beleuchtung sind die Lokomotionen des Protoplasma nicht mehr ziellos.

Auch ist eine in manchen Fällen rhythmische $\mathrm{Ab}$ wechslung der Ruhe und Bewegung, eine Einkapslung und Entkapslung beobachtet worden, welche dem Wachen und Schlafen vergleichbar $\mathrm{zu}$ sein scheint. Doch entspricht beim freien Protoplasma die Kugelform nicht jedesmal dem Ruhezustande.

Vom höchsten Interesse ist das Wachstum und die Teilung des lebenden Protoplasma. Wenn in der erwähnten Weise Fremdkörper in dasselbe gelangt sind, dann wird ein Teil derselben zu integrierenden Bestandteilen des Protoplasma, so daß auch nach Ausstoßung des nicht löslichen Teiles die Masse zunimmt. Dieses Wachsen erreicht aber nach kurzer Zeit ein Ende und es tritt dann eine Zweiteilung ein. Die beiden Teilstücke wachsen wieder eine Zeitlang, um wieder in zwei Teile zu zerfallen. So vermehren sich die Amöben in geometrischer Progression unter günstigen Umständen, namentlich bei genügender Nahrung und genügendem Raum, immerzu. Dabei ist besonders zu beachten, daß nicht ein Teilstück als älter und 
das andere als jünger, als Ei, Sproß oder Kieim bezeichnet werden darf, denn es findet noch während der Teilung: eine vollständige Durchmischung des Protoplasma beider Stücke mittels der sie noch eben zusammenhaltenden Brücke in einzelnen Fällen nachweislich statt.

Dazu kommt die Thatsache, daß auch künstlich mit dem Messer das Protoplasma, z. B. der Protamöben, geteilt worden ist und die Stücke sich gerade so weiter bewegten und lebten, wie das Ganze und wie die Teilstücke nach der natürlichen Teilung.

Nur auf diesem Wege, durch Wachstum und Teilung. findet eine Neubildung des Protoplasma statt, also entsteht niemals lebendes Protoplasma, wo nicht vorher lebendes Protoplasma war. Es gehört zum Begriffe des letzteren nicht nur, daß, so lange es lebt, ununterbrochen chemische Veränderungen in ihm stattfinden, sondern auch eigentümliche Nolekularbewegungen in ihm ablaufen. Doch können - eben wegen der chemischen Umsetzungen - die Moleküle nicht gleichartig sein. Tagmen heißen diejenigen kleinsten Protoplasmateile (Konglomerate von Molekülen), welche für sich noch Lebenserscheinungen zeigen, d. h. sich bewegen. Tagmen (Micellen) enthalten also chemisch differente Noleküle. Inotagmen sind die für die Kontraktilität erforderlichen Teile der Tagmen und für sich nicht mehr lebensfähige, kontraktile Elemente hypothetischer Natur, aus Molekülen bestehend.

Über diese Moleküle, die Beziehungen der Inotagmen $\mathrm{zu}$ den übrigen Bestandteilen der Tagmen und die Physiologie des Protoplasma überhaupt haben die künstlich mittels elektrischer, mechanischer, thermischer, chemischer Einwirkungen herbeigeführten Veränderungen noch wenig Aufschluß gegeben. Alle diese Mittel können das Protoplasma schnell töten. Durch Erwärmung tritt leicht Gerinnung ein, und jedes Protoplasma hat ein Temperatur- 
minimum, bei welchem die Bewegungen aufhören, ein Optimum, bei welchem sie ohne störende Nachwirkung am lebhaftesten sind und ein Maximum, welches dieBewegungen sogleich aufhebt, nicht lange ertragen und nicht ohne Lebensgefahr überschritten wird. Geschieht es, so tritt Wärmestarre ein, welche, wenn die Temperatur nicht bald wieder sinkt, leicht in Totenstarre übergeht. Luftentziehung, Verdunstung des Protoplasmawassers, Luftdrucksteigerung führen ähnlich wie zahlreiche Gifte (z. B. Chinin, Cyanwasserstoff, alle Säuren und Alkalien) in geringer Konzentration Bewegungslosigkeit herbei.

In einigen Fällen wirkt auch monochromatisches Licht auf die Beweglichkeit verändernd ein.

Von der Phosphorescenz mancher Protoplasma-Arten ist bekannt, dab sie nur bei Gegenwart von Sauerstoff stattfindet.

\section{Verschiedenheit und Veränderlichkeit chemischer Ver- bindungen in ungleichen lebenden Körpern.}

Es ist keinem Zweifel unterworfen, daß die wenigen in allen lebenden Wesen präexistierenden einfachen chemischen Verbindungen, wie das Wasser, die Kohlensäure u. a. in jedem Falle dieselben Eigenschaften besitzen; auch für einige kompliziertere Stoffe, wie Harnstoff, Traubenzucker u. a., ist es gewiß, daß sie in jedem lebenden Wesen, in welchem sie vorhanden sind, sich gleich bleiben. Aber ebenso steht fest, daß sehr häufig im natürlichen System sich nahestehende Tiere, bez. Pflanzen, kompliziertere chemische Verbindungen mit wesentlich verschiedenen Eigenschaften bilden. Schon der specifische Blumengeruch, der nach der Tierart verschiedene Blutgeruch, die Bildung 
giftiger Alkaloide (z. B. des Strychnins, Curarins, Morphins u. v. a.) nur in gewissen Pflanzenfamilien, die Bildung der freien Schwefelsäure nur in gewissen Mollusken beweisen, daß an gewisse Organisationen eigentümliche Chemismen ebenso fest (erblich) geknüpft sind, wie ihre Formen.

Thatsache ist auch - und diese bildet ein wichtiges chemisches Problem - daß eine höchst komplizierte Verbindung, der rote Blutfarbstoff, obgleich er bei allen Tieren, in denen er vorkommt, dieselben fundamentalen Erscheinungen bezüglich der Lichtabsorption zeigt, bei allen dasselbe krystallisierte Zersetzungsprodukt (Hämin) liefert und bei allen gegen Sauerstoff sich gleich rerhält, doch je nach der Tierart, aus deren Blut er gewonnen wird, verschieden krystallisiert, verschiedene Löslichkeit, Koagulierbarkeit und Härte besitzt. Es gibt also funktionell identische Immediatbestandteile, welche bei den verschiedensten Tieren - hier z. B. Wirbeltieren, Gasteropoden, Würmern identische fundamentale chemische und physikalische Eigenschaften besitzen und in anderen ebenso fundamentalen differieren, je nach der Art im zoologischen Sinne. Es muß also, weil es sich hierbei um erbliche Eigenschaften der Tiere handelt, wenn z. B. alle Wirbeltiere schließlich von einer Urwirbeltierart abstammen, die nur eine Art Blutfarbstoff haben konnte, während der allmählichen phylogenetischen Entwicklung der verschiedenen Wirbeltierarten mit je einer besonderen Art Blutfarbstoff notwendig neben der morphotischen eine chemische Metamorphose stattgefunden haben. Somit sind einige Immediatbestandteile nicht allein der Art nach verschieden, sondern in der Zeit oder phylogenetisch veränderlich und zwar veränderlich in demselben Grade wie die Artcharaktere. Für die Pflanzen gilt dasselbe bezüglich der Cellulose und wahrscheinlich bezüglich des Amylums und des Chlorophylls. 
Die Physiologie muß demnach bei gewissen komplizierten Verbindungen, die in den Lehrbüchern der Chemie nur anhangsweise oder beiläufig oder gar nicht berücksichtigt zu werden pflegen, die Möglichkeit einer Veränderlichkeit mit der Formänderung erwägen und die Konstanz an die Erblichkeit der Formen knüpfen.

\section{Bezugsquellen der organischen Elemente.}

Da alle Pflanzen und Tiere aus denselben Elementen zusammengesetzt sind, so muß auch alle tierische und pflanzliche Nahrung eben dieselben Elemente enthalten. Aber die chemischen Verbindungen der Nahrung sind größtenteils andere, als die Immediatbestandteile der lebenden Gebilde, und kein Element wird als solches normalerweise in der Nahrung von Pflanzen oder Tieren aufgenommen, vielmehr jedes schon in fester chemischer Verbindung.

Die grünen Pflanzen entnehmen den Kohlenstoff der Kohlensäure der atmosphärischen Luft, welche sie vermittelst des Chlorophylls unter dem Einflusse der Sonnenstrablen - der aktuellen Energie der Ätherschwingungen - reducieren unter Sauerstoffexhalation. Diesen Prozeß nennen die Phytophysiologen "Assimilation".

Den Sauerstoff entnehmen die Pflanzen ebenfalls der Luft beim Atmungsprozeß, welcher zur Kohlensäurebildung führt, aber den zur Synthese der Immediatbestandteile erforderlichen Sauerstoff nimmt die Pflanze vorwiegend mit Wasserstoff zusammen im Wasser auf.

Den Stickst off liefern der Pflanze fast ausschließlich Nitrate und zwar Kalium- und Ammonium-Nitrat, wahrscheinlich auch, aber in ungleich geringerer Menge, Natriumnitrat. 
Den Schwefel entnimmt die Pflanze den Sulfaten des Calcium, Nagnesium, Kalium, Natrium, Ammonium, den Phosphor den Phosphaten der Erden und Alkalien, das Chlor den Chloriden der Alkalien, das Calcium, Magnesium, Kalium und Natrium (dieses oft nur in Spuren) den entsprechenden Phosphaten, Sulfaten, Nitraten, Karbonaten, Chloriden und das Eisen wahrscheinlich dem FerroKarbonat und -Phosphat.

Das Tier dagegen deckt, abgesehen von der Wasseraufnahme, seinen Bedarf an Kohlenstoff, Stickstoff, Schwefel, Wasserstoff und Sauerstoff fast ganz durch Aufnahme der von der Pflanze synthetisch erzeugten Albumine, Kohlenhydrate und Fette. Auch bei karnivoren Tieren ist schließlich die Bezugsquelle der genannten Elemente das pflanzliche Protoplasma mit seinen chemischen Produkten, Stärke: Dextrin, Zucker, Fett und einigen weniger wichtigen Verbindungen. Seinen Phosphor, sein Calcium und Magnesium entnimmt auch das Tier hauptsächlich den Phosphaten des Calcium und Magnesium, sein Kalium und Natrium, sowie sein Chlor den Phosphaten und Chloriden des Kalium und Natrium, Eisen dem Karbonate oder Phosphate und noch unbekannten Eisenverbindungen in Pflanzen. Bei solchen Tieren, welche nicht ausschließlich Pflanzenteile oder Produkte des pflanzlichen Stoffwechsels in der Nahrung zu sich nehmen, neben den anorganischen Salzen, und namentlich bei solchen, welche sich ausschließlich von tierischen Teilen und Produkten des tierischen Stoffwechsels (wie Eiern und Milch) ernähren, wird der Phosphor auch in anderer Form als in Phosphaten, nämlich, wie auch das Eisen, in sehr komplizierten Verbindungen aufgenommen. Aber schließlich hängt fast alles Tierleben vom Pflanzenleben $a b$, weil die Tiere die ihnen erforderlichen Elemente den einfachen Verbindungen, die den Pflanzen genügen, nicht entnehmen können. Die meisten verhungern 
schnell, die höheren sämtlich, wenn ihnen Stickstoff und Schwefel in anderen Verbindungen als in Albuminen zugeführt werden.

Hieraus ergibt sich, daß in letzter Instanz die Bezugsquellen der organischen Elemente aller lebenden Körper nur die folgenden sind: Kohlensäure und Wasser, ferner die Nitrate, Phosphate, Sulfate, Chloride der Alkalimetalle Kalium und Natrium (nebst Ammonium) und der Erdalkalimetalle Calcium und Magnesium, sodann lösliche Eisensalze, und in der Mehrzahl der Fälle noch Kieselerde (oder Silikate) und vielleicht Calciumfluorid. In der That können viele Pflanzen bei Zutritt gewöhnlicher kohlensäurehaltiger Luft in Nährflüssigkeiten vollständig gedeihen, welche nur enthalten: Wasser, Kaliumnitrat, Natriumchlorid, Calciumsulfat, Magnesiumsulfat, Calciumphosphat, Spuren einer löslichen Eisenverbindung und Spuren von Kieselerde oder eines Silikates.

Hier sind alle wesentlichen organischen Elemente vertreten und zwar in Verbindungen, wie sie in der Natur, wo Pflanzen wachsen, ebenfalls vorkommen.

Erwägt man, wie außerordentlich verwickelt und zahlreich die chemischen Produkte der in einer solchen Nährstofflösung wachsenden Pflanzen sind, so erscheint es zur Zeit unverständlich, wie sie alle aus jenen wenigen relativ einfachen Verbindungen hervorgehen können, namentlich wie der Kohlenstoff der Kohlensäure mit dem Stickstoff der Nitrate und dem Schwefel der Sulfate unter Wasseraufnahme im Albumin des Protoplasma wiedererscheint. Es ist dabei zu bedenken, daß diese Synthese nur mittels des bereits vorhandenen lebendigen Protoplasma zustande kommt. 


\section{Abnorme chemische Bestandteile der lebenden Körper.}

Von großer Wichtigkeit für die Erforschung der Stoffwechselvorgänge ist die Kenntnisnahme der in Pflanzen, Tieren und Menschen unter besonderen Umständen vorkommenden abnormen chemischen Verbindungen, weil sie die Entstehung und Zersetzung der normalen erklären helfen. Mögen durch Krankheit oder experimentell, etwa durch Einführung eines im Organismus nicht präexistierenden Grundstoffes oder eines Giftes oder Arzneimittels, neue Verbindungen im lebenden Körper erzeugt werden, jedenfalls wird durch die Nachweisung derselben der Chemismus desselben aufgehellt. Die größte Erleichterung erhält diese biochemische Methode, wenn ein direkter Zusammenhang des neuen, abnormen Bestandteiles mit einem eingeführten erkannt werden kann. Zum Beispiel steht fest, daß nach Einführung von Benzoësäure im Harn Hippursäure erscheint. Ist diese aus der Benzoësäure direkt hervorgegangen? oder hat letztere nur die Hippursäurebildung aus anderen Stoffen angeregt? Den Beweis für die Bejahung der ersteren Frage gibt die Thatsache, daß Chlorbenzoësäure Chlorhippursäure, Nitrobenzoësäure Nitrohippur'säure liefert. Die einzuführenden Stoffe, aus welchen abnorme Verbindungen hervorgehen, können so durch Substitution gleichsam gestempelt werden.

Einige abnorme Bestandteile, z. B. das Cystin im menschlichen Harn, erscheinen in Individuen einzelner Familien mehrere Generationen hindurch, was auf einen abnormen erblichen Chemismus hinweist; dieser aber kann bei Tieren normal sein, wie die Cystinurie beim Schwein.

Sehr zahlreich sind die in den menschlichen Organismus durch Arzneimittel und narkotische und alkoholische Genußmittel eingeführten abnormen chemischen Bestand- 
teile, welche den normalen Ablauf der Funktionen erheblich stören können, daher bei den meisten physiologischen Experimenten am Menschen berücksichtigt werden muß, ob er durch Gewöhnung an Nikotin, Kaffeïn, Morphin, Alkohol und viele andere Genußgifte schon abnorm oder - wie der Säugling noch nicht merklich oder wie das Tier und die Pflanze - noch gar nicht durch dieselben verändert ist.

Endlich sind von großem physiologischem Interesse die Fälle, in denen ausschließlich von einzelnen Tier- und Pflanzenarten wohl charakterisierte chemische Verbindungen, wie die Alkaloide, auch Blausäure, fette Säuren u. a. produziert werden, ohne für sie selbst abnorm und schädlich zu sein, während sie für andere nicht nur anomale Bestandteile sind, sondern auch diese leicht töten können. 


\section{Von den Formen der lebenden Wesen.}

Die Ermittlung der Formen lebender Wesen ist keine physiologische Aufgabe, sondern Gegenstand der organischen Iorphologie, welche die Ähnlichkeiten ungleicher lebender Gestalten und die Verschiedenheiten ähnlicher lebender Gestalten feststellt, um durch Auffinden von Gesetzmäßigkeiten der Struktur und Textur, der Anzahl und Größe, der gegenseitigen Lage und Stellung aller Teile eines lebenden Körpers in jedem Zeitpunkt seiner Entwicklung eine Erklärung seinèr Organisation zu ermöglichen. Die Morphologie (Anatomie im weitesten Sinne) verfährt genetisch und vergleichend, ohne die Funktionen der von ihr gesonderten Teile mehr als beiläufig zu beachten. Die Physiologie dagegen, deren Untersuchungsgegenstand gerade die Funktionen sind, ist abhängig von der MIorphologie und muß von jedem Ergebnis der morphologischen Analyse gründlichst Kenntnis nehmen, weil es unmöglich ist, eine Funktion zu verstehen, wenn das Fungierende nicht morphotisch bekannt ist. Das Fungierende, d. h. das Substrat der Funktion, ist aber in jedem Fall gerade das durch makroskopische und mikroskopische Beobachtung und Zergliederung gefundene organische Individuum. Ergibt die physiologische Untersuchung, daß ein Individuum, ein morphologisches Element oder ein Komplex solcher funktionslos ist, dann muß nach einer früheren oder künftigen Funktion gesucht werden. Zunächst aber ist der Begriff des Individuum selbst zu bestimmen. 


\section{Individualisation.}

Das Leben haftet ausschließlich an Körpern mit leicht verschiebbaren Teilen. Diese Körper sind teils Individuen, teils nicht individualisiert.

Ein Individuum ist ein lebendes Ganzes, welches nicht ohne wesentliche Beeinträchtigung oder Verlust seiner physiologischen Funktionen zerstückelt werden kann.

Das Protoplasma ist demnach nicht individualisiert, da es in mehrere Stücke zerschnitten werden kann, von denen jedes lebt und dem ursprünglichen Ganzen sich ähnlich verhält. Der Verlust der ephemeren Individualität oder Sonderexistenz mehrerer derartiger protoplasmatischer Einzelwesen, welche zusammenfließen, eine Art Syncytium - bildend, beweist dasselbe. Ist aber die Individualisation eingetreten, dann sind zu unterscheiden Individuen niederer und höherer Ordnung und zwar im ganzen nullter bis fünfter Ordnung oder Stufe, wenn man vom Protoplasma bis zum menschlichen Organismus fortschreitet. Es ist z. B.:

Nullstufig das Protoplasma

Einstufig die Zelle (Protoplasma und celluläre Differenzierungsprodukte, z. B. Kern, Cilie)

Zweistufig das Gewebe (Zellen und Intercellularsubstanz)

Dreistufig das Organ (mindestens zweierlei Gewebe)

Vierstufig der Organapparat (mindestens zweierlei Organe)

Fünfstufig der Organismus (mindestens zweierlei Organapparate).

Sollen die Komplexe lebender Einheiten über den Organismus hinaus noch individualisiert werden, so schließt sich die sechste Stufe als das Paar (zwei sexuell differente 
Organismen) an, die siebente ist die Familie (das Paar mit seinen Nachkommen), die achte der aus den Familien zusammengesetzte Staat (Stock). Eine Hauptfunktion des Paares ist die Fortpflanzung, welche durch Trennung des Paares unmöglich wird, folglich hat auch das Paar eine Individualität. Die an die Familie gebundenen Funktionen, z. B. Pflege und Ernährung der Jungen, werden durch Trennung der Familienmitglieder beeinträchtigt, die Funktionen des Staates, zu denen Schutz der Familien gehört, durch Teilung des Staates. Paare, Familien und Staaten sind also der Definition entsprechend Individuen und zwar solche sechster, siebenter, achter Stufe, welchen alle anderen sich unterordnen.

Beispiele: Wenn die Stufigkeit $=n$, dann ist bei abgeschnittenen lebenden Protoplasmastücken $n=0$, dagegen bei jungen Zellen (kernhaltigem, nacktem, freiem Protoplasma), bei kernlosem, membranführendem oder kernlosem, cilientragendem Protoplasma oder bei kernhaltigem, membranführendem Protoplasma $n=1$, bei reinem Knochen-, Knorpel-, Nerven-Gewebe $n=2$, bei Augen, Lungen, Nieren $n=3$, beim Respirations-, Cirkulations-Apparat $n=4$, beim menschlichen Körper, beim Wirbeltier überhaupt $n=5$.

Junge Eier sind Protoplasma (0), das sich in die Eizelle (1) umwandelt. Das Ei furcht sich und wird embryonales Gewebe (2). Aus diesem differenzieren sich die Organe (3) im Embryo, welche in Apparaten (4) zusammenfungieren. Zwei oder mehr zusammenfungierende Organapparate bilden einen Organismus (5). 


\section{Einstufige Individuen.}

\section{Die Zellen.}

Obwohl die Entstehung der Zelle oder Kytogenesis, welche mit der ersten Individualisierung des Protoplasma zusammenfällt, ihrem Wesen nach unbekannt ist, kann nicht bezweifelt werden, daß sie durch Umlagerungen der kleinsten Teile des lebenden Protoplasma einzig und allein ermöglicht wird. Durch den kytogenetischen Prozeß, welcher wahrscheinlich stets mit einer Kernbildung beginnt, entstehen einfache Individuen erster Ordnung. Es empfiehlt sich die Einschränkung dieses Begriffes der Individualisierung des Protoplasma auf die Zellbildung mit permanenten Zellteilen, Niederschläge, Gerinnungen, Vakuolenbildung, Zellsaftabsonderungen dagegen daron zu trennen. Die Kerne (mit Kernkörper, Kernsaft, Kernmembran), die Cilien, mannigfaltige Skelettbildungen protoplasmatischer Gebilde sind wahre Produkte der formbildenden Molekularbewegungen des Protoplasma. Membranen können sowohl auf rein chemischem Wege (z. B. durch Niederschläge), als auch in großer Mannigfaltigkeit durch die Lebensthätigkeit des Protoplasma während und nach der Kernbildung entstehen. Damit aber dem Zellenbegriff genügt werde, ist nur das Auftreten des Kernes im Protoplasma erforderlich. Die amöboiden Bewegungen des Kernes und seine Teilung beweisen, daß er lebt.

Die Cellularphysiologie oder Physiologie der Zelle ist in Wahrheit die Physiologie des intracellulären Protoplasma. Sie befaßt sich nicht weniger mit den Lebenserscheinungen der selbständig lebenden einzelligen Körper (z. B. Amöben), als mit denen der Zellen multicellulärer Wesen, in welchen vielfach das Protoplasma sich geradeso 
verhält wie dort. Sein Verhalten in Leukocyten und in Amöben ist oft nicht zu unterscheiden.

Die Cellularphysiologie bildet die Grundlage aller Physiologie, weil schließlich sämtliche Funktionen auf die Lebensthätigkeit ron Zellen zurückzuführen sind, auf die Funktionen des Protoplasma einstufiger Individuen, welche sich zunächst zu Geweben vereinigen.

Doch ist es nicht dieses Zusammenfungieren vieler gleichartiger Zellen in den Geweben, welches den Gegenstand der Cellularphysiologie ausmacht, sondern die Funktion der einzelnen Zelle. Wo man auch den kompliziertesten Organismus zu untersuchen beginnen mag, immer gelangt man zur Zelle als demjenigen Formbestandteil, dessen Funktionen die Grundlage aller übrigen bilden. Denkt man sich das Aus- und Einströmen des Zellsaftes fort, dann steht die Ernährung des ganzen Körpers still. Die roten Blutkörper, welche den Sauerstoff aufnehmen, sind nicht unpassend dieser wichtigen Funktion wegen Atmungszellen genannt worden, die Chyluskörper können, weil sie vorzüglich assimilierbare Stoffe in die Körperteile bringen, Ernährungszellen heißen. Drüsenzellen sind Sekretionszellen. Auch die tierische Verbrennung, die Entstehung der tierischen Elektricität, Kontraktilität und Empfindung ist nur in dem Inhalt der lebendigen Zelle, niemals anderswo, etwa zwischen den Zellen, zu suchen. Die Ganglienzellen sind als der Sitz höchster psychischer Funktionen erkannt; das Wachstum geschieht durch Zunahme des Volumens und der Masse der einzelnen Zelle und ihre Teilung, die Erzengung neuer Organismen durch die beiden geschlechtlichen Zellengebilde, das Ei und das Samenkörperchen oder sogar die Eizelle allein. Die Entwicklung aller Tiere geschieht durch die Thätigkeit der sich im Ei differenzierenden Bildungszellen, und die Erblichkeit der Eigenschaften lebender Körper kann nicht begriffen werden, 
wenn nicht den Geschlechtszellen die wichtigste Rolle, die der Übertragung von einem Organismus auf den anderen, zuerteilt wird.

So zeigt schon eine flüchtige Übersicht der verbreitetsten Lebenserscheinungen, daß die Zelle für alle die wichtigste Grundlage bildet.

Es ist daher für die Physiologie notwendig, die Ergebnisse der morphologischen Untersuchungen aller Zellen, und namentlich des Protoplasma in ihnen, nicht allein zu berücksichtigen, sondern der Erforschung der Funktionen zu Grunde zu legen.

\section{Zweistufige Individuen.}

Die Gewebe.

Die Entstehung der Gewebe oder Histogenesis setzt die Existenz von Zellen voraus. Aber ein bloßes Zusammensein von selbständig lebenden Zellen ohne feste Verbindung aller miteinander ist kein Gewebe. Erst wenn gleichartige, durch Zellteilung entstandene Zellenkomplexe durch Intercellularsubstanz - einem Abscheidungsprodukte der Zellen selbst - zusammengehalten sind oder durch ein zweites Aggregat von Zellen zwischen jenen eine gesetzmäßige Anordnung erzielt ist, kann die gemeinsame Funktion der Zellengesamtheit zustande kommen, welche derselben den Charakter als Individuum zweiter Ordnung oder Ge w e be im physiologischen Sinne verleiht. Es kommen aber den in morphologischer Beziehung übereinstimmenden Geweben keineswegs übereinstimmende Funktionen zu. Zum Beispiel bieten die Epithelgewebe auffallende morphologische Übereinstimmungen, während sie funktionell sehr verschieden sind, wie schon die Namen Sinnesepithel, Flimmerepithel 
u. a. erkennen lassen. Einige Epithelien secernieren, andere resorbieren, kurz, die verschiedensten Funktionen werden vom Epithelgewebe, je nachdem es nach der einen oder anderen Richtung einseitig differenziert ist, vorwiegend vermittelt. Andere Gewebe hingegen haben überall, wo sie vorkommen, dieselbe Funktion trotz erheblicher morphologischer Verschiedenheiten, so das kontraktile Gewebe - Faserzellen, Muskelfasern - die Kontraktilität und das aus Nervenfasern bestehende Nervengewebe, dem, sofern es verschiedene central und peripher gelegene Gebilde miteinander verbindet, stets nur die Funktion zukommt, die Erregung, sei es centrifugal, sei es centripetal, fortzuleiten: die Neurilität. Im Vergleiche zu diesen mit wohl charakterisierten Funktionen verbundenen Geweben haben die mannigfaltigen Formen des Bindegewebes, zu denen auch die Knorpel- und Knochengewebe gehören, in physiologischer Beziehung viel weniger Bedeutung. Hauptsächlich sind es Stützgewebe und Bindemittel, aber zum Teil auch, wie namentlich das Fettgewebe, als schlechte Wärmeleiter und Proviantbehälter wichtig. Die Individualität dieser Gewebsformen ist eine weniger ausgesprochene, als die der anderen.

Immerhin muß eine vollständige Histophysiologie, auf der Physiologie der Zelle fußend, für alle Gewebe die Lebenserscheinungen feststellen, wie es für das Muskelgewebe die allgemeine Muskelphysiologie (Myophysik und Myochemie) zu thun unternommen hat.

So verschieden die Gewebe im ausgebildeten Organismus sind, so ähnlich sind sie in dem sich entwickelnden in der ersten Zeit, und schlieblich ist der Ursprung aller in Verschiedenheiten der bis jetzt für alle Untersuchungen vollkommen ununterscheidbaren Teilprodukte der Eizelle, deren Inhalt sich gefurcht hat, zu suchen. Der direkter Beobachtung und experimentellen Eingriffen zugängliche Differenzierungs- 
prozeß des embryonalen Gewebes im Ei, und die Bedingungen seiner Erblichkeit müssen erforscht werden, um das Problem, wie die Gewebe entstehen, der Lösbarkeit näher zu bringen.

Wenn man den Komplex der die Keimblätter zusammensetzenden Zellen als ein Gewebe auffabt, so ist dessen Hauptfunktion die Differenzierung. Diese ist aber nur möglich durch das Vorhandensein erblicher, die Anordnung der Moleküle in jeder Zelle und die Anordnung der Zellen selbst bestimmender Bewegungsursachen; denn in den von den Erzengern völlig getrennt zur Entwicklung gelangenden Eiern ist jeder Einfluß derselben (z. B. im Brütofen) auf die fernere Entwicklung vollkommen ausgeschlossen. Da nur der an sich passive, nicht der Entwicklung fähige Dotter und die Luft zu jenen sich differenzierenden Gebilden hinzukommen, so müssen diese letzteren potentiell alle Funktionen des reifen Neugeborenen, somit alle Gewebe-Anlagen schon enthalten.

Die Erblichkeit ist also ein wesentlicher Faktor für das Verschiedenwerden gleichartigen Gewebes, und eine noch so gründliche Kenntnis der Mechanik und des Chemismus der Differenzierung kann ohne sie die Entstehung der funktionellen Differenzen der Gewebe nicht erklären.

Daß aber auch die Betrachtung der Funktionen fertiger Gewebe ohne die gründlichste Kenntnis ihrer morphologischen Beschaffenheit zu keiner Erkenntnis des Wesens der Funktionen führen kann, ergibt sich am deutlichsten aus den verfrühten sich widersprechenden Theorien, z. B. der Netzhautfunktionen, der Gefäßinnervation, der Muskelkontraktion und aus der Geschichte jeder einzelnen Funktion, wo die Erklärung der anatomischen, insbesondere der histologischen Feststellung des Thatsächlichen regelmäßig voraneilte und darum nachher hinfällig wurde. 


\section{Dreistufige Individuen.}

\section{Die Organe.}

Die Entstehung der Organe oder Organogenesis setzt das Vorhandensein von mindestens zweierlei Geweben voraus. Diese aber müssen nicht nebeneinander, sondern miteinander fungieren, wenn ihrer Gemeinschaft der Name Organ im physiologischen Sinne beigelegt werden soll. Organe sind also aus funktionell differenten Geweben zusammengesetzte Gebilde mit einheitlicher Funktion oder dem Vermögen zu einer solchen. Die Organophysiologie oder specielle Physiologie der Organe ermittelt diese Funktionen und unterscheidet demgemäß Kireislaufsorgane, Atmungsorgane, Ernährungsorgane und Absonderungsorgane bei allen Tieren, auch Bewegungsorgane, elektrische Organe und Sinnesorgane bei vielen, desgleichen Zeugungsorgane. Hingegen sind besondere Organe für die tierische Verbrennung, das Wachstum, die Differenzierung und die Vererbung nicht nachgewiesen, diese Funktionen vielmehr den Zellen und Geweben jener fungierenden Organe eigen. Während die Muskelfaser sich zusammenzieht, während die Drüsenzelle secerniert, erwärmt sie sich, weil Oxydationsprozesse in ihr stattfinden. Während der Atmung, Ernährung usw. wachsen die Knorpelzellen, Epithelien, Muskelund Nerven-Fasern usw. unbeschadet ihrer sonstigen Funktionen und bekunden durch die Art ihrer konstanten Beziehungen zu einander im Gewebe, daß sie erbliche organbildende Eigenschaften besitzen. Dasselbe zeigt die Differenzierung der Zellen des embryonalen Gewebes, welchen sämtlich, so starr sie auch später werden mögen, die Differenzierung konstant als Funktion zukommt. Aber vor der Differenzierung ist kein Organ da, weder in Miniatur- 
form noch in einer Skizze, sondern nur eine Reihe von ererbten Organanlagen.

Es ist also zwar durchaus möglich, für jedes Organ die ihm entsprechende, sei es exloschene, sei es zukünftige, sei es aktuelle Funktion zu bestimmen; aber es ist nicht möglich, für jede Funktion ein Organ ausfindig zu machen, welches sie vermittelte, weil eben manche Funktionen nur Geweben zukommen, wie die Differenzierung im jungen Embryo, andere nur Zellen, wie die Oxydation, andere beiden, wie das Wachstum.

Hieraus ergibt sich die Unzulässigkeit einer verbreiteten Auffassung, derzufolge die Physiologie überhaupt nur die Lehre von den Funktionen der Organe sei. Sie hat die Funktionen der Individuen jeder Ordnung zu untersuchen. Auch ist es häufig nicht leicht $\mathrm{zu}$ bestimmen, was ein Organ ist, was nicht. Die morphologischen Nierkmale, zu denen Zahl, Größe, Bau, Stellung und Lage der Bestandteile gehören, abgesehen von der Entwicklung, können für die physiologische Bestimmung schlechterdings nicht maßgebend sein. Hier ist es allein die Funktion, welche den Bestimmungsgrund liefert. Wenn ein natürlicher Komplex von Geweben eine (wenn auch nur wenig) andere Funktion, als jedes der Konstituentien hat, dann ist er ein Organ im physiologischen Sinne. Die Differenzierungsprodukte der Zellen selbst die mit deutlicher Funktion, wie die Cilien, können demnach nicht Organe heißen. Sie werden passend als Zellenorgane bezeichnet.

Wenn durch diese Erwägungen notwendig die physiologische und morphologische Untersuchung der Organe gänzlich verschiedene Wege einschlagen müssen, so ist doch klar, daß ein Verständnis der Organfunktionen gar nicht erzielbar wäre, wenn nicht dabei fortwährend die morphologischen Zergliederungen und Entwicklungsprozesse der Organe zu Grunde gelegt würden. Ein unwissender 
Arbeiter kann sehr geschickt eine komplizierte Maschine handhaben, ihre Wirkung kennen ohne Kenntnis der Maschinenteile, er kann aber die Wirkung nicht rerstehen. So auch die Funktionen der Organe. Jeder, der einen normalen Kehlkopf hat, kann auf diesem Instrumente spielen, ohne es zu kennen, ja sogar ohne zu wissen, daß er einen besitzt, aber verstehen, wie die bekannte Stimme, wie die Funktion des Kehlkopfes zustande kommt, kann nur derjenige, welcher alle Teile desselben morphologisch im einzelnen kennt. Und so für alle Funktionen aller Organe.

\section{Vierstufige Individuen.}

\section{Die Organapparate.}

Ein zusammengehöriger Komplex von verschiedenartigen Organen, welcher einer einheitlichen Funktion tähig ist, heift ein "Organapparat", auch wohl "organischer Apparat". Die Funktionen der Organapparate sind stets kompliziert und setzen eine lange Reihe von Entwicklungen voraus, z. B. das Sprechen, welches ein Zusammenwirken des Ohres, gewisser Hirnteile, der Zunge, des Kehlkopfes und anderer Organe benötigt. Jede Funktion der höher organisierten Tiere beruht ebenso auf dem Zusammenwirken mehrerer specifisch verschiedener Einzelorgane. Die Hauptorgane des Blutkreislaufes z. B. sind nicht allein die Teile des GefäBsystemes der Anatomen, Herz, Arterien, Kapillaren und Venen, sondern auch die Herz- und Gefäßnerven. Zur Atmung der Säugetiere gehören außer den Lungen die Rippen, das Zwerchfell und andere Respirationsmuskeln nebst ihren Nerven und gewisse Nervencentren u. a. 
Zur Krnährung, Absonderung, Bewegung, Wahrnehmung, Zeugung wird bei höheren Tieren je eine Gruppe von zusammenfungierenden Einzelorganen erfordert, welche den Ernährungs-, Bewegungs-Apparat usw. bilden.

Die Individualität dieser anatomisch weit voneinander abweichenden höchst komplizierten organischen Apparate ist noch mehr ausgeprägt, als die der Organe, sofern im allgemeinen diese stärkere Eingriffe vertragen, ohne daß die Organfunktion erheblich beeinträchtigt wird oder erlischt, während die an Organapparate gebundenen Funktionen leicht gänzlich erlöschen, wenn nur ein einziges der sie konstituierenden Organe ausfällt, die Sprache z. B., wenn nur der Bewegungsnerv der Zunge nicht mehr leitet, die Zunge selbst oder eine gewisse Gruppe von Ganglienzellen im Gehirn fehlt oder die Stimmbänder gelähmt sind u. dgl. Im ganzen ist die Abhängigkeit einer Funktion von dem fungierenden Individuum um so vollständiger, je komplizierter die Funktion und je höher die Stufigkeit des Individuum, je weiter die Differenzierung fortgeschritten ist. Dieser Umstand ist für die vivisektorische Untersuchung komplizierter Funktionen darum von besonderer Wichtigkeit, weil er zeigt, daß oft sehr geringfügige und ganz unscheinbare Verletzungen die Funktion erheblich stören können, was bei wenig differenzierten Gebilden nicht oder bei weitem nicht in dem Grade der Fall ist, weil da die Teile nicht in einem so hohen Grade funktioneller Abhängigkeit von einander stehen. Aus diesem Grunde eignen sich zu vivisektorischen Versuchen im allgemeinen niedere Tiere besser als höhere, weil die Funktionen ihrer Organapparate auch nach der Isolierung letzterer voneinander noch längere Zeit fortdauern können. 


\section{Fünfstufige Individuen.}

\section{Die Organismen.}

Der Organismus ist dadurch charakterisiert, daß mehrere Organapparate in ihm zusammen fungieren. $\mathrm{Er}$ besteht aus solchen Organapparaten, welche im Normalzustande der Gesundheit vollkommen harmonisch in ihren Funktionen sich selbst regulieren. Je vollständiger diese erst zum kleinsten Teile erkannten Selbstregulierungen sind, um so komplizierter der Organismus, um so abhängiger sein Bestand von den einzelnen Apparaten der Atmung, Ernährung, Bewregung usw. und zugleich um so abhängiger der eine Organapparat von dem anderen. Die für das Wesen des Organapparates charakteristische Korrelation der Organe in funktioneller Beziehung tritt im Organismus auf eine höhere Stufe, sofern es hier die funktionelle Korrelation der Organapparate ist, welche den ganzen Organismus zusammenhält. In der That ist sein Leben nichts anderes, als die Summe der Funktionen seiner Apparate, seine Individualität aber eine sehr ausgeprägte, weil letztere alle aufeinander mehr oder weniger angewiesen sind. Wenn also die Funktion nur Eines Organapparates ausfällt, z. B. die Atmung, die Ernährung, der Kreislauf, durch Schädigung nur Eines Organes, z. B. der Lunge, des Magens, des Herzens, sogar nur eines Gewebes, wie des Herzmuskelgewebes, ja vielleicht durch Schädigung nur einiger weniger Zellen (Ganglienzellen im verlängerten Mark), dann können entweder sogleich oder allmählich alle anderen Funktionen erlöschen; je höher organisiert der Organismus ist, um so schneller. Bei Organismen, deren Organe und Organapparate weniger voneinander abhängen, in einer weniger festen Korrelation 
stehen, dem entsprechend auch eine weniger vollkommene Regulierung ermöglichen, können dagegen die Teile auch nach ihrer Trennung voneinander länger, wenn auch mit abnehmender Energie, fungieren. Zum Beispiel wird ein Bein eines Frosches, welches nur durch seinen Nerven in Verbindung mit dem Rückenmark in der frei aufgehängten Wirbelsäule blieb, wenn außer diesen drei Stücken nichts mehr vom Tiere übrig ist, doch noch gehoben, falls man die Zehen einen Augenblick in Säure taucht, als wenn der unversehrte Frosch noch da wäre und den Fuß dem schmerzerregenden Eingriffe entzöge. Bei höheren Tieren dagegen erlöschen die Funktionen des Rückenmarkes mit der Unterbrechung seiner Ernährung. In jedem Falle ist aber nicht nur der Fortbestand des Organismus als lebenden Individuum an die Korrelation der Organapparate, also der Organe, solidarisch gebunden, sondern auch sind die Funktionen dieser zum großen Teil an die Integrität des Organismus geknüpft, sofern sie eben voneinander abhängen. Ohne Kreislauf bei höheren Tieren keine Atmung und keine Ernährung, ohne Atmung keine Wärmebildung und Bewegung und ohne diese keine Empfindung und Zeugung. Wachstum, Entwicklung, Vererbung sind unmittelbar aibhängig von der Ernährung und den von dieser bedingten Absonderungen. Gerade durch diese wechselseitige Korrelation der Funktionen zeichnet sich der Organismus aus. Dieselbe kann nur durch außerordentlich lange Entwicklungsreihen zustande gekommen sein, wie denn auch fast jeder Organismus Spuren seiner Abkunft von weniger vollkommenen Formen zeigt.

Die Entwicklung des Embryo im Ei liefert dafür Beispiele genug, welche, wie die rudimentären Gebilde des entwickelten Organismus (die männlichen Brustwarzen, die Ohrmuskeln u. a. beim Menschen), auf die Abstammung höherer Tiere von niederen hinweisen. Darum muß die Physiologie des menschlichen Organismus notwendig eine 
vergleichende sein und die Abstammung desselben von weniger komplizierten Tieren berücksichtigen, also genetisch verfahren und mit den Resultaten phylogenetischer Untersuchungen der Zoologen und Botaniker nicht weniger Füllung zu behalten suchen, wie mit denen der Embryologie.

\section{Tiere und Pflanzen.}

Andere morphologische Einteilungen der lebenden Körper als die nach ihrer Individualität können nicht als physiologische gelten, so namentlich nicht die in der zoologischen und botanischen Systematik übliche in Kreise, Klassen, Ordnungen, Familien, Sippen, Geschlechter, Gattungen, Arten (Species mit den Unterarten, Varietäten oder Abarten und Spielarten) oder in Stämme, Äste, Zweige usw. Denn da werden die morphologischen Eigenschaften in erster Linie, die physiologischen Funktionen nur nebenbei berücksichtigt, so daß morphologisch ähnliche, aber physiologisch unähnliche Körper in nächste Nachbarschaft zu stehen kommen und sogar selbständig lebende Zellen, Organismen, Stöcke, also Individuen verschiedenster Stufigkeit, in der Nomenklatur sich gleichstehen.

Selbst die Teilung aller lebenden Körper in Tiere und Pflanzen gründet sich nicht auf durchgreifende funktionelle Unterscheidungen, sondern mehr auf die auffallenderen Verschiedenheiten der gewöhnlichsten Pflanzen- und Tierformen. Doch ist ein morphologisches Merkmal, das allen Pflanzen ohne Ausnahme und zugleich keinem Tiere zukäme, nicht angebbar. Ebenso gibt es kein sämtlichen Tieren ohne. Ausnahme zukommendes morphologisches Merkmal, welches bei keiner Pflanze vorkäme. Beides erscheint im Hinblick auf die gemeinsamen Anfänge des Tierreiches und Pflanzenreiches natürlich. 
142 Vermeintliche Unterschiede zwischen Tier und Pflanze.

\section{Vermeintliche Unterschiede zwischen Tier und Pflanze.}

Es sind keine durchgreifenden Unterschiede der chemischen Zusammensetzung auffindbar. Die organischen Elemente sind bei Tieren und Pflanzen dieselben.

Auch sind keine durchgreifenden physiologischen Unterschiede auffindbar.

Die animalen Funktionen der willkürlichen Bewegung und Empfindung müssen, wenn sie dem Zooplasma zugeschrieben werden, auch dem Phytoplasma zuerkannt werden. Weil Wesen mit Nerven Empfindung und Willkür haben, darf nicht geschlossen werden, daß Wesen ohne Nerven keine Empfindung und keine Willkür haben. Es gibt sowohl viele unzweifelhafte Tiere ohne Nerven, als auch pflanzliche Gebilde (Schwärmsporen), welche sich so verhalten, als wenn sie empfänden und sich willkürlich bewegten.

Darin besteht kein Unterschied, daß die Pflanzen aus Körpern, welche nicht selbst protoplasmatisch oder eiweif artig sind, in ihrem Inneren Protoplasma zusammensetzen, die Tiere dagegen nicht aus Körpern, welche nicht schon eiweißartig sind, Eiweiß zusammensetzen können, denn wenn auch die Nahrung des Tieres Eiweiß enthalten muß, so gibt es doch viele Pilze, von denen dasselbe gilt, und es ist Thatsache, daß jeder Keim jeder Pfianze Protoplasma, also Eiweiß, schon enthält.

Das Leben der Tiere ist zwar an das der Pflanzen gebunden, aber auch das vieler Pflanzen an das Leben der Tiere.

Auch darin besteht kein Unterscheidungsmerkmal, daß alle unzweifelhaften Pflanzen nur flüssige Nahrung in sich aufnehmen sollen; man kann nicht bestimmen: lebende Körper, welche andere als flüssige Nahrung in ibrem Inneren 
Vermeintliche Unterschiede zwischen Tier und Pflanze. 143

in Bestandteile des eigenen Leibes verwandeln können, sind Tiere, solche, die dieses nicht vermögen, sind Pflanzen, denn viele Tiere nehmen nur flüssige Nahrung zu sich, die insektenfangenden Pflanzen auch andere als nur flüssige, und schließlich ist im Tierreich und Pflanzenreich alles assimilierbare nur flüssig.

Die noch heute oft. wiederholte Unterscheidung, daß Pflanzen Reduktionsapparate seien, welche die aktuelle Energie (der Ätherschwingungen) in potentielle umsetzen, während die Tiere Oxydationsapparate vorstellten, welche die von den Pflanzen angesammelte Spannkraft wieder in lebendige Kraft umsetzten, ist nicht stichhaltig, weil auch die Pflanzen mannigfaltige Bewegungserscheinungen zeigen, Wärme bilden durch Oxydation und ein großer Teil derselben (viele Pilze) nicht das Vermögen der Reduktion und Synthese besitzt, wie die grünen Pflanzen, während viele Tiere beide Prozesse zeigen. Jene Verschiedenheit ist also nicht durchgreifend. Es überwiegt nur die Reduktion und Synthese bei den Pflanzen, die Oxydation und Spaltung bei den Tieren, und es herrscht nur bei jenen die Umwandlung aktueller in potentielle Energie vor, bei diesen die umgekehrte Kraftmetamorphose. Aber keines der beiden Reiche zeigt die eine oder die andere Art des Kraftwechsels für sich allein. Durchgreifende physikalische oder physiologische Unterschiede sind in der That nicht auffindbar, namentlich kommt die Sauerstoffabscheidung einigen chlorophyllhaltigen Tieren und nicht allen Pflanzen zu.

Eine eingehende Kritik sämtlicher Versuche Unterscheidungsmerkmale zu finden, welche eine scharfe Grenze zwischen Tieren und Pfianzen zu ziehen gestatteten, lehrt, daß kein solcher Versuch erfolgreich gewesen ist. Je weiter die Physiologie in ihren Detailforschungen fortschritt, um so mehr tierähnliche Pflanzen wurden entdeckt, und 
je mehr sich die mikroskopische Untersuchung niederer Tiere vervollkommnete, um so zahlreicher wurden die Entdeckungen pflanzenähnlicher Tiere. So ist es dahin gekommen, daß manche Mikrobien von den einen zum Pflanzenreich, von den anderen zum Tierreich gerechnet werden, wie die sauerstoffentwickelnden Euglenen.

Demnach ist der Satz wohlberechtigt, daß eine scharfe Grenze zwischen Tieren und Pflanzen nicht existiert. Die einfachsten lebenden Wesen, welche sich in physiologischer Hinsicht zum Teil wie Tiere, zum Teil wie Pflanzen verhalten, bilden den Übergang. Leicht unterscheidbar werden Pflanzen und Tiere erst, wenn sie nicht mehr einfach sind, sondern eine verwickelte Struktur besitzen. Da aber diese mit einer weit ausgebildeten Arbeitsteilung untrennbar verbunden ist, so folgt, daß die Verschiedenheit der Tiere und Pflanzen, wie sie thatsächlich existiert, mit einer ungleichen Teilung der Arbeit zusammengehen $m u B$, d. h. durch Vorherrschen der einen Funktionsgruppe wird das indifferente Urwesen oder Protoplasma mehr pflanzlich, durch das einer anderen mehr tierisch. Hierbei ist $\mathrm{zu}$ bemerken, daß sämtliche sogenannte vegetative Grundfunktionen auch den Tieren und die Anfänge aller animalen den Pflanzen zuerkannt werden müssen, sofern nämlich das Protoplasma beidesfalls alle Grundfunktionen aufweist, $d$. h. alle diejenigen sämtlichen lebenden Wesen ohne Ausnahme zukommenden Funktionen, welche nicht mehr voneinander abgeleitet werden können.

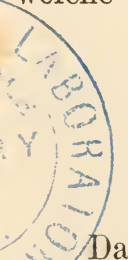

Da die Erforschung der Lebenserscheinungen in erster Ininie das morphologische Substrat derselben, also die 
organischen Individuen jeder Ordnung, zu berücksichtigen hat, um die Änderungen in der Anordnung der kleinsten materiellen Teile in ihnen $\mathrm{zu}$ ermitteln, so ist jede $\mathrm{Ab}$ normität einer organischen Form, zumal wenn diese noch lebt, von hohem Interesse für die Physiologie; daher die Funktionen der Mißgeburten, der kranken Individuen, der Invaliden, der künstlich erzeugten und natürlichen tierischen und pflanzlichen Mißbildungen besondere Beachtung verdienen.

Wenn in pathologischen Fällen, bei vivisektorischen Experimenten, Hemmungen eine Funktion wegen Schädigung ihres Substrates ron anderen Teilen vikariierend vermittelt wird, dann entstehen leicht - durch Rückwirkung der Funktion auf das Organ - abnorme Formen von kürzerer oder längerer Dauer. So bilden sich bei der Salamanderlarve, wenn sie verhindert wird, an die Oberfläche des Wassers zu schwimmen, große Kiemen statt der Lungen aus. Es kann sogar die Abnormität soweit gehen, dab die unter Wasser rerharrenden Tritonenlarven geschlechtsreif werden. Beim Menschen ist die Bildung eines Kollateralkreislaufes ebenfalls die Folge einer Funktionshemmung, welche auf das Substrat umgestaltend wirkt. Derartige Abnormitäten sind sowohl für die Erkenntnis der Abhängigkeit der Funktion rom Substrat, als auch für die der Abhängigkeit des Substrates von der Funktion besonders wichtig, während die zahlreichen angeborenen sogenannten Varietäten, Erscheinungen, wie z. B. die Polydaktylie, mehr morphologisches als physiologisches Interesse darbieten.

Physiologisch und morphologisch zugleich wichtig sind die künstlich hervorgerufenen Mißbildungen (Zwergbildungen, Doppelmißbildungen u. a.) der Embryonen im Ei, deren Untersuchung bereits begonnen hat. 


\section{Von den Kräiften der lebenden Körper.}

Naturkräfte sind nur entweder potentiell oder aktuell. Erstere gehen in letztere und letztere in erstere über ohne stoffliche Änderungen bei rein physikalischen (mechanischen), mit solchen bei chemischen Prozessen. Während aber die Kräfte beider Art, mit welchen die Kraftlehre oder Physik sich beschäftigt, mannigfaltig sind, benötigt die Chemie nur eine einzige Kraft, die Affinität, als Ursache der von ihr betrachteten Veränderungen; und wenn man den physischen Kräften "chemische Kräfte" an die Seite stellt, so ist damit nur gesagt, daß die Affinität sich in rerschiedenartiger Weise äußert. In Wahrheit ist sie nur eine Form potentieller Energie, gehört also schließlich in die theoretische Physik.

Die Physiologie muß nun die Wirkungsweise der physischen und chemischen Kräfte kennen, um zu prüfen, in wieweit sie in lebenden Körpern bei deren Funktionen beteiligt sind. Sie bedient sich dabei durchweg der physikalischen und chemischen Terminologie mit dem größten Nutzen. Demnach sind gleichbedeutend die Ausdrücke „potentielle Energie, Spannkraft, Arbeitsvorrat" einerseits, „aktuelle oder kinetische Energie, lebendige Kraft, lebendige Potenz" andererseits. Eine physiologische Arbeit wird geradeso gemessen, wie eine mechanische und wie diese in Kilogrammetern ausgedrückt, z. B. die Herzarbeit. Die Arbeit. welche der lebende ruhende Apparat leisten kann, ist ge- 
nau gleich seiner potentiellen Energie und wird in Einheiten ausgedrückt, die $1 / 0,424=2,358$ Wärmeeinheiten entsprechen. Die Wärmeeinheit oder Kalorie ist dabei diejenige Wärmemenge, welche erfordert wird, um ein Gramm Wasser von $0^{\circ} \mathrm{C}$. um $1{ }^{\circ} \mathrm{C}$. zu erwärmen. Die Arbeit also, welche einer solchen Wärmeeinheit entspricht, ist 0,424 Meterkilogramm oder 424 Grammeter.

\section{Die phỵsischen Kräfte.}

Es liegt kein Grund vor, anzunehmen, daß in lebenden Körpern die Kräfte der anorganischen Natur nicht so wirkten, wie in dieser. Alle lebenden Körper haben die allgemeinen allen physischen Körpern zukommenden Eigenschaften schon weil sie Naturkörper sind. Sie müssen aber auch als solche den für alle Naturkörper gültigen Gesetzen gehorchen, z. B. dem Fallgesetz. Sie mögen scheinbar noch so sehr abweichen in ihren Bewegungen von den anorganischen Körpern, eine Notwendigkeit sie deshalb aus dem Gebiete der Mechanik auszuschließen, liegt nicht vor, weil bei unzähligen Untersuchungen scheinbarer Abweichungen gerade die Anwendung mechanischer Principien und Lehrsätze auf Lebensvorgänge, wie Atmen, Säfteströmung, Lokomotion, Wärmebildung, Muskelarbeit sich als durchaus stichhaltig und fruchtbar erwiesen hat.

Aber damit ist keineswegs gesagt, daß die bis jetzt für die Erklärung der anorganischen mechanischen Torgänge für genügend erachteten Kräfte auch für die Erklärung der Lebensvorgänge überhaupt ausreichen. Diejenigen, welche ihnen nicht gleichen, namentlich die Entwicklungsrorgänge mit allmählicher Entfaltung psychischer Prozesse, durch die Annahme besonderer, für die Erklärung der anorganischen Naturrorgänge nicht erforderlicher Kräfte 
erklären wollen, heißt aber auf eine einheitliche Weltanschauung von vornherein verzichten und erscheint schon aus dem Einen Grunde rom wissenschaftlichen Standpunkte aus verwerflich, weil schließlich die Verschiedenheit der Lebensvorgänge und der anorganischen Bewegungen, obzwar sehr groß, doch wegen der Gleichheit der Haterie in den leblosen und lebenden Körpern nicht principiellgegensätzlicher Art, so daß Übergänge undenkbar wären, sein kann. Wenn die Materie in den lebenden Körpern andere physische oder sonstige Kräfte besäße, als in den leblosen, dann müliten auch die die Materie zusammensetzenden Grundstoffe das eine Mal andere Kräfte, d. h. andere Eigenschaften haben, als das andere Mal, dann wären die Grundstoffe aber nicht unveränderlich, nicht elementar, was ihrem Begriffe widerspricht. Denn mag auch die Mehrzahl der gegenwärtig unterschiedenen Elemente noch aus anderen zusammengesetzt sein, irgendwelche Elemente oder irgend ein Element wird immer bleiben müssen. Dieses kann schlechterdings nicht in lebenden Körpern mit anderen Kräften ausgestattet sein, als in toten, ohne die wissenschaftlichen Begriffe „Stoff" und „Kraft" aufzuheben.

Somit bleibt nichts anderes übrig, als die physischen Kräfte, deren man bedarf, um diejenigen Vorgänge in der anorganischen Natur zu erklären, welche ohne stoffliche Teränderungen ablaufen, so $\mathrm{zu}$ bestimmen, daß sie auch die Gesamtheit der nicht stofflichen Prozesse im lebenden Körper begreiflich zu machen geeignet werden.

Es ist auch viel mehr der Mangel an zusammenfassenden Untersuchungen, als Überlegung, der einerseits die theoretische Physik auf die anorganische Natur einschränkte, andererseits der Physiologie, als Physik der Organismen, ausschließlich die mechanischer Behandlung fähigen Prozesse des körperlichen Lebens zuwies. Die Kräfte der Physik müssen die ganze Natur, nicht bloß die unbelebte, erklären, 
und die Physiologie muß als angewandte Physik nicht nur notwendig die physischen Kräfte in ihrem ganzen Umfang roll gelten lassen, sondern auch, wo diese nicht ausreichen, ihren eigenen Toraussetzungen in der Physik volle Geltung zu verschaffen wissen. Anderenfalles wäre eine einheitliche Naturwissenschaft unmöglich. Die Natur ist aber als Gegenstand der Erfahrung ein einheitliches Ganzes, folglich muß auch die Erforschung derselben nur einerlei Grundsätze haben, und nichts wäre widersinniger, als den physischen Kräften etwa specifische physiologische Kräfte gegenüber oder an die Seite zu stellen.

\section{Die chemischen Kräfte.}

Was von der Verwertung physischer Kräfte in der Physiologie gilt. gilt auch von der der chemischen Kräfte. Da trotz gehäufter Analysen aus pflanzlichen und tierischen Körpern keine anderen chemisch unzerlegbaren Stoffe erhalten worden sind, als aus den anorganischen Körpern, diese aber als Grundstoffe unveränderliche Eigenschaften besitzen, so ist es unzulässig, den organischen Elementen in lebenden Körpern andere chemische Kräfte zuzuschreiben, als außerhalb derselben. Faßt man die chemischen Kräfte unter dem Ausdrucke „Affinität“ zusammen, wie es gewöhnlich geschieht, obgleich das Wort unpassend gewählt ist, so gilt in aller Strenge der Satz, daß die Affinitäten der Elemente durch deren Eintritt in lebende Körper keine Änderung erfahren, d. h.: wenn die Affinitäten der Elemente sich nach der Aufnahme und Assimilation einer chemischen Verbindung (die immer für sich tot ist) seitens eines lebenden Körpers zu rerändern scheinen, so wird, gerade wie in der reinen Chemie, diese Teränderung stets 
auf die ver:̈̈nderten Umstände außerhalb des Elementes, auf neue Bedingungen der Verbindung und Trennung der Elemente zurückzuführen sein und die Konstanz der fundamentalen Eigenschaften derselben, ihres Sättigungsvermögens oder chemischen Wertes (d. i. ihrer Wertigkeit, Valenz oder Sättigungskapacität), ihres Atomgewichtes und Äquivalentgewichtes so lange als Axiom für unantastbar gehalten werden müssen, bis Thatsachen bekannt werden sollten, welche mit jener Konstanz nicht vereinbar wären. Solche Thatsachen liegen weder in der reinen Chemie, noch in der Biochemie vor und würden dazu nötigen, überhaupt den bisherigen Begriff des chemischen Elementes aufzugeben, dessen Merkmal eben die Unveränderlichkeit ist. Wïrden die Elemente nämlich durch den Lebensprozeß verändert oder ihre Valenzen etwa anders variieren, als in der anorganischen Natur, dann wären die Elemente nicht Elemente. Man kann zwar einwenden, die lebenden Körper beständen nicht aus den Elementen, sondern diese ließen sich nur aus ihnen darstellen, aber dasselbe gilt für alle toten Körper; und 'Thatsache ist, daß durch geeignete Vereinigung der Elemente sehr zahlreiche Produkte der Lebensthätigkeit, wie der Harnstoff und die Ameisensäure, künstlich durch Vereinigung der isolierten Elemente dargestellt werden können. Wenn auch die Bildung jener Stoffe im lebenden Wesen eine ganz andere ist, als bei den künstlichen Synthesen im Laboratorium, so zeigen doch diese, daß die der anorganischen Natur entnommenen Elemente dieselben Produkte liefern, wie die der lebenden Wesen, die chemischen Kräfte der Elemente in beiden Fällen also identisch sind. Wollte man es darum noch leugnen, weil nicht alle Produkte des tierischen und pflanzlichen Stoffwechsels, sondern nur ein Teil künstlich aus ihren Elementen zusammengesetzt werden können, namentlich nicht die Albumine, so ergäbe sich die Konsequenz, daß auch die 
chemischen Kräfte, welchen nicht künstlich darstellbare Jineralien und Gesteine (z. B. Granit) ihre Entstehung verdanken, verschieden seien von den Kräften der bekannten sie zusammensetzenden Elemente, eine Konsequenz, welcher niemand zustimmen kann. Außerdem ist nicht zu vergessen, daß die Synthese einer chemischen Verbindung, die Darstellung eines Krystalles, nicht ein „Erzeugen" oder „Machen“ ist, sondern nur ein "Werden-lassen" ähnlich dem Werdenlassen beim Züchten der Pflanzen und Tiere, beim Ausbrüten beliebiger Eier, wo ebenfalls der Experimentator nur die äußeren Bedingungen zur Neubildung herstellt.

Die in der Chemie als einzige Kraft geltende Affinität oder Süttigungskapacität, gemessen durch die Anzahl von Atomen, welche ein einziges Atom in maximo $\mathrm{zu}$ binden vermag, also gleich dem Quotienten aus dem Äquivalentgewicht dividiert durch das Atomgewicht, ist nicht weniger bei der Bildung der gewöhnlichen atomistischen chemischen Verbindungen, als bei der Bildung der durch Association von Atomgruppen oder Molekülen entstehenden physiologisch ebenso wichtigen molekularen Verbindungen wirksam; sie kann bei keinem Lebensvorgang, und sei er der einfachste, entbehrt werden, weil nirgends ohne chemische Prozesse Leben möglich ist; sie reicht aber nicht aus, alle Erscheinungen des Lebens, welche auf stofflichen Änderungen bertuhen, wie die der anorganischen Natur zu erklären. Denn wenn man sich z. B. vorstellt, es seien sämtliche in einem frischen befruchteten $\mathrm{Ei}$ gleichzeitig vorhandene chemische Verbindungen so genau bekannt, daß sie sämtlich aus ihren Elementen künstlich zusammengesetzt werden könnten, so würde ein aus diesen Kunstprodukten zusammengesetztes Ei doch niemals zur Entwicklung gebracht werden können, wenn es auch physikalisch und chemisch dem natürlichen Ei gleich wäre, weil dem künstlichen Ei die Vorbedingung jeder Entwicklung, eine Summe erblicher 
Anlagen, fehlt. Und diese sind bis jetzt weder physikalisch noch chemisch begreiflich. Sie haften nicht an den physischen Kräften, nicht an den chemischen Verbindungen. Man kann sich vorstellen, daß zwei Eier bei gründlichster Untersuchung mit den feinsten Hilfsmitteln vollkommen dieselben chemischen und physischen Eigenschaften zeigen und doch zwei verschiedene Tiere sich daraus entwickeln könnten, weil die erblichen Anlagen ungleich waren.

Der schlagendste Beweis dafür, daß die ungleichen erblichen Anlagen, somit die Verschiedenheiten ähnlicher Formen, z. B. Neugeborener, auf einer Verschiedenheit der chemischen Verbindungen im Ei (etwa verschiedener Lecithine, Nucleïne oder dgl.) nicht beruhen können, wird durch die individuelle Verschiedenheit der ähnlichsten Formen geliefert. Denn wenn z. B. die Verschiedenheiten zweier Varietäten derselben Art, zweier Abarten oder Spielarten auf Verschiedenheiten der chemischen Verbindungen im Ei beruhten, dann müßten auch die Verschiedenheiten aller Individuen jeder Varietät auf Verschiedenheiten chemischer Verbindungen im Ei beruhen, d. h. jedes einzelne Individuum hätte besondere chemische Verbindungen der vierzehn organischen Elemente nötig, und der Fall, daß ein Ei chemisch zufällig genau gleich dem anderen zusammengesetzt wäre, oder daß ungleiche Zwillinge einem Ei entstammen, wäre unmöglich, die chemischen Verbindungen, auf die es ankäme, würden überhaupt jede nur ein einzigesmal existieren, nur einmal in jedem $\mathrm{Ei}$ und nie wieder erscheinen. Diese Konsequenz widerspricht aber dem allgemeinen chemischen Gesetze, demzufolge die Elemente sich nach konstanten Verhältnissen miteinander verbinden. Eine chemische Verbindung, welche nur ein einziges Mal existieren soll, ist also keine chemische Verbindung. Somit kann die Verschiedenheit der lebenden Körper nicht auf einer Verschiedenheit der chemischen Verbindungen 
im Ei beruhen. Es muß vielmehr außer den Affinitäten derselben noch etwas wesentlich ron allen physikalischen und chemischen Kräften, wie sie gegenwärtig Geltung haben, Terschiedenes, die Erblichkeit, die Art und Weise der Wechselwirkung der im Ei rorhandenen chemischen Verbindungen aufeinander und die Anordnung ihrer Moleküle bestimmen, so daf ein Embryo, ein lebendes Wesen, das den Ei-Erzeugern älnelt, daraus sich entwickelt und auch bei qualitativ und quantitatir gleicher prozentischer $\mathrm{Zu}$ sammensetzung der Eier eine Verschiedenheit der Individuen in ihnen möglich wird. Weder die Chemiker noch die Pliysiker haben sich bis jetzt veranlaßt gefunden, die Thatsache der Erblichkeit in den Bereich ihrer Untersuchungen zu ziehen, weil sie ihmen in der anorganischen Natur nicht auffiel.

Sie drängt sich erst der chemischen Untersuchung auf, wenn man wahrnimmt, daß einige wenige chemische Verbindungen in eigentlichen Sinne zwar in allen lebenden Körpern in allen Generationen existieren, gerade diese aber entweder auch in Gesteinen und Mineralien sich finden, oder, wo dieses nicht zutrifft, eine relativ geringere Wichtigkeit für die Lebensprozesse haben und die lebenswichtigeren Stoffe, die Albumine (Proteide, Eiweißstoffe), nicht mehr den Charakter von chemischen Verbindungen aufweisen. Diese sind es, welche die erbliche Ähnlichkeit der Organismen bedingen und zugleich vermöge ihrer beispiellosen Impressionabilität und Zersetzbarkeit durch äußere Einflüsse zumeist verändert werden. Der wichtigste unmittelbar wirkende äußere Einfluß, der der Nahrung, ist demnach stets ein doppelter bei allen lebenden Körpern. Einmal bedingt die Nahrung, weil sie bei keinen zwei Individuen identisch ist, eine Steigerung der individuellen chemischen Verschiedenheiten, sodann muß die Nahrung, weil sie für alle Pflanzen und alle Tiere aus denselben 
Elementen zusammengesetzt ist - nämlich aus den Elementen der Pflanzen und Tiere selbst - notwendig die Ähnlichkeiten in der chemischen Zusammensetzung aller befestigen und erhalten. Diese letztere Wirkung kommt durch die Erblichkeit der assimilatorischen Funktionen, jene erstere durch die Labilität der Albumin-Moleküle zustande. Es ist demnach für die Erklärung der individuellen chemischen Verschiedenheit der lebenden Körper, der Embryonen und Eier, unerläßlich anzunehmen, daß die chemischen Atome und die Atomkomplexe, welche (in den zusammengesetzten Radikalen) die Rolle von Atomen spielen können, sich miteinander noch in anderer Weise verbinden, als nach konstanten atomistischen und molekularen Verhältnissen, d. h. also nach veränderlichen Verhältnissen. Die Verbindungen nach konstanten Verhältnissen, einschließlich der durch Isomerie (Metamerie und Polymerie) bedingten Mannigfaltigkeiten sind sämtlich im physiologischen Sinne tot, Produkte des Stoffwechsels, welcher im Protoplasma durch die lebhaften Atombewegungen im Eiweiß-Molekül zustande kommt. Die Verbindungen nach veränderlichen Verhältnissen entstehen und vergehen bei diesem Stoffwechsel und lassen die der chemischen Analyse allein bisher unterworfenen chemischen Verbindungen nach festen Verhältnissen übrig.

Die Albumine, welche bis jetzt rein dargestellt und analysiert wurden, gehören zu den toten Stoffen, die aktiven Albumine im Protoplasma der einzelligen Wesen, der befruchteten Eizellen, der Pflanzenzellen, der Leukocyten usw. verlangen neue chemische Untersuchungsmethoden.

Ein anderes Erscheinungsgebiet dagegen, welches früher für ebenso rätselhaft und specifisch vital gehalten wurde, wie gegenwärtig der Protoplasma-Chemismus, das der Fermentwirkungen in sämtlichen lebenden Gebilden hat Aussichten verstanden zu werden auf Grund der bestehenden 
Voraussetzungen ohne Zuhilfenahme von „katalytischen oder Kontakt-Kräften" oder Verbindungen besonderer Art. Denn die Ätherbildung, die Erkenntnis, daß durch die Einwirkung immer derselben Schwefelsäuremenge auf Alkohol immer aufs neue Äthyläther entsteht, ohne daß die Schwefelsäure nach dem Entstehen und Verschwinden der Äthylschwefelsäure im geringsten rermindert oder verändert wäre, zeigt, wie auf rein chemischem Wege durch Doppelzersetzung das scheinbare Wunder einer Wirkung durch Berührung zweier chemisch differenter Stoffe ohne Veränderung des einen zustande kommt. Weder ist es nötig anzunehmen, daß die nicht organisierten Fermente (z. B. der Verdauung) Reste ron Organismen seien, noch daß ihnen eigentïmliche, sonst nirgends wirkende Kräfte zukämen. Vielmehr hat die Untersuchung der Fermentwirkungen sich auf den Nachweis der intermediären Veränderungen der Fermente und ihre Regeneration zu richten, und sie stützt sich dabei auf eine der sichersten Errungenschaften der organischen Chemie, die Theorie der Ätherbildung, welche beweist, daß jene intermediären Veränderungen und jene Regeneration wirklich in einem nach jeder Richtung genau erforschten Falle stattfinden. So können auch die Wirkungen pflanzlicher und tierischer Fermente, des Pepsins, Ptyalins, der Diastase u. a., scheinbar ohne daß diese sich selbst verändern, zustande kommen.

\section{Unzulässigkeit der Amnahme einer besonderen Lebenskraft.}

Erst seitdem der physikalische Kraftbegriff in aller Strenge in die Physiologie eingeführt worden, haben die vitalen Kräfte, die letzten Ausläufer der Lebensgeister, der 
156 Unzulässigkeit der Annahme einer besonderen Lebenskraft.

animalischen und natürlichen „Spiritus", ihre Geltung verloren.

Das körperliche Leben besteht in einer Umsetzung von potentieller Energie $(P)$ in kinetische Energie $(\boldsymbol{K})$ und Ersetzung der verbrauchten potentiellen Energie durch den Kraftwechsel in entgegengesetzter Richtung.

In jedem lebenden Körper finden zugleich beiderlei Vorgänge statt.

Das Gesetz von der Erhaltung der Kraft (der Arbeit, der Energie) auf das Leben angewandt, verlangt, daß dabei, wie bei Maschinen, eine konstante Größenbeziehung zwischen dem Vorrat an potentieller Energie und der möglichen kinetischen Energie existiere. Der Nachweis aber, daß z. B. im tierischen Organismus die Summe der Arbeiten in Wärme umgerechnet genau der durch chemische Prozesse gebildeten Wärmemenge gleichkommt, ist experimentell noch nicht vollständig geliefert, eine Größenbeziehung der tierischen Elektricität zur mechanischen Arbeit unerkannt und überhaupt das ganze Gesetz von der Erhaltung der Energie vielmehr von regulativem Gebrauch in der Physiologie, als empirischer Begründng durch die Lebensprozesse fähig. In seiner allgemeinsten Fassung besagt das Gesetz, daß in einem allen äußeren Einflüssen entzogen gedachten Systeme in Bewegung begriffener materieller Punkte die Summe $P+K$ konstant bleibt, weun auch $K$ und $P$ ohne Unterbrechung sich ändern. Die Welt kann, der Organismus kann nicht als ein solches System angesehen werden. Außerdem sind im lebenden Körper Bewegungsursachen wirksam, welche in die Formeln der Bewegung verursachenden oder abändernden oder hemmenden Kräfte des Gesetzes von der Erhaltung der Energie nicht mit aufgenommen werden können, weil ihr Wärmeäquivalent nicht auffindbar ist, z. B. Gefühle. Wenn die Haut eines Amphibiums mit verdünnter Schwefelsäure, hierauf in gleichen Pausen mit immer mehr 
konzentrierter Schwefelsäure benetzt wird, dann erkennt man deutlich, daß die Lebhaftigkeit der Bewegungen steigt; sie steigt mit der Intensität des Schmerzes wie beim Menschen. Das Schmerzgefühl — selbst mit der Stärke des Eingriffes steigend - ist Ursache von Nassenbewegungen, und deren kinetische Energie eine Funktion der Intensität des Gefühles. Aber jene in Wärme umgerechnet gibt nicht das Kraftäquivalent des Schmerzgefühles, sonderm nur des chemischen Prozesses. Hier (und in manchen anderen Fällen, z. B. bei der Befruchtung, Fermentwirkung) ist das Gesetz bis jetzt nicht anwendbar.

Deshalb aber eine besondere Lebenskraft anzunehmen, wäre völlig unzulässig. Denn dadurch würde nur etwas Unbegreifliches durch eine weitere Unbegreiflichkeit der Unterordnung unter feste Gesetze noch mehr entzogen. gleichviel ob eine Anima, ein Archeus oder Faber oder mehrere Spiritus vitales und dergleichen angenommen werden. Noch heute spielt der Vitalismus unter alten und neuen Namen, zwar nicht mehr als Pneuma und Impetum faciens, aber als „Lebensprincip, Naturheilkraft, Bildungstrieb ( $N$ isus formativus)" und unter den unphysikalischen - überhaupt unklaren - Begriffen des „Unbewußten“, der „Zweckthätigkeit, Zielstrebigkeit" eine offene und versteckte Rolle in nicht gehörig physikalisch geschulten wissenschaftlichen Kreisen. Aber selbst von Physikern wird häufig allein durch eine nachlässige Ausdrucksweise und eine allzuweit getriebene bildliche Darstellung der Vorstellung eines Naturwillens, einer Personitikation der lebenden Natur oder einer von ihr beabsichtigten Thätigkeit sehr gegen den Willen der Autoren Nahrung gereicht.

Die Unzulässigkeit der Annahme einer Lebenskraft ergibt sich am deutlichsten aus der bereits dargelegten Notwendigkeit gleicher Wirkungsweise der physischen Kräfte innerhalb wie außerhalb der lebenden Körper und aus der 
Identität der chemischen Affinitäten in beiden Fälleri. Wegen der absoluten Übereinstimmung der organischen Elemente mit den gleichnamigen mineralischen Elementen bliebe für die Lebenskraft kein Träger mehr übrig.

\section{Unzulässigkeit der Ammahme einer permanenten specifisch-vitalen Bewegung.}

Nicht weniger unzulässig als die Annahme einer Lebenskraft im Sinne der älteren Physiologie ist die Voraussetzung, daß in den lebenden Körpern eine eigentümliche nie unterbrochene, nicht näher definierbare specifisch-vitale Molekularbewegung stattfinde. Durch diesen „Wirbel der Iaterie" sollten sich nach der Ansicht Früherer die lebenden Körper von den anorganischen unterscheiden und er sollte es sein, der von Geschlecht zu Geschlecht, von Alters her das Leben von einem Körper auf den anderen überträgt, so die Kontinuität alles Lebens vermittelnd. Hiernach wäre es nicht die besondere Beschaffenheit der chemischen Verbindungen, auch nicht eine Besonderheit ihrer Affinitäten, und nicht eine neue physikalische Kraft, sondern vielmehr eine eigenartige molekulare Bewegung, welche dem Leben zu Grunde läge und einmal völlig erloschen, nicht wieder erweckt werden könnte. Darin würde ihr Hauptcharakteristikon bestehen.

Solange es unbekannt war, daß Tiere und Pflanzen verschiedenster Struktur und Lebensweise nach Entziehung der wichtigsten unmittelbaren äußeren Lebensbedingungen, z. B. in rölliger Trockenheit und Luftleere, oder nachdem sie in allen ihren Teilen festgefroren waren, ihre Lebensfähigkeit nicht verlieren, konnte angenommen。werden, daß da jene Lebensbewegung nur herabgesetzt sei. Seit aber feststeht, 
Unzulässigk. d. Annahme e. permanenten specif.-vit. Bewegung. 159

daß sie völlig unterbrochen wird und nur durch Wiederherstellung jener Bedingungen wieder in Gang kommt, ist die Permanenz der supponierten molekular-organischen oder vitalen Bewegung hinfällig geworden. Die Anabiose widerspricht ihr, indem sie eine Umsetzung der potentiellen Energie in kinetische nach völligem Stillstand aller Massenbewegung, aller Lebensthätigkeit im festgefrorenen Körper, Tier oder Ei vorstellt.

Wollte man behaupten, es sei nur eine Verminderung und keine totale Aufhebung der Umsetzung potentieller Kräfte in die während des Lebens auftretenden aktuellen Kräfte im durch und durch festgefrorenen Rädertier, in der völlig trockenen Nostocacee, in dem hartgefrorenen befruchteten $\mathrm{Ei}$ anzunehmen, so wäre doch irgend eine Wirkung solcher minimaler physiologischer Umsetzungen nach längerem Zuwarten, nach Monaten, Jahren, Jahrhunderten (bei keimfähig gebliebenen Pflanzensamen in Bleisärgen) nachzuweisen. Dieser Nachweis aber fehlt gänzlich, und die Thatsache steht fest, daß die Lebensprozesse z. B. die Verdauung, Keimung, Fruktifikation, Muskelkontraktion - nach der Wiederbelebung mittels passender Auslösung (Herstellung der notwendigen äußeren Lebensbedingungen) genau da wieder einsetzen, wo sie vorher im Augenblick des Erlöschens der einzelnen Funktionen (wegen Entziehung der ihnen erforderlichen äußeren Lebensbedingungen) unterbrochen wurden. Von einer aufgezogenen Uhr, deren Pendel nicht schwingt, behauptet niemand, daß sie doch noch, aber unmerklich, gehe. Sie steht völlig still und setzt ihre Spannkraft in lebendige Kraft erst wieder um, wie vorher, wenn das Pendel wie rorher schwingt, wenn es durch einen Stoß in Bewegung rersetzt wird. Bei den leblosen lebensfähigen Körpern heißt der Stoß „Reiz“ und ihr Vermögen, nach Herstellung der äußeren Bedingungen durch Umsetzung 
potentieller Kraft in aktuelle darauf zu reagieren „Reizbarkeit".

Eigentümlich verwickelt, d. h. von den Bewegungen der anorganischen Körper abweichend, sind die Lebensprozesse in mehr als einer Beziehung; aber gerade die als Hauptmerkmal ihnen zugeschriebene Permanenz kommt keinem von ihnen zu, sowenig wie der Bewegung des Uhrwerkes. Diese wichtige Erkenntnis wird durch die Thatsache der Anabiose bewiesen.

Überhaupt gilt es bezüglich der Molekularbewegung im Protoplasma (und dadurch in allen lebenden Körpern) als im höchsten Grade wahrscheinlich, daß sie nicht nur verschiedenartig, sondern auch überall mit den äußeren Umständen wechselnd ist. Daher auch von dem Mangel der Permanenz ganz abgesehen eine specifisch-vitale oder molekular-organische Bewegung anzunehmen unzulässig ist.

\section{Notwendige Voranssetzungen.}

Um nun den zwischen den biologischen Thatsachen und den Axiomen der Physik und Chemie noch bestehenden von vielen für schlechterdings unauflöslich gehaltenen Widerspruch zu heben, ohne neue Widersprüche zu schaffen, ist es am besten, wenn Physik und Chemie eine Erweiterung des Begriffes der potentiellen Energie in der Weise anbahnen, daß darunter auch das Vermögen der Naterie, zu empfinden, subsumiert werde, ein Vermögen, welches unter ganz speciellen Bedingungen - wie sie in den komplizierten lebenden Körpern allein verwirklicht sind - sich bethätigen kann, sonst aber zu gering ist, um die Vorgänge der anorganischen Natur zu affizieren.

Ferner wird es, um die Erscheinungen der Erblichkeit 
mit den Thatsachen der Physik und Chemie in Einklang $\mathrm{zu}$ bringen, erforderlich sein, aller Materie eine Art Gedächtnisvermögen zuzuschreiben, wie es bereits einige gethan haben. Ein Beharren der kleinsten Teilchen in der Anordnung, in welche sie am häufigsten durch äußere Kräfte gerieten, und eine mit der Wiederholung steigende Tendenz immer wieder dieselbe Anordnung einzugehen, auch wenn die äußeren Kräfte nicht mehr in der ursprünglichen Intensität wirken, bildet die Vorstufe dazu.

Doch führen diese Betrachtungen zu weit in das Gebiet der Spekulation. Darum sei in Bezug auf den letzteren Punkt nur noch hervorgehoben, daß die besten Beobachter dem Protoplasma der niedersten Wesen psychische Funktionen mit Entschiedenheit zuschreiben. Wenn aber die Anlage derselben den lebenden Gemengen verschiedener Stoffe, aus denen das gegenwärtige Protoplasma hervorging, nicht bereits zukam, so ist nicht ersichtlich, woher das Empfindungs- und Unterscheidungs-Vermögen stammen sollen?

\section{Die Wärme als Ursache des Lebens.}

Auf Grund der vorliegenden morphologischen, chemischen und physikalischen Thatsachen und der von der Physiologie verlangten Voraussetzungen läßt sich z. Z. noch $\mathrm{keine}$ widerspruchsfreie Theorie des Lebens aufstellen. Es ist jedoch eine starke Neigung vorhanden, auf Grund des alten Satzes zu theoretisieren, daf die Wärme die Grundlage aller Lebenserscheinungen bildet.

Nur wo diejenige Bewegung, welche Wärme heilt, im Gang ist und im Gang erhalten wird, ist Leben möglich. Wo sie fehlt oder auf ein Ninimum sinkt, kann Leben nur 
entstehen, wenn vorher in dem betreffenden Komplex Leben gewesen und ein gewisser Vorrat an potentieller Energie übrig geblieben ist, so daß bei geeigneter Auslösung die Wärmebewegung aufs neue auftreten kann (Anabiose).

Thatsache ist ferner, daß alle bekannten lebenden Wesen ron der Somne abhängen, teils direkt, indem sie die aktuelle Energie der Ätherschwingungen im Sonnenstrahl in chemischen Arbeitsvorrat verwandeln, teils indirekt, indem sie diese aufgespeicherte Sonnenwärme mittels Sauerstoffaufnahme frei machen oder in Arbeit umsetzen. Alle Lebensbewegung auf der Erde führt, streng physikalisch auf ihre Ursachen zurïckverfolgt, auf den Kraftvorrat in der Sonne hin. Auch die, eine scheinbare Ausnahme bildenden Anaërobien, welche keinen freien Sauerstoff aufnehmen und nicht imstande sind, die lebendige Kraft der Ätheroscillationen in potentielle Energie umzusetzen, auch die im Dunkeln und in der Sauerstoffleere lebenden chlorophyllfreien Anaërophyten und Anaërozoen, welche Gärungen verursachen, entnehmen ihre Wärme Kohlenstoff und Wasserstoff enthaltenden, nur unter dem Einfluß der Sonnenstrahlen entstandenen Stoffen, Produkten des pflanzlichen oder des von diesem abhängigen tierischen Stoffwechsels, welche für die Gärung so notwendig sind, wie die Gärungserreger.

Ohne die Anhäufung potentieller Energie und ohne die Möglichkeit ihrer Umsetzung in Wärme, ohne jene Wärme, welche im lebenden Protoplasma höchstwahrscheinlich fortwährend zersetzend wirkt, kann Leben nicht gedacht werden.

Darüber freilich, wie, im Einklang mit der mechanischen Wärmetheorie, die Atombewegung in den zerplatzenden und durch Nahrungsaufnahme (Assimilation) sich rekonstruierenden Albumin-Molekülen des Protoplasma durch Wärme immer wieder angefacht wird und wie der fundamentale Prozeß der Oxydation in der pflanzlichen und 
tierischen Zelle verläuft, so daß in dieser die verschiedenartigste Arbeit (Strömung, Elektricität, Kontraktion, Empfindung, Teilung, Differenzierung usw.) zustande kommt, sind mehrere Ansichten möglich, zwischen denen erst künftige experimentelle und theoretische Untersuchungen entscheiden können.

Immerhin ist der Wert des Ausgangspunktes nicht zu überschätzen. Derselbe ist nicht neu, sondern vielmehr findet er sich, wie die Geschichte der Physiologie lehrt, -schon bei den bedeutendsten Denkern des Altertumes. Neu ist die Einsicht in das Wesen der Wärme, in die Abhängigkeit alles Lebendigen von der Sonnenwärme und die Anwendung der Lehrsätze der mechanischen Wärmetheorie auf die Lebensprozesse, wie sie bereits von den hervorragendsten Physiologen der Gegenwart mit Erfolg rersucht worden ist. Darum dürfen aber die früheren Theorien vom Ignis animalis, von dem Feuer als Lebenskraft, von der angeborenen Lebenswärme (Calor innatus) und dergleichen nicht als unnütze Phantasien oder luftige Spekulationen bezeichnet oder gar verspottet werden. Denn etwas Wahres liegt ihnen zu Grunde und sie genügten den Bedürfnissen der Zeiten, in welchen sie entstanden. Sie sind Vorarbeiten für die Gegenwart, wie die heutigen ungeschlossenen Theorien nur Vorläufer einer künftigen umfassenden Lebenserklärung sind.

Alle bis jetzt aufgestellten Theorien des Lebens, die neuesten nicht weniger als die ältesten, haben darum nur geringen Erfolg gehabt, weil sie zu viel aus einem stets willkürlich gewählten Princip erklären sollten, während das Leben in Wirklichkeit nicht das Resultat eines Prozesses, sondern unbegrenzt vieler Prozesse ist, so daß auch die dualistischen Hypothesen und die Zugrundelegung einer dreifachen oder vierfachen Lebenskraft unmöglich das Lebensganze erklären konnten. Bei dem einfachsten 
anorganischen Naturvorgang, z. B. dem Fallen des Regentropfens, muß eine lange Reihe von Prozessen (Verdampfung, Kondensierung, Tropfenbildung usw.) und stets mehr als eine Kraft zur Erklärung in Anspruch genommen werden (nämlich mindestens eine Form aktueller und mindestens ein e Form potentieller Energie) und es ist kein intellektuelles Bedürfnis, überall nur eine einzige Ursache zu statuieren, weil das Zusammentreften verschiedenartiger Umstände denselben Effekt haben kann und ein und dieselbe Erscheinung auf gänzlich verschiedenen Wegen zustande kommt - und doch verlangte jede der bisher aufgestellten Theorien des Lebens, also gerade des kompliziertesten Prozesses, den es überhaupt gibt, nur eine Ursache und immer dieselbe oder ein Zusammenwirken von nur zwei, drei oder wenig mehr Ursachen, um die beispiellose Mannigfaltigkeit der organischen Erscheinungen begreiflich zu machen. Bald war es das Wasser, bald die Luft, dann die Erde oder eine unbestimmte Materie, dann das Feuer, der Äther, die Lebenskraft, auch die Seele und viele Abarten materieller Lebensgeister und psychischer Principien, welche die Grundursache des Lebens als Ganzen sein sollten; neuerdings ist es der Kohlenstoff, das Eiweiß, die Wärme.

Die Ableitung aller Lebenserscheinungen aus einer einzigen Ursache oder wenigen Faktoren ist aber z. Z. schon deshalb in sich verfehlt, weil auch der einfachste lebensfähige Körper, das Protoplasma, eine Reihe sehr verschiedener und bis jetzt voneinander nicht ableitbarer Funktionen zeigt. Zuerst müssen diese Teilerscheinungen des Lebens, die physiologischen Funktionen für sich untersucht und in lückenloser Reihe eindeutig auf einfachere Vorgänge streng kausal zurückgeführt werden, die verwickelten Funktionen höher differenzierter Tiere und Pflanzen auf weniger verwickelte Protoplasmafunktionen und diese auf elementare - zunächst chemische und physikalische - 
Prozesse. Dann erst kann die Frage diskutiert werden, ob letztere noch weiter auf wenige Ursachen oder vielleicht eine letzte Ursache zurückführbar seien.

Demnach hat nur eine solche Theorie des Lebens in der Zukunft Aussicht auf Bestand, welche mit der Theorie der Funktionen begonnen haben wird. Zuerst sind die Teilerscheinungen, gleichsam die Differenziale zu ermitteln, ehe integriert werden kann. Die Analyse der Funktionen geht der Synthese derselben rorher. Beror also eine Lebensursache gesucht wird, müssen die Ursachen der Funktionen gefunden sein. Und wenn in der Gegenwart die Wärme als Grundlage der Gesamtheit aller physiologischen Funktionen gern aufgefaßt wird, so spricht sich bis jetzt darin zwar eine heuristisch ungemein wertrolle Neigung, die jüngsten Errungenschaften der theoretischen Physik und Chemie auszunutzen aus, eine Neigung aber, welche die wissenschaftliche Phantasie mehr als das Verlangen nach strenger Kritik befriedigt; denn ein Fundament für die künftige Theorie des Lebens ist damit nicht eher gewonnen, als bis jede einzelne Funktion auf dieselbe zurückgeführt sein wird. Und davon ist die gegenwärtige Physiologie sehr weit entfernt. Doch liegt schon darin ein Fortschritt, daß sie ein Ziel klar vor sich sieht, bei dessen Verfolgung sie nur gewinnen kann. 


\section{Von den Funktionen der lebenden Körper.}

Der Ausdruck „Funktion“ ist vieldentig - man spricht z. B. von logischen, von chemischen, von amtlichen Funktionen - und läßt sich nicht vollkommen verdeutschen, auch wenn man die im Altertum von MIedizinern und Philosophen in demselben Sinne verwendeten Wörter Actio und

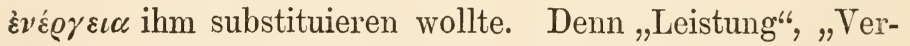
richtung", "Thätigkeit", "Arbeit" und andere deutsche Bezeichnungen treffen nicht das Wesentliche des Begriffes und entbehren geeigneter Beiwörter, welche das wichtige Wort „funktionell“ ersetzen könnten. Daher muß „Funktion“" beibehalten werden.

Es ist nun trotz des in vielen Wissenschaften sehr häufigen Gebrauches dieses Ausdruckes bis jetzt noch niemals eine zusammenfassende Untersuchung der mit ihm bezeichneten Begriffe auch nur versucht worden. Sogar die an präcise Bestimmungen gewöhnte Mathematik hat ihren, d.h. den ihr eigentümlichen Funktionsbegriff genauer zu bestimmen erst angefangen. Keine der anderen Disciplinen, welche andere Funktionsbegriffe haben, am wenigsten die Physiologie, deren ausschlieBlicher Gegenstand die physiologischen Funktionen sind, hat sich Rechenschaft über den fundamentalen Begriff zu geben unternommen. 
Im allgemeinsten Sinne bedeutet Funktionsnexus oder funktioneller Zusammenhang eine Zuordnung von Größen einer Reihe zu solchen einer anderen Reihe, so daß jeder Größe der ersten eine solche der zweiten entspricht. Etwas bestimmter ist der Funktionsbegriff, wenn er diejenige Abhängigkeit einer Veränderung von einer anderen Veränderung bezeichnet, bei der jedem Verflußwert einer Größe ein bestimmter Terflußwert einer anderen zugehört. Noch enger wird der Begriff durch den Zusatz, daß mit der Änderung der einen Größe die andere sich in stetiger Folge und eindeutig gesetzmäßig ändert. Die vielen Wandelungen, welche der erst im 17. Jahrhunderte eingeführte mathematische Funktionsbegriff durchgemacht hat, zeigen, wie schwierig es ist, zweier veränderlicher Größen allgemeine Beziehungen zu bestimmen.

Der mathematische Funktionsbegriff ist nun zwar für die Physiologie von der größten Bedeutung, als Instrument oder Mittel zur Forschung und Darstellung der Forschungsergebnisse, aber unbrauchbar zur F'eststellung des Begriffes der physiologischen Funktion.

\section{Begriff der physiologischen Funktion.}

Der Sinn des Wortes Funktion ist in der Physiologie ein gänzlich anderer, als in allen anderen Wissenschaften. Mit dem mathematischen Funktionsbegriff hat er nur das Merkmal der Abhängigkeit gemeinsam. Die mathematische Funktion ist eine Form der Zuordnung, die physiologische ein ProzeB, ein Vorgang, eine materielle Veränderung. $\mathrm{Zu}$ jeder physiologischen Funktion gehört ein Substrat (das Fungierende), nämlich ein organisches Individuum beliebiger Ordnung oder ein Teil eines solchen, ein 
Objekt (d.h. ein Gegenstand der Funktion), und ein Reiz. Letztere beide können von dem Substrat, so lange es fungiert oder lebt, nicht getrennt werden ohne die Funktion zu unterbrechen. Die physiologische Funktion ist stets ein Geschehen, bei welchem sowohl das Substrat, wie das Objekt verändert wird. Dabei gehen die Teränderungen des Substrates gesetzmäßig zusammen mit denen des Objektes. In der Ermittlung und Erklärung dieser Gesetzmäßigkeit besteht die Hauptaufgabe der ExperimentalPhysiologie.

Es kann dabei von einer Unterscheidung einer $A b$ hängigveränderlichen und Unabhängigveränderlichen im mathematischen Sinne nicht die Rede sein, weil es sich nicht um Wertpaare handelt, sondern um Mannigfaltigkeiten von Veränderungen in dem fungierenden Teil einerseits, in dem Funktionsobjekt andererseits, also beidesfalls um materielle Vorgänge. Diese sind auch schlechterdings unvertauschbar. Z. B. ist die Ernährung eine Funktion der Ernährungsorgane und kommt zustande durch die gleichzeitigen Veränderungen in diesen und in der Nahrung, dem Objekt der Funktion. Niemals würde aber der Satz, die Ernährung sei eine Funktion der Nahrung, einen physiologischen Sinn haben. Ebenso ist das Atmen Funktion der Lunge und abhängig von der Luft usw. Wollte man die Veränderungen in diesen Substraten als die Unabhängigveränderlichen ansehen (gleichsam als die Argumente der Funktion), die in den Objekten als die Abhängigveränderlichen, so würde zwar die Nichtumkehrbarkeit einleuchten (da das Atmen nicht Funktion der Luft ist usw.), aber eine derartige pseudo-mathematisierende Betrachtung ist darum unzulässig, weil das dabei als unabhängigveränderlich gedachte Substrat, sofern es fungiert, stets rom Objekt abhängt, während dieses von jenem nicht abhängt. Nahrungsstoffe und Luft bleiben was sie sind auch ohne Ernährungs- 
und Atmungs-Organe,die letzteren fungieren aber ohne jene nicht. Und doch können die Substrate auch nicht als abhängigveränderlich bezeichnet werden (im mathematischen Sinne) schon weil zu derselben Nahrung unendlich verschiedene Ernährungsorgane, zu derselben Luft rerschiedene Atmungsapparate gehören bei völliger Identität der Funktion.

Die physiologische Funktion ist also seitens des Substrates aktiv, seitens des Objektes passir.

Die Geschichte des physiologischen Funktionsbegriffes geht zwar viel weiter zurück als die des mathematischen, hat aber ungleich weniger von Schärfe des Denkens zu berichten. Was man schon lange vor der Ausbildung der Experimentalphysiologie den „Nutzen“ eines Organes nannte, ist wesentlich (in der Mehrzahl der Fälle) dasselbe, was jetzt seine „Funktion" genannt wird. Der vom "usus" oder Nutzen kaum trennbare Zweckbegriff haftet auch jetzt noch allzuoft dem Begriffe der physiologischen Funktion an, sofern viele jede physiologische Funktion so auffassen, als wenn sie die Erhaltung des Individuum oder die Erhaltung der Art bezweckte. Es gibt aber völlig zwecklose Funktionen, wie z. B. das Wachsen funktionsloser Organe, auch unzweckmäßige, welche die Selbsterhaltung und Arterhaltung schädigen. Zwecke sind den Funktionen ebenso fremd wie der Planetenbewegung, den Meeres - und Luft-Strömungen usw. Die Einführung der Teleologie in die Physiologie hat daher viel mehr geschadet als genützt und die Zugrundelegung des physikalischen Kraftbegriffes mit rein kausaler Erklärung wesentlich erschwert. Die Zwecksetzung selbst ist eine zu erklärende Gehirnfunktion.

Die alte Unterscheidung der Dynamis oder Facultas und Energie oder Actio (=Functio) entspricht keineswegs den Begriffen der potentiellen und aktuellen (lebendigen 
oder kinetischen) Kraft der Gegenwart. Der erstere Ausdruck deckt sich vielmelr oft mit dem Deutschen "Trieb“ und „Vermögen" (z. B. „Seelenvermögen" in der Psychologie), also höchst komplizierten von einfachen Funktionen nach langer Entwicklung erst abgeleiteten Anlagen, andere Male mit „Reizbarkeit" und „Funktionsfähigkeit"“. Da aber der Galenismus so viele Fakultäten wie Funktionen annahm, ohne den Einwand zu beseitigen, daß mit einer Funktion zugleich andere von ihr abhängige Funktionen gegeben sind, so konnte in der Gegenwart dieser Begriff der Fakultät nicht einmal als der einer potentiellen Funktion beibehalten werden, nachdem er viele Jahrhunderte überdauert hatte. Die Haupt- und Neben-Funktionen wurden zwar unterschieden, aber die Art der Abhängigkeit letzterer von ersteren nicht gewürdigt. Überhaupt meinte man bis in die Neuzeit viel gewonnen zu haben, wenn man den Grundsatz festhielt, daß die Funktionen durch die Beschaffenheit der fungierenden Teile in jedem Falle allein bestimmt seien, während doch die Beschaffenheit der Objekte der Funktionen und die Art der Reizung ebenso in Betracht kommen.

Die Struktur des fungierenden Substrates bedingt die Natur der Funktion nur teilweise, denn es können im morphologischen Sinne gleichwertige Apparate sehr ungleiche Funktionen haben, wie ein und dieselbe anorganische Maschine sehr ungleiche Arbeiten verrichten kann, und es sind andererseits sehr ungleiche Substrate mit derselben Funktion verbunden, wie ganz verschiedene Maschinen die gleiche Arbeit leisten können.

Eine topographische Physiologie, welche die Funktionen nach den Substraten betrachtet und bei jedem die Frage beantwortet: Welche Funktion kam und kommt jedem Teile zu? zeigt, daß je weniger entwickelt ein fungierendes Substrat ist, um so mehr Grundfunktionen ihm 
gleichzeitig zukommen und Substrate mit einer einzigen Funktion nur bei weitgehender Differenzierung erscheinen - oder, was auf dasselbe hinausläuft, daß mehrere Funktionen bei geringerer Entwicklung ein gemeinsames Substrat haben und eine Funktion ein ihr allein zukommendes Substrat nur bei weit fortgeschrittener Entwicklung erhält.

Im allgemeinen wird ursprünglich sogar die Funktion gar nicht durch die Struktur des Substrates bestimmt, sondern vielmehr wird letztere durch die Funktion bestimmt.

Allgemeine Bedingung für die Erscheinung der physiologischen Funktion ist nämlich, daß das Funktionsfähige, d. i. das Lebensfähige, verändert werde durch äußere (nicht im funktionsfähigen Substrat allein stattfindende) Veränderungen, Reize, so zwar, daß ursprünglich sogar durch diese Wechselwirkung die organischen Formen zunächst aus Protoplasma gebildet worden sein können mit ihren phyșiologischen Eigenschaften. Diese Eigenschaften sind die einfachsten physiologischen Funktionen, deren Totalsumme das Leben ausmacht. Genügt der Funktion das Substrat unter veränderten äußeren Bedingungen nicht, dann gestaltet es sich allmählich um (so daß also die organischen Apparate und Kongregate in der That von den Funktionen abhängen), oder die so betroffenen Wesen verlassen ihren Wohnort und wandern dahin, wo die gewohnten äußeren Bedingungen möglichst verwirklicht sind oder die Funktion erlischt.

Hat aber einmal ein organisches Gebilde eine einzige bestimmte Funktion unter veränderlichen äußeren Umständen lange bewahrt, dann reagiert es auf alle Reize in derselben Weise und kann gar nicht mehr oder nur äußerst unvollkommen eine andere Funktion vermitteln. Diese Eigentümlichkeit heißt specifische Energie. Bei weit fortgeschrittener Differenzierung ist daher die Funktion allerdings vollkommen abhängig von dem gewohnten Substrat, aber nurdann. 
172 Die Grundbedingungen jeder physiologischen Funktion.

Man kann daher den wesentlichen Unterschied der physiologischen Funktion oder des organischen Geschehens und der anorganischen Bewegungen oder Maschinen-Funktionen dahin zusammenfassen, daB der fungierende Apparat bei jenen sich entwickelt, bei diesen nicht. Die anorganischen Apparate und Körper entstehen nacheinander, die organischen auseinander. Jene nutzen sich während sie arbeiten $a b$, ohne sich zu ergänzen und zu erneuern, diese nutzen sich zwar ebenfalls ab, aber sie ergänzen und erneuern sich und gestalten sich um, wenn die Arbeit wechselt. Haben sie aber nach langer Entwicklung schließlich eine einseitige Ausbildung acquiriert, welche nur für eine Art Arbeit, für diese aber vollkommen taugt, dann können sie nicht mehr oder kaum noch andere Arbeit leisten und erneuern und ergänzen sich nur nach der einen, durch ihre Einseitigkeit bestimmten Richtung.

\section{Die Grundbedingungen jeder physiologischen Funktion.}

In jedem Falle ist also dreierlei zu unterscheiden:

I. Es muß etwas Materielles da sein als notwendiges Substrat der Funktion, etwas für dieselbe absolut Wesentliches, durch dessen Fortfall ohne Ersatz die Funktion sofort erlischt, auch wenn alles Übrige bleibt: der fungierende Apparat, bei höheren Tieren z. B. für die Saftströmung das Gefäßsystem, für die Ventilation die Atmungsorgane, die Assimilation Magen und Darm usw., die Sekretion drüsige Gebilde, für die Verbrennung Verbrennungsherde, die Wahrnehmung Sinnesorgane.

II. Es muß etwas Materielles da sein als notwendiges Objekt der Funktion, etwas für dieselbe absolut Wesentliches, durch dessen Fortfall ohne Ersatz die Funktion sofort 
Die Grundbedingungen jeder physiologischen Funktion. 173

erlischt, auch wenn alles Übrige bleibt. So erfordert z. B. die Strömung etwas Flüssiges, die Ventilation etwas Gasiges, das Nahlen Mahlbares, die Verbrennung Brennbares, die Sinnesthätigkeit etwas Empfindbares. Immer ist dieses materielle Objekt der Funktion gegenüber I passiv.

III. Durch die Einwirkung eines äuferen Einflusses, eines Reizes, d. h. durch den Vorgang der Reizung, kommt die Wechselbeziehung von I und II uud damit die Funktion zustande. Z. B. ermöglicht die Reizung des Herzens und anderer Teile des Cirkulationsapparates die Blutströmung, des Atemcentrums (des Respirationsapparates) den Gaswechsel; die durch die Nahrung selbst gereizten Assimilationsapparate ermöglichen die Ernährung, wie die gereizte Drüse die Absonderung, das gereizte Sinnesorgan die Wahrnehmung.

Keine Funktion kommt zustande, wenn I oder II oder III fehlt. Ein einfaches Gleichnis erläutert diese Notwendigkeit: Die Windmühle (das Substrat) kann nicht arbeiten, wenn die treibende Kraft des Windes fehlt, gleichsam der Reiz; die Getreidekörner, das Objekt der Funktion, bleiben dann unverändert, ungemahlen, zwischen den Steinen; wenn aber der Wind sich erhebt und Lrraft zuführt, so daß die Drehung der Mühlsteine beginnt, dann wird nicht nur das Korn verändert, nämlich gemahlen, sondern auch die Steinmasse verändert, nämlich erwärmt und abgenutzt. Ähnlich die physiologischen Funktionen. Wirkt auf das Substrat kein Reiz ein, dann kommt die Funktion nicht zustande, ist die Reizung da, dann werden Objekt und Substrat verändert.

Demnach sind für jede Funktion zu ermitteln: das Substrat, das Objekt und der Reiz, d. h. die Grundbedingungen der Funktion.

Gerade wie für die Gesamtheit der physiologischen Funktionen, welche man Leben nennt, gewisse äußere und 
174 Die Grumdbedingumgen jeder physiologischen Funktion.

innere Bedingungen erfüllt sein müssen, welche sich durch Beobachtung und Experiment finden lassen, so auch für jede einzelne Funktion.

Wenn alle Bedingungen einer physiologischen Funktion vollständig bekannt sind, dann ist diese selbst vollkommen erkannt.

Vorläufig können aber für keine Funktion die Grundbedingungen vollständig angegeben werden. Gerade in der Feststellung des Objektes und Substrates jeder Funktion besteht ein wesentlicher Teil der Physiologie, und die Begrenzung dieser immer wiederkehrenden Begriffe, ohne welche keine Funktion gedacht werden kann, ist für jeden einzelnen Fall nicht endgültig festgestellt.

Keine physiologische Funktion ist so einfach, daß sie als die Resultierende von nur zwei veränderlichen Faktoren anzusehen wäre. Die physiologische Analyse besteht darin, sämtliche möglichst einfache Vorgänge ausfindig zu machen, welche die physiologische Funktion ermöglichen.

Die Ermittlung der anatomisch gesonderten Teile, welche für die Funktion notwendig sind und physiologisch zusammengehören, findet in der vergleichenden Anatomie und Entwicklungsgeschichte, sowie in der pathologischen Anatomie wesentliche Förderung, oft aber auch Erschwerung. Schließlich muß das Experiment mit vorsichtiger Handhabung des Exklusionsverfahrens oft die Entscheidung geben.

Besonders muß beachtet werden, daß nach Feststellung der zusammenwirkenden Teile im morphologischen Sinne, eine möglichst weitgehende morphologische Analyse vorzunehmen ist und dann erst die chemische Analyse der morphologisch gesonderten Teile zu beginnen hat. Denn eine chemische Analyse ganzer Organe z. B. hat, wegen der großen chemischen Verschiedenheit der sie zusammensetzenden Teile, wenig Wert für die Ermittlung der 
Die Grundbedingungen jeder physiologischen Funktion.

für das Zustandekommen einer Funktion notwendigen chemischen Prozesse.

Sind die chemischen Bestandteile und ihre Wechselwirkungen in den fungierenden Teilen und deren Objekten genau bekannt, so ist damit für das Verständnis der Funktion zwar viel gewonnen, aber die unmittelbare Beziehung der funktionellen Änderung zu ihnen ist damit noch lange nicht erkannt.

Dasselbe gilt für die bei jeder Funktion mit den chemischen Veränderungen stets zugleich stattfindenden physikalischem Prozesse. So lange nicht eine gesetzmäßige Beziehung zwischen ihnen und den funktionellen Änderungen erkannt ist, können sie eine physiologische Bedeutung nur in bedingter Weise beanspruchen. Namentlich gilt dieser Satz ron vielen zoo-elektrischen und phytoelektrischen Erscheinungen.

Wenn beispielsweise die chemischen und elektrischen Veränderungen bekannt wären, welche in der Muskelfaser auftreten, sowie sie sich kontrahiert, so wäre damit die Funktion derselben, nämlich die Zusammenziehung ihrer kontraktilen Teile, keineswegs schon erklärt. Desgleichen wäre durch eine noch so genaue Kenntnis der chemischen Prozesse und physikalischen Veränderungen des befruchteten Eies die Embryogenesis nicht erklärt. Erklärungen würden beidesfalls erst gefunden sein, wenn die wesentlichen chemischen und physikalischen Prozesse, olne welche die Funktion nicht zustande kommt, von den begleitenden nicht wesentlichen Prozessen getrennt und die Funktion als notwendige Konsequenz der wesentlichen Prozesse erkannt wäre. 


\section{Reiz und Reizbarkeit.}

Reize sind Veränderungen, welche dadurch, daß sie mit einer gewissen Geschwindigkeit verlaufen, Zustandsänderungen an den von ihnen betroffenen, im labilen Gleichgewichte befindlichen Gebilden hervorrufen können. Ist die Geschwindigkeit der Änderung und ihre Größe sehr gering, dann bleibt die Störung des labilen Gleichgewichtes aus; derjenige Wert der Reizstärke, welcher die Reizschwelle oder die Schwelle heißt, wird dann nicht erreicht; der Reiz ist dann unterschwellig oder subliminal, die Zustandsänderung bleibt aus, weil keine Auslösung zustande kommt, d. h. keine hinreichende Umsetzung potentieller Energie in kinetische.

Diese Bestimmungen gelten allgemein für alle Reizungsarten, z. B. für Änderungen der Dichte eines elektrischen Stromes, der Druckwirkung, der Wasserentziehung, der Abkühlung oder Erwärmung, der chemischen Zersetzung, für Äther- und Luft-Schwingungen.

Ferner gilt für alle Reize, daß sie eine obere Grenze ihrer Größe (Stärke) haben, indem die beiden Werte der Reizgröße, innerhalb derer die Änderung, also die schnell verlaufende Schwankung, stattfindet, nicht allzuweit auseinander liegen dürfen, wenn das Gebilde, auf welches der Reiz wirkt, nicht dauernd geschädigt oder vernichtet werden soll.

Auf lebende Körper angewendet erhalten diese Sätze eine bestimmtere Form. Denn bei diesen besteht die durch einen Reiz hervorgerufene Veränderung allemal in dem Beginn oder der Hemmung oder der Änderung einer Funtion, vorausgesetzt, daß das Gebilde reizbar ist, sich nicht im stabilen Gleichgewicht befindet.

Reizbarkeit, Erregbarkeit, Irritabilität, Incitabilität, Excitabilität (auch Empfindlichkeit und 
Sensibilität in manchen Fällen) sind Ausdrücke, welche sich nur auf lebende Gebilde beziehen und deren Eigenschaft $\mathrm{zu}$ fungieren (funktionieren) betreffen. Jedesmal nämlich, wenn ein lebendes Gebilde funktionsfähig ist, ist es reizbar. Aber die Begriffe Funktionsfähigkeit und Reizbarkeit decken sich nicht. Denn auch funktionslos gewordene rudimentäre Gebilde sind noch reizbar, sofern eine Änderung in ihnen durch die Reizung eintreten und sogar durch Wiederholung derselben die Funktion wiederhergestellt werden kann.

Der Worterklärung nach ist die Beziehung der Krraft (im physikalischen Sinne) zur Bewegung sehr ähnlich der Beziehung des Reizes (im physiologischen Sinne) zur Funktion. Denn Kraft wird dasjenige genannt, was Ruhe in Bewegung verwandelt oder eine vorhandene Bewegung ändert oder hemmt. Und $\mathrm{Reiz}$ ist dasjenige, was eine Funktion hervorruft oder eine vorhandene Funktion ändert oder hemmt. Inhaltlich oder begrifflich sind aber Reize etwas anderes als Kräfte und nicht jede Funktion notwendig eine Bewegung; denn die Funktion des Empfindens, obwohl nicht ohne begleitende materielle Änderungen (Bewegungen) möglich, kann selbst keine Bewegung sein; jedenfalls ist es nicht statthaft anzunehmen, daß die Änderungen der einfachen reinen Empfindung räumlich seien; sie sind nur zeitlich. Um daher die Gesamtheit aller durch Reize herrorgerufenen Funktionen, solcher, die Bewegungen sind und solcher, die es nicht sind, mit einem nichts präjudizierenden Ausdrucke zu bezeichnen, nennt man zweckmäßig den unmittelbaren Erfolg einer Reizung Erregung und sagt statt „Reizbarkeit" „Erregbarkeit", wemn die Eigenschaft ruhender lebender Gebilde durch Reize in Funktion zu treten oder die fungierender durch Reize gehemmt oder geändert zu werden, bezeichnet werden soll. Daß Reiz und Kraft nicht dasselbe sind, zeigt folgende Preyer, Physiologie. 
Überlegung: Beim anorganischen toten Körper ist es der Trägheitswiderstand, die Llasse, welche die Art bestimmt, wie er gegen eine auf ihn wirkende Kraft reagiert, in der Amnahme einer gewissen Beschleunigung, beim lebenden Körper dagegen wirken viele Faktoren zusammen, welche die Erregbarkeit bestimmen und dadurch die Art, wie er gegen eine auf ihn wirkende Kraft reagiert. Eine solche Kraft kann unter Umständen ein Reiz sein, es ist aber bei weitem nicht jede Kraft ein Reiz, sondern nur diejenige, welche das organische nicht stabile Gleichgewicht ändert. Ohne dieses Gleichgewicht kann die für die Reizung charakteristische Auslösung nicht stattfinden. Wenn also beispielsweise ein lebender Fisch von Menschenhand durch die Luft geschleudert wird, so ist die Bewegung des Tieres nicht Folge einer Auslösung in ihm, die Kraft, welche ihn in Bewegung versetzt, kein Reiz und die Bewegung von der eines toten Fisches nicht verschieden, also nicht Gegenstand physiologischer Untersuchung. Daß aber irgendwelche Form aktueller Energie bei jeder Reizung als Erstwirkung auftritt, ist gewiß. Und wenn man mit dem Worte Reiz Chemikalien, Berührungen, elektrische Entladungsschläge, Temperaturen bezeichnet, so ist eine solche nachlässige Ausdrucksweise tadelnswert. In allen Fällen ist die Applikation des Reizes auf den erregbaren Teil, d. h. der Vorgang der Reizung, verbunden mit der Übertragung aktueller Energie auf denselben, auch wemn die Endwirkung, der endliche Reizerfolg selbst keine Bewegung, sondern die Hemmung einer solchen oder Empfindung ist.

Die Begriffe des Gleichgewichtes und der Bewegung in der Mechanik und die der Erregbarkeit und der Erregung in der Physiologie entsprechen einander in folgender Weise: 
Stabiles Gleichgewicht : Unerregbarkeit

Labiles Gleichgewicht : Erregbarkeit

Bewegung

Beschleunigung

Stabil wird labil

: Erregung

: Erregungszunahme

Zunahme der Labilität : Erregbarkeitszunahme

Auslösung

Wirksame Reizung

Der Zustand der Erregbarkeit ist vergleichbar dem der Explodierbarkeit chemischer Präparate. Denn da wird ebenfalls durch eine Auslösung ein labiles Gleichgewicht in ein weniger labiles übergeführt, wobei die Abweichung der einzelnen Moleküle von der Stabilität so groß werden kann, daß die Explosion, sogar ohne Erhitzung von außen oder Berührung, durch unmerkliche Erschütterungen und intramolekuläre Temperatursteigerung allein eintreten kann, entsprechend den ohne nachweisbaren Reiz im lebendigen Organismus vorkommenden sogenannten spontanen und automatischen Bewegungen. Je leichter eine einfache chemische Verbindung, wie Jodstickstoff oder Chlorstickstoff, explodiert, je größer der Ausschlag einer empfindlichen Wage bei minimaler Belastung, um so größer die „Erregbarkeit", die Empfindlichkeit derselben. Die Explosion selbst, die Oscillation des Wagebalkens entsprechen der Erregung. Der wesentliche Unterschied zwischen Explodierbarkeit und Erregbarkeit besteht aber darin, daß die lebenden Wesen nach den durch Reizung hervorgerufenen Auslösungen sich wieder regenerieren können, so daß dieselbe Reizung bald wieder denselben Effekt hat, während explosive Stoffe nach der Explosion total zerstört sind.

Von der größten Wichtigkeit für die experimentelle Untersuchung der Funktionen sind nun die Veränderungen der Erregung und Frregbarkeit und zwar in erster Linie diejenigen, welche schon durch die künstliche Zubereitung 
des zu prüfenden lebenden Gebildes behufs seiner Reizung; verursacht werden. Wenn z. B. ein Nerv präpariert oder nur an einer beschränkten Stelle behufs Reizung bloßgelegt wird, so ändert sich schon seine Reizbarkeit, und wenn man ganze Muskeln mit ihren Nerven ausschneidet und an diesen im "Stadium des Überlebens" befindlichen wesentlich veränderten, keinesfalls normal lebenden Präparaten Änderungen der Reizbarkeit konstatiert oder künstlich herrorruft, so ist es völlig unzulässig, die Befunde auf den nor'mal ernährten Muskel und Nerven im unversehrten Organismus zu übertragen. Durch die Mannigfaltigkeit der bei solchem Experimentieren zu Tage tretenden Erscheinungen ist die neueste Physiologie vielfach in die Irre geführt und von der direkten Beobachtung unverletzter lebender Gebilde abgelenkt worden.

Endlich ist bei der Prüfung mittels der Reizversuche stets zu berücksichtigen, daß ein Ausbleiben des erwarteten Reizerfolges beruhen kann (abgesehen von ungenügender Reizstärke) auf einer Lähmung durch Überreizung oder einer gleichzeitig erregten Hemmung. Bei höheren Tieren mit Nerven finden sich weit verbreitet empfindliche Hemmungs-Apparate namentlich in enger Beziehung zu Bewegungs-Apparaten. Bei der Reizung sind dann vier Fälle möglich und, wie die folgende Übersicht zeigt, kann dreimal der Erfolg negativ sein und nur zweimal positiv.

Hemmungs- Bewegungs-
$\underbrace{\text { Apparat }}$
1. unerregt
2. erregt
3. erregt
4. unerregt

Apparat
erregt
erregt
unerregt
unerregt

\section{Reizerfolg}
Bewegung
(a) entweder Bewegung
(b) oder
Ruhe
Ruhe
Ruhe

Der Fall 1 tritt immer dann ein, wenn bei genügender 
Reizstärke Hemmungs-Apparate fehlen oder noch nicht entwickelt sind oder nicht mitgereizt werden, der Fall $2 \mathrm{a}$, wenn der Hemmungs-Apparat zwar mitgereizt, aber schwach erregt wird im Verhältnis zur Erregung des BewegungsApparates, $2 \mathrm{~b}$ wenn beide Erregungen dieselbe Größe haben oder die der Hemmung überwiegt, 3 wenn allein der Hemmungs-Apparat erregt ist, weil der Bewegungs-Apparat von dem Reize nicht getroffen oder gelähmt wurde und 4 wenn beide nicht genügend stark gereizt oder (etwa durch Überreizung) gelähmt wurden.

Ein Beispiel zur Erläuterung der vier Fälle liefert das Atmungs-Centrum höherer Wirbeltiere, in welchem der Bewegungs-Apparat durch das Inspirations-Centrum, der Hemmungs-Apparat durch das Exspirations-Centrum repräsentiert ist.

\section{Ursprung der physiologischen Funktionen.}

Die Frage nach dem Ursprung der Grundfunktionen einfachster lebender Körper, also des Protoplasma, fällt zusammen mit der Frage nach dem Ursprung des Lebens. Die Strömungen, der Gaswechsel, der Stoffwechsel, die Erwärmung, Bewegung, Massenzunahme, kurz alle Funktionen des Protoplasma sind als Grundlagen gegeben, wenn man eine Ableitung der verwickelten Funktionen aus relativ einfachen physikalischen und chemischen Prozessen versuchen will. Für diese Ableitung ist wesentlich eine ursprüngliche Veränderlichkeit (Variabilität) der lebenden Gebilde, die Einwirkung mannigfaltiger Reize auf dieselben und eine dauernde Nachwirkung dieser Reize, wenn sie in gleicher Weise sehr oft wiederholt wurden, so daß die neugebildeten lebenden Körper schließlich 
wesentlich verändert und weniger veränderlich geboren werden.

Die Tariabilität bezieht sich auf sämtliche Eigenschaften lebender Gebilde, in erster Linie aber auf die Formen derselben. Wenn ein Teil eines protoplasmatischen Gebildes sehr häufig durch immer denselben Reiz in gleicher Weise in derselben Richtung zur Zusammenziehung gebracht worden ist, dann werden die impressionabeln Tagmen desselben schließlich (wie durch eine Art Übung oder Dressur) sich in der gewohnten Weise leichter auch bei anderer Reizung zusammenziehen, als in irgend einer anderen Weise oder Richtung. Dann ist das Protoplasma bereits verändert und weniger veränderlich, es ist differenziert; kontraktile Membranen, Fasern oder Blasen haben sich gebildet, und damit ist eine Lokalisation der Funktionen eingeleitet. Was vorher in gleicher Weise von jedem Teile geleistet wurde, wird nun rollkommener nur ron einem Teile oder einzelnen Teilen geleistet, während die anderen entweder noch gar nicht differenziert sind, oder in anderer Weise differenziert sind durch Einwirkung anderer Reize.

Wenn nun ein solches schon teilweise differenziertes Wesen wächst, sich teilt oder Teile abschnürt oder sonst sich vermehrt, so werden die Teilstücke bereits Differenzierungsspuren an sich tragen und nach häufiger Wiederholung der Teilung durch inzwischen fortgesetzte Gewöhnung an dieselben Reize schließlich schon beim Entstehen einige lokalisierte Funktionen haben. Diejenigen Funktionen, welche sich dann bewähren (sofern ihre Träger lange bestehen bleiben) und daher in vielen Generationen erscheinen, heißen erblich, vererbt, ererbt im Gegensatze zu denen, welche ein Individuum zeigt, ohne daß seine Vorfahren sie besaßen, und welche erworbene Funktionen genanint werden. Schließlich sind alle diese sekundären, abgeleiteten zusammengesetzten Funktionen erworben, aber sie können 
sich nicht alle rererben. Es ist durchaus nicht statthaft. den Satz, daß einige erworbene Funktionen sich vererben kömnen, zu verallgemeinern. Auch treten nicht selten neue Funktionen auf, die weder auf erbliche Eigenschaften noch äußere Bedingungen bezogen werden können und einstweilen unverständlich erscheinen.

Kommt num ein schon teilweise differenziertes Wesen unter andere Verhältnisse, andere Lebensbedingungen, wird es anderen Reizen ausgesetzt, dann wird es vermöge der ihm verbliebenen Tariabilität anders differenziert. Es adaptier't sich der neuen Umgebung, soweit wie möglich, wird dadurch teils kompliziert, teils reduziert in seinen Funktionen und zeigt auch ganz neue Funktionen, die aber immer als Modifikationen der ursprünglichen Grundfunktionen sich zu erkennen geben. So fallen z. B. die komplizierten Akte des Kauens und Schluckens unter den allgemeinen ursprünglichen Funktionsbegriff der Aufnahme fremder Stoffe, die Gesamtheit der psychischen Vorgänge (Gehirnfunktionen) unter die ursprünglichen Begriffe der Empfindung und Bewegung, auf welchen sie alle schließlich beruhen.

Der Tersuch, diese und alle anderen höheren oder' zusammengesetzten Funktionen von einigen ursprüıglichen abzuleiten, würde jedoch unausführbar sein, wenn nicht durch die Betrachtung der Beziehungen der lebenden Wesen zu einander eine große Anzahl ron Thatsachen sich ergeben hätte, welche die physiologische Arbeitsteilung als das Wesentliche für das Terständnis der Mannigfaltigkeit der Funktionen erkennen lassen. Nit der Lokalisierung der Funktion ist nämlich die Organbildung (Organogenesis) verbunden, die Folge der Differenzierung. Diese ist die morphologische Erscheinungsweise der Arbeitsteilung.

Die Arbeitsteilung ist das physiologische Korrelat $\mathrm{zu}$ dem rein morphologischen ProzeB der Differenzierung. Mit dieser morphologischen Differenzierung geht aber eine 
chemische zusammen. So enthält zum Beispiel junges Muskelgewebe andere Stoffe als altes. Junge Cellulose verhält sich chemisch anders als alte.

Diese mit der morphologischen Differenzierung zusammen stattfindende chemische Veränderung begleitet und bedingt auch

\section{Die physiologische Arbeitsteilung.}

Aus der Thatsache, daß alle lebenden Wesen einige fundamentale Eigenschaften gemeinsam haben und das Leben aller an gewisse unmittelbare äußere Lebensbedingungen, wie Luft, Wasser, Nahrung geknüpft ist, folgt mit Notwendigkeit überall da, wo viele lebende Körper zu gleicher Zeit existieren, eine Beeinträchtigung des einen durch den anderen, weil die Thätigkeit aller zum Teil derselben Objekte bedarf oder gleichartig ist, wie gerade die Aufnahme von Luft, Wasser und Nahrung, und bei schneller Zunahme der lebenden Individuen jene Lebenserfordernisse knapp werden. So entsteht eine Konkurrenz, welche schon, wo nur zwei Wesen zusammen existieren, sich geltend machen mus, und sich allüberall, sei es auch nur in der Behauptung eines bevorzugten Standortes, mit bald mehr Sonnenwärme, Sonnenlicht, bald mehr Schatten und Kühlung kundgibt.

Diese allgemeine Thatsache der Konkurrenz aller lebenden Wesen miteinander um die Lebensbedingungen ist es, welche zur physiologischen Arbeitsteilung und damit zur Divergenz der Formen führt. Wenn alle an demselben Ort zu gleicher Zeit dasselbe verrichteten, die gleichen Bedürfnisse in gleicher Weise befriedigen müßten, mit anderen Worten die Funktionen aller in identischer Art verliefen, dann wäre es unmöglich, daß so viele zugleich 
lebten, als faktisch zugleich leben. Wenn z. B. nur die im Wasser absorbierte atmosphärische luft geatmet würde, gäbe es keine Lungentiere. Wenn die Luft im Wasser an einer besonders reich belebten Stelle schnell verbraucht wird, so werden diejenigen Wesen, welche eine Zeitlang ohne absorbierten Sauerstoff leben können, im Vorteil sein, noch mehr diejenigen, denen der Versuch, außerhalb des Wassers zu atmen, glückt. Je öfter in der Not, bei Sauerstoffmangel im Wasser, dieser Versuch wiederholt wird, um so mehr wird die Haut oder die Schwimmblase oder welcher Teil sonst zur Aufnahme atmosphärischen gasförmigen Sauerstoffes sich eignet als provisorische Lunge (wie etwa der Darm des Schlammpeizgers) die Funktionen der Kiemen beeinträchtigen. So kömnen durch Teilung der Arbeit im buchstäblichen Sinne die ursprünglichen Funktionen modifiziert werden und aus ihnen neue komplizierte Funktionen entstehen. DaB diese mit dem Absterben ihrer Träger nicht jedesmal wieder verschwinden, ist durch ihre Vererbung zu erklären, indem die in der allgemeinen Konkurrenz von vornherein durch ihren Bau Bevorzugten und durch äußere Umstände Begünstigten länger ausdauern, existenzfähiger sind, als die anderen, so daß ihre neu erworbenen Funktionen sich befestigen und leichter auf ihre Nachkommen, in der Anlage wenigstens, übergehen können, was dem Darwinismus zufolge das Wesen des Selektionsprozesses in der Natur ausmacht.

Besonders wichtig bei dieser durch die Konkurrenz verursachten Teilung der Arbeit ist der Rückgang bereits vorhandener Funktionen, wenn neue einseitige entstehen. In dunklen Höhlen erlischt z. B. das Sehvermögen, während der Tastsinn sich verfeinert. Dem ersteren fehlen die Reize, dem letzteren drängen sie sich auf.

Entsprechendes gilt für alle Funktionen aller lebenden Individuen jeder Ordnung. Jede dauert so lange es ihr 
an Reizen nicht fehlt, so lange Substrat und Objekt nicht mangeln und deren gewohnte Beschaffenheit nicht wesentlich alteriert wird. Die durch die Konkurrenz herbeigeführte Veränderung - sei es Reizmangel, sei es Schädigung des Substrates oder wesentliche Änderung des Objektes führt dagegen sehr leicht zum Erlöschen der einen Funktion, z. B. zu Atrophie, Anästhesie, Akinesie, während eine andere nur um so mehr hervortritt. Es kann sogar die Begünstigung einer Funktion auf Kosten der anderen einen für sie selbst nachteiligen Grad erreichen, zu einer krankhaften Steigerung oder Ausartung führen, z. B. zu Hypertrophie, Hyperästhesie, Hyperkinesie.

So entstehen schließlich entartete hyperplastische Gebilde ebenso wie rudimentäre funktionslose durch die funktionelle Interferenz. Durch diese, welche einerseits fördernd, andererseits hemmend wirkt, muß notwendig eine Reihe von Funktionen, welche dem lebenden Individuum unter gewissen äußeren Umständen für sein Leben, d.h. den Ablauf und das Imgangbleiben seiner gesamten Funktionen vorteilhaft war, unter neuen äußeren Umständen nutzlos, nachteilig und tödlich werden. Namentlich ist eines einseitige Differenzierung, welche ganz specielle Lebensbedingungen voraussetzt, wie z. B. beim Parasitismus, der vielseitigen mit möglichst großem Reste der ursprünglichen Variabilität gegenüber im Nachteil bezüglich der Accommodation an neue Verhältnisse.

Übrigens erstreckt sich die Wirkung der Konkurrenz auf Individuen jeder Ordnung und kann auch auf die anorganische Natur ausgedehnt werden, sofern die Undurchdringlichkeit der Materie und ihr Beharrungsvermögen als Mittel zur Behauptung des Raumes, also der Existenz, angesehen werden können und das stabile Gleichgewicht den Konflikt bis zur folgenden Störung beendigt. Auch chemische Prozesse lassen sich als Konkurrenzrorgänge um 
möglichst vollständige und möglichst schnelle Sättigung der freien Affinitäten auffassen, es kann also auch ein Kampf ums Dasein der Moleküle in der lebenden Zelle statuiert werden. Die Zellen konkurrieren miteinander, so lange sie leben, die Gewebe miteinander, die Organe miteinander im Organismus und die Organismen miteinander, nicht weniger die Paare, Familien und Staaten je miteinander.

Es sind namentlich zwei Konsequenzen dieser allgemeinen Konkurrenz physiologisch wichtig, einmal die Notwendigkeit des Lebensendes oder Todes jedes Individuums (weil es ron anderen jüngeren verdrängt wird), dann die Notwendigkeit des Zusammenseins mehrerer um die Funktionen zur Erscheinung kommen zu lassen. Nur was konkurrenzfähig ist, ist lebensfähig, funktionsfähig.

Bezüglich des ersteren Punktes ist die Thatsache wichtig, daß viel mehr Sprossen und Eier erzengt werden, als möglicherweise zur Reife gelangen können. Aber selbst weun alles Gezeugte unter noch so günstigen Lebensbedingungen alt würde, müßte allein schon wegen der Raumgrenzen an der Erdoberfläche die Nehrzahl zu Grunde gehen. Denn der beschränkte Raum, der unbegrenzten Vermehrung entgegenwirkend, ist es, welcher die Konflikte und Kiollisionen steigert, so daß schließlich die benachteiligten Individuen verdrängt, erdrückt, getötet werden.

In betreff des zweiten Punktes leuchtet ein, daß olne Konkurrenz irgend welche Differenzierung unmöglich wäre. Wem niemand die Nahrung streitig macht, der braucht nicht zu arbeiten, um sie sich $\mathrm{zu}$ rerschaffen, und wo keine Arbeit nötig ist, da kann auch keine Arbeitsteilung sein. Also ist schon die Grundfunktion der aktiven Nahrungsaufnahme durch das Zusammensein mehrerer bedingt, die sich in die vorhandene Nahrung teilen. Was an dieser Teilung als Konkurrent nicht tellnehmen kann, ist nicht lebensfähig, 
nicht existenzfähig. Was daran teilnimmt, erhält sich, ohne daß jedoch die Selbsterhaltung Zweck wäre. Sie ist die Folge der Konkurrenz.

\section{Konstauz der Funktionen bei wechselndem Substrat.}

Wenn nun in der allgemeinen Naturkonkurrenz eine Anzahl lebender durch ununterbrochene Interferenz ihrer Funktionen sehr verschiedenartig differenzierter Individuen gleichsam als Sieger in dem Kampfe um das Dasein nebeneinander bestehen können, indem sie durch den der künstlichen Züchtung vergleichbaren Ausleseprozeß, die natürliche Züchtung, alle anderen weniger günstig differenzierten - den äuferen Umständen weniger adaptierten - Wesen überdauern, dann tritt ein Zustand ein, welcher am zweckmäßigsten als Kompromiß bezeichnet wird. Jedes Individuum kann vermöge seiner weit fortgeschrittenen Arbeitsteilung, d. h. Lokalisation seiner komplizierten Funktionen, mit jedem anderen neben ihm eine Zeitlang, sogar unter konstanten äußeren Bedingungen sehr lange Zeiträume hindurch, bis zu einem gewissen Grade ohne Funktionsstörung harmonieren, weil es nicht in derselben Weise wie die anderen differenziert ist, seine Funktionen anders kompliziert, anders lokalisiert sind, seine Lebensbedingungen von denen des Nachbars etwas abweichen. So ist jeder Organismus durch Kompromisse entstanden. So ist das Nebeneinanderbestehen und die gegenseitige Abhängigkeit der' Pflanzen und Tiere, der höheren und niederen Tiere durch eine Art Kompromiß zu erklären. Dadurch, daß eines dem anderen gleichsam Konzessionen macht, bleibt es selbst existenzfähig, d. h. funktionsfähig. So können dieselben sich gleichbleibenden Formen Jahrtausende unter gleichen Verhältnissen zusammenleben. 
Zu den merkwürdigsten Erscheinungen der lebenden Körperwelt gehört aber die teils allmählich, teils plötzlich in vielen Fällen vor sich gehende Substitution eines fungierenden Apparates durch einen anderen, ohne Änderung des Wesens der Funktion. Ein lehrreiches Beispiel hierfür liefert die Grundfunktion der Atmung. Nachdem die Amphibienlarven längere Zeit ausschließlich durch Haut und Kiemen, oder Haut, Kiemen und Darm den im umgebenden Wasser diffundierten Sauerstoff, auch wohl Luftblasen ron der Oberfläche aufgenommen haben, während ihre noch wenig entwickelten.Lungen funktionslos sind, verlassen sie in Intervallen das Wasser und atmen in der atmosphärischen Luft mit Haut und Lungen, oder Haut, Lungen und Darm und sind bald gar nicht mehr imstande, den Sauerstoff mittels der Kiemen aufzunehmen, weil diese durch die ungleich reichlichere Sauerstoffaufnahme mittels der Lungen weniger vorteilhaft und zuletzt funktionslos werden und sich zurückbilden. Hier tritt also die Lunge an die Stelle der Kiemen, und zwar nur, wenn die Beschaffenheit der einzuatmenden Luft (des Objektes der Funktion) sich ändert. Verhindert man künstlich diese Änderung, indem die Larven (des Erdsalamanders) dauernd unter lufthaltigem Wasser gehalten werden, dann bleibt es bei der Kiemenatmung. Eine ähnliche Substitution findet statt bei der Geburt der Säugetiere - auch des Menschen - welche im Uterus mittels der Placenta, in der Luft mittels der vorher funktionslosen Lungen den erforderlichen Sauerstoff aufnehmen. Hier geschieht die Ersetzung des einen Substrates durch das andere plötzlich, so daß oft genug, wenn die Placentar-Atmung aufgehört hat, ehe die Lungenatmung begann, Lehensgefahr entsteht.

Ähnlich verhält es sich mit anderen Funktionen, namentlich assimilatorischen. Sogar bei dem höchstentwickelten menschlichen Körper können erhebliche dauernde Verwand- 
lungen des Substrates ohne wesentliche Veränderungen der Funktion zustande kommen, wie namentlich chirurgische Erfahrungen beweisen. Wenn nach nicht reponierten Verrenkungen in der Jugend Gelenke veröden, dann bilden sich daneben neue Gelenkflächen (Nearthrosen), mittels derer in manchen Fällen durch systematische Übung ein großer Teil der vor der Luxation ausgeführten Bewegungen wiederum ebenso vollkommen ausgeführt werden kann. Hier hat sich also die Funktion (z. B. Pronation, Supination, Abduktion, Adduktion, Extension, Flexion) ein neues Substrat gebildet.

Das Princip des Substratwechsels bei konstanter Funktion ist auch für das Verständnis der Ökonomie in der lebenden Natur und der physiologischen Ähnlichkeit der Organismen trotz aller Formverwandlungen wichtig. Denn es kann vermöge desselben ein in der allgemeinen Konkurrenz funktionslos gewordenes Organ für eine andere Funktion frei werden, also Funktionswechsel stattfinden, wie beim Batrachier der auf dem Lande unnütze Ruderschwanz der Larve dadurch, daß er resorbiert wird, Ernährung und Wachstum fördert. Schließlich ist jede erbliche Funktion ein Beweis für das Princip. Denn die die Eltern überlebenden den Eltern ähnlichen aber nicht gleichen jungen Organismen haben dieselben Funktionen wie diese, nur ist das Substrat ein anderes, und im Laufe vieler Generationen kann es sich wesentlich verändern ohne wesentliche Änderung der Funktion.

\section{Funktionswechsel.}

Wenn unter den normalen, stets einem dynamischen Gleichgewichtzustande vergleichbaren Lebensverhältnissen 
eine wesentliche Ïnderung der äußeren Lebensbedingungen eintritt, welche nichts anderes sind, als die äußeren Bedingungen der gerade gleichzeitig sich abspielenden Funktionen, so kann eine oder mehr als eine davon teils ohne sofortige wesentliche Änderung des fungierenden Substrates teils mit solcher gehemmt oder gesteigert oder in ihrem bisherigen Ablauf gestört werden, sogar ganz in Wegfall kommen und durch eine andere Funktion ersetzt werden. Diese wichtige physiologische Veränderung heißt Funktionswechsel. Sie kommt sowohl normalerweise während der freien Entwicklung der Pflanzen und Tiere, namentlich bei den Wanderungen derselben von Gebieten mit ungïnstigen Lebensbedingungen in solche mit günstigeren, als auch bei krankhaften Zuständen, also bereits gestörten Funktionen oft vor. Wenn zum Beispiel die kurzen Haftwurzeln des Epheus in feuchte Erde gelangen, so verzweigen sie sich und werden Nahrungswurzeln; ähnlich die Luftwurzeln mancher Orchideen, welche sogar; wenn sie im Licht in feuchter Luft verharren chlorophyllhaltig werden und dann die atmosphärische Kohlensäure zerlegen können, was nicht Wurzelfunktion ist.

Unter den Tieren liefern namentlich die Krustaceen auffallende Beispiele. Pagurus-Arten atmen mit Kiemen im Meere und mit denselben Kiemen in der Luft auf dem trockenen Lande. Hier ist also ein und dasselbe Organ bald als Kieme, bald als Lunge thätig. Die hydrostatische Funktion der Schwimmblase vieler Fische tritt bei einigen zurück gegen die respiratorische, wie denn morphologisch die Lunge ihr homolog ist.

Die Funktionen niederer Tiere, welche noch nicht lokalisiert sind, können in manchen Fällen durch vorübergehende Bildungen unvollkommen lokalisiert werden. Mit dem Auftreten der Funktion, z. B. der Geschlechtsthätigkeit, wird dann erst eine morphologische Differenzierung 
wahrnehmbar, die nach dem Ablauf der Funktion nicht mehr kenntlich ist, indem die frühere Indifferenz wieder erscheint. In diesem Falle ist also die Arbeitsteilung nicht permanent. Sie ist unvollständig, der Funktionswechsel nur ein Vorläufer definitiver Lokalisation.

Solche Fälle sind besonders merkwürdig, weil sie den Konflikt zwischen Variabilität und Vererbungsvermögen anschaulich machen. Die nur zu der einen Funktion (der Fortpflanzung) und nur temporär nötigen Organe verschwinden und vererben sich noch nicht.

\section{Symptomatologie der Funktionen.}

Nach Ausscheidung aller für das Zustandekommen der einzelnen Funktion nicht erforderlichen Teile ist die Feststellung und Beschreibung des ganzen sie bildenden Erscheinungskomplexes wesentlich erleichtert, oft erst ermöglicht. Es handelt sich dabei vor allem um Vollständigkeit und Vermeidung des Überflüssigen. Vollständig ist nur die Funktion nach beendigter Entwicklung des fungierenden Substrates. Und hier muß wieder unterschieden werden die normale Ausbildung einer Funktion, wie sie bei ungetrübter Gesundheit, z. T. erst nach Vollendung des Massenwachstumes erreicht wird und die abnorme, wie sie nur unter besonders günstigen, $d . h$. gerade die eine Funktion fördernden Umständen (Übung, Dressur, Fortfall anderer Funktionen) im Gegensatz zu der unter ungünstigen Umständen beobachtet wird (Verkümmerung als unvollständige Entwicklung und Krankheit).

In allen Fällen ist die Hauptaufgabe die Ermittlung derjenigen Veränderungen des Substrates und Objektes, welche für die rolle Entfaltung der Funktion notwendig und charakteristisch sind. Hierbei kommt aber die Rück- 
wirkung exceptioneller Steigerung und Abnahme einer Funktion selbst auf das Substrat wesentlich in Betracht.

An jeder physiologischen Funktion ist mehreres quantitativ bestimmbar, meßbar, wägbar, zählbar; für jede gibt es unveränderliche und veränderliche Faktoren. Beide mïssen nach Möglichkeit quantitativ bestimmt werden, und in der Ausführung dieser Bestimmungen besteht eine Hauptthätigkeit der neuesten Physiologie, welche von vornherein jede Funktion als eine Terwicklung chemischer und physikalischer Prozesse betrachtet und demgemäß, soweit wie möglich, quantitativ chemisch und physikalisch behandelt.

\section{Verlauf der Funktionen.}

Gleichwie das Leben jedes Individuums hat jede Funktion einen Anfang und ein Ende. Das Teilleben, welches jede Funktion für sich betrachtet darstellt, hat auch, wie das individuelle Gesamtleben, ein erstes zunehmendes oder progressives und ein zweites abnehmendes oder regressives Stadium, welche durch ein oft nur momentanes, oft aber lange währendes Stadium angenäherter Konstanz miteinander zeitlich verbunden sind.

Diese Thatsachen gelten allgemein für die Zellenfunktionen, wie für die Funktionen der Gewebe, der Organe, Organismen, Familien, Staaten, so daß also die Lebensdauer eines Individuums höherer Ordnung die einzelner Teile in ihm - der Individuen niederer Ordnung - weit übertrifft, da deren Funktionen z. T. früh erlöschen, z. T. spät auftreten. Fin und derselbe Baum überdanert das Leben seiner Blüten leicht um das Hundertfache und ein Blutkörperchen, eine Iymphoidzelle haben eine viel kürzere Lebensdaner als der Nensch oder das Tier, dem sie zu- 
gehören. Aber auch bei gleicher Lebensdauer der Organe und der Individuen, denen sie zugehören, ist der Verlauf der Funktionen ganz ungleich.

Die Entwicklung des Einzelwesens bringt es nämlich mit sich, daß die Funktionen in ungleichen Zeitabschnitten auftreten. Eine physiologische Aufgabe von hoher theoretischer Bedeutung besteht darin, die Reihenfolge zu finden, in welcher die Funktionen während der individuellen Entwicklung erscheinen. Mit dieser Aufgabe beschäftigt sich auch die experimentelle Embryologie. Die Ausbildung der einzelnen Funktion vom Anfang an bis zu ihrer völligen Erscheinung erfordert aber eine besondere Rücksichtnahme auf die Jugendstadien der fungierenden Apparate und Kongregate und die Beschaffenheit ihrer Objekte auch lange nach dem Ablauf der embryonalen Zeit.

Ähnlich wie in der Zeit der Entwicklung in der Jugend die einzelnen Funktionen ungleichzeitig auftreten und sich entfalten, treten sie auch in der Zeit der Rückbildung im Alter ungleichzeitig zurück und schwinden nicht zugleich. Für das Sterben ist ein beschleunigter Rückgang charakteristisch.

Hierbei ist vor allem die Abhängigkeit des Rückganges von den materiellen Änderungen des Substrates und Objektes und umgekehrt der Einfluß des Ausfalles einer Funktion auf den Verlauf der übrigen zu erforschen.

Den Hauptgegenstand der modernen Physiologie bildet jedoch die Funktion bei völliger Entwicklung, ehe die Rückbildung begonnen hat.

\section{Unterbrechung und Wiederherstellung der Funktionen.}

Viele physiologische Funktionen sind periodisch oder rhythmisch, d. h. sie intermittieren in meist regelmäßigen 
Intervallen, viele andere erscheinen und verschwinden in ungleichen Pausen. Wenn alle unterbrochen sind, so ist der Lebensprozeß total unterbrochen. Die Experimentierkunst kann es nun dahin bringen, daß einzelne Funktionen nach Belieben unterbrochen und nach einiger Zeit wiederhergestellt werden, wie auch die Gesamtheit aller Funktionen zeitweise so unterbrochen werden kann, daß man nach der Wiederbelebung (Anabiose) keine Folge des temporären Stillstandes mehr wahrnimmt. Es gelingen derartige Versuche mit einzelnen Funktionen besonders leicht durch Anwendung der Kälte, der Trockenheit, der Sauerstoff- und Nahrungs-Entziehung. Sie sind vom höchsten theoretischen und praktischen Interesse.

\section{Die künstliche Nachahmung der Funktionen.}

Obgleich es principiell unmöglich ist, irgend einen lebenden Körper aus einzelnen anorganischen - für sich leblosen lebensunfähigen - Stücken ohne Vermittlung lebensfähiger oder lebender Körper zusammenzusetzen, so können doch einzelne Funktionen auf künstlichem Wege nachgeahmt werden. Zum Teil sind durch Automaten, z. T. durch andere Maschinen mancherlei Verrichtungen höherer Organismen in der That nachgeahmt worden. Aber in allen derartigen Fällen handelt es sich immer nur um eine Imitation, nie eine Reproduktion. Die Mittel, welche angewendet werden, sind in jedem Falle andere, als die im lebenden Körper angewendeten. Selbst die künstlichen Synthesen der chemischen Verbindungen, welche im lebenden Körper vorkommen, werden auf anderem WTege, als in diesem bewerkstelligt, jedoch ist hier noch am ehesten eine wahre Wiederholung des Naturvorganges zu erwarten. 
196 Die Vergleichung der Funktionen verschiedener Individuen.

\section{Die Vergleichung der Funktionen verschiedener Individuen.}

Bei der Vergleichung der Funktionen kommt es darauf an, streng zu präcisieren und festzuhalten was man rergleichen will. Es soll im Gegensatz zur vergleichenden Anatomie nicht was sich in übereinstimmender Weise entwickelt, das Homologe, verglichen werden, sondern diejenigen Teile sollen ermittelt werden, welche in übereinstimmender Weise fungieren: die is odynamen Teile, welche funktionell äquivalent sind, mögen sie auch noch so verschieden geformt und entwickelt sein.

Also sind bei jeder Vergleichung zweier Funktionen und ihrer Substrate vier Fälle zu unterscheiden, es sind nämlich: die Funktionen die fungierenden Substrate

1. gleich

2. gleich

3. ungleich homolog

4. ungleich nicht homolog homolog nicht homolog.

Dabei ist außer der Rücksichtnahme auf die morphotische Zusammensetzung auch die Vergleichung der chemischen Zusammensetzung der morphologisch gesonderten Teile vorzunehmen (vergleichende Histochemie), qualitatir und quantitativ.

Es wird dann die Aussicht eröffnet aus den durch die vergleichende Physiologie ermittelten Übereinstimmungen der Funktionen Rückschlüsse zu machen auf die Geschichte der Funktionen, indem aus einer möglichst vollständigen Zusammenstellung der typischen Erscheinungsweisen jeder Funktion, von der einfachsten bis zur verwickeltsten, Rückschlüsse auf die Funktionen der nicht mehr existierenden Vorfahren der jetzt lebenden Körper gemacht werden können. 
Wie nämlich während der individuellen Entwicklung das Auftreten und die Ausbildung der einzelnen Funktionen an bestimmte Epochen geknüpft erscheinen, so kann man anch phyletisch den Stammbaum eines lebenden Apparates und Kongregates mit Rücksicht auf seine Funktionen betrachten und festzustellen suchen, in welchen Generationen zum erstenmal diese und jene Funktion auftrat im $\mathrm{Zu}$ sammenhang mit der morphologisch-chemischen Frage, wie sich ihr Substrat und Objekt änderte, bevor es das der gegenwärtigen fungierenden Wesen geworden. Die artikulierte Sprache z. B. fehlte unzweifelhaft den Vorfahren des Menschen; es fragt sich, in welchem Stadium die Vorstufen der Verständigung durch Sprachlaute zuerst nachgewiesen werden können. Sogar in historischer Zeit scheint in einzelnen Fällen diese Betrachtung der Funktionen Resultate zu versprechen. Denn z. B. das Hören ist nachweislich bezüglich der Bevorzugung einiger musikalischer Intervalle als Konsonanzen gegenwärtig ein anderes, als vor mehreren Jahrhunderten. Doch ist diese sogenannte Palaeophysiologie erst im Werden und setzt eine vergleichende Physiologie voraus.

Um nun unabhängig von den wechseInden Benennungen der vergleichenden Anatomie und Entwicklungslehre rein physiologisch, d. h. nur mit Rücksicht auf die Funktionen, die organischen Apparate behufs funktioneller Vergleichung zu bezeichnen sind besondere Namen notwendig:

Polydynam heißen diejenigen organischen Apparate, welche gleichzeitig mehrere Funktionen haben, z. B. der Gastrovascularapparat der Coelenteraten,

Monodynam diejenigen, welche nur eine einzige Funktion haben, z. B. das Auge,

Isotyp heißen die (identischen) Funktionen homotyper organischer Apparate, z. B. das Hören links und rechts beim Menschen, 
198 Die Vergleichung der Funktionen verschiedener Individuen.

Polytop die Funktionen, welche mehrere gleichartige Substrate bei einem und demselben Individuum besitzen, z. B. das Tasten des Menschen.

Coenomere Funktionen sind solche, welche keinen ihnen ausschließlich zukommenden organischen Apparat haben,

Idiomere Funktionen haben einen solchen.

Demnach ist jede Funktion eines polydynamen Apparates coenomer, die eines monodynamen idiomer und die Hauptaufgabe der vergleichenden Physiologie besteht darin, die idiomeren Funktionen von den coenomeren durch Auffindung von Übergängen abzuleiten, so daß die Extreme, z. B. die Körnchenströmungen im Protoplasma einerseits, die Blut- und Iymph-Strömung im Menschen andererseits durch eine lückenlose Reihe von Mittelstufen verbunden werden, welche alle Arten der Saftströmung in Tieren ohne Rücksicht auf ihre zoologische Stellung umfaßt. Und so für jede Funktion. Was von der ersten Lokalisierung jeder Funktion gilt, gilt ebenso von dem weiteren Lokalisieren derselben in den sie vermittelnden Organen: die Teilung der Arbeit. Bei niederen Tieren hat die einzelne Funktion ein einfaches Organ, bei höheren ein kompliziertes, ein differenziertes, indem ein Teil desselben den einen Teil der Funktion, ein anderer den anderen vermittelt. Durch diese Teilung der Funktion und ihres Substrates wird eine einseitige Ausbildung der Organteile bedingt und die Funktion selbst kompliziert, daher alle idiomeren Funktionen sehr verwickelt sind, während die Coenomerie an relativ einfache Bedingungen gebunden erscheint. Von ihr also muß die physiologische Vergleichung ausgehen. Jede Funktion des Menschen, sei sie auch noch so rerwickelt, hat ihre durch Vergleichung auffindbare eine Wurzel im Protoplasma, während die andere in den äußeren Einwir- 
kungen, den Beziehungen der lebenden Gebilde zu einander und zur Umgebung, zu suchen ist.

Nur die gründlichste Vergleichung der Funktionen ermöglicht es, die durch Vererbung bedingte Konstanz der allem Lebendigen zukommenden Grundfunktionen in der (durch Beeinflussung von außen vermöge der organischen Veränderlichkeit zustande gekommenen) kaum übersehbaren Mannigfaltigkeit der abgeleiteten Funktionen wiederzuerkennen und dadurch den Zusammenhang aller lebenden Wesen zu verstehen.

\section{Antagonismus und Korrelation der Fanktionen.}

Während der Ausbildung der lebenden Körper, wie nach derselben, müssen einige Funktionen mit anderen interferieren, mit wieder anderen aber harmonieren, so daß in ersterem Falle ein Konflikt oder Antagonismus, im letzteren eine Korrelation zustande kommt. Im völlig entwickelten Zustande ist scheinbar Ebenmaß vorhanden, welches durch eine Art Kompromiß entsteht. In Wahrheit aber dauert der Antagonismus als eine Form der Interferenz der Funktionen ununterbrochen fort und die eine oder die andere Funktion erhält abwechselnd auf kurze. Zeit das Übergewicht.

Antagonismus der Funktionen ist übrigens ein doppelsinniger Ausdruck. Er bedeutet einerseits einen Konfliktzustand, wie er etwa zwischen Ausatmen und Schlucken beim Menschen besteht, andererseits eine Korrelation wie etwa zwischen Beugung und Streckung. Auch letztere wird wegen des entgegengesetzten Charakters Antagonismus genannt. In beiden Fällen schließt die eine Funktion die antagonistische an demselben Substrat zur selben Zeit aus. 


\section{Funktionsstörungen.}

Nur dadurch, daß die physiologischen Funktionen miteinander interferieren, die eine die andere nicht allein oder überwiegend ohne Unterbrechung bestehen läßt, ist die Erhaltung des Lebens möglich. Diese normale Störung der Funktionen durcheinander wird durch eigentïmliche erst in den wenigsten Fällen genauer bekannte regulatorische und kompensatorische Einrichtungen der Organismen innerhalb gewisser Grenzen gehalten, welche die Gesundheit charakterisieren. Die Leistungsfähigkeit dieser Regulatoren - bei höheren Tieren vorzugsweise Nerven ist eine erstaunliche, wie man schon daran erkennt, daß gesunde Menschen unter den allerverschiedensten Verhältnissen auf dem Neere, auf dem Lande, in den Tropen, in den arktischen Zonen, auf Bergen, in Thälern leben, mit rein tierischer und rein pflanzlicher Nahrung sich ernähren, sich viel bewegen, wenig bewegen und bei der mannigfaltigsten Berufsthätigkeit gesund bleiben.

Es kommt aber bei Pflanzen, Tieren und Menschen oft vor, daß durch den Wechsel äußerer Bedingungen ihrer Existenz, zumal wenn er plötzlich stattfindet, durch unerwartete Eingriffe, Verletzungen, Vergiftungen und allerlei ungewohnte Eindrücke eine oder mehr als eine Funktion teils direkt, teils indirekt durch Überwiegen anderer Funktionen erheblich gestört wird und nun jene bis dahin bewährte Regulation nicht mehr ausreicht. Dann ist die Gesundheit gestört und, wenn die Wiederherstellung derselben, die Ausgleichung der schädlichen Wirkungen nicht bald eintritt, der lebende Körper krank. Jede Krankheit beruht auf irgend welcher Störung irgend einer physiologischen Funktion, und zwar ist eine solche Störung in weitaus den meisten Fällen durch äußere Einflüsse ver- 
ursacht, in relativ seltenen Fällen angeboren oder in der Anlage ererbt. Aber auch in diesen Fällen, bei sämtlichen erblichen Krankheiten, ist die letzte Ursache auf irgend eine äußere Schädlichkeit zurückzuführen, die schon im Ei, oder schon bei den Vorfahren, zustande kam. So bei erblichen Gehirnkrankheiten, bei Geschwiilsten. Worin freilich die erste Störungsursache oder Anomalie vor dem Auftreten jener krankhaften Erscheinungen in dem letzten noch gesunden Individuum der daron betroffenen Generation bestehen mag, ist nicht in allen Fällen ermittelt.

Alle derartigen nicht sogleich durch die physiologische Regulation zu beseitigenden und darum krankhaften Funktionsstörungen gehören nun nicht mehr in die Physiologie, sondern sie bilden den Gegenstand der Pathologie. Sie sind aber deshalb für die Physiologie höchst wertvoll, weil aus der pathologisch veränderten Funktion Schlüsse auf das normale Zustandekommen derselben gemacht werden und weil die Krankheit sehr oft eine unausführbare Vivisektion ersetzt. Das schlagendste Beispiel dafür liefern die Sprachstörungen, ohne welche man ron dem nervösen Substrat der normalen Funktion des Sprechens wenig wissen wïirde.

\section{Nameng'ebung und Geschichte der Erforschung der Fnnktionen.}

Ein wenig sorgfältig bearbeitetes Gebiet ist die Geschichte der Erkenntnis der einzelnen physiologischen Funktionen. Schon aus einer Kritik der vorhandenen Bezeichnungen, mehr noch der alten und neuen Darstellungen und Erklärungen derselben ergeben sich viele lehrreiche Irrtümer. Besonders wird deutlich, wie schwer es ist, die 
reine Thatsache von allen Zuthaten eigener Meinungen des Beobachters, Experimentators, Darstellers frei zu halten. Verhältnismäßig am leichtesten ließen sich die äußeren Funktionsbedingungen ermitteln. Die Feststellung der zu einer bestimmten Funktion notwendigen organischen Teile und Objekte bot schon größere Schwierigkeiten, noch größere der Mechanismus und Chemismus jeder Funktion und der ihr notwendig zukommende Reiz. Das Terhältnis der einzelnen Funktionen zu einander in demselben Individuum, sowie ihre Ausbildung und Rückbildung im physiologischen Sinne hat noch keine Geschichte.

Die Geschichte der Lehre von den Funktionsstörungen fällt im wesentlichen zusammen mit der Geschichte der Pathologie.

Es ist aber in hohem Grade wünschenswert, in der Pathologie keine anderen Bezeichnungen für die physiologischen Funktionen zu wählen, als in der Physiologie. Eine nach streng wissenschaftlichen Grundsätzen durchgeführte T'erminologie erleichtert das Studium außerordentlich; und wie die naturhistorische Nomenklatur der Zoologie und Botanik allein durch ihre Konsequenz sich schnell einen dauernden Beifall erwarb, so wird auch nur eine physiologische Nomenklatur, welche konsequent eine abgeleitete Funktion von einer ursprünglichen trennt und nicht in die künstlichen Einteilungen des Galenismus und die willkürlichen Benennungen der früheren Anatomie zurückverfällt, Aussichten auf Bestand haben. Zuvor muß aber die Einteilung der ursprünglichen Funktionen festgestellt werden. 


\section{Einteilung der physiologischen Funktionen.}

\section{Die Ermittlung aller, sämtlichen lebenden Wesen ge- meinsamen Funktionen.}

Die Unterscheidung derjenigen Veränderungen, welche die Organismen zeigen, sofern sie nur Naturkörper sind, von denen, welche ihnen als lebenden Körpern zukommen, ist im einzelnen Falle oft sehr schwierig. Da aber die allen lebendigen Körpern ohne Ausnahme eigenen Grundfunktionen auch dem am wenigsten komplizierten lebendigen Körper zukommen müssen, dem Protoplasma (welches jedoch selbst immer noch von einer unbegreiflichen Kompliziertheit ist), so wird zur Ermittlung der allen lebenden Körpern zukommenden physiologischen Grundfunktionen zunächst nur die Feststellung aller physiologischen Funktionen des Protoplasma erforderlich sein. Alle lebenden Kïrper enthalten nicht nur Protoplasma, sondern alle lassen sich auch von ihm ableiten. Ist doch selbst der höchst entwickelte Organismus im Anfange seines Daseins ein protoplasmatisches Gebilde, ein amöboides Ei.

Im folgenden sind nun die sämtlichen bekannten Lebenserscheinungen des Protoplasma so dargestellt, daß die Darstellung zugleich für jedes beliebige tierische oder pflanzliche selbständig lebende Gebilde gilt, indem nur 
Grundfunktionen in Betracht genommen sind. Physiologische Grundfunktionen sind aber solche Lebensvorgänge, welche nicht mehr voneinander abgeleitet werden können. In Zukunft wird eine solche Ableitung unzweifelhaft möglich sein, zur Zeit ist ein Beweis für die Notwendigkeit sämtlicher Grundfunktionen ebensowenig zu geben, wie ihr genetischer Zusammenhang zu erkennen.

\section{Die Grundfunktionen.}

Zuvörderst strömt im Inneren des Körpers einetrop fbare Flüssigkeit oder Emulsion. Der allgemeinste Ausdruck für dieses Fluidum, mögen darin Tropfen anderer Flüssigkeiten oder feste Körper aufgeschwemmt sein oder nicht, ist Saft. Der erste funktionelle Vorgang ist eine Saftströmung.

Die in dem zirkulierenden Safte aufgelösten (und die von den in ihm suspendierten Körperchen verdichteten, locker gebundenen oder gleichfalls aufgelösten) Gase, sowie die in dem Safte aufgelösten tropfbarflüssigen und festen Stoffe, auch die darin aufgeschwemmten Körper selbst, stehen durch Kapillarattraktion und Druckdifferenzen, namentlich durch Diosmose und Filtration, mit den Gasen, Flïssigkeiten und aufgelösten festen Stoffen der Umgebung des strömenden Saftes in Beziehung. Es findet dabei statt: Einerseits ein Eintritt aus dem den Körper umgebenden Medium in diesen und zwar unmittelbar und mittelbar, d. h. direkt in den strömenden Saft oder vorher in die ihn umgebenden Teile des Körpers. Der Vorgang ist allgemein zusammengesetzt aus Gasabsorption, Endosmose und Filtration tropfbarer Lösungen und Verschiebung fester Stoffe von außen nach innen, sofern diese fein verteilt sind; 
sind sie nicht fein rerteilt, so dringen sie entweder nicht in den Körper oder, wenn auch in diesen, dann doch nicht in den strömenden Saft ein. Andererseits findet statt: erstens eine Fortbewegung aus dem strömenden Safte, wo er mit dem den Körper umgebenden Medium in Kontakt kommt in dieses, sonst zuvor in die den strömenden Saft umschließenden Körperteile und zweitens eine direkte Ausstoßung von zwar in den Körper, nicht aber in den strömenden Saft aufgenommenen Stoffen. Dieser Torgang ist zusammengesetzt allgemein aus Gasentwicklung, Exosmose und Filtration tropfbarer Flüssigkeiten, und Verschiebung fester Stoffe von innen nach außen. Bei dem zweiten den Lebensmaschinen zukommenden Bewegungskomplex dringen also Gase, Lösungen und feste Stoffe aus der Umgebung in den Körper ein, und eben dergleichen werden aus ihm in die Umgebung ausgestoßen. Die hierunter subsumierten zwar verwickelten aber rein mechanischen Erscheinungen werden zusammen der Kürze wegen Stoffwanderung genannt. Sie umfassen den Mechan ism us des Gaswechsels oder der Atmung, der Ernährung, der Abscheidungen (Ábsonderungen und Ausscheidungen).

Ist die Saftströmung und die Stoffwanderung im Gange, so treten die in die strömenden Säfte gelangenden Stoffe mit den darin bereits vorhandenen in Wechselwirkung und die aus dem Safte in die Körperteile gelangenden Stoffe wirken auf die Bestandteile dieser chemisch ein. Desgleichen werden durch die unmittelbar in die Körperteile aufgenommenen Stoffe, auch wenn sie nicht in den strömenden Saft gelangen, Veränderungen der sie einschließenden Teile bedingt, und die letzteren können wiederum auf diese aufgenommenen Stoffe chemisch verändernd wirken. Die bei diesen Wechselwirkungen stattfindenden Prozesse sind die des Chemismus der Atmung, der Ernährung und Absonderung. Mit der Stoffwanderung geht 
demnach einher ein Stoffwandel, eine Veränderung in der Zusammensetzung fast aller Teile des Körpers durch chemische Prozesse und zwar unter Wärmebildung durch Oxydation und mit häufig nachweisbarer Elektricitätsentwicklung, indem die genannten, mit der Stoffwanderung unzertrennlich verknüpften Vorgänge zum Teil nicht ohne daß die von ihnen betroffenen Teile sich erwärmen und wenigstens zeitweise elektromotorisch wirksam werden, stattfinden können.

Die sämtlichen bis hierher betrachteten Prozesse können ohne eine Änderung der Gestalt der lebenden Gebilde vor sich gehen, da im Falle die eindringenden Stoffe sämtlich gelöst in gleichmäßigem Strome ankommen und die imbibierende Oberfläche frei ist (wie bei vielen Eiern im Wasser), keiner notwendig eine Zusammenziehung oder Ausdehnung herbeiführt. Aber kein lebender Körper befindet sich in einer solchen Lage, daß er, selbst wenn die genannten Prozesse keine Kontraktionen und Expansionen benötigten, dauernd in Ruhe bleiben könnte. Vielmehr finden durch äußere, unmittelbar die Oberfläche treffende Einflüsse Veränderungen der Oberfläche statt, sei es unmittelbar, sei es mittelbar, welche Massenbewegungen der Körperteile bedingen. Diese Gestaltänderungen hervorrufenden Reize sind hauptsächlich Druckschwankungen und Strömungen des die Körperoberfläche umgebenden Mediums, Luft oder Wasser und Stöße fremder fester Körper, sodann Temperaturschwankungen der Umgebung, endlich chemische Vorgänge, wozu Verdrängtwerden eines Körpers durch einen von ihm chemisch verschiedenen durch Gas - und Flüssigkeits-Ströme gehört, sofern dieser Platzwechsel die Berührung der Oberfläche des Körpers von Seiten chemisch differenter Stoffe ermöglicht. Die Wirkung des Lichtes reiht sich den genannten an, ohne jedoch von eben solcher Allgemeinheit des Vorkommens zu sein, da es nicht wenige lebende Körper gibt, 
welche ihm nicht ausgesetzt sind. Dasselbe gilt für manche elektrische und wahrscheinlich auch magnetische Einwirkungen. Der Wirkung der Schwere hingegen sind alle unterworfen, sofern sie bei allen imnere Verschiebungen teils mit, teils ohne Gestaltänderungen herbeiführt.

Alle diejenigen äußeren Einflïsse, welche Reize sind, haben die gemeinsame Eigenschaft, daß sie nur dann eine Massenbewegung einzelner Teile des Körpers bewirken, wenn ihre Stärke (Größe, Intensität) einen gewissen unter allen Umständen endlichen Wert überschreitet, nämlich den Schwellenwert, und daß die durch sie ausgelösten Gestaltänderungen nur durch Kontraktionen zustande kommen. Die Kontraktion ist eine Lebenserscheinung nicht mehr und nicht weniger, als die Saftströmung, Atmung, Ernährung, Absonderung, Wärmebildung und Elektricitätsentwicklung. Sie ist, wie diese Erscheinungen, ein Lebensprozeß oder eine Funktion, welche durch Reize zustande kommt. Sie bildet den letzten von drei zusammengehörigen Einzelvorgängen: 1) der primären Zustandsänderung, Reizung; 2) der sekundären Zustandsänderung in dem Körper, Erregung, welche an sich die Lage und Gestalt des Körpers nicht ändert; 3) der gestaltändernden Massenbewegung, welche stets auf einer Kontraktion beruht, und welche man die Antwort auf den Reiz nennt. Sie ist die Folge der Erregung.

Die Reize bewirken außer den erwähnten Kontraktionen noch eine Veränderung, nämlich Empfindùng. Das Zustandekommen der Empfindung ist nicht weniger an Erregung gebunden wie das der Bewegung. Sie ist einerseits Folge einer Erregung, andererseits Bewregung veranlassend. Sie ist, wie die Kontraktion, ein Zustand, welcher um so mehr von dem Zustande, der dem Nullpunkte entspricht, abweicht, je weiter bis zn einer gewissen, durch die Beschaffenheit des empfindenden Gebildes bedingten Grenze der zugehörige Reiz von dem Schwellenreiz entfernt ist. Das Zustande- 
kommen der Empfindung bildet eine besondere Lebensfunktion.

Bei den bisher betrachteten Lebensvorgängen handelt es sich um Stoffwechsel und Kraftwechsel, denen der Empfindungswechsel sich anreiht; bei den folgenden ist die Form-Umbildung und -Neubildung das Wesentliche.

Jeder lebende Körper ist aus einem anderen durch Abspaltung hervorgegangen, sei es unmittelbar durch Selbstteilung, sei es durch Teilung nach vorheriger Berührung: mit einem anderen Körper. Inmer kommt die Erzeugung eines lebenden Körpers durch eine Teilung oder Abspaltung von einem anderen lebenden Körper zustande, keineswegs aber ist jeder lebende Körper imstande, einen anderen zu erzeugen. Das wesentliche Allgemeine dieses Prozesses besteht vielmehr in dem Akte des Abgespaltenwerdens. Dieses hat jeder lebende Körper olme Ausnahme an sich erlebt. Es ist der Prozeß der Erzengung. Gezengt ist noch nicht entwickelt. Aber erzeugt ist gezeugt und entwickelt oder im Entwickeln begriffen.

Unmittelbar nach der Erzeugung beginnt nämlich bei allen lebenden Wesen die Funktion des Wachstumes, eine Zunahme des Volumens und des Gewichtes, welche bis zu einem gewissen Zeitpunkt fortgesetzt wird und dadurch ermöglicht ist, daß aus der Umgebung mehr Stoffe in den Körper eintreten, als aus ihm in die Umgebung austreten. Es findet ein Stoffansatz statt, eine Aufspeicherung von aufgenommenem (verdautem und assimiliertem) Material.

Als eine besondere Funktion unterscheidet sich $11 \mathrm{~m}$ die Entwicklung vom Wachstum schlechthin. Beim letzteren nimmt durch Zunahme der Größe und Anzahl gleichartiger Formelemente ein Ganzes zu; wenn aber aus gleichartigen Formelementen ungleichartige Formen während 
der Zunahme der Zahl jener werden, wie es bei jedem lebenden Körper zu irgend einer Zeit seines Lebens der Fall ist, dann wächst er nicht nur, sondern er entwickelt sich zugleich, indem er sich differenziert.

Und wiederum eine besondere Funktion, welche von dem einfachen Wachsen und der Differenzierung in der Entwicklung verschieden ist, bildet die Vererbung der Eigenschaften eines lebenden Wesens auf die von ihm abgespaltenen lebenden Wesen, ohne daß es sie selbst dadurch verliert. Dieser Prozeß setzt den Übergang von Teilen der Erzeuger in die jungen sich entwickelnden Wesen voraus, welche Teile in der gewohnten Anordnung verharren und neues Wachstumsmaterial durch chemische Anziehung erhalten.

Hiermit sind die bis jetzt bekannten allgemeinen Grundfunktionen, welche jedem lebenden Wesen zukommen, erschöpft. Alle im Vorhergehenden nicht ausdrücklich namhaft gemachten Lebensvorgänge kommen nicht allen, sondern nur einem Teile der lebenden Körper $\mathrm{zu}$, fallen aber entweder unter einen der genannten Begriffe als deren Konsequenzen, oder sie lassen sich auffassen als die notwendige Folge des Ineinandergreifens und Zusammenstattfindens der genannten Lebensprozesse, sind in jedem Falle aus ihnen mittels des Darwinismus principiell geradeso ableitbar, wie die verwickelten Formen aus einfacheren Formen.

Zur Kennzeichnung des Lebens ist in der That die Gesamtheit der aufgezählten Vorgänge ausreichend aber auch notwendig sofern überall da, wo sie zusammen stattfinden unzweifelhaft Lebendiges existiert, wo nur ein er fehlt, kein Leben möglich ist, es sei denn, daß man dem Pflanzenprotoplasma im Gegensatze zu dem Zooplasma das Empfindungsvermögen absprechen will. 


\section{Selbsterhaltumg und Arterhaltung.}

Die Selbsterhaltung und Arterhaltung, welche mitunter als weltbeherrschende Principien aufgestellt worden sind, können nicht als physiologische Funktionen bezeichnet werden. Beide sind auf anthropomorphosierenden Naturauffassungen beruhende, in die objektive Welt verlegte Zweckthätigkeiten, welche den lebenden Wesen ebenso fremd bleiben wie den Maschinen. Gerade wie diese fungieren die Pflanzen und Tiere, weil sie nicht anders können, und sie können nicht anders, weil die äußeren und inneren Lebensbedingungen keine anderen sind. Sowie man die Funktionen nur für Vorgänge hält, welche stattfinden, damit das betreffende Individuum sich und seine Nachkommen durch dieselben erhält, verfährt man teleologisch und setzt an die Stelle der Frage nach der Ursache (warum?), die nach dem Zwecke des Lebens (wozu?). Diese gehört aber nicht in die Physiologie.

Sowohl der Begriff des Selbst, d. h. des einheitlichen Ich, als auch der der Art sind nirgends verwirklicht, sondern Abstraktionen. Jede einzelne Funktion kann als Selbstzweck, als Bethätigung eines besonderen Ich höherer oder niederer Ordnung, jede Art als veränderlich, somit als solche garnicht erhaltbar angesehen werden, wodurch jene den exakten Boden der reinen Physiologie verlassenden Anschauungen vollends hinfällig werden. Nicht das Selbst, nicht die Art wird durch die Funktionen erhalten, sondern das Leben. Das Protoplasma hat kein Selbst und bildet keine Arten oder Species im Sinne der naturhistorischen Systematik, ist nicht einmal individualisiert und lebt doch. 


\section{A npassung.}

Außer der Selbsterhaltung und Arterhaltung ist auch die Anpassung oder Adaptation lebender Gebilde an wechselnde äußere Verhältnisse als eine physiologische Grundfunktion mit Unrecht bezeichnet worden. Sie ist eine Folgeerscheinung, und sie läßt sich in keiner Weise als ein Fungieren, wie die übrigen aufgezählten Lebensprozesse bezeichnen. Denn wenn ein organisches Individuum beliebiger Ordnung sich an andere Individuen oder anorganische Umgebungen, die ihm vorher ganz oder zum Teil fremd waren, anpaßt, so erleidet es Veränderungen vermöge der allem Lebendigen immanenten Variabilität und zwar morphologische, chemische und funktionelle Veränderungen, welche ebenfalls partiell oder total sein können. Aber diese Veränderungen sind ebensowenig selbst als physiologische Funktionen der lebenden Wesen aufzufassen, wie etwa die Gestaltung des Modellierthones zu einer menschlichen Figur oder zu einer Kugel durch Menschenhand eine Funktion des Thones ist. Wenn sich Protoplasma zu einem Embryo differenziert oder auf Reize zur Kugel zusammenballt, so liegt darin ein eminent physiologischer ProzeB, eine Funktion, sowie aber durch Änderung der ihnen notwendigen äußeren Bedingungen das Wachstum und die Kugelbildung etwa verzögert oder beschleunigt werden, liegt darin nicht eine neue Funktion der Anpassung, sondern die vorhandenen Funktionen erfahren nur Änderungen wegen Änderungen der Substrate derselben. Ähnlich wie künstliche Maschinen mit regulatorischen Vorrichtungen unter wechselnden Temperatur - und Druck-Graden weiter arbeiten können, indem sie sich denselben anpassen, können lebende Körper nur viel vollkommener - vermöge ihrer regulatorischen Funktionszusammenhänge unter veränderten Umständen 
innerhalb gewisser Grenzen, indem sie sich verändern, weiter leben. Das Wort "Anpassung" bezeichnet diese Thatsache und hat wegen der Erblichkeit vieler durch Anpassung erworbener Änderungen, welche dadurch bleibende Eigenschaften werden können, namentlich eine außerordentliche morphologische Bedeutung.

Physiologisch bezieht sich aber der Ausdruck „Anpassung" nur auf die Funktions bedingungen. Jede Funktion kann durch Anpassung erhebliche Änderungen erfahren, durch Reizmangel und Überreizung erlöschen, durch gewohnten Wechsel der Ruhe und optimalen Reizung erhalten bleiben, während durch ungewöhnliche Einflüsse ihr Substrat sich wesentlich abändern kann. Die Anpassung ist eine Folge der Reizbarkeit und Veränderlichkeit der lebenden Gebilde. Und wenn man sie zu einer besonderen physiologischen Funktion stempelt, so liegt darin ein Rest von Teleologie, welche die Wirkung eines Vorganges für den Zweck einer Handlung hält. In der That erscheinen viele Anpassungen höehst zweckmäßig, so daß es oft schwer ist, sie als Wirkungen von Ursachen oder Folgen von Reizungen zu erkennen.

\section{Übersicht der Funktionen des Protoplasma.}

Alle Funktionen des Protoplasma sind polytop und coenomer:

1. Die Saftströmung im Protoplasma: direkt beobachtet.

2. Der Gasaustausch mit der Umgebung: experimentell erwiesen.

3. Die Aufnahme fremder Körper aus der Umgebung: direkt beobachtet. 
4. Die Abscheidung gelöster und fester Teile: direkt beobachtet.

5. Die Wärmebildung: experimentell indirekt nachgewiesen.

6. Die Elektricitätsentwicklung: experimentell erwiesen.

7. Die aktive Bewegung, Wechsel von Ruhe und Thätigkeit, Kontraktion und Expansion: direkt beobachtet.

8. Die Empfindung: wird auf Grund von Beobachtungen und Experimenten dem Protoplasma zugeschrieben.

9. Das Wachsen und dadurch die Reproduktion abgetrennter Teile: direkt nachgewiesen.

10. Die Erzeugung. Das Protoplasma wird durch Teilung von vorhandenem Protoplasma neu gebildet: direkt beobachtet.

11. Die Entwicklung: das junge Protoplasma differenziert sich, das reife zeigt Kernteilung: direkt beobachtet.

12. Die Vererbung: die Eigenschaften des Protoplasma gehen auf seine Teilstücke über: direkt beobachtet.

Kein lebendiges Protoplasma ist bekannt, welchem mit Bestimmtheit auch nur eine dieser zwölf physiologischen Funktionen abgesprochen werden kann, und bis jetzt ist keine jedem Protoplasma zukommende Funktion außer ihnen bekannt.

Die vier ersten betreffen den Stoffwechsel, die vier mittleren den Kraftwechsel, die vier letzten den Formenwechsel. Nan kann auch die drei Gruppen der Funktionen des Protoplasma als die der nutritiven, der dynamischen, der formativen Funktionen bezeichnen.

Entsprechend dieser Einteilung zerfallen die zwölf Grundfunktionen der Tiere einschließlich des Menschen in drei große Abteilungen. 
214 Die Einteilung d. Lehre v. d. Funktion. d. Tiere u. d. Menschen.

\section{Die Einteilung der Lehre von den Funktionen der Tiere und des Menschen.}

I. Die Lehre von den tierischen Saftströmungen: Cirkulationslehre.

II. Die Lehre rom tierischen Gaswechsel: Respirationslehre.

III. Die Lehre von der tierischen Ernährung: Nutritionslehre.

IV. Die Lehre von den tierischen Absonderungen: Sekretionslehre.

V. Die Lehre von der tierischen Wärme oder Verbrennung: Oxydationslehre.

VI. Die Lehre von der tierischen Elektricität: Elektrophysiologie (Polarisationslehre).

VII. Die Lehre von den tierischen Bewegungen: Kontraktionslehre.

VIII. Die Lehre von der Sinnesthätigkeit: Perceptionslehre.

IX. Die Lehre von dem tierischen Wachstum: Inkretionslehre.

X. Die Lehre von der Erzeugung der Tiere: Generationslehre.

XI. Die Lehre von der Entwicklung der Tiere: Evolutionslehre.

XII. Die Lehre ron den tierischen Vererbungen: Hereditätslehre.

Es bilden $I$ bis IV zusammen die vegetative, $\mathrm{V}$ bis VIII die animale Physiologie, IX bis XII die generative Physiologie, deren Anfänge jedoch von der Morphologie sich noch nicht abgetrennt haben. 


\title{
DIE AUFGABEN
}

\author{
DER
}

\section{SPECIELLEN PHYSIOLOGIE}

ODER

\section{BIOGNOSIE}

DES MENSCHEN UND DER TIERE. 



\section{Erste Gruppe.}

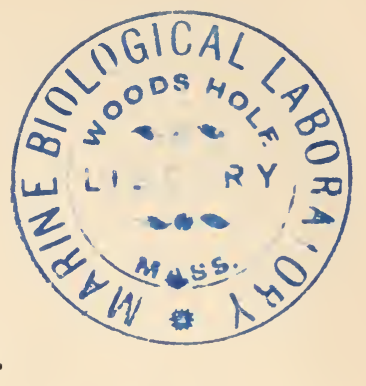

\section{Die Funktionen des Stoffiwechsels.}

I. Die Lehre von den Saftströmungen. In allen Tieren finden Strömungen tropfbarer Flüssigkeiten statt, so lange sie leben, in den einfachen unregelmäßig, doch meist centripetal und centrifugal, wie in allen höher organisierten mit regelmäßigem Kreislauf. So schnell erlischt nach Unterbrechung dieser Funktion die Gesamtheit der anderen Lebensvorgänge, daß sie als fundamentale Lebenserscheinung passend zuerst betrachtet wird. Die physiologische Untersuchung ermittelt für alle Tiere jedes Alters auf Grund der vergleichenden Anatomie und Entwicklungsgeschichte zuerst was strö mt, die Beschaffenheit, Zusammensetzung und Nenge der strömenden Säfte (beim Menschen des Blutes und der Lymphe), sodann in welchen Röhren (Gefäßen), Behältern und sonstigen Hohlräumen die Strömungen stattfinden und welche diesen zugehörige Teile für die Inganghaltung der Strömung erforderlich sind, d. h. die Kreislaufsapparate. Hierauf sind die Wechselbeziehungen der strömenden Säfte und Cirkulationsapparate zu untersuchen, die Mechanik des Kreislaufes und die in den Säften während ihrer Strömung stattfindenden chemischen Veränderungen, sowie die Reize, durch welche der ganze Kreislauf im Gange bleibt. 
II. Die Lehre von der Atmung. Alle Tiere nehmen, so lange sie leben, Gase in sich auf und geben Gase ab. In diesem Gaswechsel bildet Sauerstoffbindung und Kohlensäureentwicklung das Wesentliche der respiratorischen Funktionen oder der Atmung. Die physiologische Untersuchung derselben muß die Beschaffenheit, Zusammensetzung und Menge des Atembaren, der Luft oder der sonstigen respirabeln Gase fuir alle Tierarten feststellen und bei denselben die A tmungsapparate auf Grund der vergleichenden Anatomie und Entwicklungsgeschichte ermitteln, dann die Wechselbeziehungen der Luft und dieser Apparate erforschen und die zum Atmungsprozesse erforderlichen Reize auffinden. Naturgemäß wird dabei der Mechanismus des Gasaustausches, beim Einatmen und Ausatmen, vom Chemismus desselben getrennt betrachtet, beidesfalls aber die äußere und innere Atmung im Zusammenhang untersucht.

III. Die Lehre von der Ernährung. Alle Tiere nehmen Nahrung auf und verwandeln einen Teil davon in Bestandteile ihrer Gewebe durch Assimilation, indem sich die vorherigen Bestandteile derselben durch Dissimilation verändern, so daß sie normalerweise nicht mehr Gewebsbestandteile bleiben können. Diese Funktion der Assimilierung und Dissimilierung ist das Wesentliche der Ernährung. Die physiologische Untersuchung derselben muß zuvörderst die Beschaffenheit, Zusammensetzung, Menge des Assimilierbaren für alle Tierarten und deren Embryonen ermitteln, d. h. der Nahrung, welche nach der Assimilation das Dissimilierbare vorstellt. Hierauf müssen auf Grund der vergleichend-anatomischen und entwicklungsgeschichtlichen Untersuchungen die Ernährungs apparate, mittels welcher die Aufnahme, Aufspeicherung, Assimilierung und die Dissimilierung der Vorräte zustande kommt, bestimmt werden. SchlieBlich sind die Wechsel- 
beziehungen zwischen diesen organischen Apparaten und der Nahrung zu ermitteln, wobei der Mechanismus des Ergreifens, Zerkleinerns, Fortbewegtwerdens und der Resorption assimilierbarer Stoffe ron dem Chemismus der Verdauung zweckmäßig getrennt betrachtet und die beiderlei Prozesse auslösenden Reize für sich untersucht werden.

IV. Die Lehre ron den Ibsonderungen. Alle Tiere sondern teils ununterbrochen, teils in Pausen verschiedenartige Stoffgemenge, die sich in geeigneten Behältern in ihrem Innern ansammeln, entweder nach vorheriger Beteiligung derselben am Stoffwechsel oder ohne solche, nach außen ab. Letztere heißen Exkrete, erstere Sekrete. Da aber viele Sekrete zugleich Exkrete sind, so ist eine Trennung der Absonderungen in Sekretionen und Exkretionen nicht streng durchführbar. Die physiologische Untersuchung sucht erstens für möglichst verschiedene Tiere und Entwicklungsstufen festzustellen, was von dem Angesammelten abgeschieden wird, das Sercernierbare und Excernierbare, zweitens was abscheidet, die sekretorischen und exkretorischen Apparate, drittens durch welche Reize die aus den Beziehungen beider zu einander resultierende Funktion der Abscheidung zustande kommt und im Gang bleibt. Es ist bei dieser Untersuchung für jede einzelne Art der Absonderung eine getrennte Betrachtung des Mechanismus und Chemismus derselben nötig.

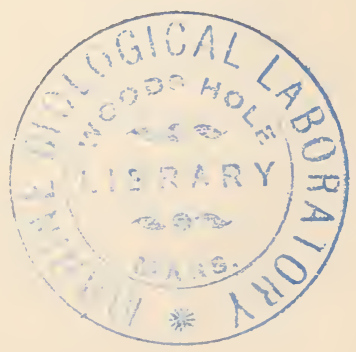




\section{Zweite Gruppe.}

\section{Die Funktionen des Kraftwechsels.}

\section{Die Lehre von der tierischen Verbrennung.} In allen Tieren finden, so lange sie leben, chemische Prozesse statt, welche mit Wärmebildung verbunden sind, und, weil es dabei wesentlich auf Oxydationen mittels des eingeatmeten Sauerstoffes ankommt, zusammen als Verbrennungsvorgänge bezeichnet werden. Weil aber die Wahrnehmung der tierischen Verbrennung, obgleich sie als eine der ursprünglichsten Lebensfunktionen anzusehen ist, nicht ohne weiteres in die Augen fällt, so muß sie durch Beobachtungen und Versuche dargethan werden. Die Lehre von der tierischen Verbrennung beginnt daher mit dem Nachweis und der thermometrischen und kalorimetrischen Messung der Wärme der verschiedensten Tiere und ihrer Embryonen. Dann ist die Beschaffenheit und Menge des verbremnlichen Materiales in denselben zu ermitteln, das Oxydierbare. Hierauf muß festgestellt werden, in welchen Teilen die Verbrennung stattfindet, wo also die organischen Heizapparate oder Verbrennungsherde sich befinden. Endlich sind die Beziehungen der letzteren zum Oxydierbaren zu erforschen, und die die thermogenen Prozesse anslösenden Reize, ohne welche die tierische Wärme nicht entsteht, aufzusuchen, die Frage zu beantworten: "Wie findet die Verbrennung statt?" Dabei empfiehit es sich, die Vorgänge der Zufuhr des Verbrennlichen zu den Verbrennungsherden und der Wegschaffung des Verbrannten von denselben, also den IIechanismus der tierischen 
Oxydation, welcher mit dem der inneren Atmung innig verwachsen ist, ron dem Chemismus derselben in der lebenden Zelle, im Protoplasma, getrennt zu betrachten.

\section{Die Lehre von der tierischen Elektricitiit.}

Alle lebenden Tiere enthalten Teile, welche gesetzmäßig elektromotorisch wirksam werden können. Ob aber die von ihnen ausgehenden elektrischen Ströme als wesentliche Lebenserscheinungen, wie der Entladungsschlag des Zitteraales, oder nur als unphysiologische Begleiterscheinungen solcher anzusehen sind, erfordert eine eingehende Untersuchung. Es wird daher zunächst der Beweis zu liefern sein, daß tierische Teile funktionell Elektricität entwickeln. Erst wenn die elektrischen Eigenschaften der lebenden Gebilde sich als wesentlich und gesetzmäßig den unversehrten lebenden Teilen zukommend erwiesen haben und mit deren Thätigkeit sich gesetzmäßig ändern, sind sie als funktionell zu bezeichnen und von physiologischem Interesse. Anderenfalls hätten die von tierischen Gebilden abgeleiteten elektrischen Ströme kaum mehr Bedeutung für die Physiologie, als die von irgendwelchen feuchten nicht lebenden Gemengen erhaltenen. Da nun viele Fische funktionell Elektricität entwickeln, so erscheint es nicht unmöglich, daß auch andere Tiere, vielleicht alle, dieselbe Eigenschaft nur in geringerem Grade besitzen. In der That haben zahlreiche Experimente an lebenden pflanzlichen und tierischen Gebilden es im höchsten Grade wahrscheinlich gemacht, daß es zu den wesentlichen Eigenschaften des lebenden Protoplasma gehört, wenigstens zeitweise elektromotorisch wirksam zu sein. Ist der Nachweis funktioneller zoo-elektrischer Erscheinungen geliefert, dann müssen durch Vergleichung und genetische Untersuchungen die Stoffe gefunden werden, welche durch ihre elektrochemische Spannungsungleichheit zur Entstehung: der Ströme in den lebenden Teilen notwendig sind - sie 
mögen der Kürze halber elektrogene Substanzen heißen - und die elektrischen Apparate, in welchen die Ströme durch das Zusammensein jener elektropositiven und elektronegativen Stoffe erzengt werden. Endlich müssen die durch Reizung bedingten Wechselbeziehungen zwischen den organisierten Elektromotoren und dem zu ihrer Ladung erforderlichen elektrogenen Material untersucht werden. Hierbei wird es nützlich sein, die rein physikalischen Vorgänge, sowie die Messung der tierischen Elektricität von den chemischen gesondert darzustellen.

VII. Die Lehre von der tierischen Bewegung. Alle Tiere zeigen, so lange sie leben, Bewegungserscheinungen, welche, sofern sie funktionell sind, ausnahmslos durch Kontraktionen und Expansionen zustande kommen. Diejenigen tierischen Bewegungen, welche nicht direkt durch Zusammenziehung und Ausdehnung kontraktiler Gebilde bedingt werden, sind entweder passiv und dann als solche von keinem physiologischen Interesse (wie der Transport im Wagen und der freie Fall) oder sie sind die Folgen der kontraktilen Bewegung, wie die Saftströmungen und die Strömungen der Atmungsgase. In allen Fällen, wo tierische Bewegungen Lebenserscheinungen sind, liegt ihnen Kontraktilität zu Grunde. Die physiologische Untersuchung hat daher, vergleichend und genetisch verfahrend, zu prüfen, welchen organischen Gebilden diese Eigenschaft, sich auf Reize zusammenzuziehen und dann wieder zu expandieren, zukommt, welche Teile Bewegungsapparate sind, indem sie jene kontraktilen Elemente enthalten und schlieblich welche Reize diese (die kleinsten noch für sich kontraktilen Gebilde in dem ganzen Bewegungsapparate) zur Kontraktion bringen. Dabei werden die mechanischen Vorgänge von den sie begleitenden chemischen in der Darstellung zu trennen sein. Um aber über die Ursachen und das Wesen der tierischen Bewegungen 
Aufschluß zu erhalten, ist es außerdem notwendig, sämtliche der Beobachtung zugängliche Bewegungen der Tiere jedes Entwicklungsgrades in Gruppen zu ordnen nach den erforderlichen Reizen und hierbei der Mechanik und Chemie noch nicht erforschbare psychische Prozesse zu berücksichtigen. $\mathrm{Zu}$ diesen gehört der Wille, welcher an chemische Vorgänge in Ganglienzellen geknüpft ist.

VIII. Die Lehre ron der Sinnesthätigkeit. Alle Tiere verhalten sich, so lange sie leben, gegen die auf sie wirkenden Reize so, als wenn sie, ähnlich wie der Mensch, ein Empfindungsvermögen und damit die Fähigkeit der Unterscheidung besäßen. Es ist auch in heuristischer Hinsicht die Annahme, daß Protoplasma, folglich alles Lebendige auf gewisse Eindrücke reagiert, indem es empfindet, gerechtfertigt. Die physiologische Untersuchung geht davon aus und ermittelt zunächst für möglichst verschiedene und ungleich entwickelte Tiere das Empfindbare, dann vergleichend und genetisch prüfend die Empfindungsapparate (Sinnesorgane) und schließlich die bei der Reizung sich ändernden Beziehungen beider zu einander, d. h. die Sinnesthätigkeit, welche bei höheren Organismen stets mit einer Nervenerregung beginnt; auf diese folgt eine Empfindung, die im Raum und in der Zeit geordnet zur Wahrnehmung wird. Kommt zu dieser noch die Kausalität, dann erhebt sich die Wahrnehmung zur Vorstellung. Sowohl mit dieser wie mit der Wahrnehmung können sich Gefühle verbinden, welche aber stets eine Empfindung voraussetzen. Alle diese psychischen Veränderungen sind an chemische Prozesse in Ganglienzellen geknüpft und kommen nur zustande, wenn solche durch Mechanismen und auch chemische Vorgänge in den peripheren Sinnesorganen erregt worden sind. Die Lehre von den Beziehungen der Empfindungen und ihren psychischen Folgezuständen zu den Sinnesreizen heißt Psychophysik, 
die Lehre von den chemischen Prozessen, welche jenen zu Grunde liegen, Psychochemie.

\section{Dritte Gruppe.}

\section{Die Funktionen des Formenwechsels.}

IX. Die Lehre vom Wachstum. Alle Tiere zeigen Wachstumserscheinungen, welche teils über die Rückbildungen entwickelter Formen überwiegen, teils dieselben äquilibrieren, teils ihnen nicht gleichkommen, je nach dem Alter. Jedes Wachstum erfordert aber, daß mehrNahrung assimiliert, als dissimilierte Substanz ausgeschieden werde. Die physiologische Untersuchung hat vor allem für die verschiedensten Tiere und namentlich die Embryonen diese zum Ansatz geeigneten Stoffe zu bestimmen und festzustellen, welche Gebilde den Stoffansatz vermitteln, und wie im einzelnen und im ganzen qualitativ und quantitativ die Beziehungen jener Stoffe zu diesen Gebilden, d. h. die Wachstumsprozesse, sich gestalten. Dabei ist die Mechanik der Apposition mit der Messung der Massenzunahme und Vermehrung wachsender Zellen getrennt von den chemischen Veränderungen darzustellen, welche bei jenem Stoffansatz stattfinden und besonders der noch gänzlich unbekannte das Wachstum bedingende Reiz zu er-' forschen.

x. Die Lehre von der Erzeugung der Tiere. Alle Tiere sind aus Protoplasma erzeugt und zwar alle höheren Tiere durch sexuelle Zeugung. Die physiologische 
Untersuchung dieses mechanischer und chemischer Analyse noch nicht unterworfenen Vorganges erforscht erstens vergleichend und genetisch das zur Erzeugung eines neuen Tieres erforderliche Material, den weiblichen Kieim, das Ei, und den männlichen Keim, das Samenkörperchen, zweitens die Zeugungsapparate, in welchen die Keime bereitet werden, drittens den für die Vereinigung des männlichen und weiblichen Keimes bei der Befruchtung erforderlichen Reiz und die Befruchtung selbst.

XI. Die Lehre von der tierischen Entwicklung. Alle Tiere entwickeln sich, indem alle aus morphologisch gleichartigen Zellen nach der Befruchtung des Eies hervorgehen. Die Entwicklung gibt sich durch das Verschiedenwerden jener Bildungszellen zu erkennen. Die physiologische Untersuchung hat sich zunächst vergleichend und genetisch mit der genauen Bestimmung des zu dieser Differenzierung nötigen Materiales, des Differenzierbaren, also mit dem Inhalt des befruchteten Fies in chemischer Hinsicht, zu befassen, dann mit der Frage, welche geformten Teile die Differenzierung der verschiedensten Tiere im Ei und später ermöglichen und schließlich mit den durch beide zusammen bedingten Differenzierungsprozessen selbst, welche durch ebenfalls noch unbekannte Reize ausgelöst werden.

XII. Die Lehre von der tierischen Vererbung. Alle Tiere haben Eigenschaften, welche auf ihre Abstammung von ihnen ähnlichen Vorfahren hinweisen, und wenn sie als unmittelbar oder mittelbar von diesen überkommen sich nachweisen lassen, erblich genannt werden. Die physiologische Untersuchung der Vererbungserscheinungen als Lebensvorgänge hat drei Fragen zu beantworten: 1) Welche Substanzen werden direkt von den Erzeugern auf das Erzeugte uibertragen, so daß erbliche Eigenschaften später zum Vorschein kommen? Die Stoffe müssen im Ei und

Preyer, Physiologie. 
Samen enthalten sein; 2) Welche organischen Teile vermitteln die Vererbung? Einzig der männliche und weibliche Keim können sie zustande kommen lassen, also ist dem Ursprunge dieser nachzugehen; 3) Wie kommt der Vererbungsprozeb zustande? d. h.: durch welche Reize wird das erbliche Material in den Keimen abgelagert und in den vereinigten Keimen entfaltet? Nur durch die Entwicklung, niemals plötzlich ist die Entfaltung der im Li und Samen potentiell vorhandenen, d. h. angelegten, erst künftig aktuellen Eigenschaften ermöglicht. -- Bei allen aus Eiern entstehenden Tieren sind selbstverständlich alle erblichen Eigenschaften in der Anlage angeboren. Nicht alles Angeborene ist erblich, aber alles Erbliche ist in der Anlage angeboren. Überhaupt sind streng genommen bei höheren Tieren nur Anlagen angeboren. Da nun diese als solche der physiologischen Experimentierkunst fast unzugänglich sind, so ist bei dem Versuche, die obigen Fragen zu beantworten, vor allem die vergleichende und genetische Methode auf niedere Tierformen anzuwenden, welche weniger Anlagen haben und weniger kompliziert sind. 


\section{ELEMENTE}

DER

\section{ALLGEVEINEN PHYSIOLOGIE.}

KURZ UND LEICHTFASSLICH DARGESTELLT

roN

\section{W. PREYER,}

O. PROFLSSOR DER PHYSIOLOGIE UND DIREKTOR DES PHYSIOLOGISCHEN INSTITUTES DER UNIVERSITÄT JENA.

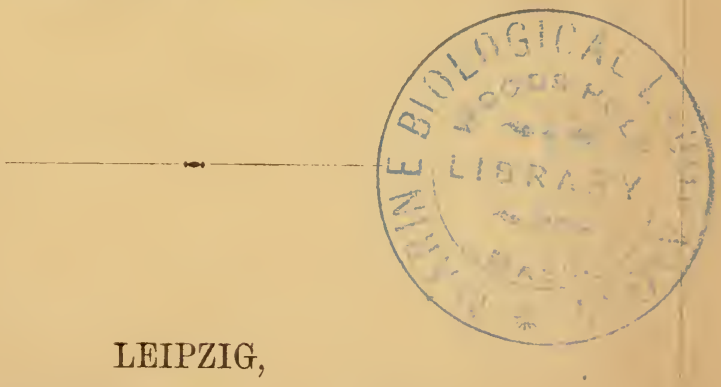

TH. GRIEBEN'S VERLAG (L. FERNAU). 


Im gleichen Verlage sind erschienen:

\title{
Die Seele des Krindes.
}

Beobachtungen

über die

geistige Entwickelung des Menschen in den ersten

Lebensjahren

\author{
ron \\ Prof. Dr. W. Preyer.
}

Preis 8 Mark.

\section{Die Genesis des Thier-Eies.}

Untersuchungen

\author{
von \\ Dr. Emil Valaoritis.
}

Nach dem Tode des Verfassers herausgegeben

ron

Prof. Dr. W. Preyer.

Mit 3 lithographischen Tafeln und 1 Holzschnitt.

Preis 6 Mark.

\section{Leitfaden der Physik.}

Von

Prof. Dr. W. von Beetz.

Mit 336 in den Text gedruckten Holzschnitten.

Siebente Auflage.

Preis 4 Mark.

Druck von Metzger $\&$ Wittig in Leipzig. 



